\title{
MECANISMOS DE TENACIDAD EN MATERIALES COMPUESTOS INSPIRADOS POR LA NATURALEZA
}

\author{
Ing. Isaías Ezequiel Gallana
}

Tesis presentada ante la Facultad de Ingeniería de la Universidad

Nacional de La Plata para acceder al grado académico de

\section{DOCTOR EN INGENIERIA}

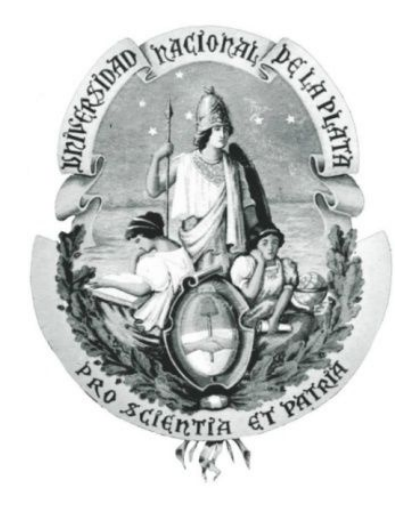

Dirección de tesis

Dr. Pablo Zavattieri, Dr. Marcos Actis

Jurados

Dra. Celina Bernal, Dra. Vera Álvarez Dr. Javier Amalvy

Departamento de Aeronáutica - Facultad de Ingeniería Universidad Nacional de La Plata

La Plata, Argentina

Noviembre de 2017 
La presente tesis doctoral se entrega ante la Facultad de Ingeniería de la Universidad Nacional de La Plata como requisito para la obtención del grado de Doctor en Ingeniería. El trabajo en ella descripto se desarrolló en el Departamento de Aeronáutica entre los años 2011 y 2017, con el apoyo del Grupo de Ensayos Mecánicos Aplicados de la Facultad de Ingeniería de la Universidad Nacional de La Plata, la Universidad de Purdue en West Lafayette, Indiana y el Laboratorio de Riverside de la Universidad de California, los dos últimos ubicados en Estados Unidos.

La realización de esta investigación fue posible por el financiamiento parcial a través de

- una Beca Doctoral otorgada mediante el "Programa de Formación de Doctores en Aéreas Tecnológicas Prioritarias - Programa Recursos Humanos (PRH)" co-n anciado por la Agencia Nacional de Promoción Cientí c a y Tecnológica y la Universidad Nacional de La Plata (PRH2007-15).

- Una Beca Tipo II otorgada por la Universidad Nacional de La Plata

- Una beca para estadías cortas en el exterior proporcionado por el Ministerio de Educación a través de su Programa Bec.Ar. 


\section{Índice}

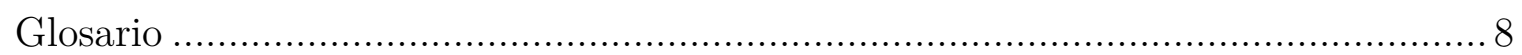

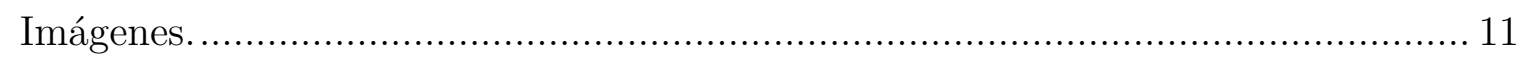

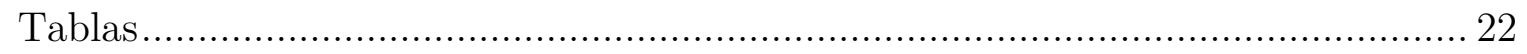

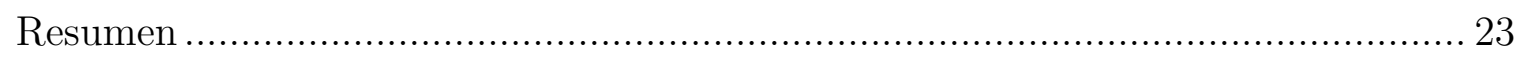

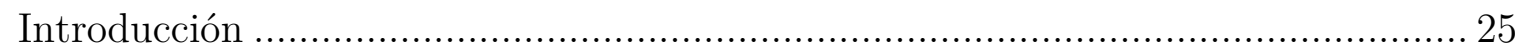

Alcance - organización y metodología........................................................... 28

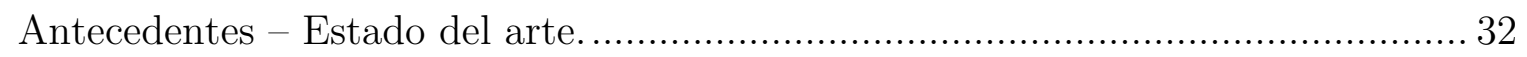

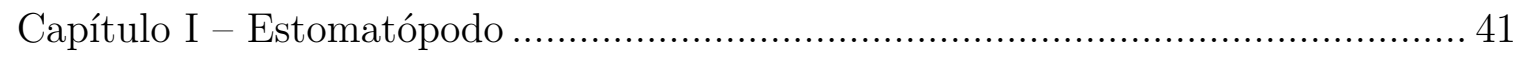

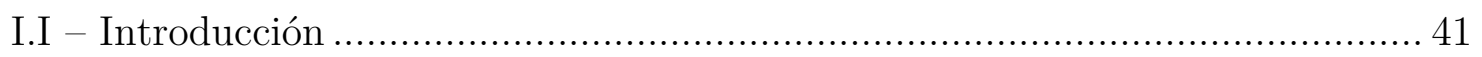

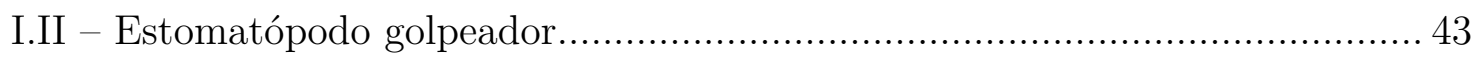

I.II.I - Estomatópodo: Martillo Dáctilo. ....................................................... 43

I.II.II - Modelado numérico y resultados............................................ 47

I.II.III - Origen de los mecanismos de tolerancia al daño y resistencia a la propagación de fisura. 51

Capítulo II - Regiones dentro del martillo dáctilo - Región de estrías y periódica-

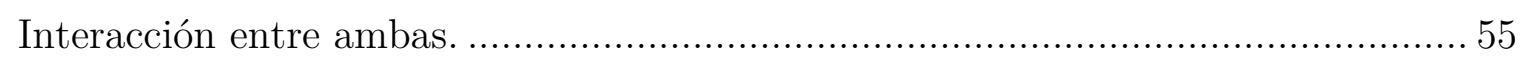

II.I - Introducción ............................................................................. 55

II.II - Caracterización Estructural.......................................................... 57

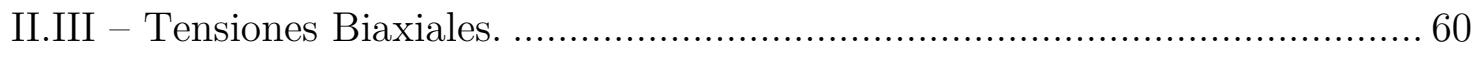

II.IV - Región periódica y de estrías - interacción - .................................. 62

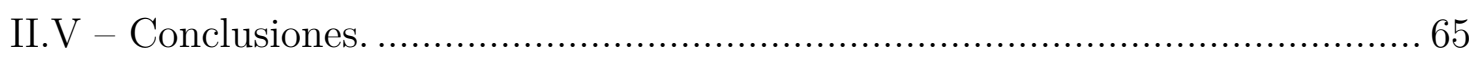

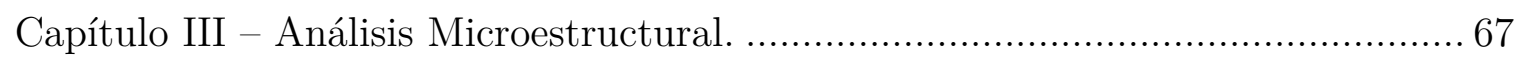


III.I - Análisis Microestructural de la Región Periódica.

III.I.I - Primer orden - fibrillas. 70

III.I.II - Segundo Orden - Matriz y fibra.

III.I.II.a - Matriz entre fibrillas. .73

III.I.II.b - Fibra 74

III.I.III - Tercer orden - Grupo de Fibras. 75

III.I.III.a - Conclusiones 76

III.I.IV - Cuarto orden - Estructura tipo honeycomb. 77

III.I.V - Resultados y conclusiones. 80

III.II -Análisis Microestructural de la región estriada. 84

III.II.I - Introducción 84

III.II.II - Modelado en 3D y 2D 87

III.II.III - Valores de indentación a recrear.

III.II.IV - Modelado numérico 90

III.II.V - Observaciones en el modelo y resultados. 94

III.II.VI - Resultados y conclusiones. 95

Capítulo IV - Mecanismos de disipación de energía. 97

IV. I - Introducción . 97

IV.II - Análisis de las interfases. 99

IV.II.I - Concepción del modelo numérico. 
IV.II.II - Condiciones de borde 101

IV.II.III - Descripción del mallado utilizado. 103

IV.II.IV - Descripción del elemento cohesivo 104

IV.II.V - Descripción del material cohesivo. 105

IV.II.VI - Descripción de la curva proporcional aplicada. 106

IV.II.VII - Ángulo de crecimiento de fisura. 107

IV.II.VIII - Regresión de datos- Mínimos cuadrados. 109

IV.II.IX - Elección del tamaño de malla y zona de análisis - Errores110

IV.III - Modelado de la interfase utilizando puentes.

IV.III.I - Elección del tamaño de los puentes.

IV.III.II - Modelado matemático de características de puentes. 114

IV.III.II - Datos de los materiales utilizados.

IV.III.III - Teorema de Buckingham - Análisis Dimensional

IV.III.III - Ángulos de modo mixto.

IV.III.IV - Desviación de la fisura respecto de la dirección de la interfase.... 125

IV.IV - Resultados numéricos y conclusiones. 131

Capítulo V - Conclusiones 143

Referencias 147 


\section{GLOSARIO}

\section{Abreviaciones}

RVE Elemento de volumen representativo.

EDS Espectroscopia de energía dispersa.

SEM Escaneo de microscopia electrónica.

TGA Análisis Térmico gravimétrico.

AFM Microscopia de fuerza atómica.

FEM Modelo de elementos finitos.

PBC Condiciones de borde periódicas.

DIC Correlación digital de imágenes.

DSC Escaneo calorimétrico diferencial.

\section{Nomenclatura}

$\Gamma_{0} \quad$ Resistencia a la fractura de la interfase.

$\Gamma \quad$ Resistencia a la fractura del material en modo 1.

$\mathrm{G}_{\mathrm{c} 0}$ Energía crítica liberada bajo un crack deflectado.

$\mathrm{G}_{\mathrm{c}} \quad$ Energía crítica liberada bajo modo 1 .

E Modulo elástico.

$\mathrm{E}_{\mathrm{e}} \quad$ Modulo elástico equivalente.

$\sigma \quad$ Tensión normal.

$\varepsilon \quad$ Deformación específica.

v Relación de Poisson.

G Tasa de energía liberada o acumulada.

$\mathrm{G}_{\mathrm{c}} \quad$ Tasa de energía crítica liberada o acumulada.

K Factor de intensidad de tensiones.

Kc Factor crítico de intensidad de tensiones.

$\mathrm{K}_{1} \quad$ Factor de intensidad de tensiones en modo I.

$\mathrm{K}_{2} \quad$ Factor de intensidad de tensiones en modo II. 
$\mathrm{K}_{0} \quad$ Factor crítico de intensidad de tensiones para modo I.

๙ $\quad$ Primer parámetro de Lamé.

$\mu \quad$ Segundo parámetro de Lamé.

$\Psi \quad$ Ángulo de modo mixto.

$\theta \quad$ Ángulo de crecimiento de la fisura.

u1 Desplazamientos en la dirección 1 .

u2 Desplazamientos en la dirección 2.

on Desplazamientos en la dirección normal del elemento cohesivo.

St Desplazamientos en la dirección tangencial del elemento cohesivo.

$T_{\max }$ Tensión máxima del elemento cohesivo.

$T_{n} \quad$ Tensión normal del elemento cohesivo.

$T_{t} \quad$ Tensión tangencial del elemento cohesivo.

k Pendiente del elemento cohesivo.

$\sigma_{\mathrm{f}} \quad$ Tensión de falla del material.

V Volumen del material (Weibull).

$\mathrm{V}_{\text {ref }} \quad$ Volumen de referencia (Weibull).

$\mathrm{P}_{\mathrm{s}} \quad$ Probabilidad de falla del material.

Lcz Longitud de fractura del material.

$l^{*} \quad$ Longitud que uso para contar el ángulo.

$h^{*} \quad$ Altura del puente.

d Diámetro del puente.

$s \quad$ Separación entre puentes.

Ao Área transversal de los puentes.

A Área total de la interfase.

$\gamma_{\mathrm{s}} \quad$ Energía de superficie.

$W_{s} \quad$ Trabajo de separación requerido para generar nuevas superficies. 


\section{IMÁGENES.}

Figura 1 - Adaptación de las gráficas de Fratzl, et al. J. Mater Chem. 2004[2]. Muestra la relación entre la rigidez y la tenacidad a la fractura para materiales actualmente utilizados en la ingeniería versus materiales naturales de estudios en estas últimas décadas. 26

Figura 2 - Distintos materiales naturales donde la estructura del material a diferentes escalas es distinta. (A) muestra la microestructura del nácar, caracterizada por la presencia de placas en una disposición de ladrillo y mortaja. (B) muestra un hueso caracterizado por la presencia de fibras en disposición longitudinal. Sin embargo (C), muestra una microestructura de un cangrejo marino compuesta de fibras dispuestas en forma helicoidal. (D) muestra la microestructura del diente de chitón, compuesta por barras dispuestas en forma paralela una de otras. Imágenes adaptadas de Meyer et. al. y Grunenfelder et. al.[5] [1].

Figura 3 - Estructura jerárquica del nácar (Barthelat 2007 [14] )

Figura 4 - Microestructura típica "ladrillo - mortero" del nacar. [11]

Figura 5-a) características geométricas de la interfase entre dos plaquetas; b) vinculo rígido, puente, entre dos plaquetas de nacar. [12]

Figura 6 - Mecanismos de disipación de energía[12]. Las ondulaciones generan un enclavamiento entre placas de nácar, generando una competencia entre disipación debido a tracción o corte. Figura adaptada de la publicación referenciada de Barthelat et.al. 35

Figura 7 - Micrografía mostrando la disipación del daño producto de micro desplazamientos de las tabletas en toda la superficie de la muestra. [12]..... 36

Figura 8 - Curva experimental tensión-deformación para una muestra de material nácar. Gráfica adaptada de la publicación de Rim et. al.(2011)[13].... 36 
Figura 9 - Características microestructurales del diente de chitón; a) fractura longitudinal del diente de chitón, se muestra en línea punteada la dirección de las barras que forman la microestructura. Con recuadro de colores se indica la ubicación de las figuras b a c. [5] 38

Figura 10 - Imagen de un ejemplar de mantis marina. .38

Figura 11 - Estomatópodos Alanceadores. La imagen A muestra un espécimen adulto atrapando un pez. La imagen B muestra de modo cercano la extremidad que utiliza para atrapar a sus presas y fue construida a partir del escaneo de un ejemplar real.

Figura 12 - Estomatópodos golpeadores. La imagen A muestra un espécimen de Odontodactylus scyllarus. La imagen B muestra diferentes vistas del martillo dáctilo utilizado como extremidad de impacto y dicho modelo fue construido a partir del escaneo de un ejemplar real. 42

Figura 13 - La imagen A y B señalan el martillo dáctilo de la mantis marina. La imagen $\mathrm{C}$ muestra un acercamiento del martillo dáctilo donde $\mathrm{D}$ y $\mathrm{P}$ corresponde al dáctilo y al propodio respectivamente. La imagen D corresponde a un corte transversal del martillo dáctilo junto con el propodio. La imagen E muestra en diferentes colores las regiones con diferentes arreglos de material dentro de cada extremidad 44

Figura 14 - Micrografías ópticas mostrando las diferentes regiones dentro del martillo dáctilo. Cada región con una orientación de fibras particulares que detallaremos más adelante. Imagen extraída de la publicación de Weaver et. al.[24]

Figura 15 - Las imágenes y gráficos presentados en esta figura fueron tomados de la misma región de un espécimen seco. La Imagen A y B muestra el área indentada para la cual se obtuvo el valor de módulo elástico (E) y dureza (H). Las imágenes 
C Y D muestran mapas de EDS mostrando la no uniformidad distribución de elementos en las regiones periódicas y de impacto. Imagen extraída de la publicación de Weaver et. al.[24] 46

Figura 16 - Muestra la variación de modulo elástico de una muestra hidratada y otra no. También muestra los valores promedios de dichas zonas, tanto en la región de impacto como en la región periódica. Imagen proporcionada por el Laboratorio de Riverside. 47

Figura 17 - En esta figura se detalla un corte transversal dáctilo y propodio señalando las diferentes regiones con modulos elasticos diferentes. Los colores indican los diferentes módulos elásticos y propiedades másicas de cada región usada para la simulación (datos obtenidos de nanoindentación en muestras hidratadas y provenientes de sincrotrón de transmisión de rayos $\mathrm{x}$ ).Imagen extraída de la publicación de Weaver et. al.[24] 48

Figura 18 - Muestra una secuencia de golpe del martillo dáctilo sobre un sensor. Puede verse en el mismo el valor de impacto cercano a los $500 \mathrm{~N}$ y un segundo pico de impacto de valor de $250 \mathrm{~N}$ correspondiente a la ruptura de las burbujas de cavitación. Datos obtenidos de Patek and Caldwell. 48

Figura 19 - Fuerza vs tiempo medida en la simulación numérica sobre el sensor... 49

Figura 20 - Análisis dinámico mediante el método de elementos finitos y modelo micromecánicos. (A) Distribución de tensiones en la geometría del martillo dáctilo y propodio impactando un sensor a $20 \mathrm{~m} / \mathrm{s}$. Se muestra la evolución de la tensión principal máxima $\sigma_{\max }$ hasta que la onda de presión llega al propodio. (B) Tensiones principales máximas dentro del martillo dáctilo a un tiempo de $2 \mathrm{~ms}$ aproximadamente después del impacto. 50

Figura 21 - Estructura helicoidal de fibras de quitina dentro de la región periódica (periodicidad 75um). Comparación entre un modelo tridimensional helicoidal (A) 
con una fractografía (SEM) (B) y con una superficie pulida de la misma sección transversal (C). (D) visualización de las orientaciones de las fibras de quitina obtenidas a través de un análisis de dispersión de rayos X de 92 difractogramas separados. (E) zona de corte en el dáctilo para visualizar las fisuras en su interior.(F) (G) Micrografía de escaneo electrónico de una muestra de la sección coronal, mostrando las microfisuras en su interior.[29][30].

Figura 22 - Patrón de microfisuras generado al flexionar fibras dispuestas en forma helicoidal. Imagen proporcionada por el Laboratorio de Riverside. 53

Figura 23 - Diferentes regiones del martillo dáctilo de la mantis marina. .58

Figura 24 - Imágenes de escaneo microscópico electrónico de la región periódica (A) (B) y de estrías (C) del martillo dáctilo (D). La escala en B es de 20um. Las imágenes SEM fueron proporcionadas por el Laboratorio de Riverside. 59

Figura 25 - Tensiones biaxiales. En color azul oscuro se muestra la tensión biaxial en el plano r- $\theta$. Esto significa que la tensión radial y tangencial tienen valores similares y se corresponden con las tensiones principales. La tensión en la dirección longitudinal (z) es siempre de compresión.

Figura 26 - Estructura Helicoidal. La imagen A muestra un conjunto de fibras dispuestas en forma radial con cierta curvatura, formando un patrón helicoidal en planos paralelos. La imagen B muestra cómo actúa un tensión biaxial sobro una porción de fibras en la misma región. Imagen adaptada a partir de figuras e imágenes SEM proporcionadas por Riverside.

Figura 27 - Esquemas de región de estrías y su ubicación dentro de las diferentes regiones del martillo dáctilo.

Figura 28 - Tensiones y deformaciones en la región periódica. (A) Muestra la distribución de tensiones en 3.5 useg, para cambios de modulo elástico en la región de estrías. Con flechas se indica la magnitud y dirección de las tensiones principales 
máximas. (B) Para explicar los efectos que produce la región de estrías en la región periódica, se realiza un cambio en el módulo elástico de la región de estrías de 10 GPa a $100 \mathrm{GPa}$. Cuanto mayor E (modulo elástico) en la región de estrías, menor tensión en la región periódica.

Figura 29 - Corte transversal del martillo dáctilo, mostrando microfisuras en las diferentes regiones. Imagen proporcionada por el Laboratorio de Riverside.

Figura 30 - Esquema del modelo adoptado para describir la microestructura

Figura 31 - Valores de módulo elástico obtenidos por indentación sobre la región de periódica del dáctilo. Imagen adaptada de la publicación de Weaver et. al. [24]

Figura 32 - Primer orden jerárquico- Materiales constitutivos y esquemas de modelado.

Figura 33 - Modelo numérico de las fibrillas

Figura 34 - Segundo Orden- Matriz - Propiedades efectivas. 74

Figura 35 - Segundo orden jerárquico - Propiedades de la fibra. 75

Figura 36 - Tercer orden - Grupo de Fibras. .76

Figura 37 - Imágenes de microscopia electrónica mostrando la región periódica y sus características en la composición de fibra y mineral y la geometría que tiene la misma al generarse una apertura en la dirección indicada por las flechas. Figura adaptada a partir de imágenes SEM proporcionadas por el Laboratorio de Riverside 77

Figura 38 - Modelo micromecánico. 78

Figura 39 - Modelo numérico de la región periódica 79 
Figura 40 - Condiciones de borde aplicadas a los modelos de elementos finitos .... 80

Figura 41 - Resultados del modelo de elementos finitos.

Figura 42 - Mosaicos mostrando la deformación de las fibras.

Figura 43 - Distribución de tensiones sobre la celda unidad considerada.

Figura 44 - Microestructura de la región de estrías. Imágenes SEM proporcionadas por el Laboratorio de Riverside.

Figura 45 - La imagen A corresponde a un acercamiento de la cara sagital de la región de estrías. La imagen $\mathrm{B}$ muestra un acercamiento hacia un agujero conjuntamente con su modelización. La imagen C muestra un conteo de agujeros en la imagen. Imagen SEM A y C proporcionada por Riverside. 86

Figura 46 - Foto de indentación de la cara transversal mostrando de manera cercana la alineación de las fibras en la región de estrías. Imágenes SEM proporcionadas por Riverside.

Figura 47 - Imagen de la cara transversal de la región de estrías, donde se ve con claridad los planos de fibras y las estrías entre ellos. Imagen SEM proporcionada por Riverside.

Figura 48 - Representación en 3D de la celda unidad de la región de estrías. 88

Figura 49 - Modelo de celda unidad de la cara sagital.

Figura 50 - Dirección de indentación de una porción de material de la región de estrías. Las imágenes SEM de cada cara fueron proporcionadas por Riverside..... 89

Figura 51 - Datos de indentación sobre la cara transversal. Información proporcionada por el laboratorio de Riverside.

Figura 52 - Modelo numérico utilizado 90 
Figura 53 - Esquema de jerarquización de modelos-Estructura jerárquica de la región de estrías del Estomatópodo. (I) Primer orden jerárquico: fibrillas formadas por cadenas de $\alpha$-quitina recubiertas de proteínas. (II) Segundo orden jerárquico: fibras formadas por fibrillas en una matriz de mineral y proteína. (III) tercer orden jerárquico: Fibras (amarillo) rodeadas por una matriz mineral (verde). (Escala 0.5 um en el cubo de la escala IV)

Figura 54 - Resultados de análisis térmico gravimétrico, mostrando el porcentaje de material orgánico versus material mineral. Debido a que la pérdida de masa ocurre a diferentes temperaturas es posible diferenciar dichos materiales. Información proporcionada por el laboratorio de Riverside, Universidad de California, EEUU.

Figura 55 - Modelo de fibrilla y fibra para FEM 93

Figura 56 - Porosidad en la región de estrías. Imágenes SEM proporcionadas por Riverside. 94

Figura 57 - Consideraciones de solo mineral sin $\alpha$-quitina. Imagen SEM proporcionada por Riverside.

Figura 58 - Gráfica de módulo elástico del compuesto versus la porosidad en el material. 96

Figura 59 - (A) Puentes minerales entre placas de nácar. También se muestra un corte transversal de un puente a escalas menores [43][44]. (B) Se muestra la presencia de puentes entre barras de la microestructura del diente de chitón 98

Figura 60 - (izquierda) Imagen de fractura de la región de estrías en su cara sagital del martillo dáctilo de la mantis marina. A diferencia del nácar o chitón, el tamaño de grano es tan pequeño dentro de las fibras mineralizadas que es difícil distinguir puentes entre fibras. (derecha) En una fibra perteneciente a los canales de la zona 
de estrías es posible ver las nano-asperidades en ella. Imágenes SEM proporcionadas por Riverside.

Figura 61 - Modelado de la región semi infinita

Figura 62 - Factor de intensidad de tensiones aplicado en términos de $\mathrm{u}_{1}$ y $\mathrm{u}_{2}$ sobre la periferia de la región semi-infinita 102

Figura 63 - Se muestra la secuencia de mallado de un modelo típico. La geometría en (1) con inicio de fisura en la coordenada $(0,0)$ es mallada con elementos triangulares en posición aleatoria usando K-means (2). Luego se subdividen cada uno de esos elementos (3) usando una subdivisión Baricéntrica. Finalmente se introducen los elementos cohesivos entre estos elementos (4)..... 104

Figura 64 - Ley cohesiva tracción-separación para un elemento de interfase. 106

Figura 65 - Ley proporcional 107

Figura 66 - Esquema de orientación de ejes adoptados ante el crecimiento de fisura. 108

Figura 67 - Errores asociados al tamaño de elemento versus el costo computacional.

Figura 68 - La imagen de la izquierda corresponde a un area de estudio rectangular mientras que la de la derecha a una elíptica....

Figura 69 - Comportamiento de una región de análisis rectangular frente a una elíptica. Errores asociados a dichas configuraciones de áreas de análisis.

Figura 70 - Esquema del modelo utilizado para el cálculo de diámetro de puente optimo entre placas circulares.

Figura 71 - Gráfica del radio de puentes en función de la tensión en la placa. Cuando la relación entre la tensión de la placa y la tensión de la placa por Weibull 
sea 1 , significa que tanto los puentes como la placa se encuentran trabajando a la tensión máxima dada por Weibull para el material.

Figura 72 - Gráfica del número de puentes en función de la tensión en la placa. Cuando la relación entre la tensión de la placa y la tensión de la placa por Weibull sea 1 , significa que tanto los puentes como la placa se encuentran trabajando a la tensión máxima dada por Weibull para el material. Particularmente en esta gráfica, se muestra que se necesita para llegar a esta condición un menor número de puentes de mayor diámetro que de menos diámetro.

Figura 73 - Gráfica del área total de puentes $\left(\mathrm{A}_{\mathrm{b}}\right)$ en relación con del área de la placa $\left(A_{p}\right)$ versus la tensión en la placa en relación de la tensión máxima de la misma dada por Weibull. Particularmente en esta gráfica, muestra que en términos de eficiencia de área, un radio menor llega a la condición optima de tensiones antes que un radio mayor.

Figura 74 - Longitudes de fractura utilizadas en los modelos.

Figura 75 - Caracterización de la interfase. Se muestran los parámetros de separación, diámetro de puente y altura de la interfase.

Figura $76-\mathrm{s} / \mathrm{d}=0.56$

Figura $77-\mathrm{s} / \mathrm{d}=1.11$

Figura $78-\mathrm{s} / \mathrm{d}=1.67$

Figura $79-\mathrm{s} / \mathrm{d}=2.22$

Figura $80-\mathrm{s} / \mathrm{d}=3.33$

Figura $81-\mathrm{s} / \mathrm{d}=4.44$ 125

Figura 82 - Valores de $G / G_{0}$ en función de $\theta_{0}$. 126 
Figura 83 - (a) muestra una distribución pentagonal de puentes en la plata. (b) muestra una distribución rectangular de puentes en la placa.

Figura 84 - Relación entre área de los puentes vs el área de la placa para distintas relaciones de diámetro de puente y separación, y distinta configuración ya sea un arreglo rectangular de puentes como pentagonal. El eje de las abscisas está representado en forma logarítmica para mejor visualización del gráfico. 128

Figura 85 - En función de la relación del diámetro de los puentes y sus separaciones se muestra el comportamiento teórico y semi -teórico de la interfase para modos mixtos de carga. Las curvas separan dos regiones: la derecha corresponde a las relaciones de s/d y ángulos de modo mixto para el cual la fisura crece por la interfase. La zona de la izquierda a la curva indica donde crecerá por el sólido. L1 y L3 corresponden a longitudes de fractura donde L3>L1. 130

Figura $86-\mathrm{s} / \mathrm{d}=0.55 ; \Psi=0^{\circ} ; \mathrm{L} 1$. La figura de la izquierda muestra la distribución de tensiones antes de la fisura y la derecha una vez fracturado un puente y a un instante de producirse la fractura total de ellos. Las distancias en las figuras se encuentran en um

Figura $87-\mathrm{s} / \mathrm{d}=1.11 ; \Psi=0^{\circ} ; \mathrm{L} 1$. La figura de la izquierda muestra la distribución de tensiones antes de la fisura y la derecha una vez fracturado la totalidad de los puentes. Puede observarse que la fisura no es completamente recta y construye un zigzag dentro de la interfase. Las distancias en las figuras se encuentran en um. 132

Figura $88-\mathrm{s} / \mathrm{d}=1.11 ; \Psi=40^{\circ} ; \mathrm{L} 1$. De izquierda a derecha se muestra la secuencia de la fractura, la cual inicia en una dirección y luego va hacia otra por el sólido. Las distancias en las figuras se encuentran en um. 132

Figura $89-\mathrm{s} / \mathrm{d}=1.66 ; \Psi=40^{\circ} ; \mathrm{L} 1$. De izquierda a derecha se muestra la secuencia de la fractura, la cual se propaga por la interfase un par de puentes y luego se deflecta hacia el sólido. Las distancias en las figuras se encuentran en um. 133 
Figura $90-\mathrm{s} / \mathrm{d}=4.44 ; \Psi=85^{\circ} ; \mathrm{L} 1$. A pesar del ángulo de carga tan extremo, esta interfase resulta tan débil estructuralmente que la fisura crece a través de ella antes de continuar por el sólido. Las distancias en las figuras se encuentran en um ..... 133

Figura $91-\mathrm{s} / \mathrm{d}=1.66 ; \Psi=40^{\circ}$. La figura de la izquierda corresponde a una longitud de fractura L1 y la de la derecha a L3. Las distancias en las figuras se encuentran en um

Figura $92-\mathrm{s} / \mathrm{d}=1.66 ; \Psi=80^{\circ}$.La figura de la izquierda corresponde a una longitud de fractura L1 y la de la derecha a L3. Las distancias en las figuras se encuentran en um 134

Figura 93 - Esquema del comportamiento de las interfases con puentes en su interior. A la hora de la fractura, la energía liberada en la interfase se contrapone al control de la dirección de propagación de fisura dentro de ella. 135

Figura 94 - Se muestran los resultados de los análisis numéricos de las interfases para tres tipos de longitudes de fractura L1, L2 y L3. Las curvas muestran para qué combinación de s/d y ángulo de carga $\Psi$ la fisura crece en la interfase y para cuál no lo hace. A estas curvas se agregó el resultado de curvas teóricas las cuales son comparables a los resultados numéricos pero sensibles al valor de $\Gamma_{0}$. En contraposición a los efectos de estas curvas se agregó la relación entre $\mathrm{W}_{\mathrm{s} 0} / \mathrm{W}_{\mathrm{s}}$ la cual indica en términos de presencia de material solido en la interfase la rigidez de misma. Para finalizar se indican los valores de s/d que ha elegido la naturaleza para sus diseños en el Nácar o diente de chitón.

Figura 95 - Esquema del comportamiento de las microfisuras esparciéndose por todo el sólido versus la coalescencia de microfisuras en una fractura del material. 
Figura 96 - Valores del angulo de crecimiento de fisura $\theta_{0}$ en función del ángulo de modo mixto $\Psi$ para una longitud de fractura $\mathrm{L} 1=25 \mathrm{~nm}$ y distintos casos de análisis $\mathrm{s} / \mathrm{d}$.

Figura 97 - Valores del ángulo de crecimiento de fisura $\theta_{0}$ en función del ángulo de modo mixto $\Psi$ para una longitud de fractura $L 2=125 \mathrm{~nm}$ y distintos casos de análisis s/d. 140

Figura 98 - Valores del ángulo de crecimiento de fisura $\theta_{0}$ en función del ángulo de modo mixto $\Psi$ para una longitud de fractura $L 3=490 \mathrm{~nm}$ y distintos casos de análisis s/d. 140

Figura 99 - Imágenes de microscopia electrónica de la zona periódica del martillo dáctilo de la mantis marina (izquierda) y de la zona de estrías (derecha) mostrando la presencia de microfisuras en el material. Imágenes SEM proporcionadas por Riverside 141

\section{TABLAS}

Tabla 1 - Resultados, módulo elástico de las fibrillas para una fracción volumétrica de $\alpha$-quitina de $90 \%$ y $86 \%$.

Tabla 2 - Módulo elástico de la fibra para una fracción volumétrica de fibrillas de $90 \%$ 75

Tabla 3 - Parámetros del análisis dimensional y los valores utilizados en los modelos 


\section{RESUMEN}

La búsqueda de mejoras en materiales está, en gran medida, orientada a la modificación química de sus componentes o nuevas combinaciones de los mismos. Avances en técnicas de fabricación, permiten actualmente la manipulación de la estructura de material a escalas macro, micro y nanométricas, en pos de mejoras en alguna propiedad en particular. Este camino hacia una performance superior de materiales ya ha sido llevado a cabo por la naturaleza a través de años de evolución. En ella podemos ver que el foco no solo se coloca en los componentes a combinar, el cual yace en los materiales que tiene en el medio, sino también en la morfología a diferentes escalas del material en sí. En este estudio nos enfocamos en la morfología de la microestructura de materiales naturales de algunos crustáceos con buen desempeño en resistencia a la propagación de fisura.

Un estudio mediante el uso de modelos computacionales detallados se desarrolló a diferentes escalas tratando de recrear las características más notorias de algunos materiales naturales. Si bien para esta investigación fueron abordados estudios de particularidades de diferentes organismos, como la coraza del abulón rojo de california, el diente de chitón y el exoesqueleto del martillo dáctilo del estomatópodo mantis marino, fue en esta última en la cual se centraron los análisis y de los cuales se presentan en esta investigación. En cada caso se trató de separar una celda unidad representativa en cada una de las escalas de estudio que representa el material y mediante el uso de herramientas computacionales utilizando el método de elementos finitos y técnicas de homogenización, fue posible determinar el funcionamiento y características mecánicas de estos materiales.

Observaciones de imágenes de microscopia electrónica, permitieron dar luz a un hecho importante del material: la existencia de microfisuras observadas en las diferentes regiones indica que este tipo de material convive con el daño y trata de mitigarlo a través de mecanismos que disipan la energía. Otra observación indica 
además que el crecimiento de fisura sucede paralelo a la longitud de las fibras, por lo que una microestructura con arreglo de fibras en forma helicoidal como el que la mantis presenta, favorece a la disipación. Es por ello que una interfase entre fibras que guie la fisura y a su vez eleve la disipación de energía no resulta extraña de ser utilizada por la naturaleza.

La presencia de uniones rígidas en las interfases entre placas del nácar o barras de la microestructura del chitón y su fractura inicial, por ejemplo, son una característica común que actúa como uno de los primeros mecanismo de disipación de energía. La presencia de estas uniones rígidas entre fibras, es factible en la microestructura de la mantis, por lo que modelos de fractura lineal elástica conjuntamente con modelos de zonas cohesivas fueron llevados a cabo de modo de determinar la cantidad y distribución óptima de estos elementos que a su vez permiten guiar la fisura a través de la interfase. Esta investigación representa un pequeño paso hacia el entendimiento de mecanismos de disipación del daño, donde el foco no reside en impedir la ocurrencia de la fisura sino en tratar de manejarla y mitigarla mediante la dispersión de la misma.

***Convivir con el daño y tratar de mitigarlo*** 
Introducción

Muchos materiales naturales de componentes frágiles encontrados en la naturaleza, presentan alta rigidez, alta tensión de rotura y gran tolerancia al daño [1]. Algunos ejemplos que desarrollaremos a lo largo de esta investigación lo constituyen familias de organismos biológicos como mantis marinas, ostras etc. La observación de estos organismos otorga conceptos e ideas que abren un nuevo espectro de soluciones a problemas ingenieriles y ofrecen una fuente de información de muy alto valor.

Actualmente, nuevas técnicas de fabricación permiten experimentar con materiales y arreglos micro-estructurales y alcanzar buenas propiedades de dureza, rigidez y tenacidad a la fractura en un solo compuesto. La introducción de técnicas de microscopia de fuerza atómica (AFM), la manipulación de materiales a escala nanométricas y nuevos procesos de fabricación, han redefinido el concepto de diseño de materiales aumentando su performance sin variar su composición química intrínseca. Diseños jerárquicos, autorreparables, multifuncionales, adaptables son algunos ejemplos de funciones que deben cumplir hoy los materiales y donde el concepto fundamental de la mejora reside en la modificación estructural a diferentes escalas, manteniendo los componentes inalterables. En esta investigación nos enfocamos en características geométricas de la estructura a diferentes escalas que otorgan mejoras en la tenacidad a la fractura sin comprometer otras características como dureza o resistencia tal como lo posiciona el gráfico de la Figura 1. 


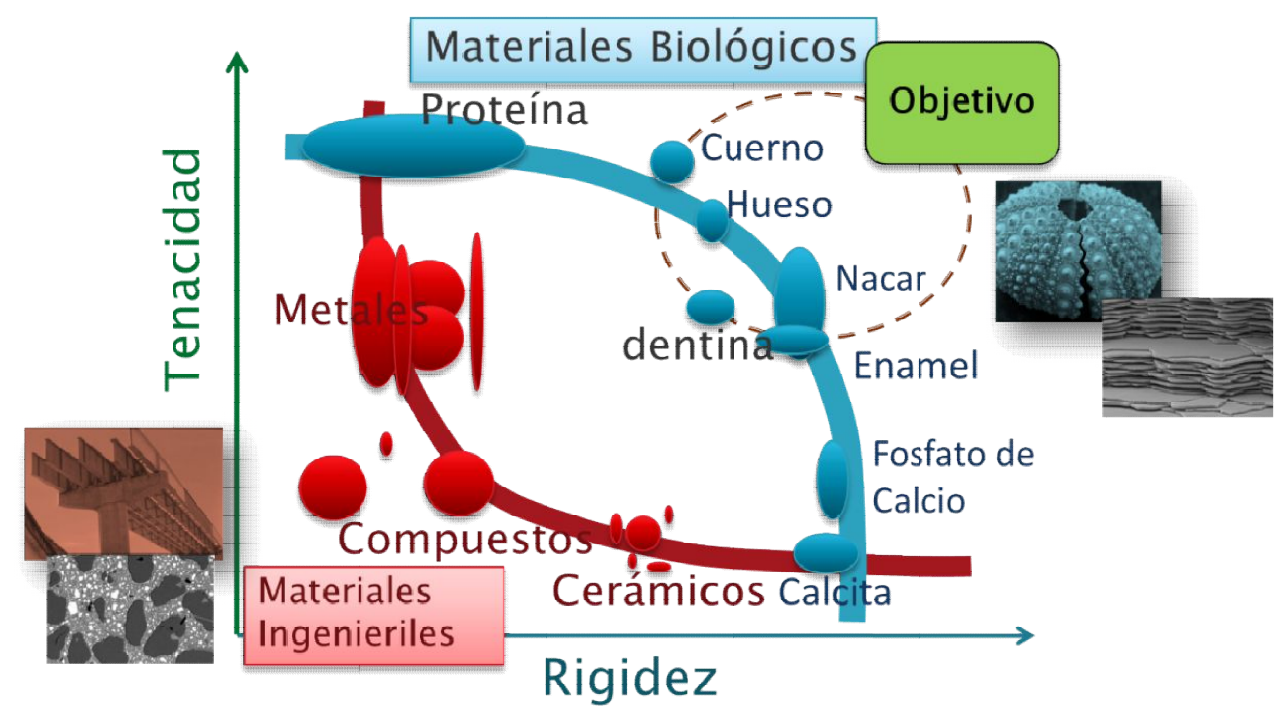

Figura 1 - Adaptación de las gráficas de Fratzl, et al. J. Mater Chem. 2004[2]. Muestra la relación entre la rigidez y la tenacidad a la fractura para materiales actualmente utilizados en la ingeniería versus materiales naturales de estudios en estas últimas décadas.

Estudios experimentales y observaciones de estos materiales a través de imágenes de microscopia electrónica permiten vislumbrar estrategias elegidas por la naturaleza para la mejora de las propiedades mecánicas de los mismos. En algunos compuestos como el nácar, estas estrategias son conocidas[3][4], sin embargo en estas últimas décadas nuevos materiales naturales fueron encontrados y sus estrategias de funcionamiento no han sido develadas aún (Figura 2). Complejos mecanismos micro-estructurales generan deflexión de fisura, ramificación y crecimientos de fisuras helicoidales por ejemplo, otorgando alta tenacidad a la fractura a pesar de estar constituidos por compuestos frágiles. 


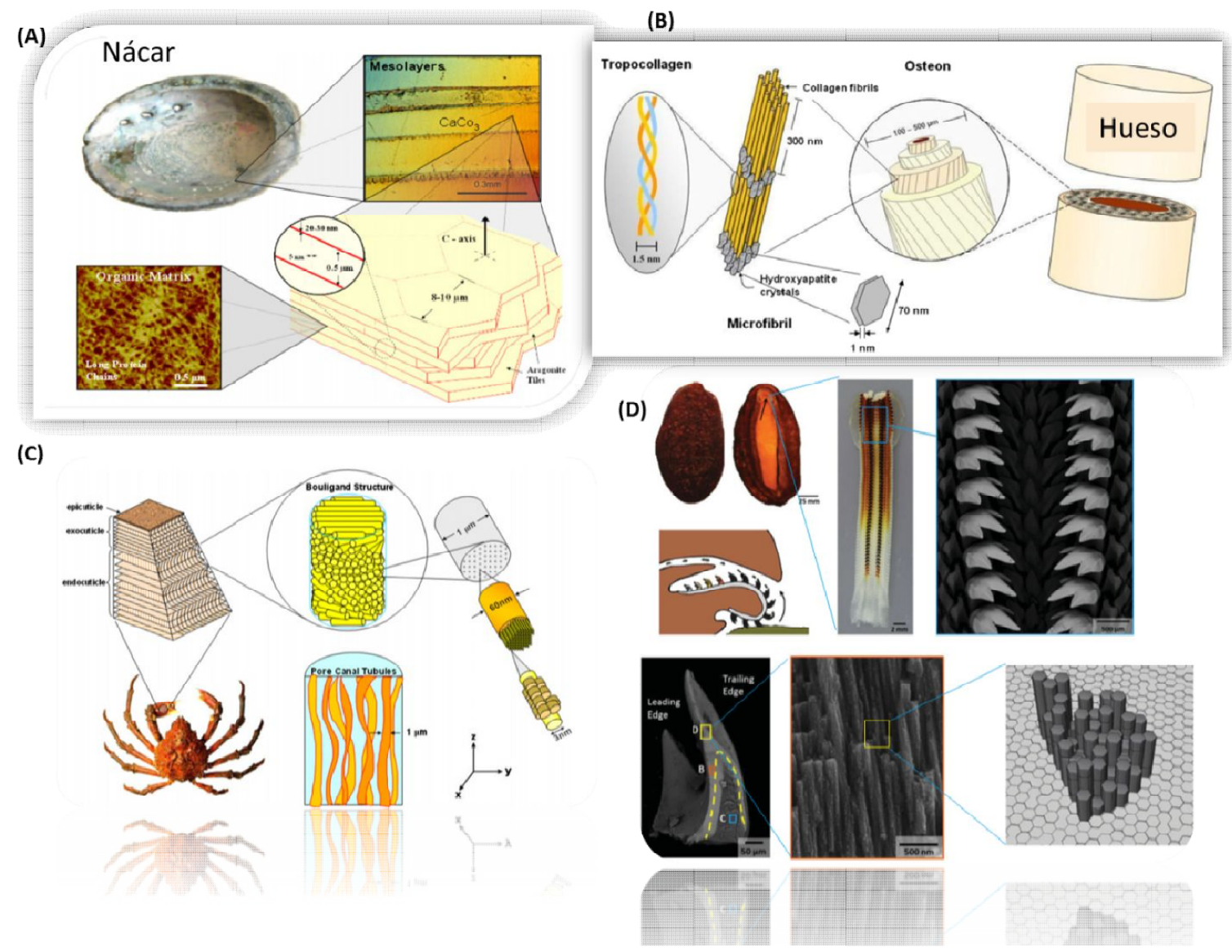

Figura 2 - Distintos materiales naturales donde la estructura del material a diferentes escalas es distinta. (A) muestra la microestructura del nácar, caracterizada por la presencia de placas en una disposición de ladrillo y mortaja. (B) muestra un hueso caracterizado por la presencia de

fibras en disposición longitudinal. Sin embargo (C), muestra una microestructura de un cangrejo marino compuesta de fibras dispuestas en forma helicoidal. (D) muestra la microestructura del diente de chitón, compuesta por barras dispuestas en forma paralela una de otras. Imágenes adaptadas de Meyer et. al. y Grunenfelder et. al.[5] [1].

El objetivo general de esta investigación consiste en el estudio de las características micro-estructurales de algunos materiales biológicos destacables en dureza, resistencia al impacto y resistencia a la fractura. Nuestra meta es reconocer y aislar características claves de dichos materiales para ser volcadas al diseño de materiales compuestos novedosos que sean aptos ante cargas externas extremas, superando las performances de materiales ingenieriles conocidos hasta el momento.

Este estudio da luz sobre los mecanismos responsables de la alta resistencia al daño del exoesqueleto del martillo dáctilo de la mantis marina, desde el punto de vista mecánico. 
En particular, los objetivos específicos de este proyecto son:

1) Comprender los mecanismos de disipación de energía de fractura a diferentes escalas del martillo dáctilo de la mantis marina (Odontodactylus Scyllarus). La investigación utiliza conceptos adquiridos a través del estudio del nácar, material con alta resistencia a la fractura.

2) Evaluar el comportamiento frente a la generación de daño. En particular, estudiar la capacidad de disipar energía mediante la dispersión del daño y el control de la dirección de propagación de fisura, en detrimento de la rigidez de la interfase.

\section{AlCANCE - ORGANIZACIÓN Y METODOLOGÍA.}

A lo largo de esta investigación nos enfocaremos en el estudio de mecanismos ocultos en el interior de microestructuras de materiales naturales, aquellas que permiten que el material compuesto que forman tenga una resistencia al daño destacable frente a los materiales que lo forman. Se buscará aislar y estudiar estos mecanismos para que, finalmente, sean aplicables a otros tipos de materiales creados por el hombre.

El estudio será llevado a cabo utilizando herramientas de simulación numérica. Los modelos se apoyarán en fotografías provenientes de microscopía electrónica obtenidas a través de la Universidad de California, USA, Riverside Laboratory, con los cuales se ha trabajado en conjunto a lo largo de esta investigación.

Inicialmente se realizó una selección de materiales que presentaban características mecánicas excepcionales. Se analizó la funcionalidad de esos materiales en el medio en el cual se encuentran desde el punto de vista de 
solicitaciones mecánicas, y se prestó particular atención a las microestructuras de los mismos. Los estudios se realizaron a diferentes longitudes de escala dentro del material. En una escala superior, se analizaron estos materiales en su ambiente natural. Se estudiaron crustáceos como el estomatópodos (mantis marina) y moluscos como el abulón rojo. Las microestructuras de interés se encuentran en los exoesqueletos de dichas criaturas, por lo que se realizaron análisis sobre ellos. En una escala menor, analizamos la microestructura en sí. En ellas se puede observar las características jerárquicas que caracterizan a estos materiales. Nano-esferas formando fibras, barras o placas unidas de forma sólida mediante ligaduras o puentes en una matriz de compuesto orgánico blando generalmente formado por proteínas que llenan todas las cavidades.

A continuación explicaremos cuales es el alcance y la metodología utilizada en cada uno de los capítulos del documento.

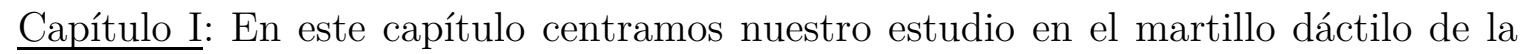
mantis marina, el cual utiliza para romper ostras marinas y otros caracoles. Estos últimos de excepcionales características a la resistencia al daño, por lo que la elección del martillo dáctilo dentro de los materiales naturales en estudio, no fue una tarea difícil. Se realizó un modelo numérico del martillo dáctilo de la mantis marina para poder determinar el mapa de tensiones en las diferentes regiones micro-estructurales. El análisis se realizó numéricamente utilizando el método de los elementos finitos. El objetivo es tratar de elucidar el papel que juegan las diferentes regiones micro-estructurales en la disipación de energía frente a una carga de impacto. El modelo numérico fue concebido utilizando modelos elásticos de materiales para cada región, como una aproximación para determinar el campo de tensiones y deformaciones en las mismas.

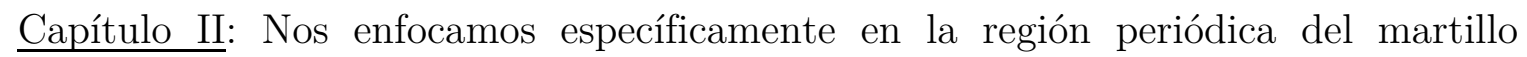
dáctilo y su dependencia en las regiones adyacentes. En este capítulo nos centramos 
en su relación con la región de estrías y sus características mecánicas. Usando los resultados provenientes de los modelos dinámicos de elementos finitos buscamos zonas donde predominen tensiones biaxiales, mostrando de esta forma que las fibras en esas regiones se encuentran bajo cargas de tracción (Modo 1) y relacionadas unas de otras mediante tensiones y deformaciones.

Capítulo III: Analizamos la microestructura a través de modelos micromecánicos basados en imágenes de microscopia de barrido electrónico (SEM) proporcionados por la universidad de California. Separamos un elemento de volumen representativo (RVE) y analizamos los mecanismos de disipación de energía dentro de la microestructura. Los RVE fueron aislados tanto para la región de estrías como la región periódica. Cada uno de ellos tiene un arreglo de fibras característico. Un análisis de Espectroscopia de energía dispersa (EDS) y de indentación proporcionados por el laboratorio de Riverside, nos permitió conocer la composición y propiedades mecánicas de cada región, como se mencionó para el capítulo 1. Sin embargo la información no fue completa por lo que se realizaron modelos numéricos para poder determinar por ejemplo la fracción volumétrica de cada compuesto. Se utilizaron técnicas de homogenización, además del modelado numérico. Cotas de Void y Reuss o Teoría de Mori Tanaka son algunas de ellas. Simulaciones mediante el uso de elementos finitos nos permitieron reproducir los valores encontrados en los test de indentación y así validar los modelos realizados.

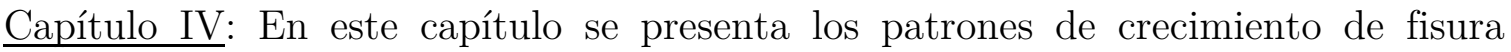
dentro de la microestructura antes mencionada. A través de un estudio de interfases intentaremos corroborar la capacidad del material para desperdigar y controlar el daño luego de una carga de impacto. Este control de la energía de disipación es posible debido a la presencia de un arreglo de fibras de gran resistencia mecánica y una matriz conforme, que permiten el crecimiento de la fisura a través de la interfase entre fibras. Durante esta investigación las características de las interfases han sido un punto de interés. Como se ha visto 
entre las placas del nácar, las barras que conforman el diente de chitón o las fibras de la microestructura del estomatópodo, las interfases son los mecanismos claves donde se disipa la energía de impacto. En estos materiales, la presencia de uniones rígidas o puentes entre sus elementos como placas o barras, desempeñan un rol importante en la resistencia al daño de los materiales compuestos que forman. Creemos que existe una distribución óptima de esta clase de vínculos dentro de la interfase como así también de sus características geométricas, que permite el control de la dirección de crecimiento de la fisura a través de sus interfases, además de generar una disipación óptima de energía de fractura.

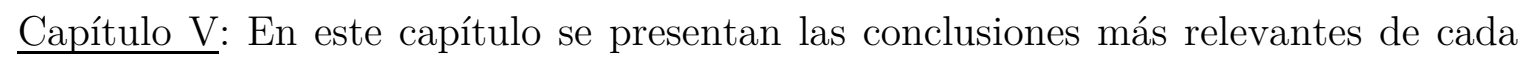
uno de los capítulos anteriores enfocadas en una conclusión general del trabajo completo. También se presenta el trabajo a futuro o lo que se considera que puede aportar a la investigación. 


\section{AnteCEDENTES - Estado DEL ARTE.}

El diseño de materiales basados en arquitecturas biológicas ha generado un gran interés en los últimos años. La eficiencia de los materiales biológicos en sus funciones, producto de años de evolución, ha captado nuestra atención. El entendimiento de los objetos y procesos que se encuentran allí, pueden guiarnos a desarrollar materiales con alta performance mecánica, térmica, eléctrica, por ejemplo.

En esta investigación nos centramos en el estudio de materiales compuestos con microestructura laminar o helicoidal que exhiben propiedades mecánicas superiores a la de los componentes que lo forman. El estudio se interesa particularmente en el martillo dáctilo de la mantis marina, de arreglo microestructural helicoidal. Algunas de las líneas de investigación fueron originadas en los estudios anteriores acerca del material nácar perteneciente al abulón rojo, de microestructura laminar pero de arquitectura jerárquica similar a la del martillo dáctilo. No fue el fin de esta investigación el describir las características microestructurales de estos material, podemos citar grupos de investigación como Gao et. al., Meyer et. al., Nikolov et. al., Rim et. al, Romano et. al, entre otros, donde presentan las características de dichos materiales a diferentes escalas[6][7].

Respecto al Nácar, fue estudiado inicialmente por autores como Currey en 1977 [8]. Podemos encontrar en la literatura la generación y composición de este material [9], todos elementos surgidos del propio ambiente en el cual se encuentra. Podemos mencionar $\mathrm{C}, \mathrm{N}, \mathrm{Ca}, \mathrm{H}, \mathrm{O}, \mathrm{Si}, \mathrm{P}$, en resumen todos componentes de características frágiles. Sus características microestructurales tanto geométricas como mecánicas [10]a diferentes escalas y el rol de cada componente en el material, fueron presentadas por autores como Gao et. al., Meyer et. al. y Zavattieri et. al. Es de particular interés para esta investigación los mecanismos de disipación de 
energía que generan, en estos tipos de materiales, sus características de alta tenacidad a la fractura y rigidez [11][12][13].

El nácar posee una estructura jerárquica compleja (Figura 3), optimizada en todos los niveles de escala. Los mecanismos de disipación se dan en varias escalas del material.

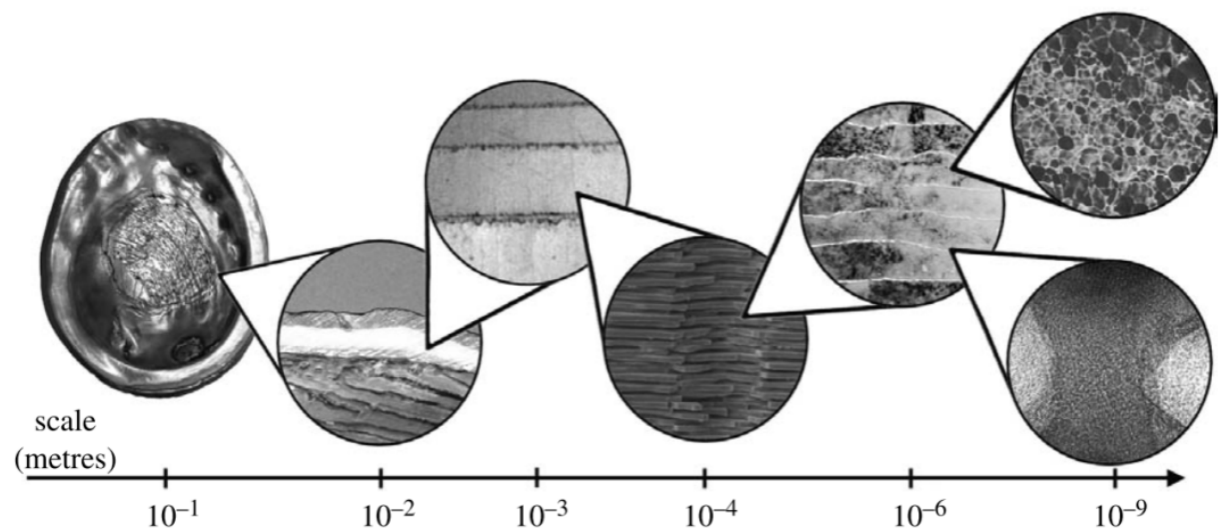

Figura 3 - Estructura jerárquica del nácar (Barthelat 2007 [14] )

La coraza externa del abulón rojo, posee una capa externa dura y de comportamiento frágil compuesta de cristales de calcio unida a una capa más blanda y dúctil que protege a un cuerpo blando en su interior. El nácar constituye esa capa relativamente blanda y dúctil. El mismo está compuesto en un 95\% de su volumen por materiales rígidos y el resto lo constituyen interfases delgadas de proteínas y polisacáridos [15]. Una microestructura típica del nácar se presenta en la Figura 4. En una escala microscópica podemos distinguir la estructura de "ladrillo-mortero" característica del mismo (Figura 4). Las tabletas o placas (ladrillos) tienen características poligonales y una dimensión de 0.5 um de espesor y entre 5 y 8 um de diámetro aproximadamente. Las mismas están apiladas con una separación entre ellas bien definidas y que ronda los $30 \mathrm{~nm}$. El tipo de apilamiento puede ser columnar o aleatorio y las tabletas presentar ciertas ondulaciones para permitir el encastre entre ellas [14]. Si realizamos observaciones a escalas menores podemos distinguir características estructurales como nanoasperidades [16] o 
puentes de minerales en la interfase (Figura 5), todo eso rodeado por un compuesto orgánico de material[17].

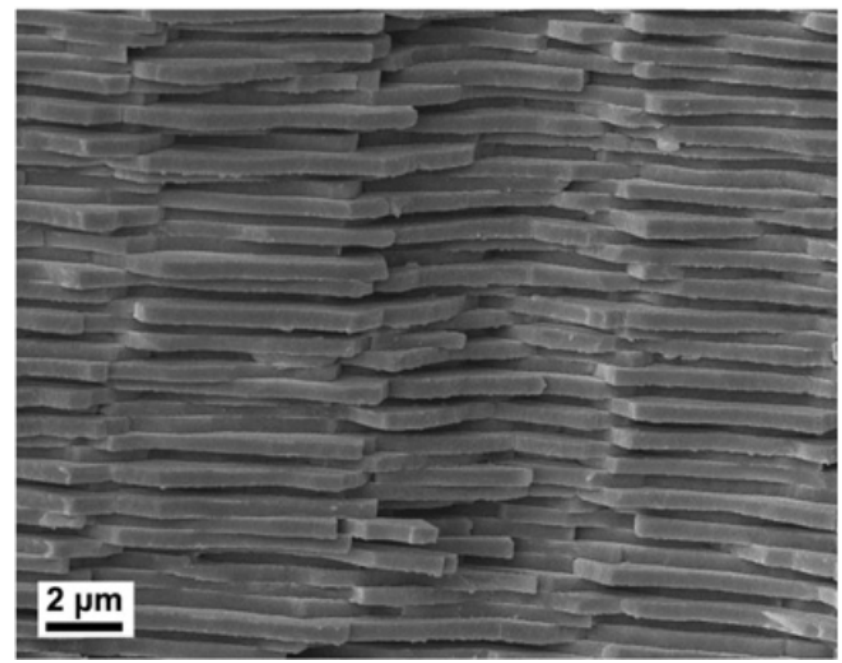

Figura 4 - Microestructura típica "ladrillo - mortero" del nacar. [11]

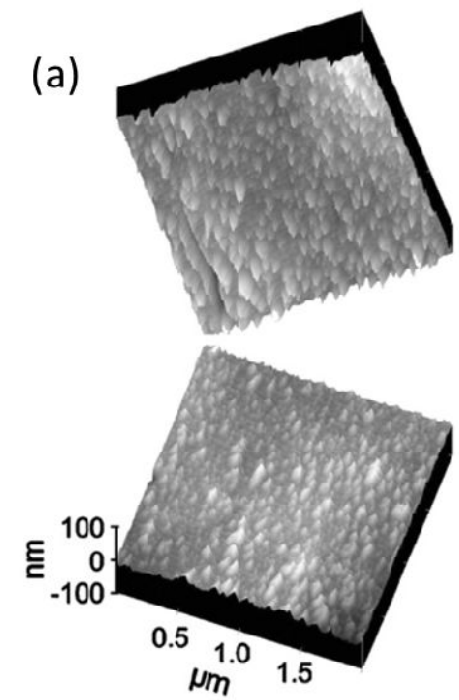

(b)

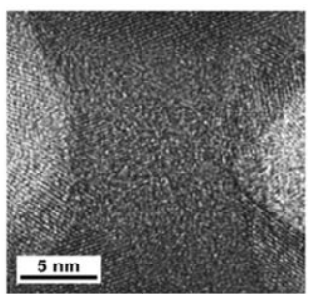

Figura 5-a) características geométricas de la interfase entre dos plaquetas; b) vinculo rígido, puente, entre dos plaquetas de nacar. [12]

En este material conviven diferentes mecanismos de disipación de energía, producto de la microestructura jerárquica que mantienen. Autores como Rim o Gao presentan mecanismos de disipación muy localizados como el deslizamiento entre placas seguido de una superposición de las mismas, el cual constituye un mecanismo dominante a la hora de considerar la tenacidad a la fractura[13][12]. Para ello se han llevado a cabo modelos numéricos de celdas unitarias tratando de cuantificar la disipación de energía. 
Bajo esfuerzos normales las tabletas del nácar se deslizan una sobre otra entrelazándose progresivamente. Los puentes en la periferia de las placas fallan generando microfisuras todo a lo largo del material. Sin embargo, los puentes en la zona central permanecen enteros impidiendo la expansión lateral del material y generando una competencia de mecanismos de tracción-compresión mostrado en la Figura 6.

A medida que los puentes se van fracturando se generan microfisuras en el material que dispersan el daño por toda la región como muestra la Figura 7. A medida que esa distribución de daño sucede, se disipa energía sobre un área mayor que si el daño fuese concentrado. En particular para este material, este comportamiento se ve reflejado en un endurecimiento por deformación en la curva tensión deformación Figura 8.

(a)

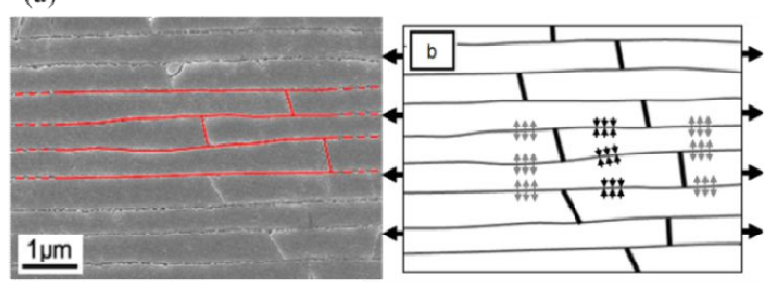

(b)

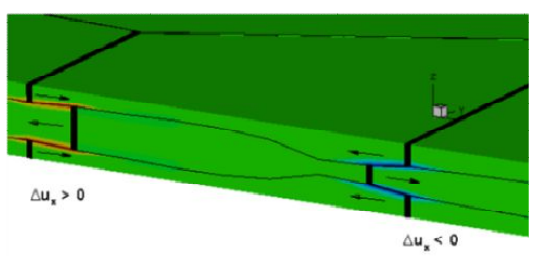

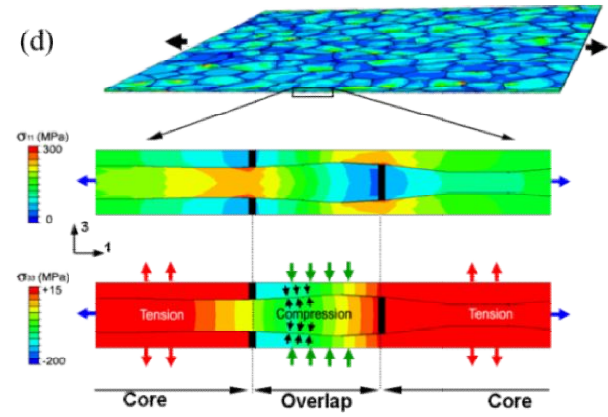

Figura 6 - Mecanismos de disipación de energía[12]. Las ondulaciones generan un enclavamiento entre placas de nácar, generando una competencia entre disipación debido a tracción o corte.

Figura adaptada de la publicación referenciada de Barthelat et.al. 


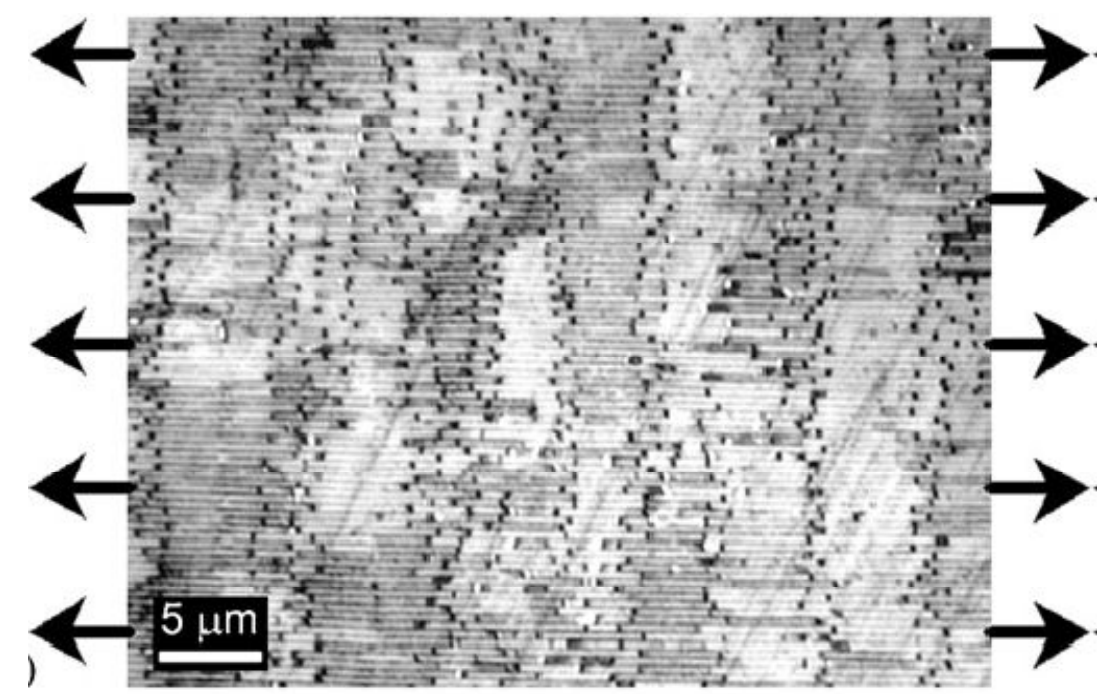

Figura 7 - Micrografía mostrando la disipación del daño producto de micro desplazamientos de las tabletas en toda la superficie de la muestra. [12]

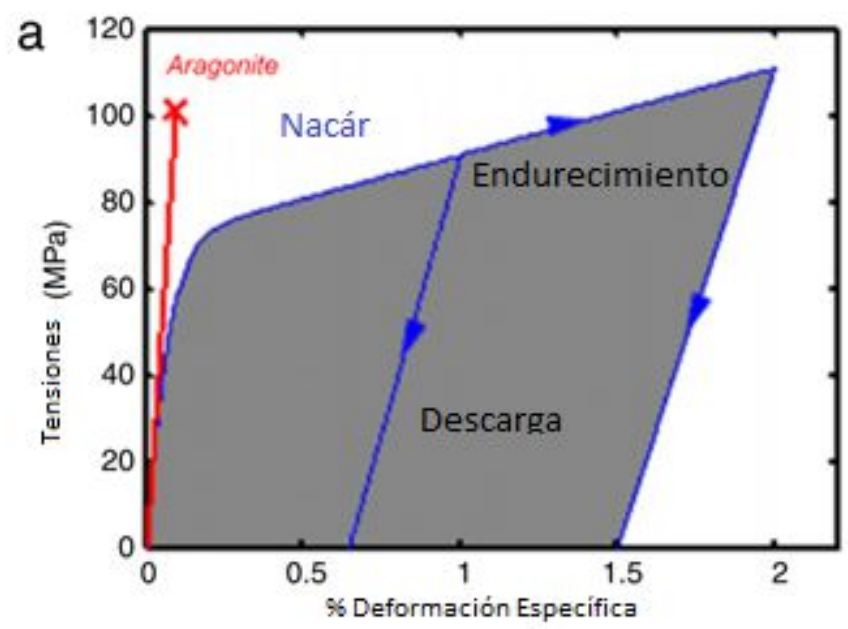

Figura 8 - Curva experimental tensión-deformación para una muestra de material nácar. Gráfica adaptada de la publicación de Rim et. al.(2011)[13]

La presencia de puentes en el interior de las interfases no solo permite un incremento de la energía disipada a medida que la misma se fisura sino que contribuye a un control de la dirección de crecimiento de la misma. Esto nos lleva a estudiar la configuración que adopta la naturaleza para favorecer este fenómeno. Autores como Barthelat [18] han planteado el control de la dirección de propagación a través de la generación de interfases débiles. De esta forma es posible direccionar la fisura como ya lo ha mencionado Hutchingson and Het en 1988[19].

Hutchingson establece que cuando una fisura se encuentra con una interfase, la misma puede atravesarla o deflactarse y continuar dentro de la misma. Este 
comportamiento está caracterizado por la relación entre la tasa de liberación de energía en la interfase $\left(\mathrm{G}_{0}\right)$ frente a la del material sólido y la relación entre la tasa crítica de liberación de energía de la interfase frente a la misma del material sólido.

$$
\frac{\Gamma_{0}}{\Gamma}>\frac{G_{0}}{G}
$$

$\Gamma_{0}$ : resistencia a la fractura de la interfase

$\Gamma$ : resistencia a la fractura del material en modo 1.

$\mathrm{G}_{0}$ : Energía critica liberada bajo una fractura deflectada.

G: Energía critica liberada bajo modo 1.

Barthelat et al. [18] han presentado resultados de ensayo utilizando la técnica de grabado por láser. Un arreglo de láseres genera microfisuras sobre una probeta de policarbonato. Un plano de defectos alejado de la punta de fisura es grabado formando un ángulo con el plano de la fisura. El material testeado presenta una resistencia a la propagación de fisura mucho más baja que el material sin microfisuras, sin embargo, presenta un aumento en su tenacidad.

Respecto al material presente en el diente del chitón, el mismo corresponde a un compuesto con características de dureza y microestructura compleja[20] también de interés. Está formado por óxido de hierro, oxihidróxido de hierro y apatita[21]. El mismo presenta una estructura ordenada jerárquicamente al igual que el nácar desde una escala nanométricas a micrométricas. El exterior del diente consiste en una coraza dura haciéndose más blanda hacia el interior. Posee una microestructura en forma de barras orientadas paralelamente unas con otras de un diámetro en su sección transversal de $200 \mathrm{~nm}$ aproximadamente (Figura 9). La presencia de nanoasperidades y puentes en sus interfases muestra una reminiscencia hacia el material nácar remarcable. 
(a)

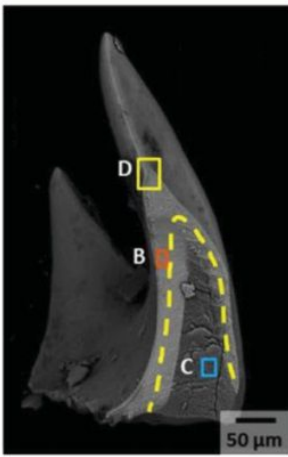

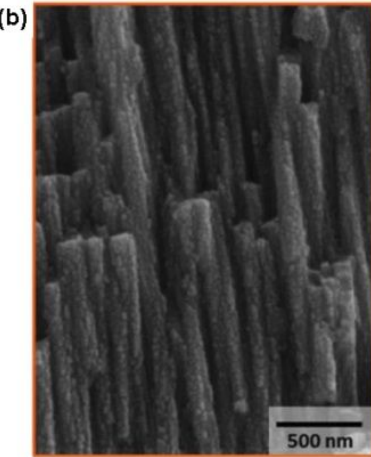
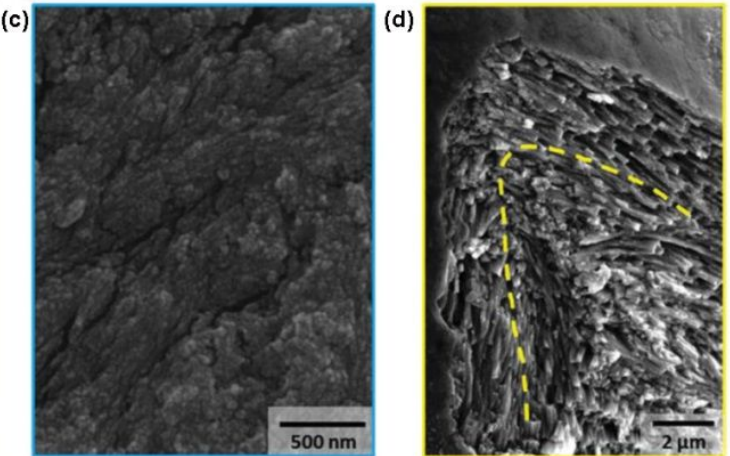

Figura 9 - Características microestructurales del diente de chitón; a) fractura longitudinal del diente de chitón, se muestra en línea punteada la dirección de las barras que forman la microestructura. Con recuadro de colores se indica la ubicación de las figuras b a c. [5]

Por otro lado, respecto al material presente en el dáctilo de la mantis, esta investigación presentará una descripción de las diferentes microestructuras que componen el material, teniendo como base los conceptos aprendidos del estudio del nácar o el diente de chitón.

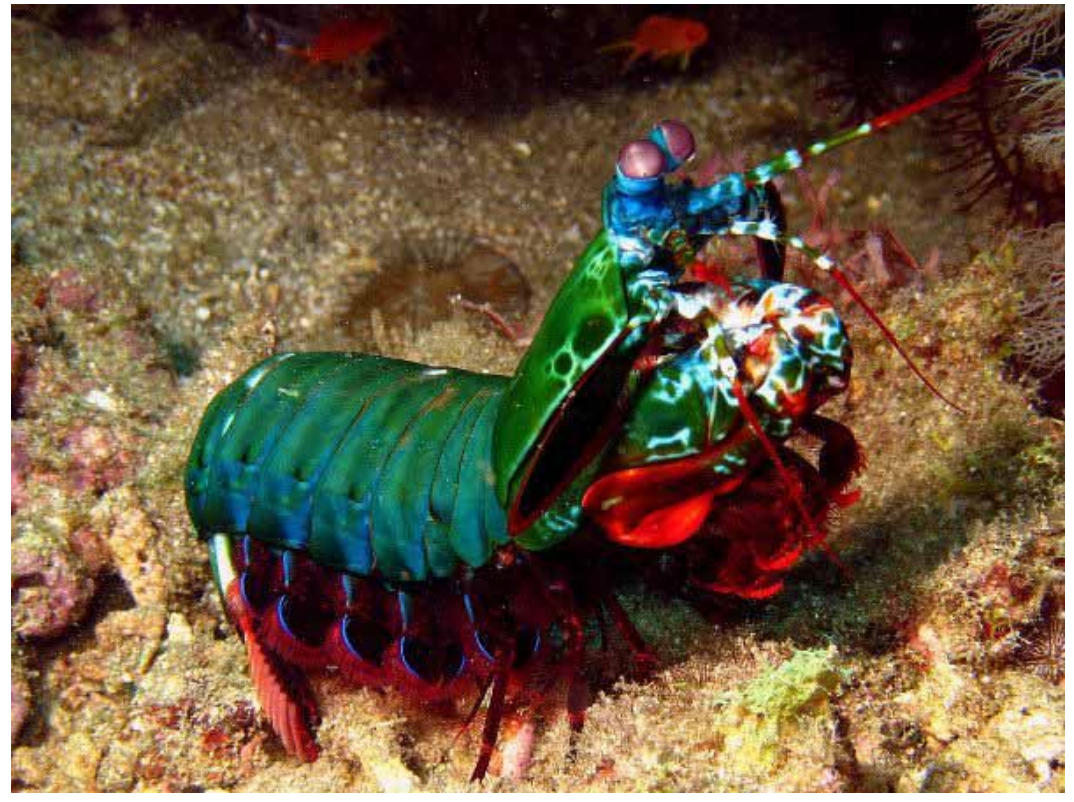

Figura 10 - Imagen de un ejemplar de mantis marina.

La mantis marina (Figura 10), fue descripta por primera vez en 1835 por Frederick Corbin Lukis. Sin embargo, fue Patek et al. en 2005 [22] quien registró características de aceleración y velocidad de impacto de sus extremidades, datos que llamaron la atención para desarrollar esta investigación. Podemos encontrar autores como Nikolov o Romano donde presentan microestructura de especímenes similares. 
Aquí se ha abordado el estudio del material dáctilo de una Mantis marina (Odontodactylus Scyllarus) el cual es un material que presenta mecanismos capaces de mitigar el daño durante altas fuerzas de impacto. Estos mecanismos aún no se conocen en su totalidad, por lo que el análisis de la estructura de este material es de gran interés. Es en este punto donde los avances que se realicen en el estudio mecánico de la microestructura de este material, constituyen un aporte original y novedoso.

El estudio numérico contemplará el análisis de la resistencia a la propagación de fisura de estos materiales además de su rigidez. Se utilizarán modelos numéricos cohesivos [23] en los cuales se predecirá la energía necesaria para la fractura a diferentes escalas usando teorías descriptas por Bazant y Chen entre otros. Las estrategias de disipación de daño y los resultados obtenidos con este modelado numérico, constituirán otra parte del aporte novedoso de esta investigación. 


\section{CAPÍtulo I - EstomatóPodo}

\section{I.I - Introducción}

El estomatópodo, comúnmente conocido como camarón mantis, es un crustáceo depredador que vive en aguas bajas de los mares tropicales y subtropicales. Habita generalmente madrigueras o cavidades en el lecho marino y se alimenta principalmente de gusanos anélidos, caracoles, almejas, camarones, cangrejos y peces. Se caracterizan por ser extremadamente agresivos tanto para cazar sus presas como para defender su territorio. Como especie, se encuentran entre los más hostiles. Una de sus características físicas más notables radica en sus extremidades anteriores el cual usa para atacar a sus presas. Estos crustáceos están adaptados tanto para golpear a sus presas como alancear a las mismas con sus extremidades. La anterior característica generó dos tipos de mantis donde sus miembros evolucionaron para dichas formas de caza. Existen alrededor de 350 especies de estomatópodos y se descubre alrededor de una nueva especie por año. El rango de longitud de estas especies varía entre 15 y 335 milímetros y se los puede encontrar del más variado rango de colores.

Las estomatópodos alanceadores, Figura 11, presentan un par de extremidades anteriores equipada con varias espinas puntiagudas (entre 3 y 17). Estas espinas son utilizadas para alancear con cuerpos blandos de sus presas como peces o otros camarones. La velocidad de la embestida a través de los miembros anteriores lo posiciona entre uno de los animales con movimientos más veloces. El movimiento es completado entre 4 y 8 milisegundos y su velocidad de movimiento ronda los 10 metros por segundo bajo el agua. 

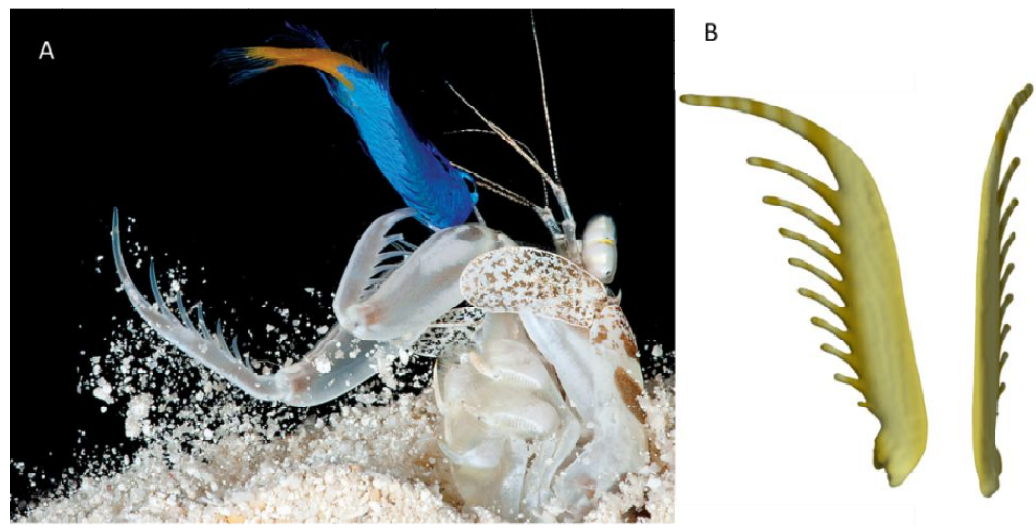

Figura 11 - Estomatópodos Alanceadores. La imagen A muestra un espécimen adulto atrapando un pez. La imagen B muestra de modo cercano la extremidad que utiliza para atrapar a sus presas y fue construida a partir del escaneo de un ejemplar real.

Los estomatópodos golpeadores, Figura 12, poseen una extremidad anterior con una espina o ninguna, pero en la mayoría de ellos el talón del dáctilo esta agrandado. Durante el golpe, el dáctilo se mantiene retraído y la presa es golpeada por esa parte del talón. Los estomatópodos golpeadores usualmente se alimentan de animales tales como caracoles, cangrejos ermitaños, almejas y cangrejos que corresponden a crustáceos con exoesqueletos fuertes. Un golpe de un ejemplar adulto de Hemisquilla Ensigera (250 mm de longitud) desarrolla una fuerza cercana a la de un calibre pequeño de arma de fuego. Los especímenes adultos recolectados en el sur de california, EEUU, son capaces de quebrar una pared de acuario formado por una capa doble de vidrio reforzado. Hasta los ejemplares pequeños de 80mm de longitud pueden quebrar el vidrio de un pecera común.
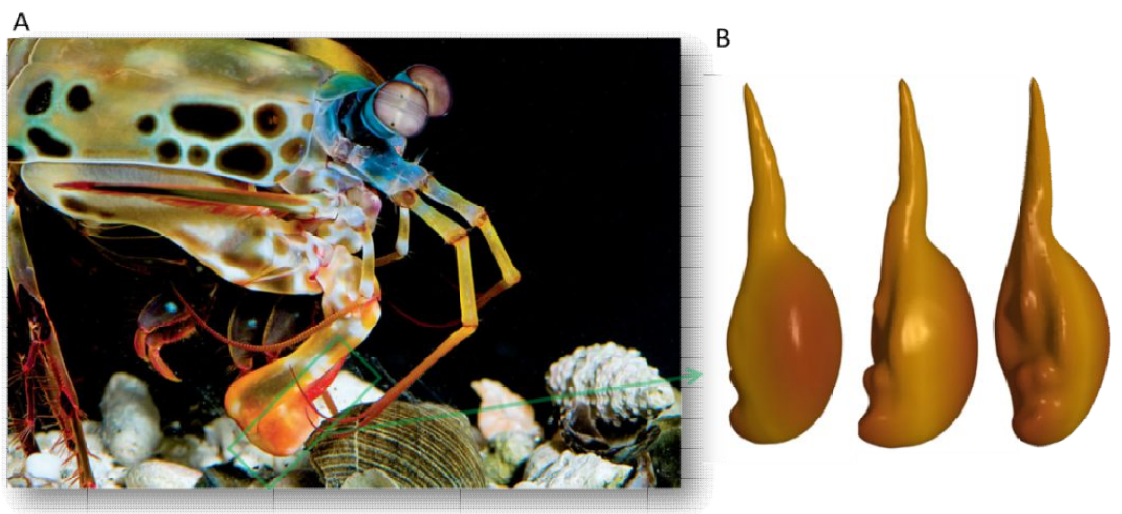

Figura 12 - Estomatópodos golpeadores. La imagen A muestra un espécimen de Odontodactylus scyllarus. La imagen B muestra diferentes vistas del martillo dáctilo utilizado como extremidad de impacto y dicho modelo fue construido a partir del escaneo de un ejemplar real. 


\section{I.II - Estomatópodo golpeador.}

El Odontodactylus Scyllarus, es un estomatópodo de arrecife comúnmente encontrado en la región Indo-Pacífico, como fue descripto por Patek et. al. en 2005 [22]. Las extremidades anteriores de estos individuos son capaces de desarrollar aceleraciones de $10.4 \mathrm{~g}$ y velocidades del orden de $\operatorname{los} 23 \mathrm{~m} / \mathrm{s}$, partiendo de una posición estática. Más aún, la velocidad del golpe es tal que la diferencia de presiones genera burbujas de cavitación sobre el apéndice y sobre la estructura que está recibiendo el golpe. Más aún en el momento del colapso de esas burbujas, se generan tensiones muy altas sobre las superficies respectivas. La fuerza debido al impacto es del orden de los 500 newtons. Más allá de los altos valores de fuerza de impacto que es capaz de generar, el martillo dáctilo es capaz de soportar miles de ciclos de carga como el mencionado, una característica que sin duda posiciona a este animal dentro de los individuos con materiales excepcionales.

En este capítulo determinaremos los esfuerzos a los cuales es sometido el martillo dáctilo, como así también la distribución de tensiones en el interior de las regiones del mismo. Nos valdremos de los resultados de imágenes e indentación proporcionados por el laboratorio "Biomimetics and Nanostructured Materials" de la Universidad de California, Riverside, EEUU. A partir de sus datos analizaremos y construiremos un modelo numérico para su utilización en el entendimiento del funcionamiento mecánico del martillo dáctilo.

\section{I.II.I - Estomatópodo: Martillo Dáctilo.}

A una escala macroscópica, el martillo dáctilo está formado por dos segmentos terminales (el propodio y el dáctilo) del segundo apéndice torácico (Figura 13). Durante una secuencia de golpe, el dáctilo se pliega hacia atrás apoyándose en el propodio para formar la extremidad funcional. 

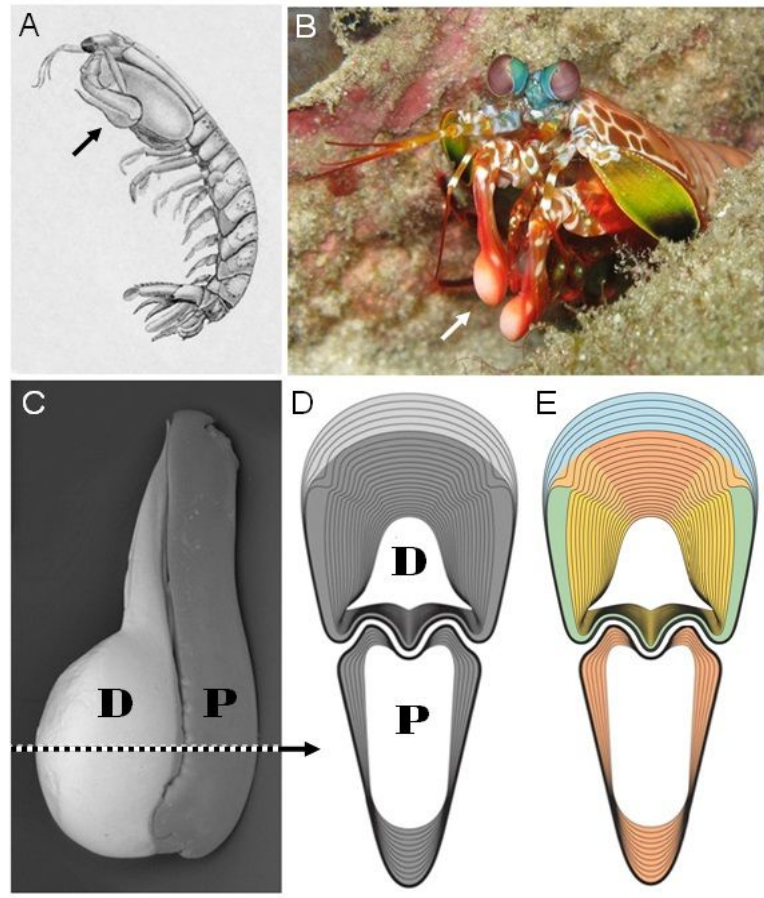

Figura 13 - La imagen A y B señalan el martillo dáctilo de la mantis marina. La imagen C muestra un acercamiento del martillo dáctilo donde $\mathrm{D}$ y $\mathrm{P}$ corresponde al dáctilo y al propodio respectivamente. La imagen $\mathrm{D}$ corresponde a un corte transversal del martillo dáctilo junto con el propodio. La imagen E muestra en diferentes colores las regiones con diferentes arreglos de material dentro de cada extremidad.

Una tomografía computada de un espécimen Odontodactylus Scyllarus revela que el extremo dáctilo es el que presenta las regiones de mayor densidad electrónica del exoesqueleto de la mantis, hasta 5 veces mayor densidad que los apéndices adyacentes. Cuando realizamos un corte transversal del dáctilo, podemos reconocer tres regiones (Figura 14): la región de impacto, región periódica y la región de estrías. 

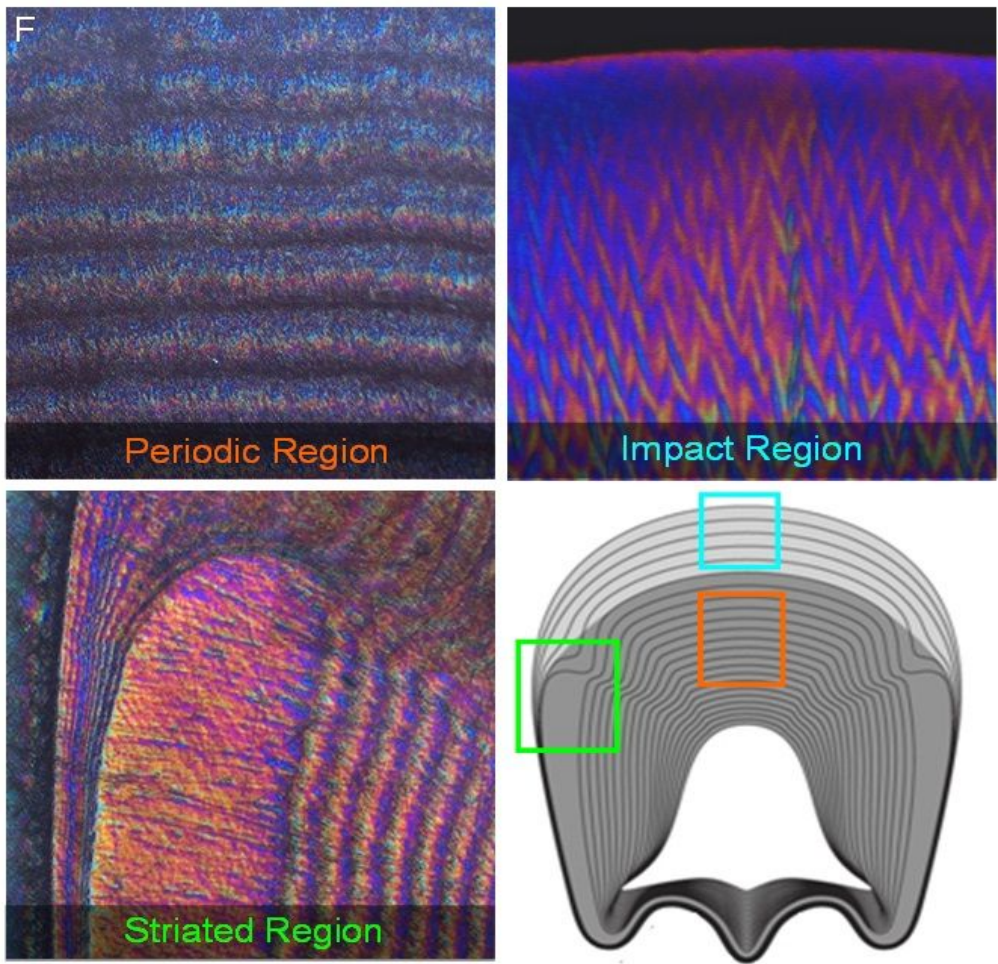

Figura 14 - Micrografías ópticas mostrando las diferentes regiones dentro del martillo dáctilo. Cada región con una orientación de fibras particulares que detallaremos más adelante. Imagen extraída de la publicación de Weaver et. al.[24]

Medidas de nanoindentación y espectroscopia de energía dispersa (EDS) de las diferentes regiones (Figura 15), revelan una correlación entre el grado de mineralización y las propiedades mecánicas de dichas zonas. Mediciones de EDS revelan la disminución de concentraciones de fósforo y calcio desde la zona de impacto hacia el centro pero en contraste un aumento de carbono y magnesio en la misma dirección. De hecho, existe un salto marcado en las concentraciones de calcio en la zona de transición entre la zona de impacto y la región periódica. Las concentraciones de fósforo sin embargo disminuyen en forma gradual (Figura 15D). Esto revela una zona bifásica mineral, donde la zona de impacto se caracteriza por la presencia de fosfato de calcio, y el resto de las regiones formadas por fosfato de calcio y carbonato de calcio. Mapas de nanoindentación muestran en la zona central del dáctilo valores de dureza y modulo elástico(Figura 15 A y B). Esta muestra que las zonas que presentan altos valores de fosfato de calcio posee los valores más altos de dureza y modulo elástico. Esta tendencia fue reafirmada tanto para muestras secas como hidratadas (Figura 16). Basados en las mediciones se 
puede dividir el dáctilo en tres regiones mecánicamente distintas: (i) la región de impacto, la cual es la región más externa y más dura de todas, tiene un espesor aproximado de 50 a 70 micrómetros y un módulo elástico de 65 a 70 GPa (sin variaciones en las mediciones de especímenes secos o hidratados); (ii) luego de un cambio abrupto en el módulo elástico encontramos la región estriada (45 GPa seca a 35 GPa hidratada); (iii) y finalmente la región periódica donde presenta un módulo elástico oscilante que varía entre 10 a $25 \mathrm{GPa}(3$ a $8 \mathrm{GPa}$ en muestras hidratadas). En la Figura 16 podemos ver las variaciones entre muestras secas o hidratadas.
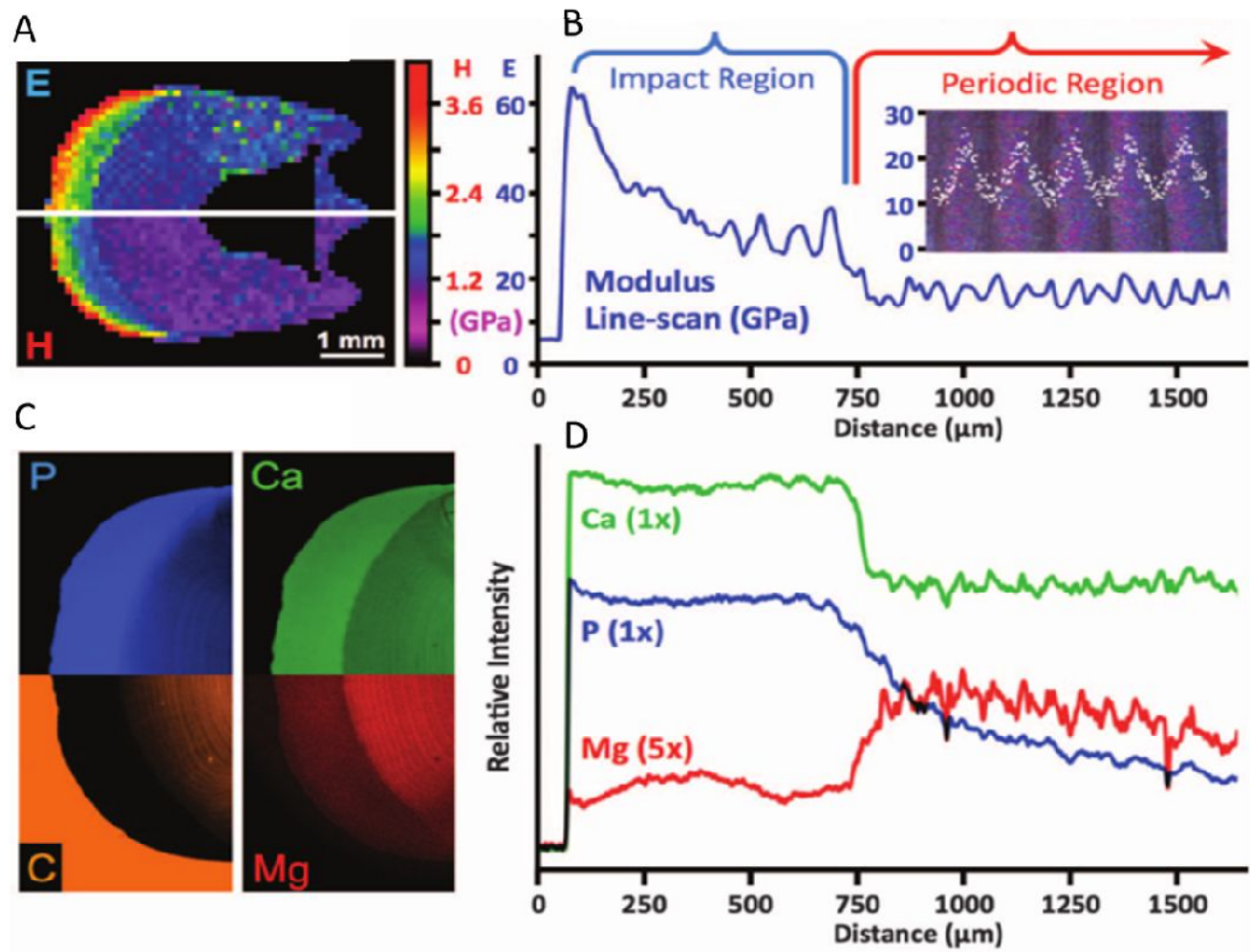

Figura 15 - Las imágenes y gráficos presentados en esta figura fueron tomados de la misma región de un espécimen seco. La Imagen A y B muestra el área indentada para la cual se obtuvo el valor de módulo elástico $(\mathrm{E})$ y dureza $(\mathrm{H})$. Las imágenes C Y D muestran mapas de EDS mostrando la no uniformidad distribución de elementos en las regiones periódicas y de impacto. Imagen extraída de la publicación de Weaver et. al.[24] 


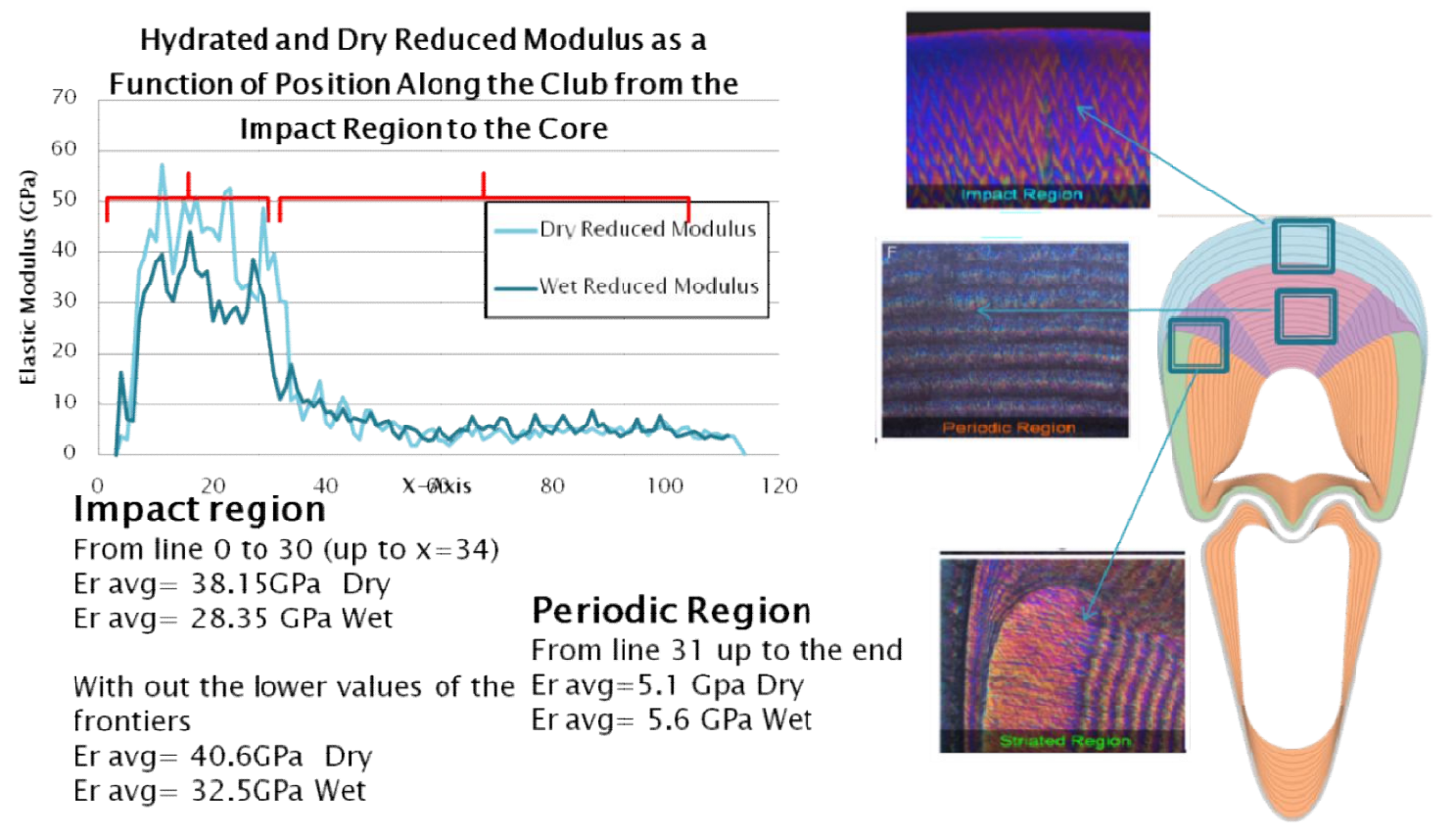

Figura 16 - Muestra la variación de modulo elástico de una muestra hidratada y otra no.

También muestra los valores promedios de dichas zonas, tanto en la región de impacto como en la región periódica. Imagen proporcionada por el Laboratorio de Riverside.

\section{I.II.II - Modelado numérico y resultados.}

Para determinar la tolerancia al daño del dáctilo, se realizó un modelado del mismo mediante el uso de elementos finitos. Se desarrolló un modelo dinámico en el cual se reprodujo un golpe del mismo sobre un objeto sólido (Figura 17). Las características del mallado mantienen las particularidades geométricas complejas del dáctilo y propodio. Para validar el impacto del dáctilo se utilizaron los datos proporcionados por Patek y Caldwel[25] (Figura 18), los cuales midieron el impacto de ejemplares reales utilizando sensores de carga en el ambiente de los mismos Se modeló el sensor como un cilindro de acero de modo de representar las mismas características de masas involucradas a la hora del impacto $(\mathrm{E}=200 \mathrm{GPa}, 5 \mathrm{~mm}$ de diámetro, $1 \mathrm{~mm}$ de espesor). La velocidad de impacto corresponde a $20 \mathrm{~m} / \mathrm{s}$. 


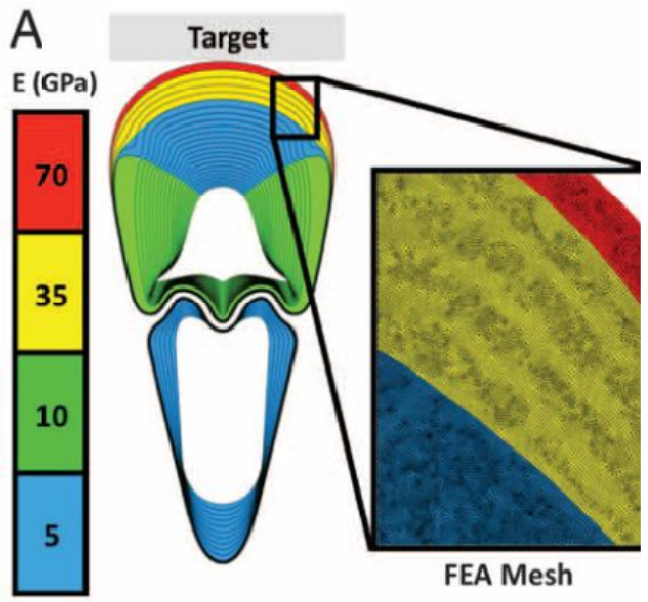

Figura 17 - En esta figura se detalla un corte transversal dáctilo y propodio señalando las diferentes regiones con modulos elasticos diferentes. Los colores indican los diferentes módulos elásticos y propiedades másicas de cada región usada para la simulación (datos obtenidos de nanoindentación en muestras hidratadas y provenientes de sincrotrón de transmisión de rayos $\mathrm{x}$ ).Imagen extraída de la publicación de Weaver et. al.[24]

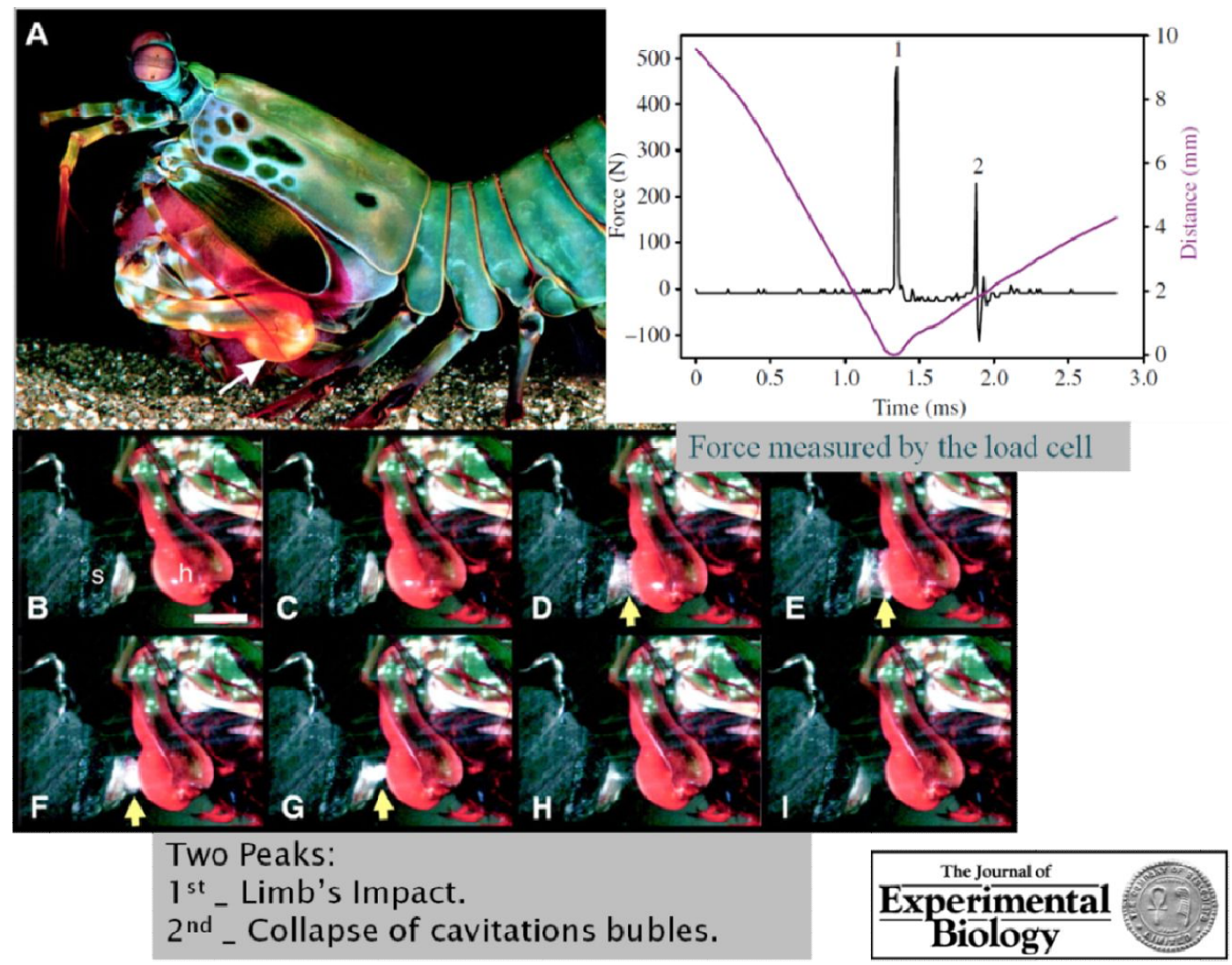

Figura 18 - Muestra una secuencia de golpe del martillo dáctilo sobre un sensor. Puede verse en el mismo el valor de impacto cercano a los $500 \mathrm{~N}$ y un segundo pico de impacto de valor de 250 N correspondiente a la ruptura de las burbujas de cavitación. Datos obtenidos de Patek and Caldwell.

Una forma de validar la simulación consistió en comparar la fuerza de impacto en la simulación con la obtenida a través del sensor. Los valores fueron 
comparables, 740 a $690 \mathrm{~N}$ (Figura 19) en la simulación contra 550 a $575 \mathrm{~N}$ en los experimentos (Figura 18). Simulaciones adicionales se realizaron para evaluar la influencia de daño isotrópico (cracking) o plasticidad, en la distribución de tensiones con un daño iniciado y posterior plasticidad en el rango de los 10 a 50 MPa. La energía de impacto absorbida por microfisuras y microplasticidad reducen la fuerza de impacto en un 15\%. Los valores críticos de tensiones y su distribución en la zona de impacto no cambian sustancialmente.

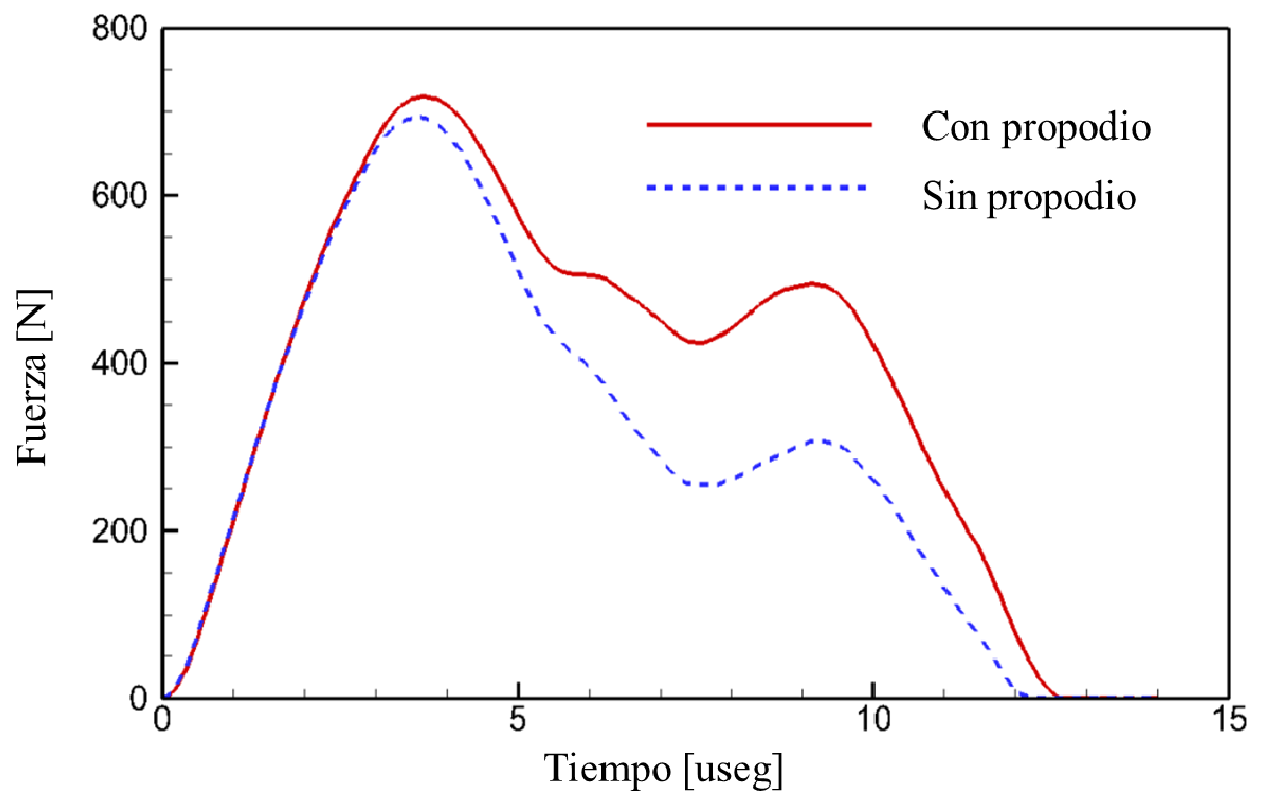

Figura 19 - Fuerza vs tiempo medida en la simulación numérica sobre el sensor.

La evolución dinámica de la tensión principal $\left(\sigma_{\max }\right)$ luego de producirse el contacto (Figura 20) revela que la propagación de ondas de impacto viajan a través de las distintas regiones llegando al extremo opuesto del dáctilo en 2.5 microsegundos y luego es traducida al propodio. Dado que la simulación revela que el máximo de tensión en el dáctilo llega a los 2 milisegundos luego del impacto, implica que el propodio no tiene efectos apreciables en los picos máximos de tensión como tampoco en la fuerza de impacto. El análisis de tensiones principales a los 2 milisegundos revelan en la Figura 20C (i) la presión hidrostática inmediatamente debajo de la zona de impacto $\sigma_{\mathrm{H}}$ (tonos azules), (ii) las tensión principales máximas en el plano $\sigma_{\mathrm{IP}}$ (iii) las tensiones principales máximas fuera del plano $\sigma_{\mathrm{OP}}$ (tonos 
rojos). Los cálculos revelan que el dáctilo se encuentra sometido a tensiones de compresión hidrostática extremadamente alta en la zona de impacto, $\sigma_{\mathrm{H}}$ hasta 4 GPa alcanzadas en un radio hasta los $0.2 \mathrm{~mm}$ desde el punto de contacto. Como comparación a este valor presentado, los cerámicos usualmente utilizados como zirconia o carburo de silicio llegan a un valor de tensión máxima de compresión del orden de los 2 a $3.5 \mathrm{GPa}$ [26]. Dado que el martillo dáctilo no falla de forma catastrófica luego de este impacto, este hecho pone en evidencia la habilidad de soportar valores extremos de compresión localizada.

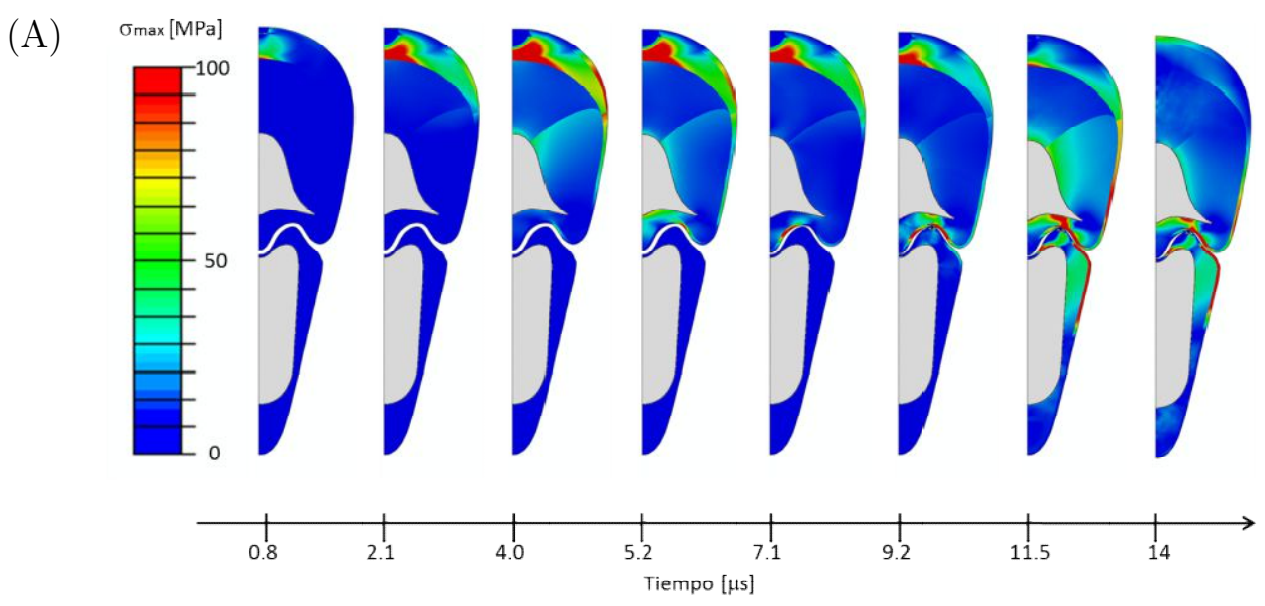

(B)

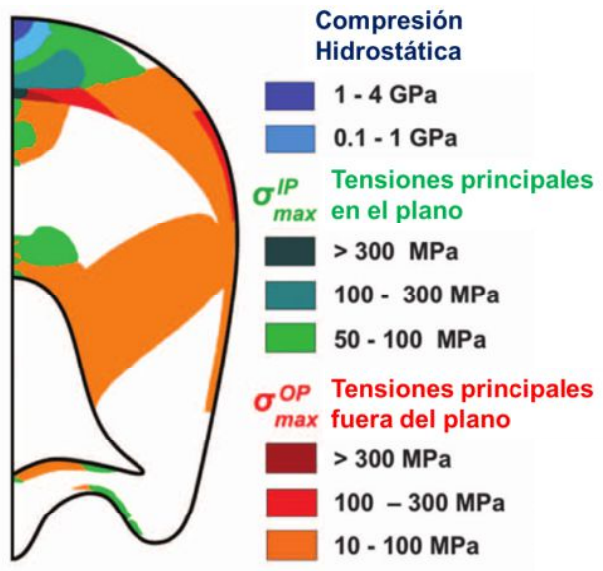

Figura 20 - Análisis dinámico mediante el método de elementos finitos y modelo micromecánicos. (A) Distribución de tensiones en la geometría del martillo dáctilo y propodio impactando un sensor a $20 \mathrm{~m} / \mathrm{s}$. Se muestra la evolución de la tensión principal máxima $\sigma_{\max }$ hasta que la onda de presión llega al propodio. (B) Tensiones principales máximas dentro del martillo dáctilo a un tiempo de $2 \mathrm{~ms}$ aproximadamente después del impacto. 
El valor máximo de tensión en el plano $\left(\sigma_{\mathrm{IP} \max }\right)$ se encuentra justo por debajo de la superficie de impacto y muy cercano a la interfase con la región periódica, alcanzando valores cercanos a $100 \mathrm{MPa}$, comparable con la tensión última en cerámicos monolíticos. Se esperaría que la fractura cónica comience (nuclee) cerca de la zona de interfase entre la región de impacto y la periódica. La región periódica está sujeta a tensiones menores en el plano debido a su bajo porcentaje de mineral. El máximo valor de tensión fuera del plano $\left(\sigma_{\mathrm{OP} \max }\right)$ en el dáctilo se encuentra localizado justo por debajo del punto de impacto, alcanzando valores superiores a los $300 \mathrm{MPa}$. Este valor sugiere también la ubicación de una zona de inicio de fisura. La parte restante del dáctilo está sujeta a tensiones moderadas $\sigma_{\mathrm{OPmax}}$ de valores que varían ente los 10 y $100 \mathrm{MPa}$, lo cual implica la poca probabilidad de que la fisura radial se genere en esas zonas.

\section{I.II.III - Origen de los mecanismos de tolerancia al daño y resistencia a la propagación de fisura.}

Las simulaciones dinámicas realizadas proveen de datos importantes acerca de la distribución de tensiones en el dáctilo, integridad macroscópica estructural y potencial puntos de nucleación de fisura. Estas no tienen en cuenta las complejas características microestructurales del dáctilo. Para correlacionar la tolerancia al daño observado y la alta dureza del dáctilo, un análisis micromecánico también debe ser considerado.

Intuitivamente, no es sorprendente encontrar una capa exterior dura en estructuras empleadas para impactos de alta energía. Esta característica es ampliamente utilizada en tejidos duros mecánicamente activos [27], [28] o de protección. Más allá de esta primera línea de defensa, la compleja microestructura interior dota al martillo dáctilo de múltiples mecanismos para prevenir el daño catastrófico. Los análisis dinámicos sugieren que la zona de inicio de fractura (nucleación) ocurre justo por debajo de la zona de impacto. La arquitectura 
helicoidal (Figura 21) provee varios mecanismos de "endurecimiento" que impiden la propagación catastrófica de tales fisuras. Micrografías electrónicas de la sección coronal (Figura 21F) ilustra la tendencia de las fisuras a nuclearse dentro de la zona periódica entre las fibras de quitina. En tres dimensiones, esta representación puede asimilarse como una fractura de patrón helicoidal propagándose entre las diferentes capas de fibras, cuyo frente de fisura permanece paralelo a las fibras sin cortar a ninguna de ellas.
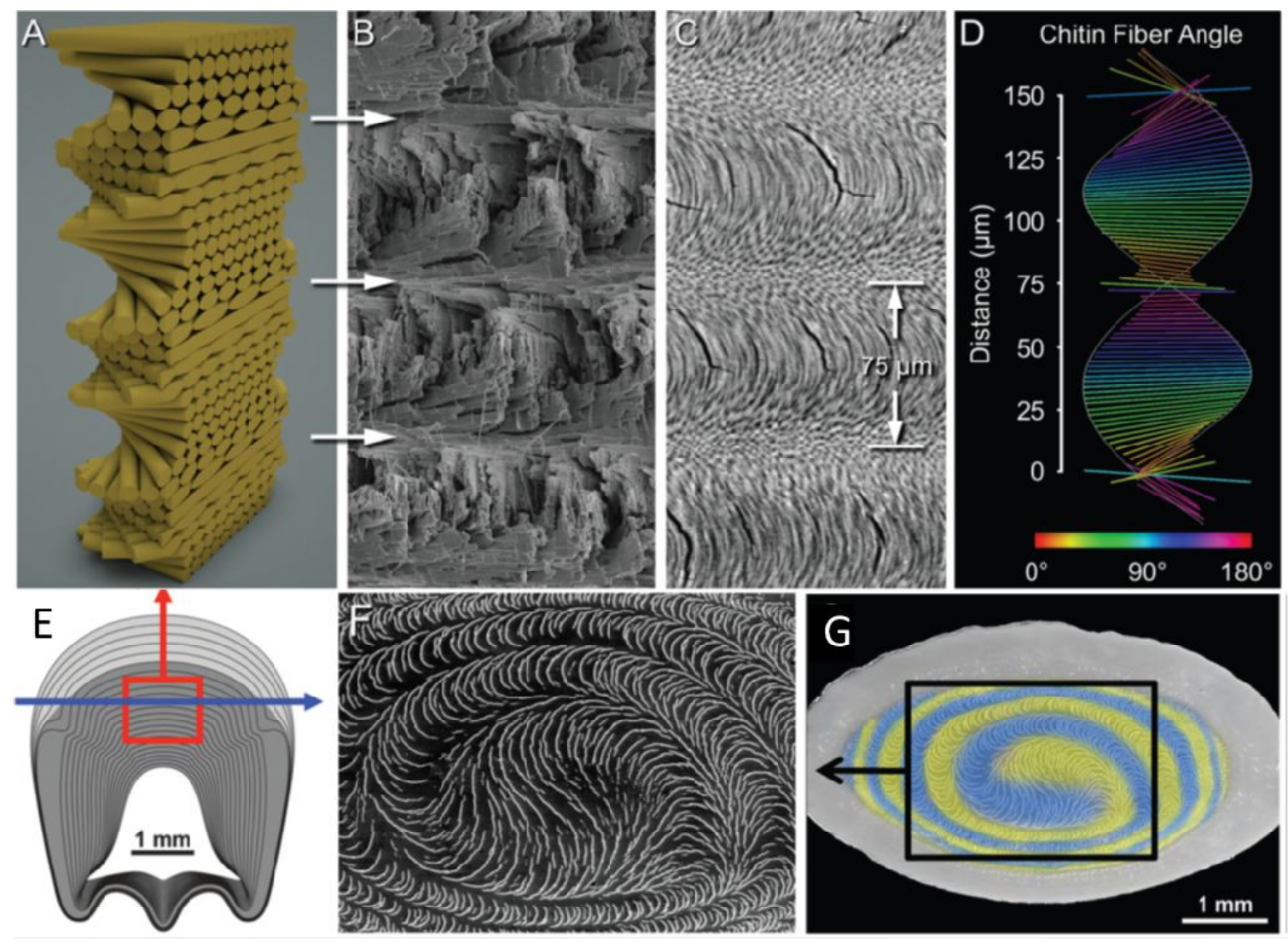

Figura 21 - Estructura helicoidal de fibras de quitina dentro de la región periódica (periodicidad 75um). Comparación entre un modelo tridimensional helicoidal (A) con una fractografía (SEM)

(B) y con una superficie pulida de la misma sección transversal (C). (D) visualización de las orientaciones de las fibras de quitina obtenidas a través de un análisis de dispersión de rayos $\mathrm{X}$ de 92 difractogramas separados. (E) zona de corte en el dáctilo para visualizar las fisuras en su interior.(F) (G) Micrografía de escaneo electrónico de una muestra de la sección coronal, mostrando las microfisuras en su interior. [29][30]

Se pudo representar un patrón similar de microfisuras utilizando un conjunto de fibras paralelas posicionadas a distintos ángulos entre capas y luego curvadas alrededor de un núcleo esférico. De esta forma se obtuvo el patrón distintivo de una doble espiral como se muestra en la Figura 22. 


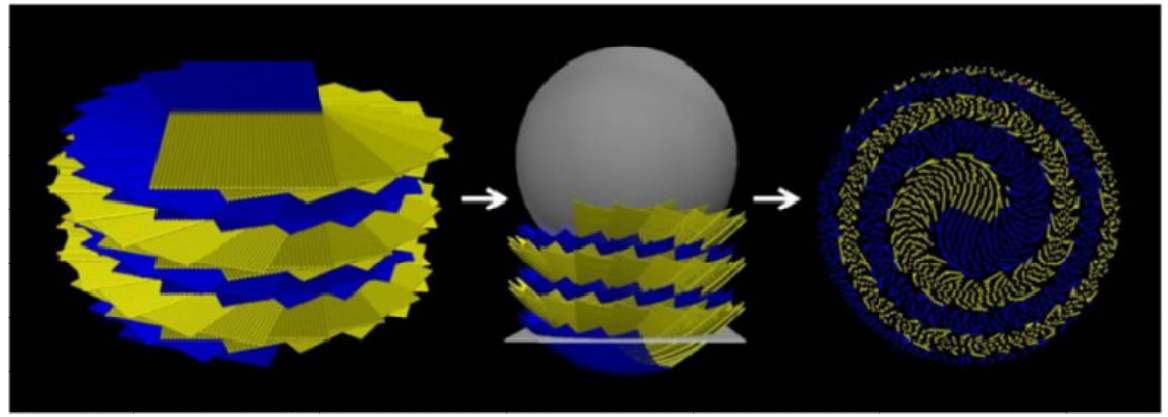

Figura 22 - Patrón de microfisuras generado al flexionar fibras dispuestas en forma helicoidal. Imagen proporcionada por el Laboratorio de Riverside.

Los modelos anteriores de fractografía (Figura 21) proporcionan una fuerte evidencia de que las fracturas se propagan predominantemente en dirección helicoidal entre las fibras de quitina. Una implicancia clave corresponde a que este camino de fractura crea una superficie mucho más grande por unidad de longitud en la dirección principal de propagación, por lo tanto, la energía total disipada durante el impacto se ve absorbida en este camino, un comportamiento que también se ha observado en materiales compuestos helicoidales de ingeniería [31]. 
Capítulo II - Regiones dentro del martillo dáctilo - Región de estrías y periódicaInteracción entre ambas.

CAPÍtulo II - Regiones DENTRO DEL MARTILlO DÁCtilO REGIÓN DE ESTRÍAS Y PERIÓDICA- INTERACCIÓN ENTRE AMBAS.

La complejidad de las regiones sub-estructurales existentes en el martillo dáctilo del estomatópodo Odontodactylus Scyllarus, representa un sistema con muchos interrogantes frente al entendimiento de su funcionamiento en el estudio de materiales naturales tolerantes a impacto. Por lo que una visión cercana de estas regiones es necesaria.

La región estriada del dáctilo es una de estas regiones, la cual previene el daño sobre la región periódica limitando su desplazamiento radial. El objetivo de este capítulo es presentar el efecto de la región estriada en la región periódica y cómo ambas regiones actúan en conjunto amortiguando el impacto del martillo dáctilo.

\section{II.I - Introducción}

Las cargas de impacto se caracterizan por la aplicación de fuerzas elevadas en un período de tiempo muy corto. Es un efecto dinámico muy difícil de modelar debido a la cantidad de suposiciones que son necesarias realizar, que no aplican para modelados estáticos. Esa misma fuerza en un período de tiempo corto tiene efectos superiores que una fuerza menor en períodos de tiempo más largos. Una fuerza de impacto no provee de tiempo suficiente para poder disipar la energía de deformación o vibración del material. Es por ello que la mayoría de los materiales se comportan de modo más frágil bajo este fenómeno, dado que la mayoría de la energía genera fractura del material. En muchos casos se llama a la resistencia de impacto como resistencia a la propagación de fisura, aunque no debemos confundir términos. Materiales Elastoméricos presentan un comportamiento excepcional a la propagación de fisura, sin embargo al aumentar las velocidades de aplicaciones de carga, las fuerzas de impacto tienen menor tiempo para poder distribuirse y es por 
ello que pueden superar fácilmente el valor de tensión máxima sin llegar a utilizar los mecanismos de disipación de energía propios de los elastómeros. Esta transición de dúctil a frágil es un ejemplo de las dificultades a la hora de diseñar materiales resistentes a impacto. Sin embargo, los materiales naturales fueron optimizados en estas propiedades por millones de años a través de la selección natural.

La estructura y tolerancia al impacto del martillo dáctilo del estomatópodo Odondactylus Scylarrus, fueron investigados anteriormente por Currey en 1982 y más tarde por Weaver et al. 2012. Weaver mostró que una sección transversal del martillo dáctilo revela una estructura de regiones variables con interfases que pueden utilizarse para definir los límites entre las regiones. Estas regiones incluyen la región de impacto, la región periódica y la región de estrías. La región de impacto y periódica pueden dividirse en subregiones y son probablemente homólogas a la endocutícula y exocutícula descripta en los artrópodos. La región periódica es nombrada así por la periodicidad de colores de material que es posible ver a simple vista. Esta se debe al arreglo microestructural helicoidal de los planos de fibras de $\alpha$-quitina embebidas en una matriz de mineral, que es característico de la morfología de endocutículas de artrópodos. Contrariamente, la región de estrías presenta una morfología única en cutícula de crustáceos. Una aproximación a la descripción de esta microestructura indicaría que se trata de un conjunto de fibras/barras dispuestas paralelamente en una matriz de $\alpha$-quitina. Este patrón microestructural puede ser único en crustáceos aunque tiene una reminiscencia a la microestructura del diente de chiton (Towe, 1967 - Weaver, 2010).

La aplicación más obvia de esta microestructura radica en la resistencia a cargas de compresión o tracción en la dirección paralela a las fibras. Es por ello que para entender los esfuerzos que aparecen en cada región luego del impacto, se utilizó una simulación por medio de elementos finitos. Si bien la simulación presentada es incompleta debido a que no contiene las características adecuadas de cada material, nos da una idea de las fuerzas que aparecen en cada región. Uno de 
Capítulo II - Regiones dentro del martillo dáctilo - Región de estrías y periódicaInteracción entre ambas.

los defectos del modelo es la entrada de los valores medidos desde técnicas de nanoindentación[27]. Esta última provee las propiedades mecánicas de cada región a través de una técnica de compresión. Esto significa que el valor colocado en el modelo puede no ser representativo para los valores de propiedades mecánicas de tracción.

\section{II.II - Caracterización Estructural.}

A partir de un corte transversal del martillo dáctilo del Odontodactylus Scyllarus podemos distinguir diferentes regiones (Figura 23 y Figura 24) y la orientación de las fibras en cada región. La región estriada se encuentra hacia los lados laterales del dáctilo ( fibras orientadas en forma radial paralelas unas con otras), la región de impacto en la parte superior (microestructura sólida muy mineralizada) y la región periódica se encuentra por debajo de ese último (fibras orientadas en forma helicoidal). La región periódica puede dividirse en 3 subregiones: la media y las laterales, con una cuarta subregión que se interpone en la unión de estas dos. La región periódica lateral, contenida en los lados del martillo dáctilo, es más dura, más rígida, y más mineralizada que el resto de las periódicas. Esta región suponemos que tiene la finalidad de proporcionar apoyo a la región más suave que absorbe la mayor parte de las fuerzas de impacto, la cual es la zona media de la región periódica. 


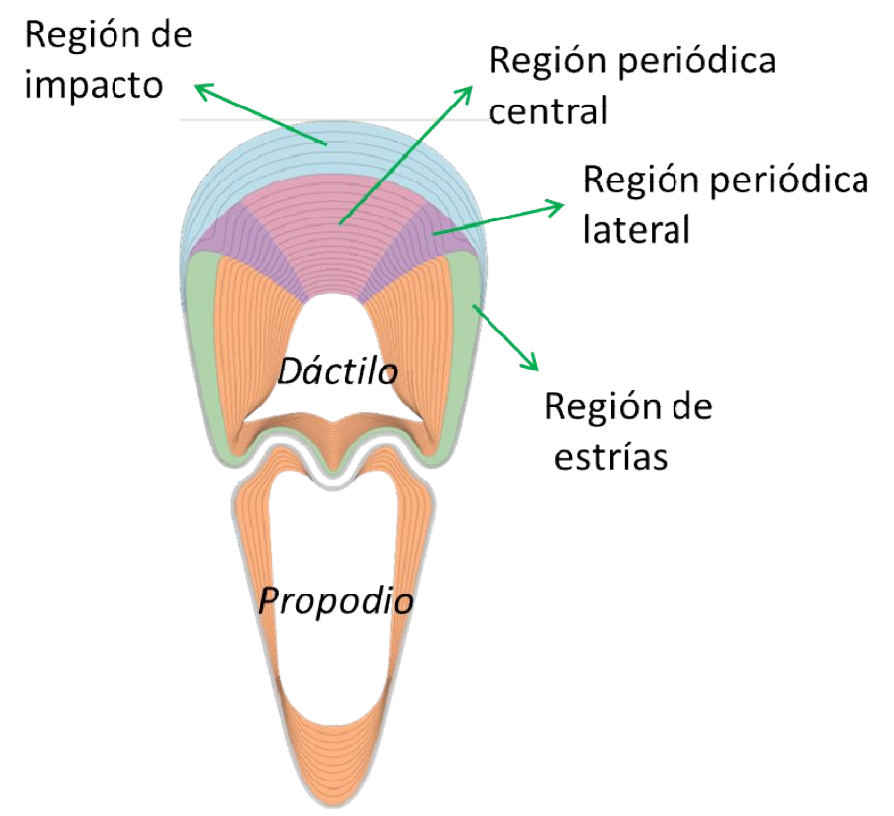

Figura 23 - Diferentes regiones del martillo dáctilo de la mantis marina.

Cada capa observada en la imagen óptica de la región periódica (Figura 24 A y B) es en realidad un conjunto de planos de fibras de quitina que van rotando gradualmente hasta completar los $180^{\circ}$ entre la parte superior e inferior de cada capa, esta porción de fibras se la llama "supercapa". Para la imagen de la Figura 24C lo que inicialmente es visto como una capa gruesa de fibras en un lateral de la región periódica es en realidad una microestructura completamente diferente llamada región de estrías. Contrastando con la región periódica, aquí las fibras mantienen su orientación en cada capa. Las fibras se orientan en forma longitudinal, abrazando al dáctilo y formando anillos de fibras. 
Capítulo II - Regiones dentro del martillo dáctilo - Región de estrías y periódicaInteracción entre ambas.

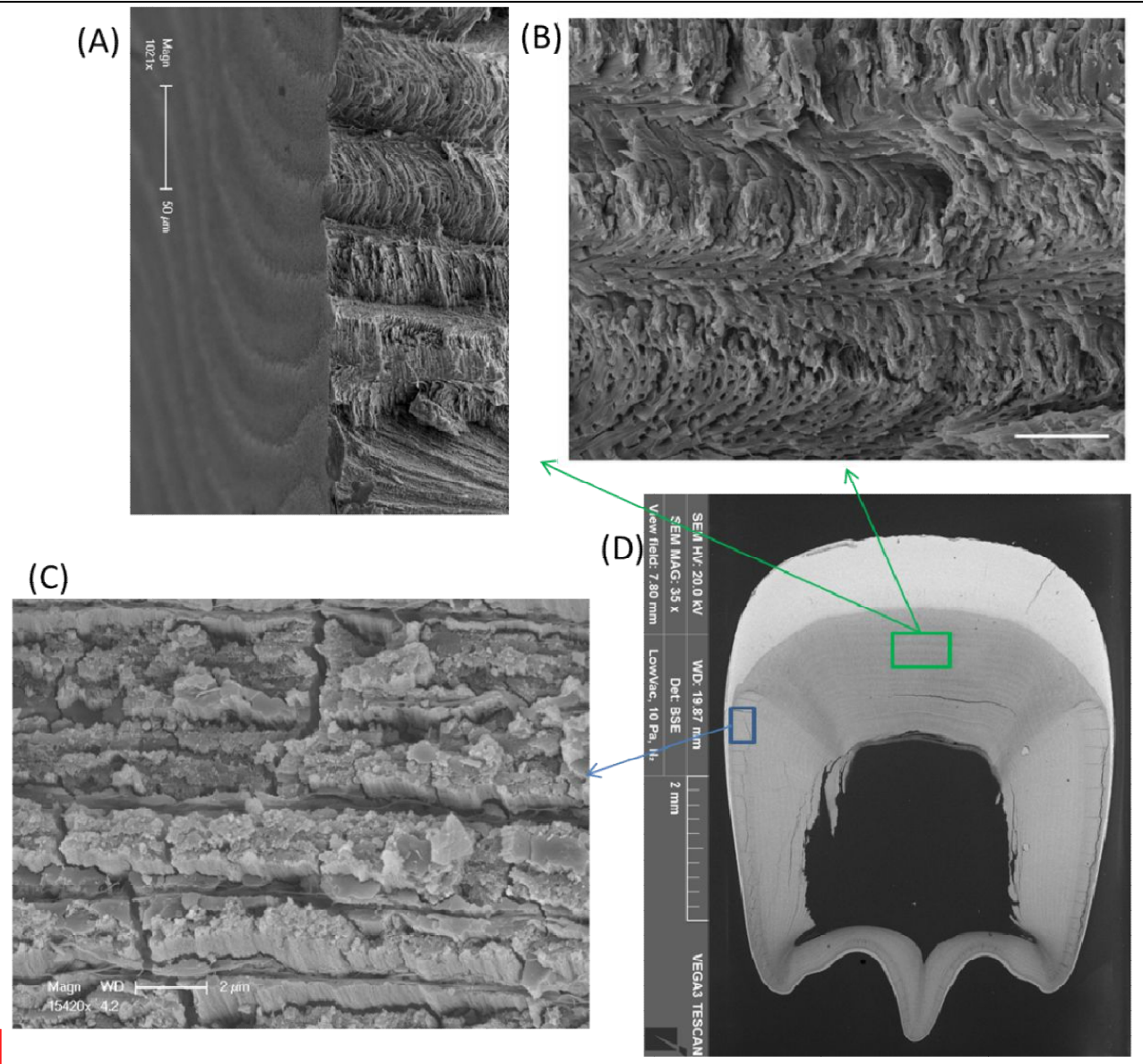

Figura 24 - Imágenes de escaneo microscópico electrónico de la región periódica (A) (B) y de estrías (C) del martillo dáctilo (D). La escala en B es de 20um. Las imágenes SEM fueron proporcionadas por el Laboratorio de Riverside.

La región de estrías o estriada es llamada así por la presencia de estrías que recorren en forma radial la parte de los laterales de la región periódica. Estas son claramente observables a través de microscopia electrónica de barrido (SEM). Información proporcionada por el laboratorio Riverside, revela a través de EDS la presencia de fósforo en las estrías en porcentajes mayores que su entorno. El fósforo está presente también en el mineral hidroxiapatita en la región de impacto, como así también en carbonato de fósforo en forma de cristales amorfos en la región periódica. La información obtenida por difracción de rayos X (Synchrotron X-ray diffraction) sugiere que las fases de material de la región periódica y de estrías son comparables. Los mapas de microscopia de fuerza atómica (Atomic force microscopy -AFM-) revelan que las estrías sin embargo, tienen diferentes propiedades mecánicas que las zonas que lo rodean. 


\section{II.III - Tensiones Biaxiales.}

Al igual que en capítulo anterior, se llevó a cabo un análisis dinámico a través de elementos finitos de un evento de impacto entre el martillo dáctilo y un sensor sólido. El modelo contempla toda la geometría del martillo y el sensor. Debido a la aproximación del dáctilo con un sólido revolución, se llevó a cabo un análisis 2D axisimétrico. El martillo dáctilo tiene una longitud aproximada de $5 \mathrm{~mm}$ de altura y $2 \mathrm{~mm}$ de radio. La distancia total desde el extremo del dáctilo hasta el final del propodio es de $10 \mathrm{~mm}$. Estas dimensiones son representativas de un ejemplar adulto de Odontodactylus Scyllarus. La respuesta mecánica de los materiales fue modelada como isótropa lineal elástico, con diferentes propiedades mecánicas y densidades másicas según la región correspondiente. La zona central del martillo dáctilo en forma de campana se encuentra llena de agua, la misma fue modelada como un medio acústico para poder tener en cuenta la propagación de ondas en ese fluido y la interacción del mismo con el medio que lo rodea. En las simulaciones, el sensor viaja a una velocidad de $20 \mathrm{~m} / \mathrm{s}$ e impacta el martillo dáctilo. Debido a que no hay un interés en el evento total de impacto y solo en lo que le sucede en el interior del dáctilo, no se consideraron los efectos del medio acuoso que rodea dáctilo, por lo tanto la ruptura de burbujas de cavitación no es considerada.

Como resultado del evento dinámico, esta vez nos centraremos en las regiones periódica y de estrías. La simulación muestra una región de tensión biaxial que abarca la zona central de la región periódica, Figura 25. La tensión en esa zona forma una distribución en forma de "toroide" para el cual el valor en el plano es aproximadamente el mismo que el valor de tensión fuera del plano. Tomando en cuenta la distribución de fibras en la región periódica, este tipo de tensiones genera sobre las fibras cargas longitudinales y cargas radiales en el mismo plano. 
Capítulo II - Regiones dentro del martillo dáctilo - Región de estrías y periódicaInteracción entre ambas.

$$
\left\{\begin{array}{l}
\sigma_{1} \cong \sigma_{2} \\
\sigma_{\mathrm{zz}}<0
\end{array}\right.
$$

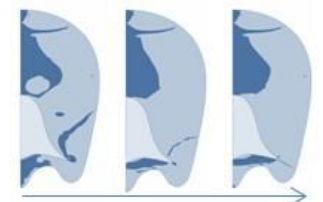

\section{Tiempo}

Zona de tensión biaxial dominante a través del tiempo

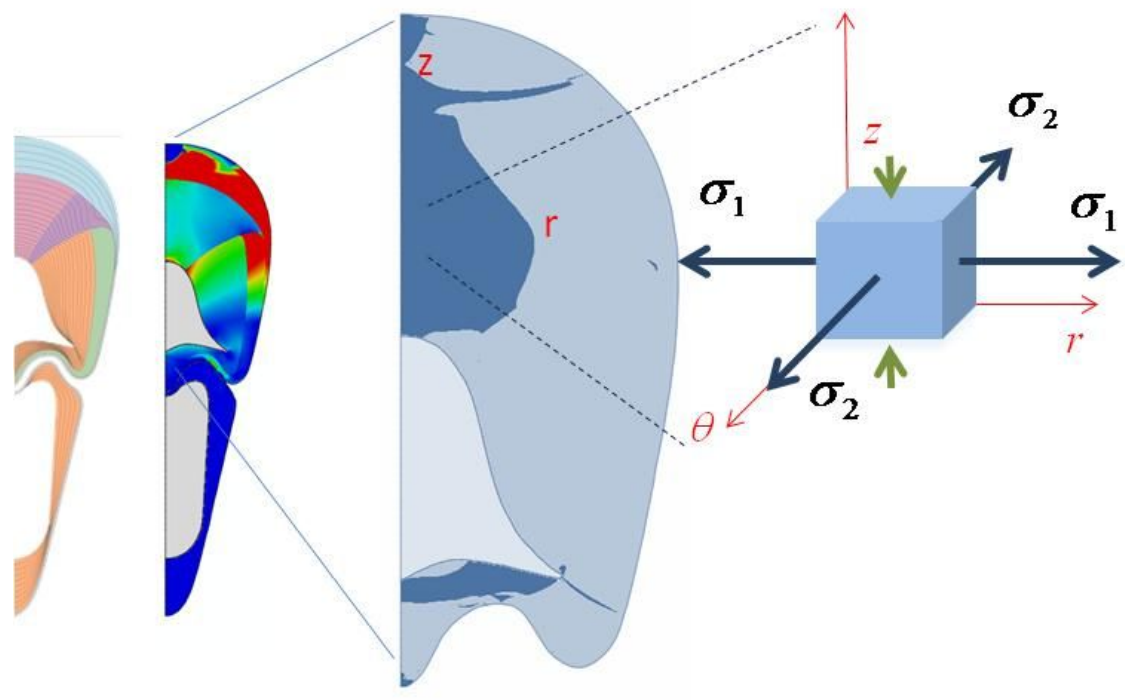

Figura 25 - Tensiones biaxiales. En color azul oscuro se muestra la tensión biaxial en el plano r$\theta$. Esto significa que la tensión radial y tangencial tienen valores similares y se corresponden con las tensiones principales. La tensión en la dirección longitudinal (z) es siempre de compresión.

En términos de propagación de fisura, estos esfuerzos apuntan a un crecimiento de fisura con la misma dirección longitudinal de las fibras y transversal en la matriz. Aunque no es fácil encontrar este tipo de patrón de fractura en las muestras seleccionadas, la razón yace en el tipo de microestructura. La región periódica presenta una microestructura en forma helicoidal, que se caracteriza, como mencionamos en el capitulo anterior, por fibras dispuestas en forma radial con cierta curvatura formando un patrón helicoidal en planos paralelos y apilándose en la dirección del eje longitudinal del martillo dáctilo, Figura 26. 
A
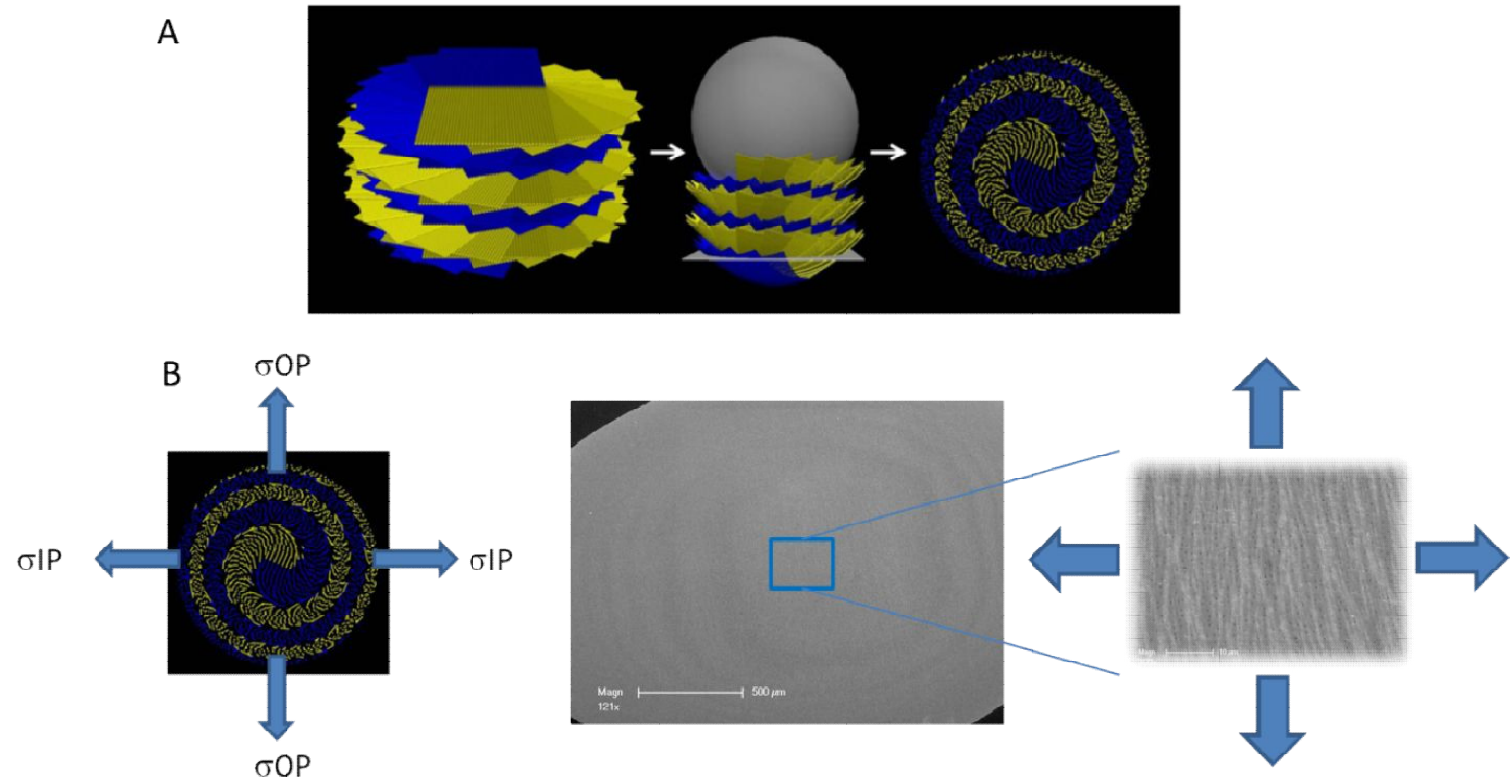

Figura 26 - Estructura Helicoidal. La imagen A muestra un conjunto de fibras dispuestas en forma radial con cierta curvatura, formando un patrón helicoidal en planos paralelos. La imagen B muestra cómo actúa un tensión biaxial sobro una porción de fibras en la misma región. Imagen adaptada a partir de figuras e imágenes SEM proporcionadas por Riverside.

Debido a las dimensiones de las fibras (una relación de aspecto alta) y el bajo ángulo de curvatura de la microestructura helicoidal, las tensiones sobre la región periódica generan que las fibras trabajen a tracción (dirección longitudinal) y en la dirección radial. El desprendimiento o despegue de las fibras entre si es un patrón común de falla en este tipo de microestructura (fractura cónica por microestructura helicoidal). La presencia de una microestructura en forma helicoidal y el crecimiento de fractura siguiendo la interfase entre fibras denota la necesidad de gran cantidad de energía para el desprendimiento total de una sola. La interfase entre las fibras es un factor clave para que se produzca este patrón de falla. La misma debe ser lo suficientemente blanda/permisible para que la fisura se propague por ella, pero a su vez dura/rígida para que la disipación de energía sea óptima. El análisis de las interfases se abordará en profundidad en el capítulo IV.

\section{II.IV - Región periódica y de estrías - interacción -.}

La región periódica se encuentra rodeada por un arreglo de fibras en forma de anillo. Esta región sostiene la microestructura helicoidal propia de la región periódica y permite o restringe la expansión de la misma de acuerdo a las 
Capítulo II - Regiones dentro del martillo dáctilo - Región de estrías y periódicaInteracción entre ambas.

propiedades mecánicas de esos anillos. Esta región de anillos es la región de estrías (Figura 27) y actúa como un cilindro a presión, un suncho, restringiendo la expansión de la región periódica.
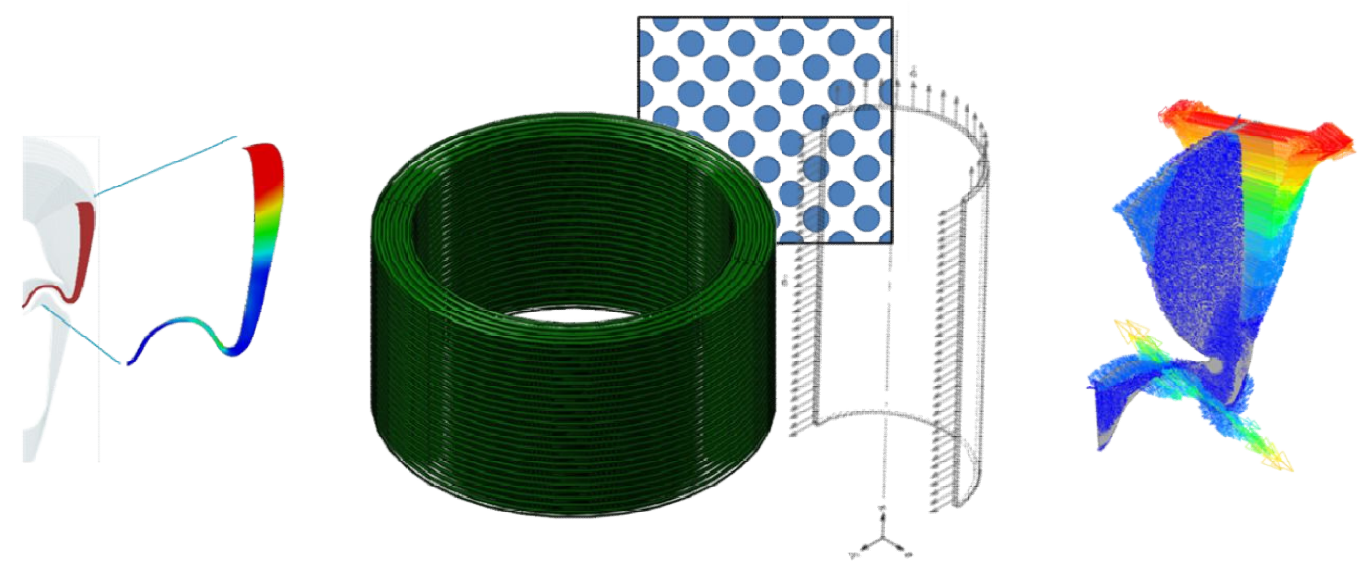

Figura 27 - Esquemas de región de estrías y su ubicación dentro de las diferentes regiones del martillo dáctilo.

De acuerdo a la configuración en las propiedades mecánicas de la región de estrías podemos encontrar una región de tensiones biaxiales en la región periódica justo por debajo de la región de impacto.

Mediante una simulación con diferentes propiedades mecánicas en la región de estrías podemos obtener y medir la variación de tensiones en la región periódica (Figura 28). Notamos que mientras más aumentamos el módulo elástico en la región de estrías, mayores son las tensiones en la región periódica (como es de esperar) y menor la deformación. Analizamos la variación de tensiones y las deformaciones logarítmicas de la región periódica utilizando valores de módulo elástico para la región de estrías de 10 y 100 GPa. Presentamos los resultados en la Figura 28B. 


\section{(A)}

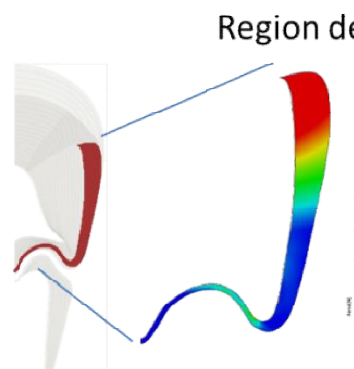

Max. Tensiones principales [Mpa]

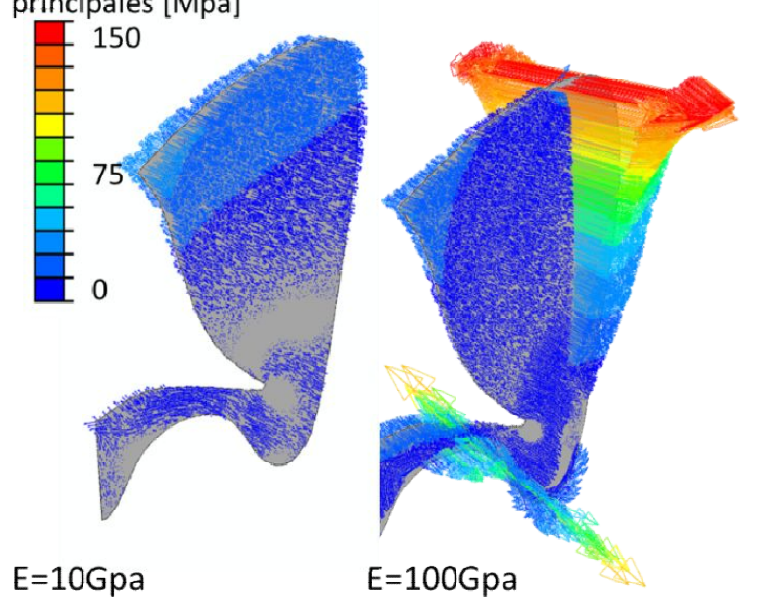

(B)
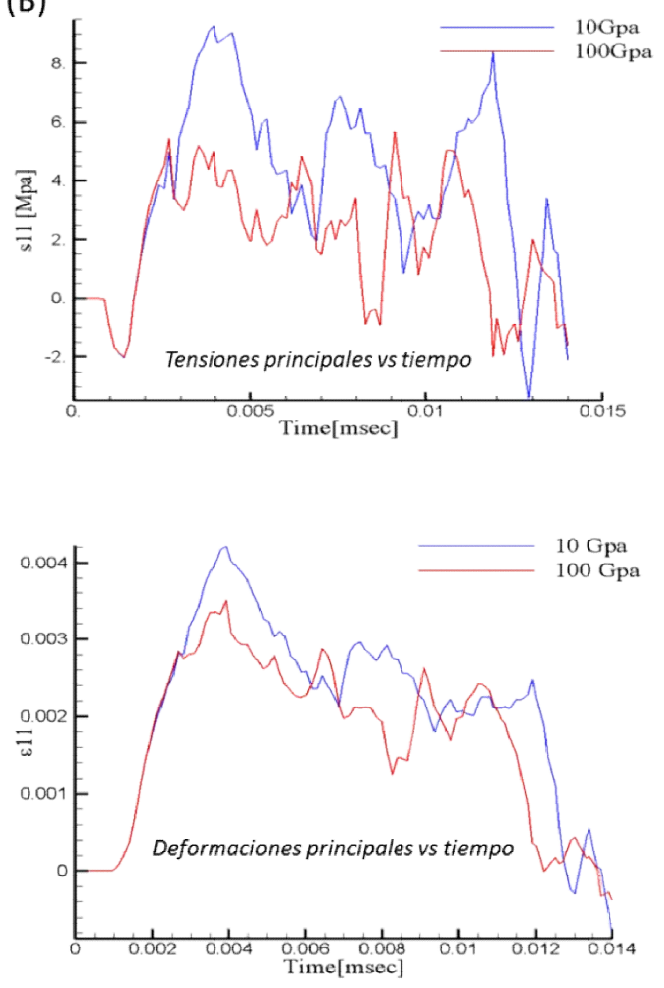

Figura 28 - Tensiones y deformaciones en la región periódica. (A) Muestra la distribución de tensiones en 3.5 useg, para cambios de modulo elástico en la región de estrías. Con flechas se indica la magnitud y dirección de las tensiones principales máximas. (B) Para explicar los efectos que produce la región de estrías en la región periódica, se realiza un cambio en el módulo elástico de la región de estrías de $10 \mathrm{GPa}$ a $100 \mathrm{GPa}$. Cuanto mayor E (modulo elástico) en la región de estrías, menor tensión en la región periódica.

Un punto a analizar aquí es que, a pesar de tener tensiones biaxiales en la región periódica, no se observa un daño catastrófico en el material pero si microfisuras en un corte del mismo.

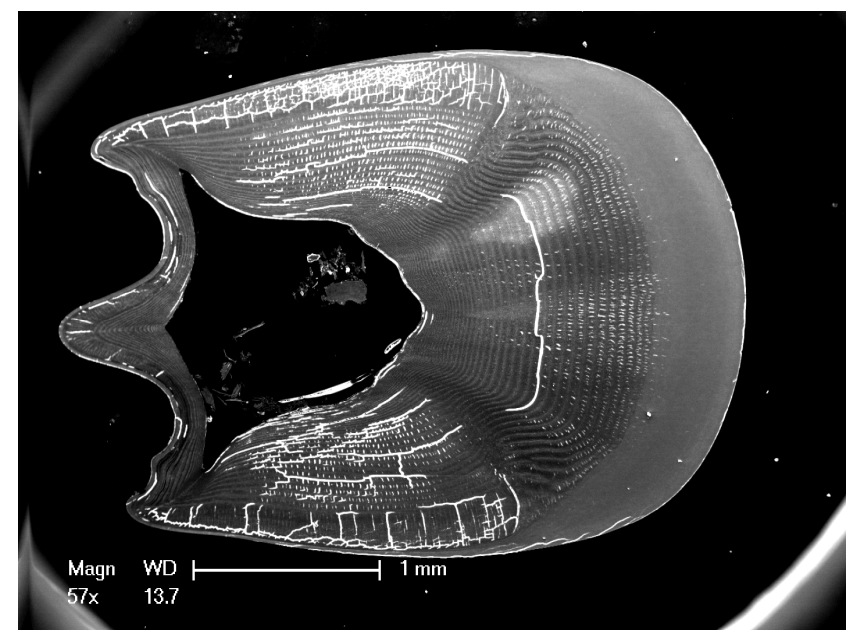

Figura 29 - Corte transversal del martillo dáctilo, mostrando microfisuras en las diferentes regiones. Imagen proporcionada por el Laboratorio de Riverside. 
Capítulo II - Regiones dentro del martillo dáctilo - Región de estrías y periódicaInteracción entre ambas.

\section{II.V - Conclusiones.}

Luego de actualizar las propiedades mecánicas del modelo de elementos finitos que representa el impacto del martillo dáctilo, la región de estrías muestra su capacidad para resistir tensiones fuera del plano. La presencia de esas tensiones durante el impacto sugiere que esta región provee de soporte o amortiguador de la región periódica. Durante el impacto, los planos de fibras de la región periódica media se comprimen entre sí. Debido a la relación de Poisson positiva, los planos de fibras experimentan fuerzas de tracción en todas direcciones, provocando fracturas que se nuclean y crecen en la región periódica media. La nucleación, crecimiento y control de esas fracturas parecen ser un mecanismo dominante de dispersión del daño en esa microestructura (exoesqueleto del martillo dáctilo). Si este mecanismo fallara entonces la fractura podría concentrarse y terminaría resultando en una falla catastrófica del material.

Por otro lado, debido al bajo módulo elástico de la región media periódica (Weaver et al 2012) se necesitan de fuerzas muy pequeñas para inducir largos desplazamientos o alargamientos. Como cada plano de fibras es desplazado hacia el exterior, se induce modo 1 de carga sobre las fibras. Este desplazamiento produce tensiones de tracción sobre las fibras de la región de estrías que a su vez restringen el desplazamiento de la región periódica media. Nos encontramos con que estas dos regiones llegan a un balance en el cual, la región periódica media es restringida hasta el punto de falla catastrófica en las fibras de la región de estrías. Se sabe que si los mecanismos de disipación de energía son contenidos por la microestructura helicoidal de la región periódica, la fractura debe ser confinada en esa región. La región estriada ayuda a cumplir con ese control de daño. 


\section{CAPÍtulo III - ANÁlisis Microestructural.}

Para entender las propiedades macroscópicas de cada región, debemos tener en cuenta las relaciones entre propiedades materiales y estructuras geométricas a diferentes escalas de material. Algunos avances en la comprensión de las relaciones estructura-propiedades para tejidos mineralizados se ha logrado mediante la combinación del modelado teórico/numérico y ensayos experimentales. Se utiliza mecánica del continuo a una escala meso o macro tanto para las técnicas de homogenización como el modelado mediante método de elementos finitos, acompañado a su vez, de datos experimentales como por ejemplo ensayos de nanoindentación.

Las propiedades mecánicas de importantes proteínas y biominerales como así también algunos detalles de su microestructura exacta, no son conocidas. Se ha encontrado, en otras escalas del material, similitudes respecto del modelo micromecánico presentado por Nikolov [28] en 2010. En este capítulo hemos propuesto seguir el modelado mencionado para escalas no conocidas, de modo de tener un mejor entendimiento de la formación de este material. El objetivo de este capítulo radica en elaborar una metodología de cálculo y modelado para las distintas escalas de material pertenecientes a la región periódica y de estrías. Aquí aislaremos una celda unidad representativa de la microestructura de cada región, basándonos en imágenes de microscopia electrónica (SEM). Los modelos representan la microestructura real tanto mecánica como geométricamente.

\section{III.I - Análisis Microestructural de la Región Periódica.}

Como fue mencionado en el capítulo anterior, la región periódica presenta una microestructura con disposición de fibras en forma helicoidal. Sin embargo, esta última característica es solo real para una determinada escala. Podemos 
determinar diferentes características a diferentes niveles de escala para el tejido en general.

Para este tejido en particular, podemos encontrar similitudes con el modelo presentado por Nikolov en 2010 [28]. El tejido está formado por quitina en forma de múltiples cristales de nanofibras, varias proteínas, nanopartículas minerales (en general, carbonato de calcio amorfo -ACC-, fosfato de calcio y calcita cristalina aragonita-) y agua. Una representación de la organización jerárquica de la cutícula se muestra en Figura 30, la cual ilustra un diseño genérico del exoesqueleto de un estomatópodo.

La región está caracterizada por fibras entrelazadas de proteína-quitina organizadas en múltiples planos (Bouligand structure [32][33]). Cada fibra esta embebida en una matriz de mineral y proteína, organizando y reforzando la red de fibras. Es por eso que como contraste tenemos un diseño multicapa a un nivel macroscópico con marcada heterogeneidad en una escala nanométrica entre proteínas blandas y minerales duros (o fibras de quitina).

En la Figura 30 se muestra un esquema multiescala del material estudiado. En el nivel más bajo de la jerarquía tenemos moléculas de N-acetyl-glucosamine formando cadenas de polímeros de $\alpha$-quitina (i); largas cadenas cristalinas de $\alpha$ quitina, orientadas en forma paralelas unas con otras, forman nanofibras (ii). Estas nanofibras son envueltas individualmente con proteínas y agrupadas formando fibras (iii) de quitina-proteína embebidas en una matriz de mineral-proteína. En el plano de la cutícula, el tejido mineralizado aparece como una estructura tipo honeycomb con agujeros elípticos (iv). Siguiendo en la jerarquía, los planos de proteína-quitina van rotando gradualmente alrededor de la dirección normal de la cutícula, lo cual resulta en una estructura de planos retorcidos (twisted plywood) (v) agujereada por canales helicoidales con sección elíptica. 


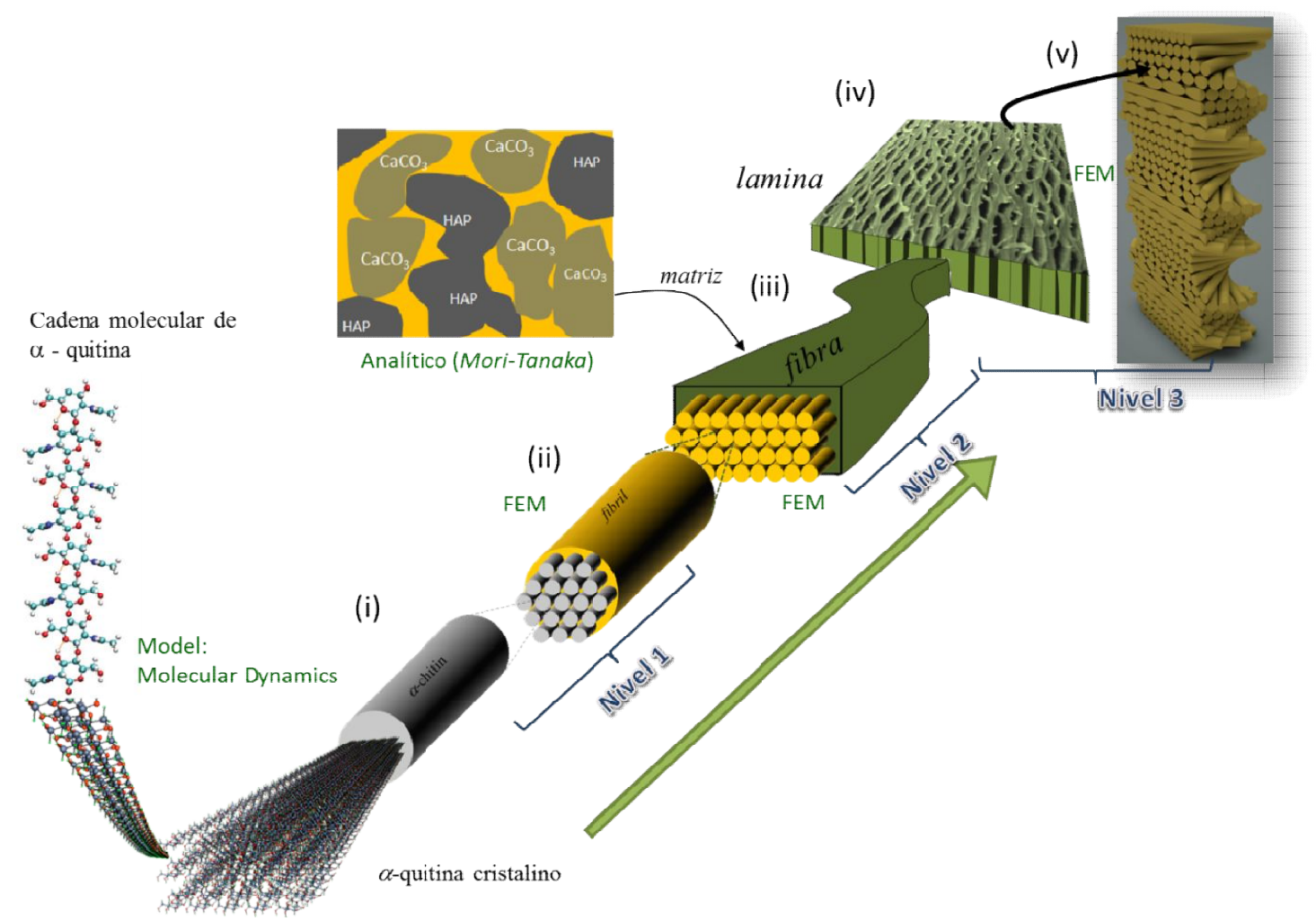

Figura 30 - Esquema del modelo adoptado para describir la microestructura.

Curiosamente, estos tipos de diseños multicapas, donde una de las capas exteriores es sorprendentemente dura y resistente, son encontrados también en otras especies con coraza. Un ejemplo lo constituye el pez Polypterus Senegalus [34][35] con un sistema de escamas (placas óseas) de gran dureza. El mismo parece estar muy bien adaptado a resistir cargas concentradas de compresión como por ejemplo, debida a mordidas de depredadores. Basados en la descripción de la estructura del párrafo anterior, la representación numérica del mismo resulta altamente complejo, por lo cual se ha desarrollado un modelado jerárquico con modelos constitutivos, los cuales incluyen cálculos a escalas nanométricas, donde no existen datos experimentales y por lo tanto se utilizan técnicas de homogenización en niveles jerárquicos superiores.

Para un nivel jerárquico dado, definimos un elemento de volumen representativo (RVE) del material heterogéneo y hallamos las propiedades como material homogéneo usando un modelo micromecánico adecuado. Estas propiedades serán utilizadas como datos de entrada de materiales heterogéneos que componen el 
siguiente nivel para el cálculo de las propiedades homogéneas del mismo. El procedimiento es luego recreado de igual forma para todos los niveles superiores de material.

Los valores de módulo elástico para la región periódica se muestran en Figura 31. Los valores de esta propiedad varían entre 10 y 20 GPa, producto de la orientación de las fibras en el punto donde se está indentando.

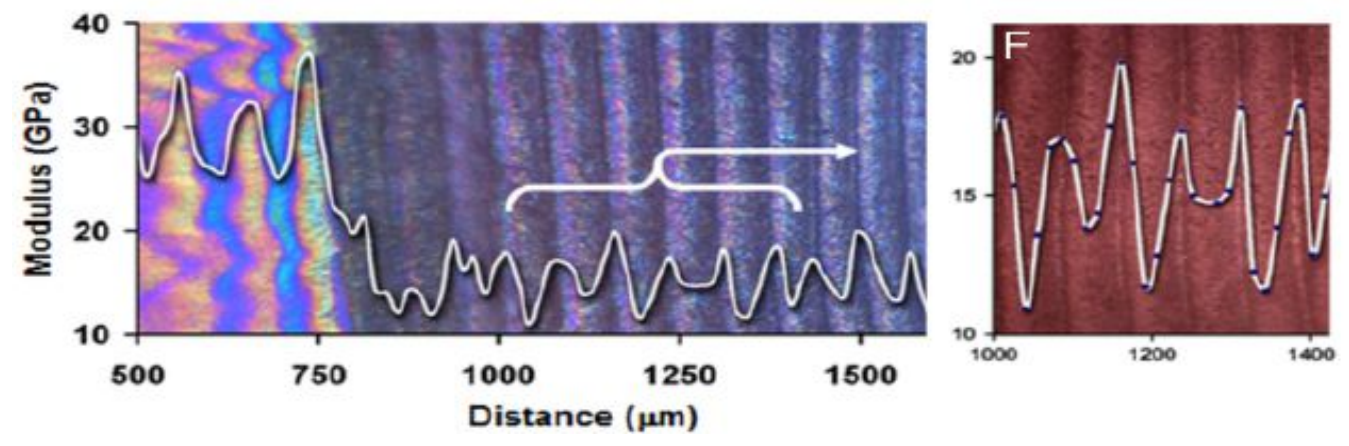

Figura 31 - Valores de módulo elástico obtenidos por indentación sobre la región de periódica del dáctilo. Imagen adaptada de la publicación de Weaver et. al. [24]

\section{III.I.I - Primer orden - fibrillas.}

Usando las propiedades mecánicas de la $\alpha$-quitina y proteína obtenidas a través de dinámica molecular por Nikolov en 2010 y considerando que las cadenas de $\alpha$-quitina están alineadas paralelamente entre ellas, calculamos un rango de valores de las propiedades mecánicas (módulo elástico y relación de Poisson) usando modelado numérico mediante el método de elementos finitos. Prestamos particular atención a las fracciones volumétricas de la $\alpha$-quitina que rondan entre el 70 y $90 \%$. Aunque si bien los valores de $\alpha$-quitina para la langosta americana son un poco inferiores (entre $59 \%$ y $76 \%$ ), intercambio de opiniones con el equipo de investigadores de Riverside nos llevó a considerar valores superiores. En la Figura 32 se muestra un esquema de este primer orden jerárquico considerado. 


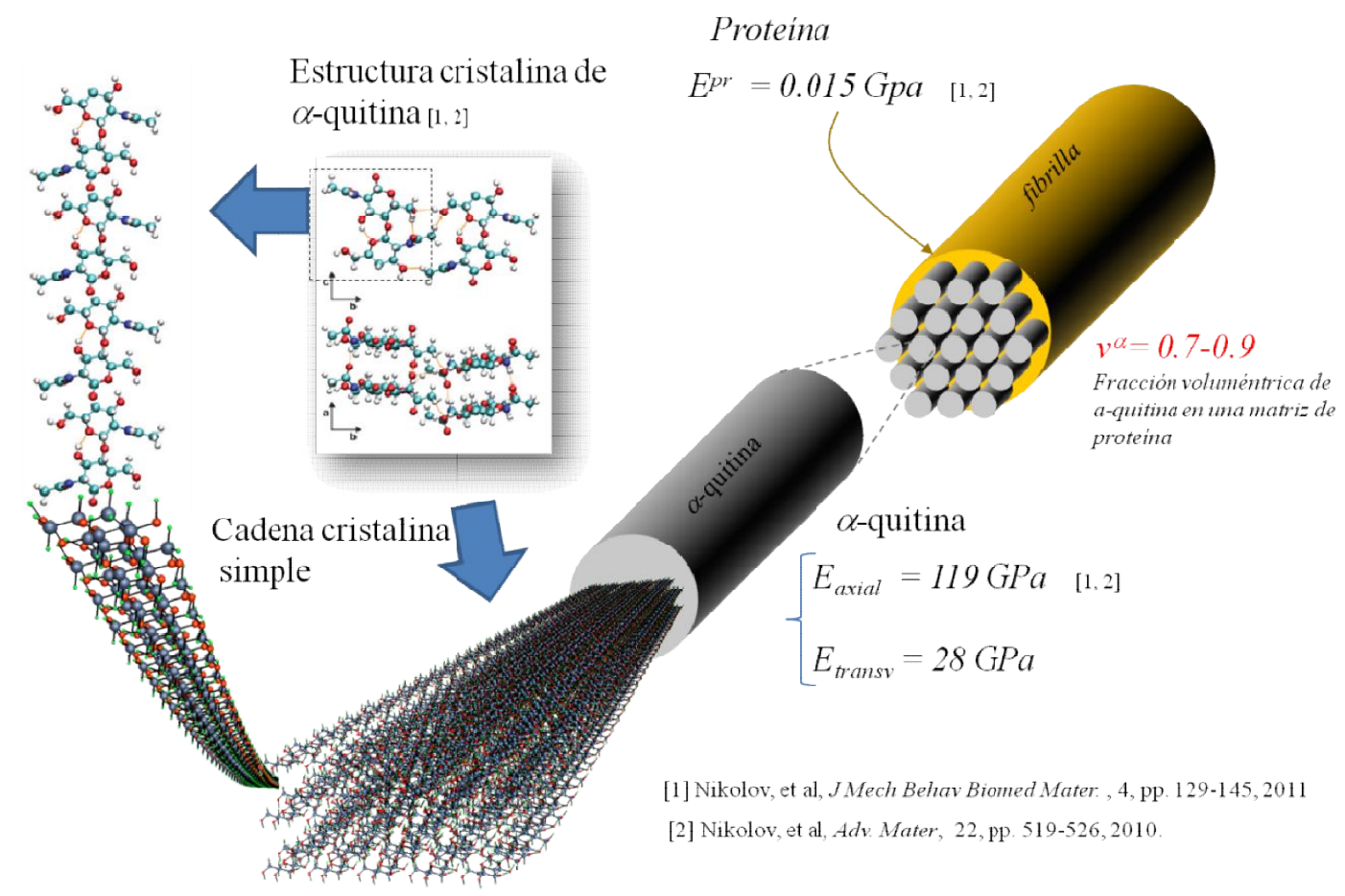

Figura 32 - Primer orden jerárquico- Materiales constitutivos y esquemas de modelado.

Para determinar las propiedades mecánicas, realizamos un modelo elementos finitos (Figura 33) enfocándonos en el primer orden jerárquico. Aislamos una celda unidad de la fibrilla, generamos un modelo numérico de la misma y le damos la flexibilidad geométrica para cubrir valores de volumen de $\alpha$-quitina que van de 73.6\% a 90.8\%. Aplicamos condiciones de borde periódicas para recrear la condición de celda unidad. Una vez generado el modelo, determinamos las propiedades mecánicas en las tres direcciones posibles. Nos enfocamos en el módulo elástico del material que es la propiedad a comparar con los resultados de indentación. 


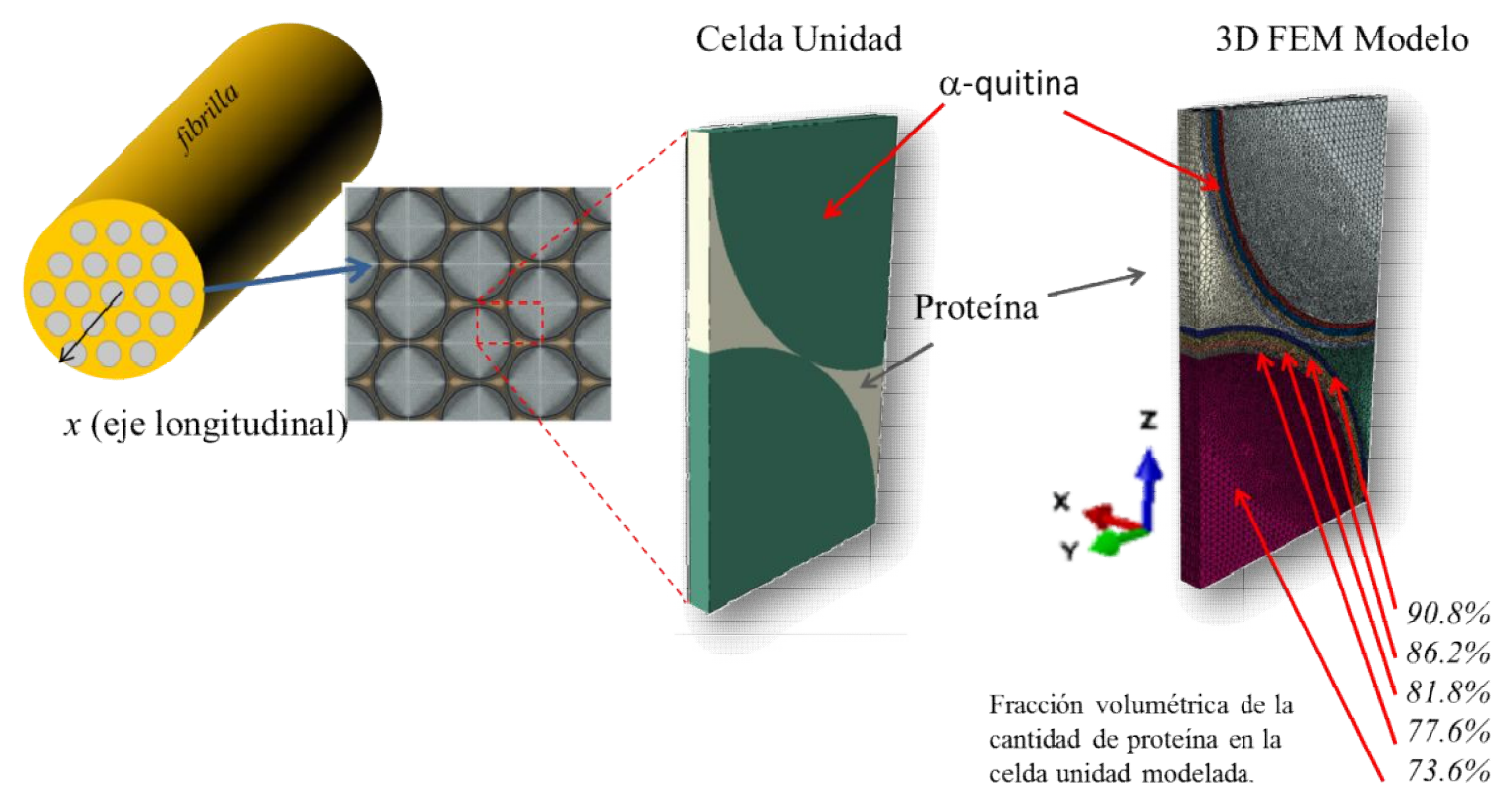

Figura 33 - Modelo numérico de las fibrillas

Tabla 1 - Resultados, módulo elástico de las fibrillas para una fracción volumétrica de $\alpha$-quitina de $90 \%$ y $86 \%$.

\begin{tabular}{|c|c|c|}
\hline \multicolumn{3}{|c|}{ Módulo elástico de la fibrilla E[Gpa] } \\
\hline Fracción volumétrica de $\alpha$-quitina & $90.80 \%$ & $86.20 \%$ \\
\hline Transversal Y & 5.76 & 0.16 \\
\hline Transversal Z & 5.37 & 0.19 \\
\hline Longitudinal X & 108.26 & 101.92 \\
\hline
\end{tabular}

La Tabla 1 muestra los resultados para el nivel más pequeño de análisis. Puede notarse una dependencia muy fuerte de la fracción volumétrica de $\alpha$-quitina en el resultado del módulo elástico en la dirección transversal tanto en Y como en Z. En la dirección longitudinal sigue imponiéndose las propiedades de la $\alpha$-quitina.

Para la siguiente sección entonces, modelamos un conjunto de fibrillas que forman una fibra y entre las fibrillas tenemos una matriz mineral formada por hidroxiapatita (HAP) y carbonato de Calcio $\left(\mathrm{CaCO}_{3}\right)$ también tenemos la presencia de proteína dentro de la matriz. 


\section{III.I.II - Segundo Orden - Matriz y fibra.}

\section{III.I.II.a - Matriz entre fibrillas.}

Para determinar las propiedades de la matriz, usamos la aproximación de cotas de Mory-Tanaka [36] para homogenización y modelamos partículas en una matriz infinita. Esta teoría solo es aplicable para una partícula en un medio infinito, es decir, que para nuestro uso solo es compatible para bajas concentraciones de partículas en el medio. Por esta razón consideramos que la matriz está compuesta por $\mathrm{HAP}$ o $\mathrm{CaCO}_{3}$ y la partícula es la proteína, cuyas concentraciones son bajas.

El método de Mori-Tanaka es usado para predecir las propiedades elásticas de un compuesto de dos fases como función de la fracción volumétrica y geometría. El tensor de rigidez elástica del compuesto con constituyentes isotrópicos es el siguiente,

$$
\begin{gathered}
C=\left(c^{m} C m+c^{p} C p T p\right)\left(c^{m} I+c^{p} T p\right)^{-1} \\
T p=\left[I+S p(C m)^{-1}(C p-C m)\right]^{-1}
\end{gathered}
$$

Donde m es la matriz, p la partícula, c es la fracción volumétrica, Sp tensor de Eshelby para la partícula y C es la matriz flexibilidad para la partícula (Cp) o para la matriz $(\mathrm{Cm})$.

Las hipótesis utilizadas son las siguientes,

- Condiciones de borde homogéneas, cuerpos homogéneos.

- Contacto perfecto entre las partículas y la matriz.

- Consideramos una partícula sola en una matriz infinita (bajo contenido de partículas, en nuestro caso proteína). 
Presentamos los valores de módulo elástico para diferentes composiciones de HAP - $\mathrm{CaCO}_{3}$ y proteína. Estamos interesados en compuestos con valores bajos de proteína.

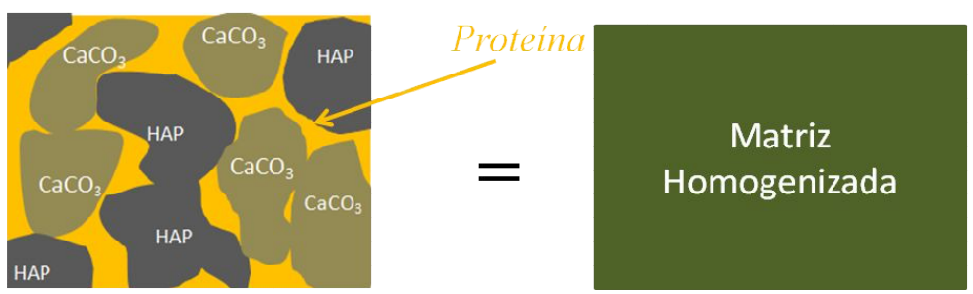

$$
\left\{\begin{array}{l}
E^{p r o t}=0.015 \mathrm{Gpa} \\
E^{\mathrm{HAP}}=90 \mathrm{Gpa} \\
E^{\mathrm{CaCO}}=37 \mathrm{GPa}
\end{array}\right.
$$

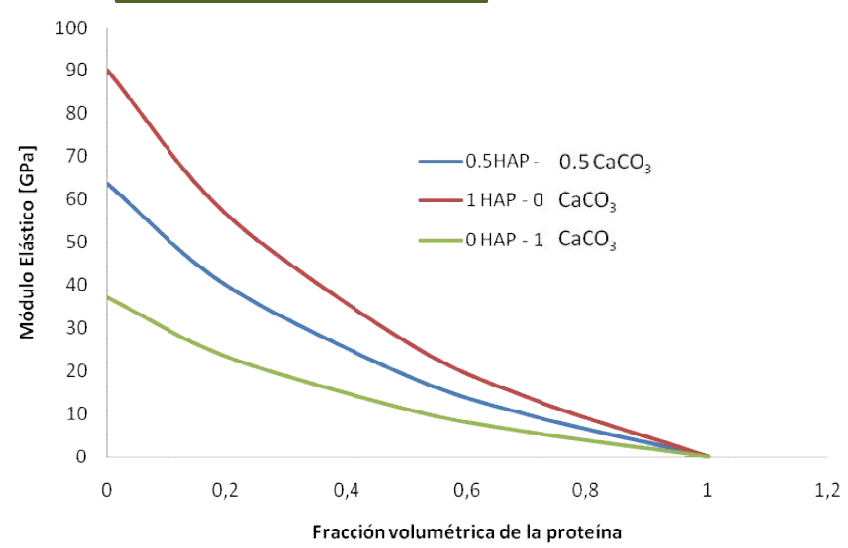

Figura 34 - Segundo Orden- Matriz - Propiedades efectivas.

Con el cálculo presentado en la Figura 34, obtenemos la matriz rigidez de la matriz compuesta de $\mathrm{HAP}-\mathrm{CaCO}_{3}$ y proteína.

\section{III.I.II.b - Fibra}

Con la información obtenida en el primer orden jerárquico y los valores de la matriz entre fibrillas descripta anteriormente, calculamos las propiedades mecánicas de una fibra, Figura 35. Estamos particularmente interesados en concentraciones de fibrillas cercana al 90\% del volumen del compuesto. Usando un modelo de elementos finitos calculamos las propiedades mecánicas de la fibra. 


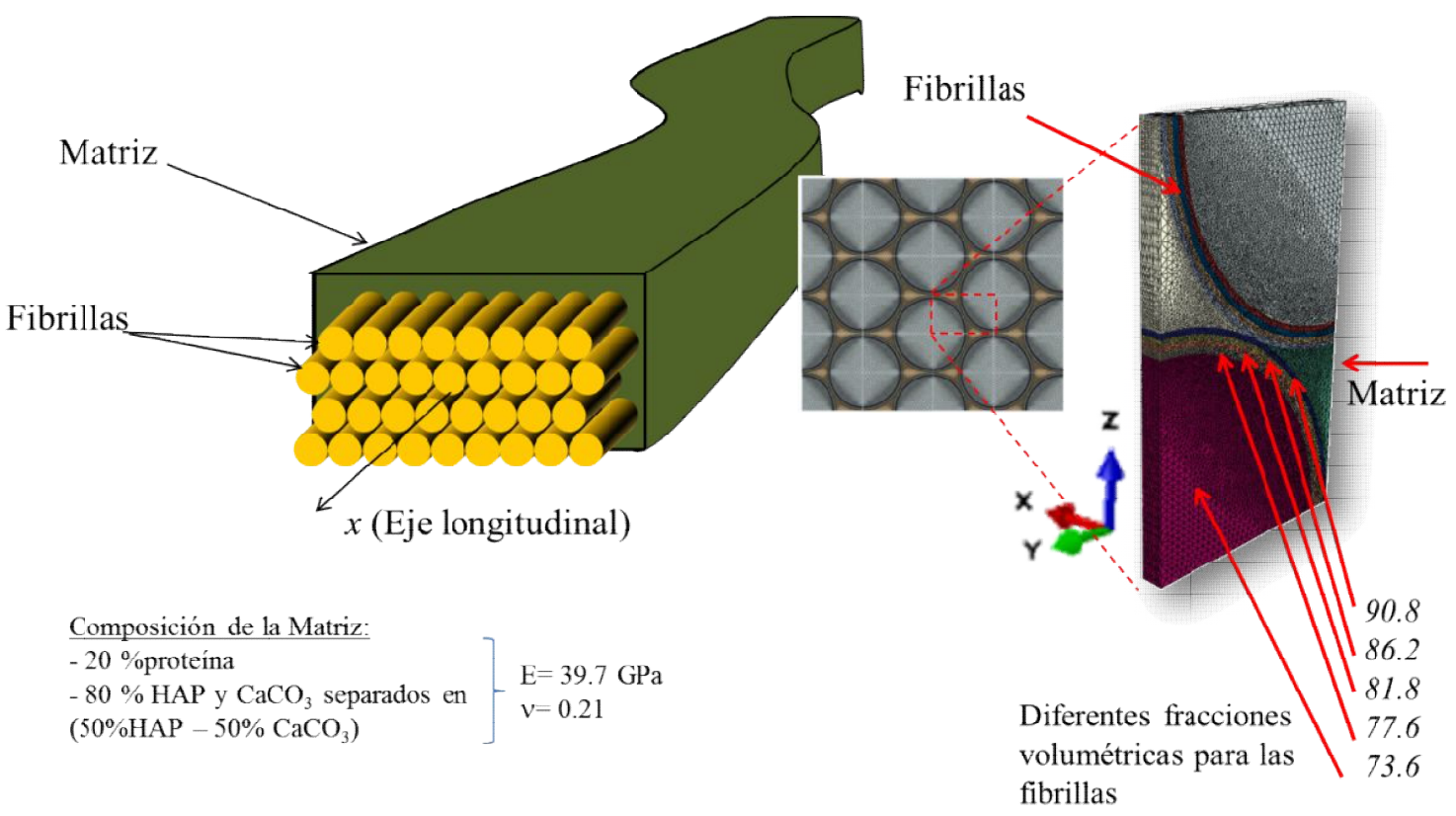

Figura 35 - Segundo orden jerárquico - Propiedades de la fibra.

Los resultados obtenidos a través del modelo de elementos finitos se muestran a continuación en la Tabla 2.

Tabla 2 - Módulo elástico de la fibra para una fracción volumétrica de fibrillas de $90 \%$.

\begin{tabular}{|c|c|}
\hline \multicolumn{2}{|c|}{ Módulo elástico de la Fibra E [Gpa] } \\
\hline $\begin{array}{c}\text { Fracción Volumétrica } \\
\text { Fibrillas }\end{array}$ & $90.80 \%$ \\
\hline Transversal $Y$ & 11.14 \\
\hline Transversal $Z$ & 11.14 \\
\hline Longitudinal $X$ & 101.04 \\
\hline
\end{tabular}

\section{III.I.III - Tercer orden - Grupo de Fibras.}

Utilizando las propiedades de las fibras obtenidas anteriormente y agrupándolas en forma paralela unas de otras, calculamos las propiedades mecánicas.

Para el análisis barremos todo el rango de concentraciones mediante el uso de cotas de Voig y Reuss. Sin embargo estamos interesados en valores de volúmenes de fibras cercanas al 90\%. Presentamos el resultado del módulo elástico 
en la Figura 36 para concentraciones de $\alpha$-quitina que barren todo el rango modelado. Utilizamos valores entre $70 \%$ y $90 \%$ de $\alpha$-quitina en las fibrillas.

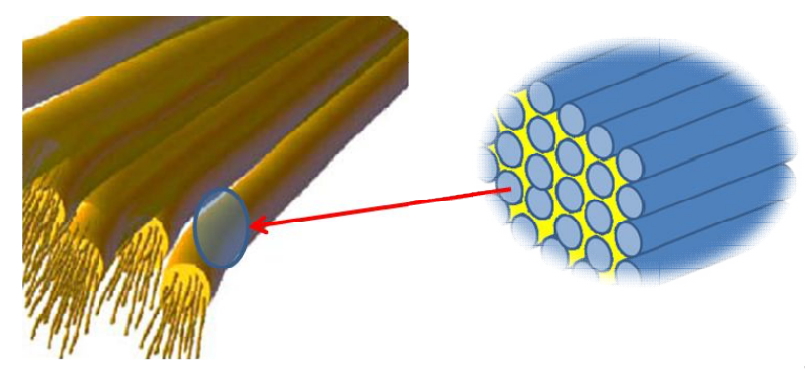

Usamos la misma composición de la matriz que para la fibra $\mathrm{E}=39.7 \mathrm{GPa}$ $v=0.21$
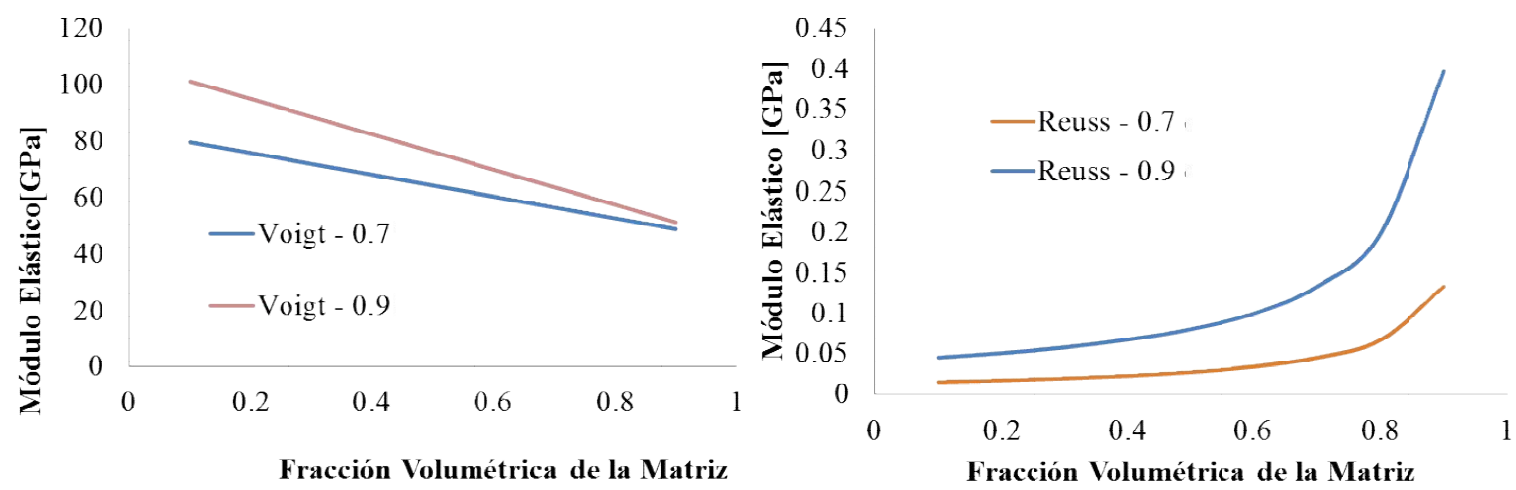

Figura 36 - Tercer orden - Grupo de Fibras.

\section{III.I.III.a - Conclusiones}

Hasta aquí, para diferentes órdenes de magnitud modelamos y analizamos numéricamente el módulo elástico del material, intentando recrear los valores experimentales de indentación de la región periódica. La confección de estos modelos y el análisis de los mismos trajo muchos interrogantes acerca de las fracciones volumétricas exactas, cristalinidad del material, y propiedades mecánicas de los componentes, preguntas que son mucho más elementales que las geometrías de modelización elegida pero que fueron encontradas a la hora de confeccionar los modelos. Los resultados obtenidos arrojaron un valor de módulo elástico del orden de los $100 \mathrm{GPa}$ en la dirección longitudinal de las fibras teniendo como consideración valores de alta concentración de $\alpha$-quitina. Estos resultados se alejan de los obtenidos en los ensayos de indentación. Más allá de la respuesta a los interrogantes aquí planteados, la indentación no se ha realizado solo sobre fibras 
sino sobre el material compuesto: fibras y mineral. Más aún, la disposición de fibras no siempre es paralela para escalas pequeñas, sino que se han observado en algunos sitios de la región periódica, ondulaciones bien marcadas.

\section{III.I.IV - Cuarto orden - Estructura tipo honeycomb.}

A partir de imágenes de microscopia electrónica de la región periódica, pudo observarse patrones microestructurales helicoidales tipo honeycomb. La microestructura fue observada al producirse la apertura o fractura de esta región. Las flechas en la Figura 37 indican la dirección de apertura necesaria para ver el patrón descripto. La figura muestra además un acercamiento sobre las fibras, mostrándolas rodeadas por material mineral.

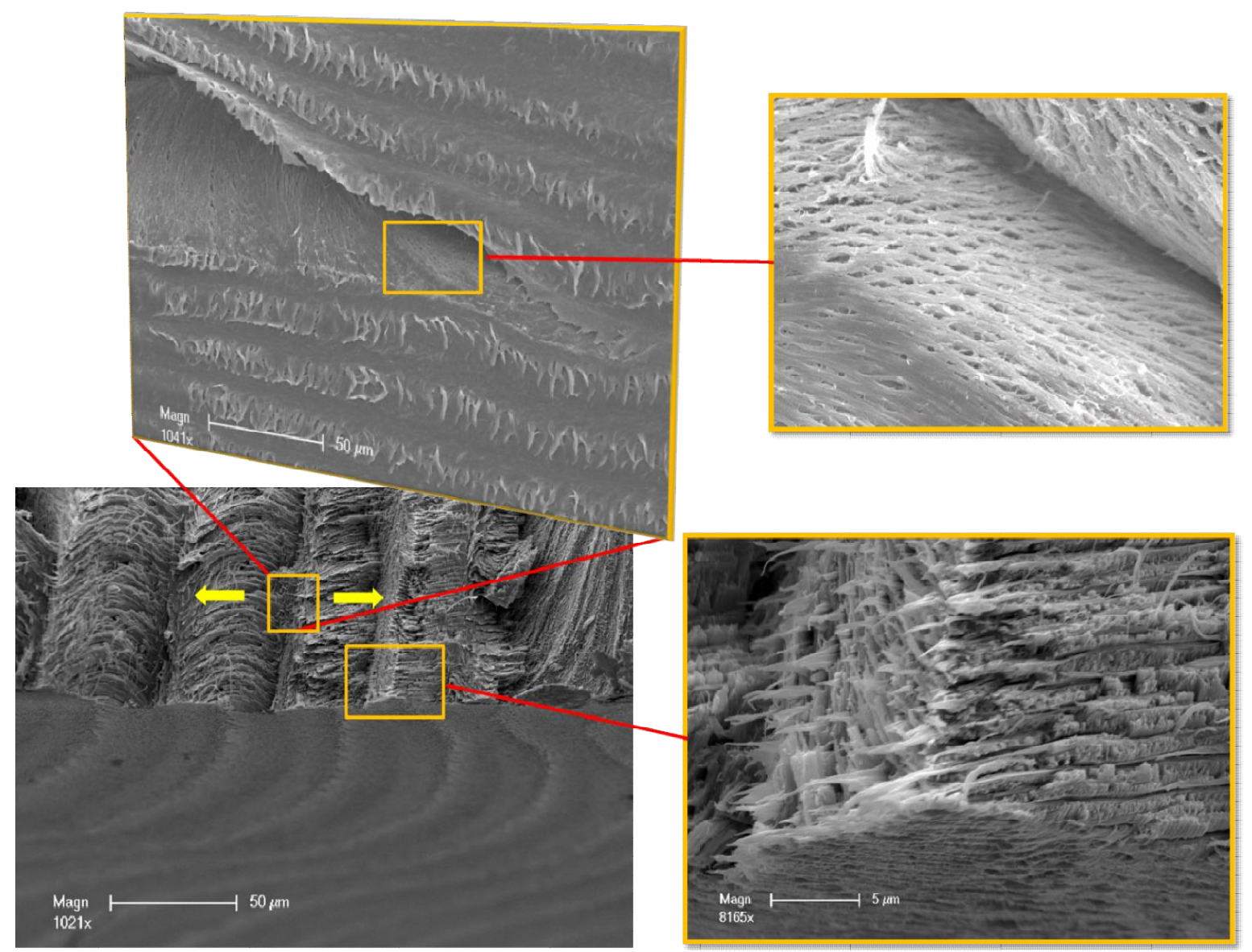

Figura 37 - Imágenes de microscopia electrónica mostrando la región periódica y sus características en la composición de fibra y mineral y la geometría que tiene la misma al generarse una apertura en la dirección indicada por las flechas. Figura adaptada a partir de imágenes SEM proporcionadas por el Laboratorio de Riverside. 
Para poder estudiar y comprender las variaciones de módulo elástico en la región periódica, desarrollamos un modelo a escala micrométrica que contiene las características geométricas de las fibras de $\alpha$-quitina con partículas de mineral y sus interacciones.

Los modelos micromecánicos utilizados aquí consideran una disposición periódica como se muestran en la Figura 38. Valiéndonos de la simetría y periodicidad que presenta la región separamos una celda unidad representativa. En el modelo consideramos diferentes condiciones de borde y de carga de modo de representar las diferentes condiciones de confinamiento en los ensayos de indentación realizados. También nuestro modelo tiene en cuenta el hecho de que la unión entre la fibra orgánica y la matriz (interfase) no es perfecta. Para modelar esto se utilizaron diferentes condiciones de contacto y condiciones de pegado o simplemente consideramos que la fibra está apoyada en la matriz.

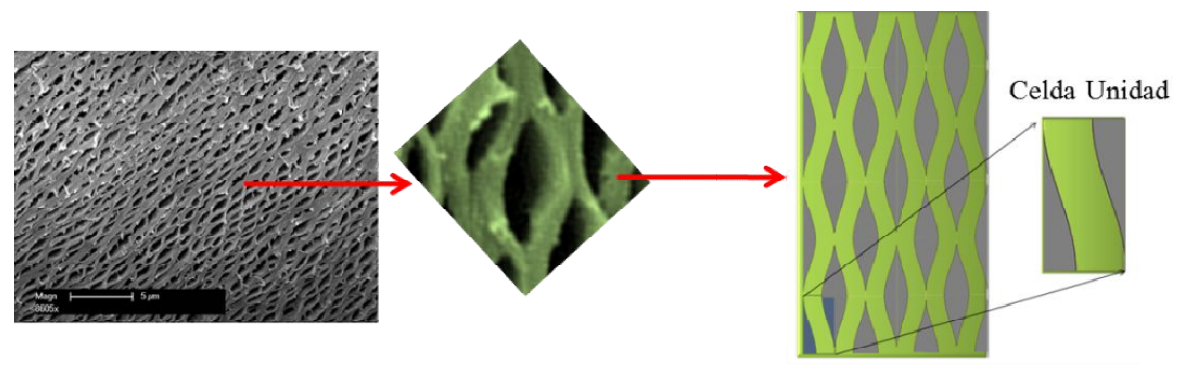

Figura 38 - Modelo micromecánico

\section{Detalles del modelo}

Se realizó un modelo que represente las características de la región periódica descripta (Figura 39). En este caso se utilizaron valores de modulo elástico de la fibra y el mineral diferentes a los calculados en las secciones anteriores [37] [38]. Nos centraremos en el comportamiento del compuesto y la variación del valor de modulo elástico resultante producto de las variaciones de las condiciones de borde. El material homogéneo resultante del modelado fue considerado como ortotrópico. 


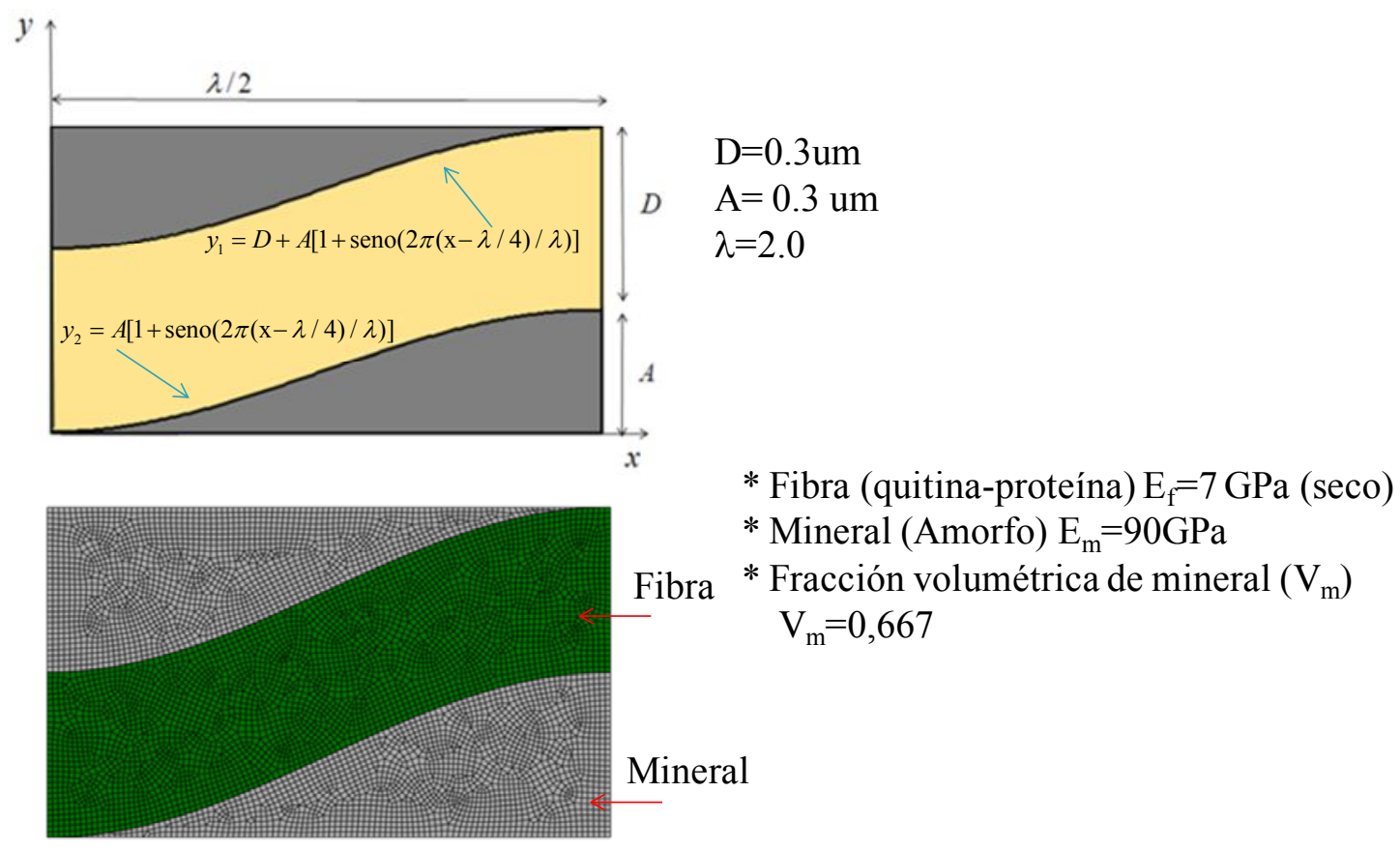

Figura 39 - Modelo numérico de la región periódica

En los análisis preliminares, estudiamos la microestructura del material bajo diferentes condiciones de carga. En particular, nos enfocamos en la obtención del módulo elástico del material compuesto cuando la carga es aplicada en la dirección paralela a las fibras y cuando la carga es aplicada perpendicular a las mismas. Modelamos la celda unidad tanto en compresión como tracción, sin embargo enfocamos nuestro análisis al caso que las fibras se encuentran en compresión, que representa el caso de nanoindentación.

Encontramos que el comportamiento de este material, especialmente cuando es cargado paralelamente a dirección de las fibras, depende fuertemente del confinamiento lateral. En esa dirección, un confinamiento lateral bajo significa que las fibras (onduladas) pueden deformarse fácilmente en la dirección perpendicular a la carga. Por otro lado un confinamiento lateral alto significa que no hay movimiento lateral posible.

Finalmente, otra importante característica del modelo es el estudio de los efectos de las interfases orgánicas o inorgánicas (especialmente considerando las condiciones en las cuales se realizaron los ensayos). Nuestros modelos preliminares consideran una unión perfecta en la interfase o que no existe unión en absoluto. 
Para los modelos se aplicaron hasta un 5\% de deformación específica, y la carga fue medida de las reacciones en los nodos. En la Figura 40 se presenta un resumen de los casos de carga y restricciones de los modelos.
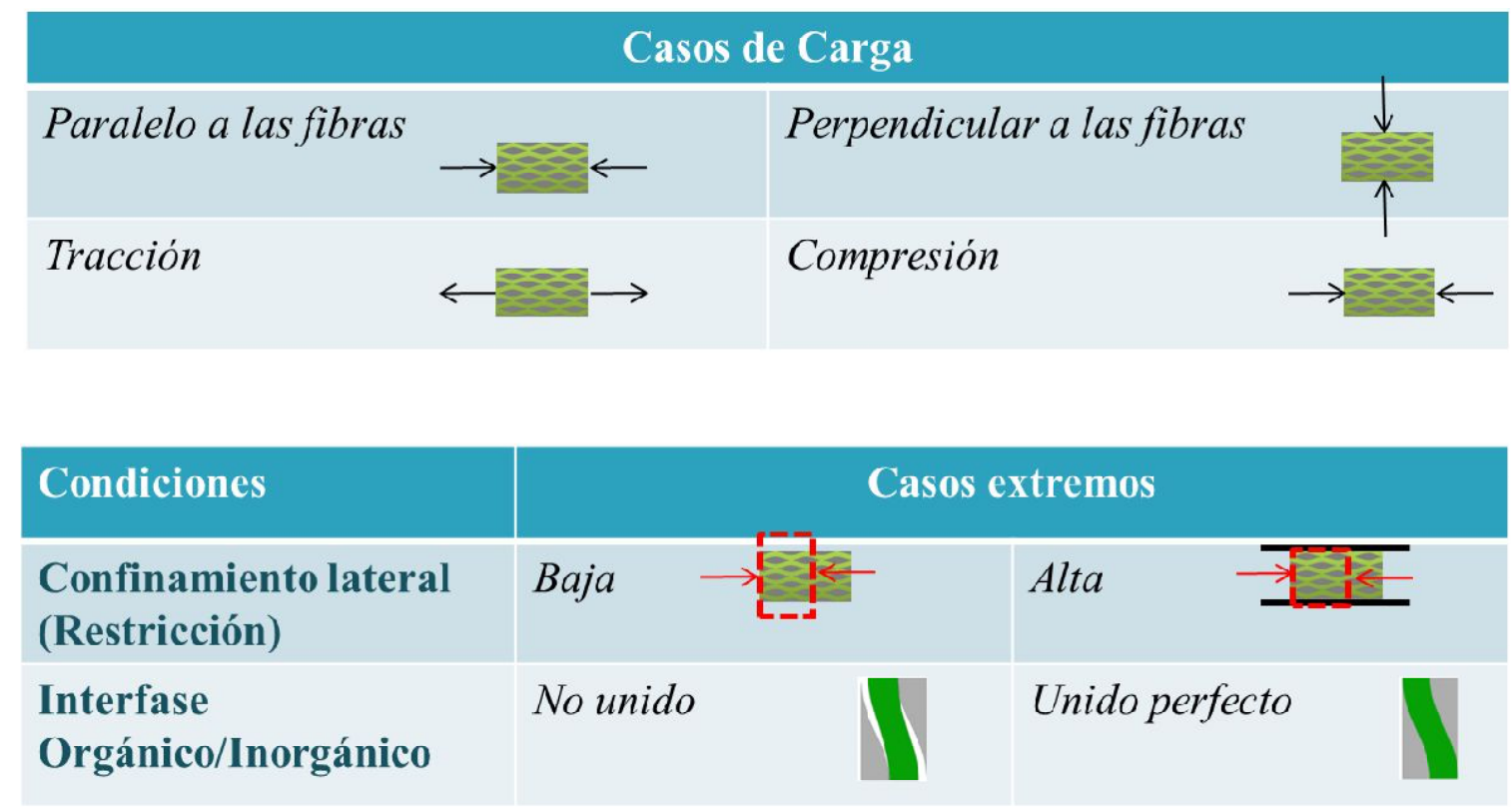

Figura 40 - Condiciones de borde aplicadas a los modelos de elementos finitos

\section{III.I.V - Resultados y conclusiones.}

Es importante tener en mente que los ensayos de nanoindentación se realizan siguiendo el procedimiento desarrollado por Oliver and Pharr [27]. El modelo analítico original desarrollado por Oliver and Pharr, J. Mater. Res. (1992, 2004) asume un modelo homogéneo y de material isotrópico. Es por eso que hay que tomar ciertos recaudos al usar este método e interpretar los resultados de un material heterogéneo con la misma longitud de escala que la punta del indentador. En los modelos aquí presentados mostramos que esas heterogeneidades conllevan a complejos modelos deformables. Limitamos los resultados y análisis a las condiciones de carga y de borde descriptas previamente.

La Figura 41 resume el módulo elástico obtenido a través de los diferentes casos. Se presentan dos tablas en la figura, una muestra los resultados cuando la carga es aplicada paralela a las fibras y la segunda cuando la carga es perpendicular. En cada tabla, cuatro condiciones son consideradas (todas bajo 
carga de compresión de la celda unidad). Las cuatro condiciones son el resultado de variar dos condiciones: confinamiento lateral y adhesión entre parte orgánica e inorgánica (interfase). Solo estas condiciones extremas fueron consideradas. No está claro el nivel de confinamiento real en los ensayos de indentación. En las simulaciones se consideraron solo deformaciones uniaxiales de compresión en alto confinamiento y tensiones uniaxiales de compresión en bajo confinamiento. Sin embargo, debe ser mencionado, que las condiciones de borde de indentación están lejos de ser tensiones o deformaciones uniaxiales ideales, de hecho, tensiones tangenciales están también presentes. Oliver and Pharr, diseñaron un método utilizando ingeniería inversa para determinar el módulo elástico de un material isótropo homogéneo. En estos modelos micromecánicos simples presentados, mostramos que la respuesta elástica del material depende de la geometría microestructural, del nivel de confinamiento lateral y de las propiedades de interfase (por supuesto que dejamos afuera del análisis la humedad de las fibras, las fibras están consideradas secas como en los ensayos).

Las tablas de la figura combinan las variaciones extremas del confinamiento lateral y las propiedades de interfase. Los casos más deformables corresponden a aquellos con un confinamiento lateral bajo e interfases débiles y los casos de mayor resistencia a la deformación, corresponden a un alto confinamiento e interfases fuertes y resistentes. No sorprende encontrar en las simulaciones que un confinamiento bajo significa que las fibras onduladas pueden flexionarse fácilmente en comparación con el caso de alto confinamiento (siempre con cargas aplicadas paralelas a las fibras). Por otro lado, la presencia de interfases débiles, permite que las fibras se separen de las partículas minerales permitiendo que se expandan lateralmente de forma fácil. Aunque, el mecanismo de expansión lateral es un poco diferente cuando la carga es aplicada de forma perpendicular a las fibras, el mismo comportamiento descripto anteriormente es observado. 


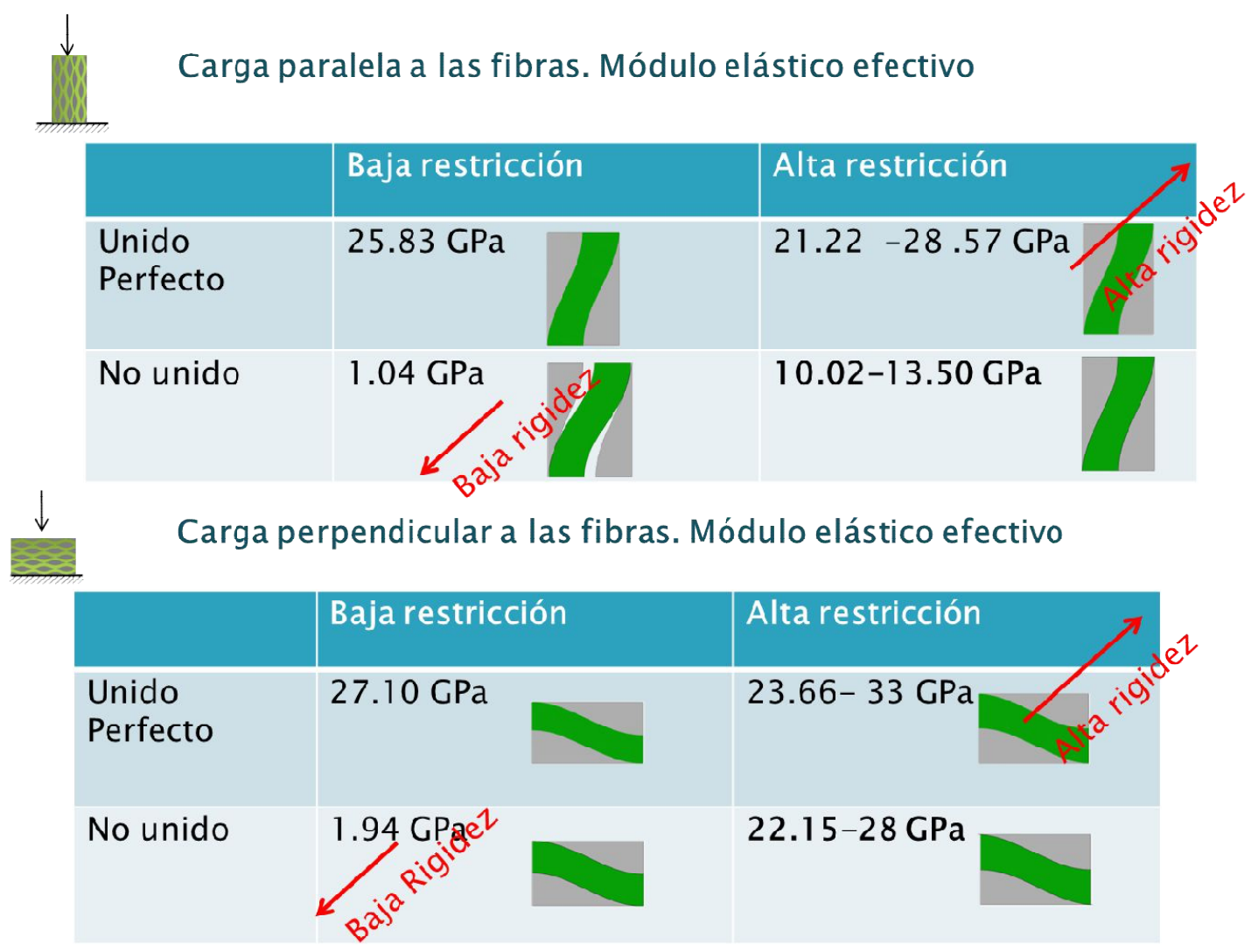

Figura 41 - Resultados del modelo de elementos finitos.

Las tablas (Figura 41) contienen los valores efectivos de módulos elásticos calculados en la dirección de carga para los diferentes casos. La interpretación del módulo elástico para el caso de bajo confinamiento lateral, baja carga, es sencillo. Sin embargo, los valores para los casos de alto confinamiento requieren de mayor información y más análisis de los resultados de tensiones en la dirección perpendicular a la aplicación de la carga.

Los casos presentados aquí dan resultados extremos. Suponemos que bajo las condiciones de nanoindentación real, estamos más cerca de los valores inferiores derecho de la tabla (relativamente alto confinamiento lateral y baja adhesión entre la fibra y el mineral). Mirando la tabla, podemos observar fácilmente que más allá del confinamiento lateral, una interfase débil afecta significativamente el valor de módulo elástico (al menos un orden de magnitud en el valor). Cuando la interfase es fuerte, la variación respecto o no al confinamiento lateral no es significativa. 
Las tablas de la figura también incluyen una imagen de la deformación al final de la simulación ( $5 \%$ de la deformación aplicada). La deformación más pronunciada se observa cuando las fibras son cargadas en la dirección paralela al eje longitudinal de las mismas con un confinamiento bajo e interfases débiles. Mosaicos de la celda unidad muestran estos casos extremos en la Figura 42. La separación de las fibras del mineral es observado en esta figura. La Figura 43 muestra una distribución típica de tensiones en la celda unidad.

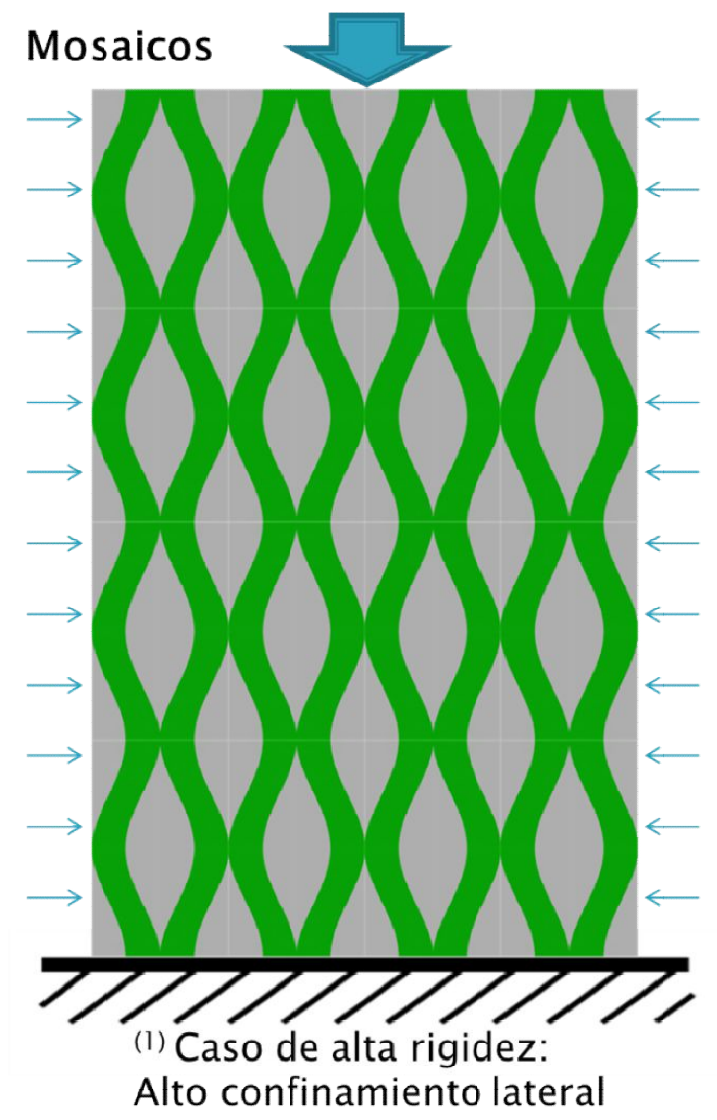

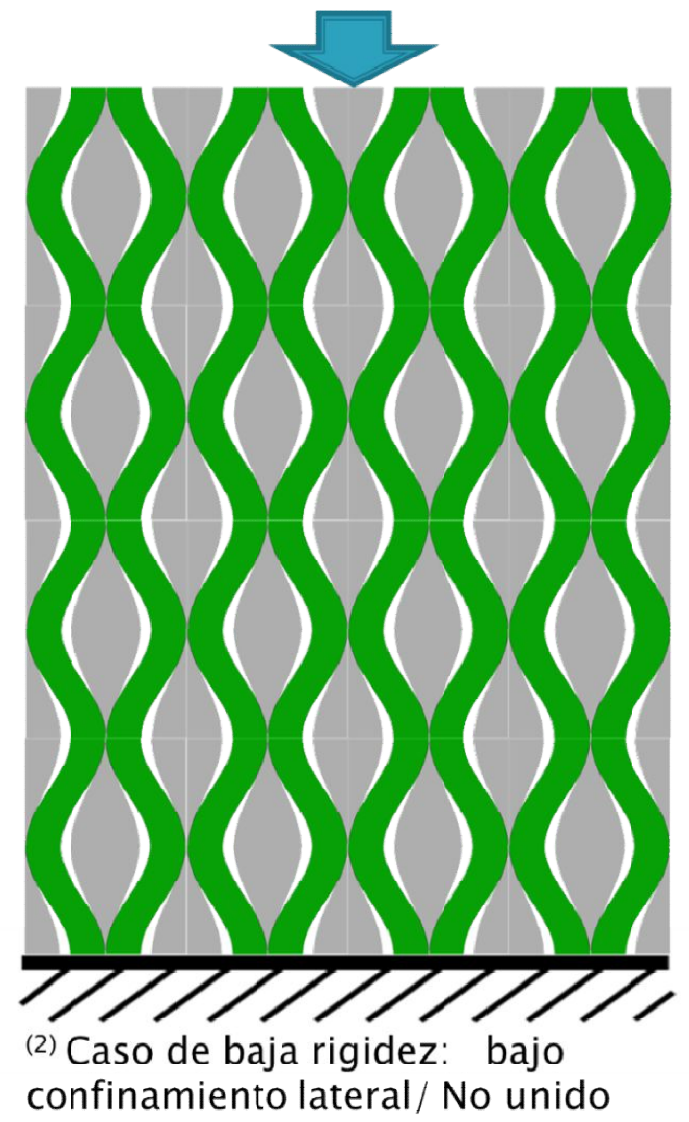

Figura 42 - Mosaicos mostrando la deformación de las fibras.

La distribución de tensiones es la siguiente. 


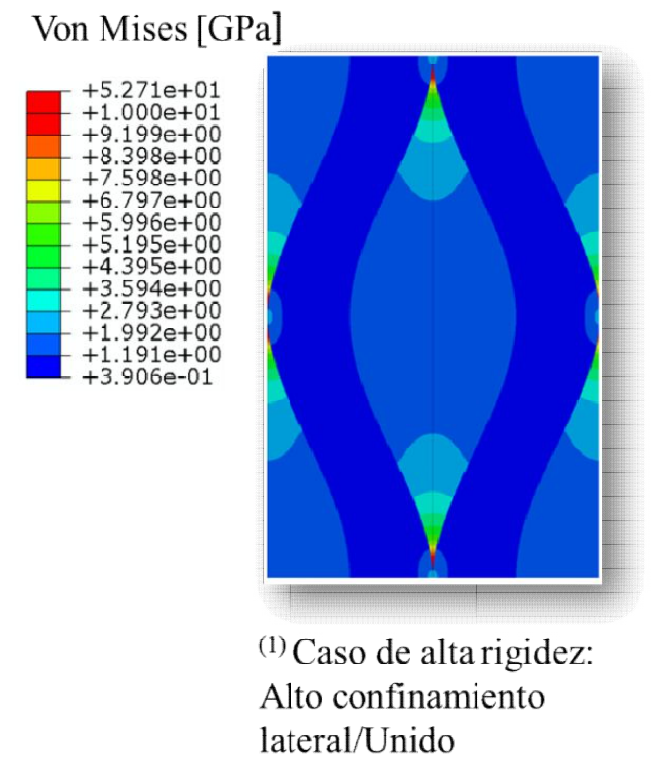

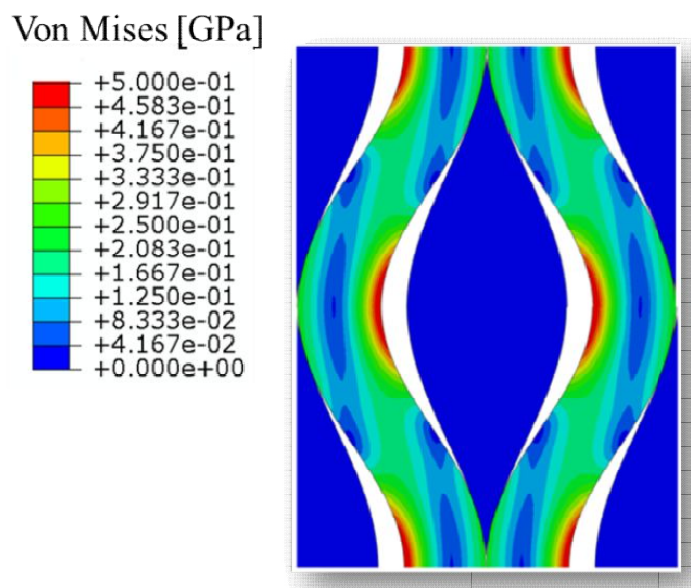

(2) Caso de baja rigidez: bajo confinamiento lateral/ No unido

Figura 43 - Distribución de tensiones sobre la celda unidad considerada.

\section{III.II -Análisis Microestructural de la región estriada.}

\section{III.II.I - Introducción}

Rodeando y envolviendo a la región periódica, podemos distinguir una región bien definida que se caracteriza por la presencia de planos de fibras mineralizadas alineadas a lo largo de su superficie. Esto es visible como estrías en el material y por lo tanto llamamos a esta región, región de estrías. La misma fue introducida en al capítulo II de este documento. Sus fibras se alinean y envuelven circularmente a la región periódica restringiendo su desplazamiento lateral durante un impacto. Actúa como un "suncho" de la región periódica. Dado la alineación de las fibras y su empaquetamiento, la región presenta un comportamiento mecánico fuerte en la dirección longitudinal de las fibras.

Analizamos diferentes imágenes de la región de estrías y construimos una celda unidad que representa su microestructura. Nuestro objetivo es poder explicar los resultados de nanoindentación obtenidos del material y así comprender un poco mejor el comportamiento de la microestructura de esta región. 
Podemos distinguir tres caras de esta celda unidad: La cara coronal, sagital y transversal (Figura 44), con diferentes características en ellas.

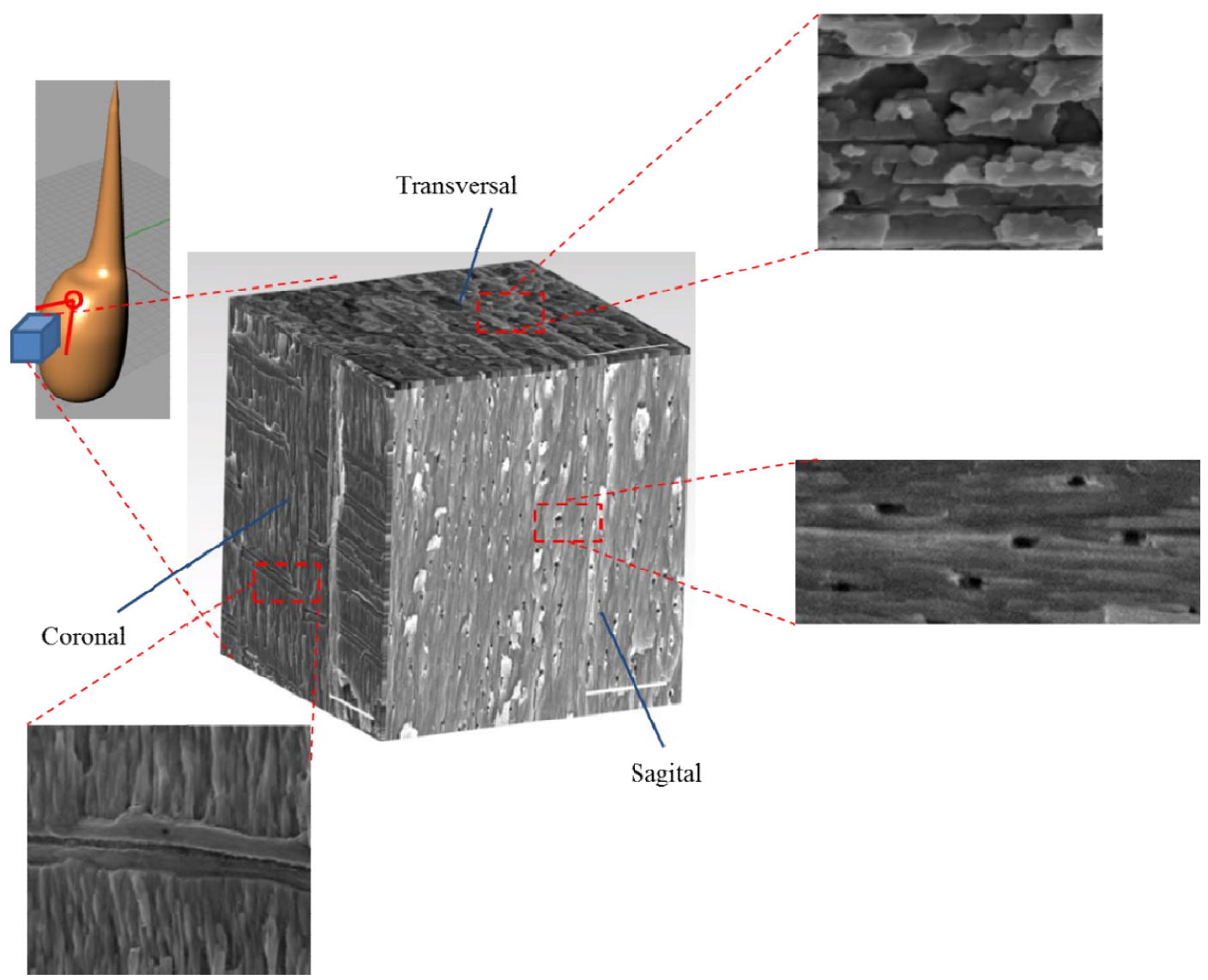

Figura 44 - Microestructura de la región de estrías. Imágenes SEM proporcionadas por el Laboratorio de Riverside

En la Figura 44 la cara coronal muestra fibras direccionadas en forma vertical que van desde la parte inferior a la parte superior de la imagen. La cara se ve interrumpida solo por ductos que la atraviesan en forma transversal y salen como agujeros en la cara sagital.

En la cara sagital podemos distinguir un grupo de fibras rodeando pequeños ductos o canales, que se visualizan como agujeros en dicha cara. La Figura 45 muestra un acercamiento a la cara sagital y también una esquematización en 2D mostrando las fibras rodeando los agujeros. Se puede apreciar además en el interior de dichos agujeros, fibras que lo recorren en su longitud. 


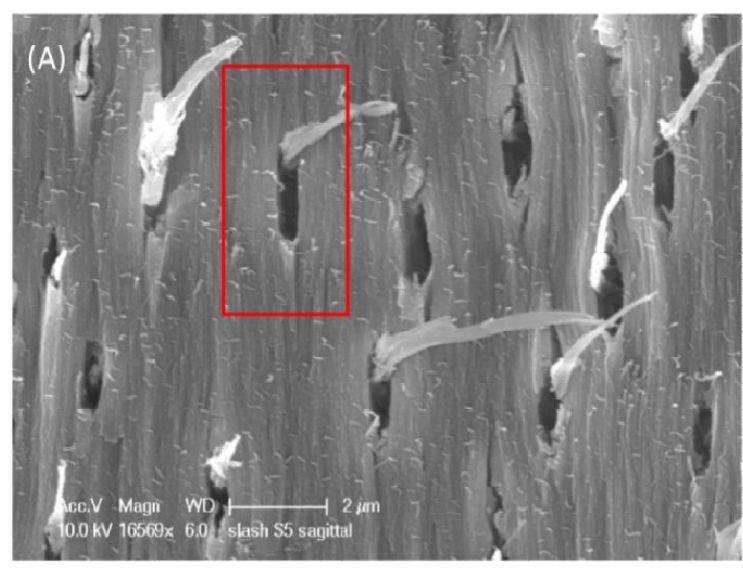

(B)
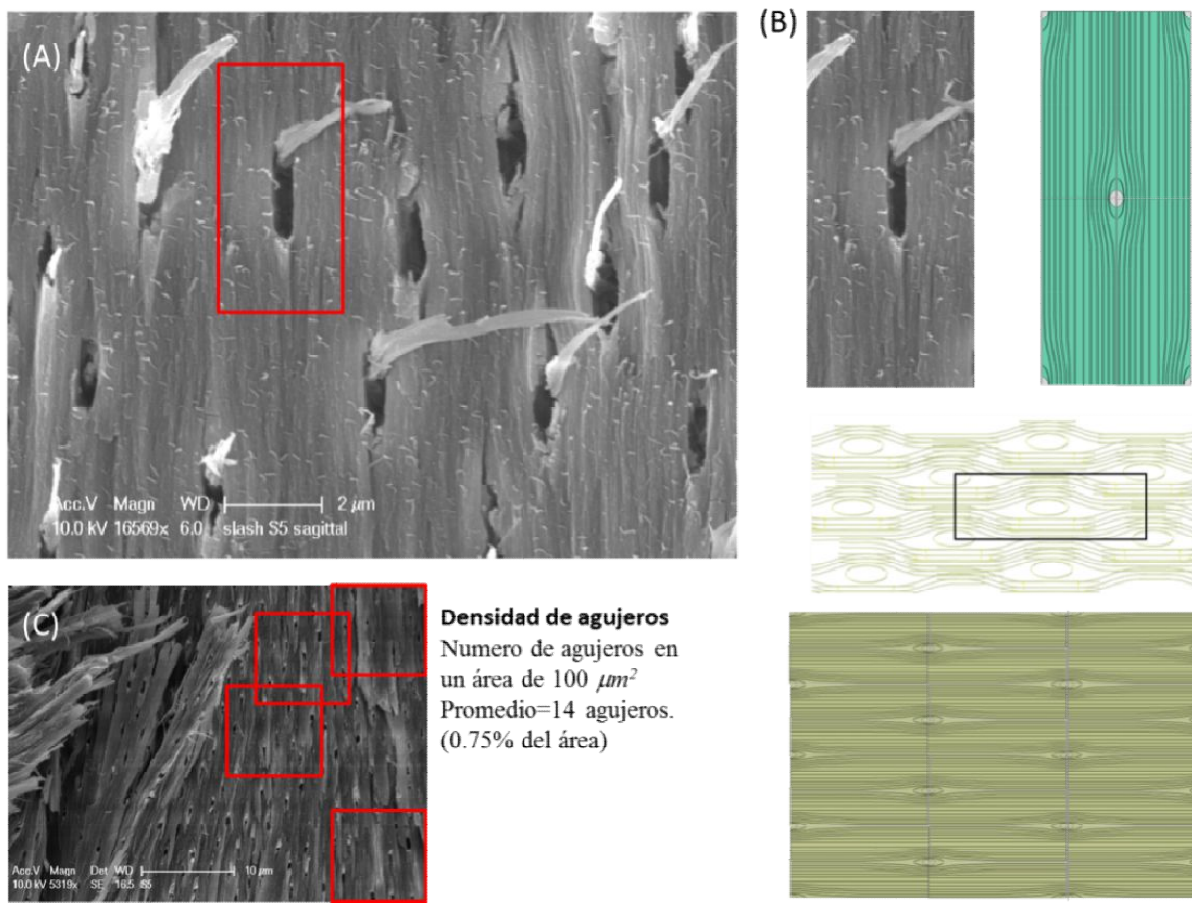

Densidad de agujeros

Numero de agujeros en

un área de $100 \mu^{2}$

Promedio=14 agujeros

( $0.75 \%$ del área)

Figura 45 - La imagen A corresponde a un acercamiento de la cara sagital de la región de estrías. La imagen B muestra un acercamiento hacia un agujero conjuntamente con su modelización. La imagen $\mathrm{C}$ muestra un conteo de agujeros en la imagen. Imagen SEM A y C proporcionada por Riverside.

La cara transversal del material muestra a las fibras cortadas perpendicularmente a la dirección longitudinal de las fibras. Los diferentes tonos de grises lo constituyen diferentes densidades de fibras en esa cara y constituyen las estrías características de esta región. Cuando nos acercamos a las imágenes no es sencillo reconocer las estrías de la región. Analizando imágenes luego de los ensayos de indentación (Figura 46) con fractura del material podemos reconocer que las estrías corresponden a fibras alineadas en un plano perpendicular a la cara y paralelo a la cara sagital. Una imagen más cercana nos muestra con claridad los planos de fibras altamente mineralizados y las estrías entre ellos (Figura 47). 


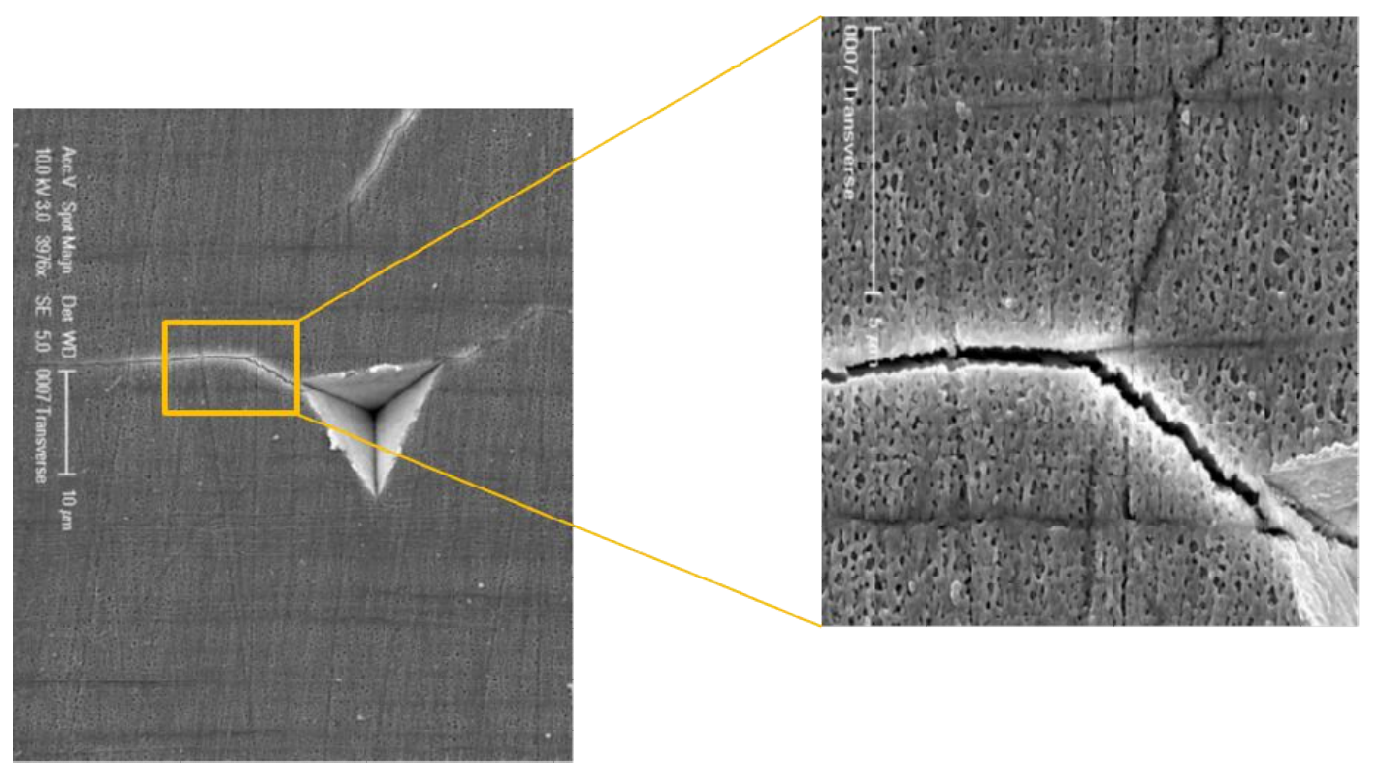

Figura 46 - Foto de indentación de la cara transversal mostrando de manera cercana la alineación de las fibras en la región de estrías. Imágenes SEM proporcionadas por Riverside.

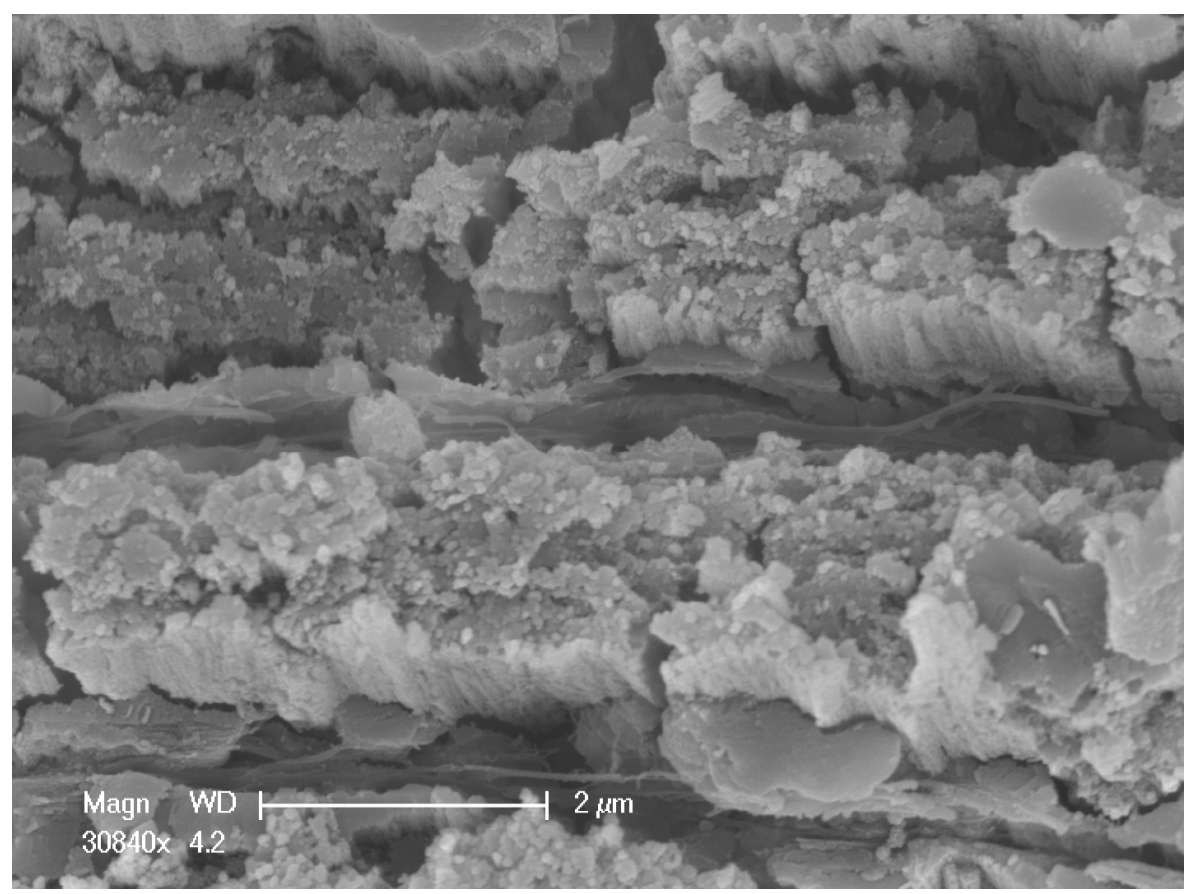

Figura 47 - Imagen de la cara transversal de la región de estrías, donde se ve con claridad los planos de fibras y las estrías entre ellos. Imagen SEM proporcionada por Riverside.

Teniendo en cuenta las características antes mencionadas, generamos un modelo en dos y tres dimensiones del material.

\section{III.II.II - Modelado en 3D y 2D}

Generamos un modelo tridimensional de este material (Figura 48). En gris claro representamos las fibras que rodean a los agujeros y en blanco los agujeros y fibras que hay dentro de ellos. Si seguimos el patrón de fibras rodeando los 
agujeros, nos encontramos con una porción donde las fibras no poseen curvaturas o no son comprimidas por otras fibras adyacentes. Esas fibras corresponden a las estrías de la región y se representan con un gris más oscuro.

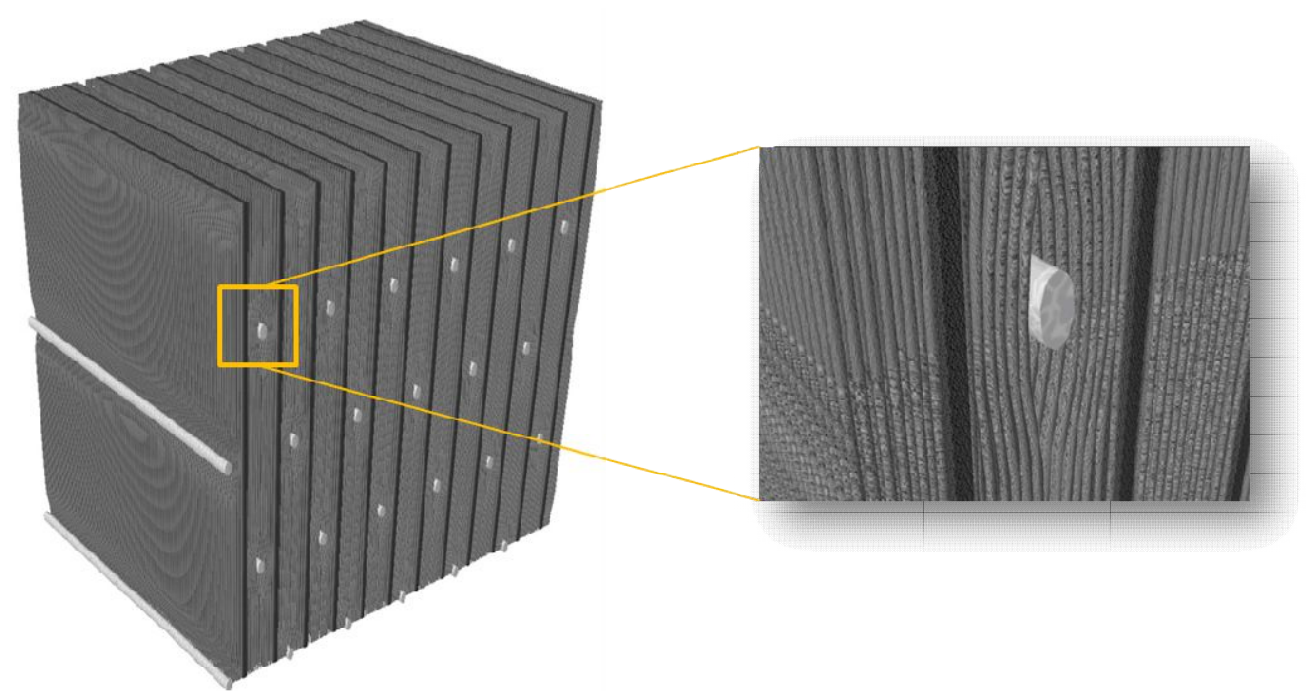

Figura 48 - Representación en 3D de la celda unidad de la región de estrías.

En dos dimensiones, la celda unidad del cubo mostrado anteriormente corresponde a una porción de la cara sagital. En la Figura 49 se muestra un modelo de la misma (presentado previamente en la Figura 45 conjuntamente con la imagen real de donde se inspira), donde el material en verde corresponde a fibras con su respectiva orientación y el material en gris corresponde a la matriz entre fibras.

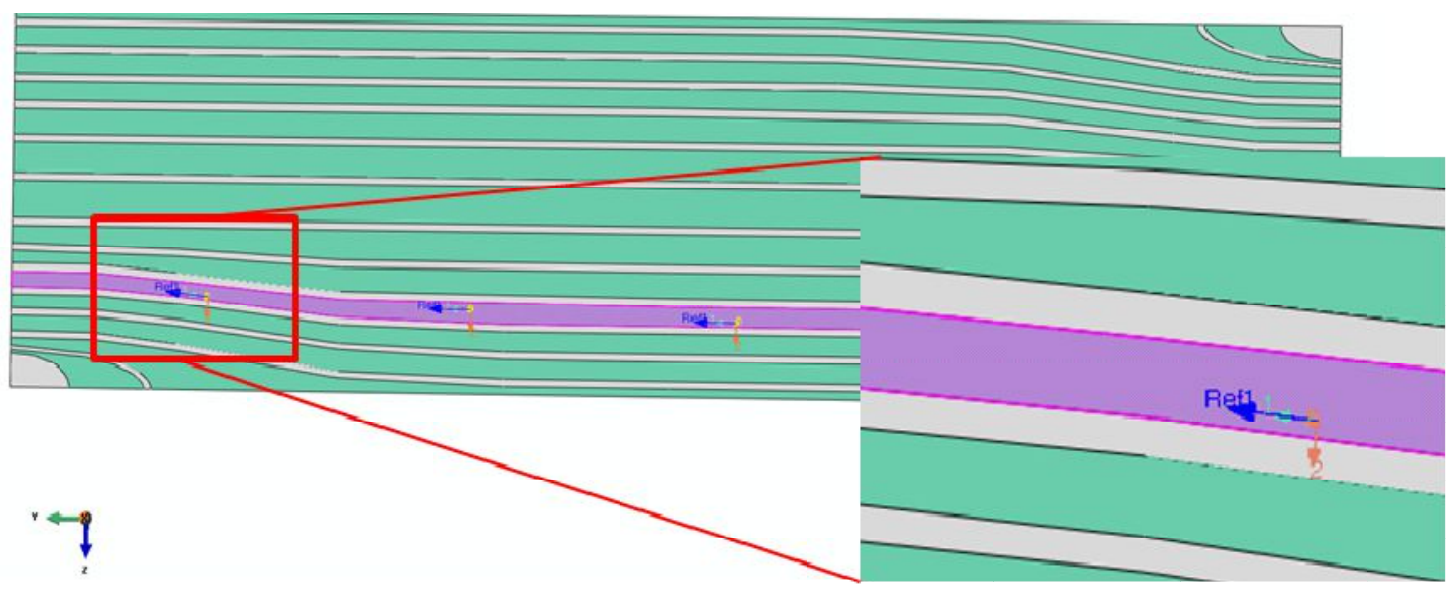

Figura 49 - Modelo de celda unidad de la cara sagital.

Como se mencionó, la orientación del material sigue la curvatura de la fibra, cuyo modelo material corresponde a un modelo ortótropo presentado en la ecuación (4). 


$$
\left(\begin{array}{l}
\varepsilon_{x x} \\
\varepsilon_{y y} \\
\varepsilon_{z z} \\
\varepsilon_{x y} \\
\varepsilon_{x z} \\
\varepsilon_{y z}
\end{array}\right)=\left(\begin{array}{cccccc}
\frac{1}{E_{x}} & -\frac{v_{y x}}{E_{y}} & -\frac{v_{z x}}{E_{z}} & 0 & 0 & 0 \\
-\frac{v_{x y}}{E_{x}} & \frac{1}{E_{y}} & -\frac{v_{z y}}{E_{z}} & 0 & 0 & 0 \\
-\frac{v_{x z}}{E_{x}} & -\frac{v_{y z}}{E_{y}} & \frac{1}{E_{z}} & 0 & 0 & 0 \\
0 & 0 & 0 & \frac{1}{2 G_{x y}} & 0 & 0 \\
0 & 0 & 0 & 0 & \frac{1}{2 G_{x z}} & 0 \\
0 & 0 & 0 & 0 & 0 & \frac{1}{2 G_{y z}}
\end{array}\right)\left(\begin{array}{c}
\sigma_{x x} \\
\sigma_{y y} \\
\sigma_{z z} \\
\sigma_{x y} \\
\sigma_{x z} \\
\sigma_{y z}
\end{array}\right)
$$

\section{III.II.III - Valores de indentación a recrear.}

El objetivo es recrear los valores de módulo elástico obtenidos a través del ensayo de indentación (Figura 50). La mayoría de las muestras fueron indentadas en la dirección transversal, es por ello que las fibras se encuentran comprimidas como se mostrará en el modelo numérico. Los resultados de los test de indentación se muestran en la Figura 51.

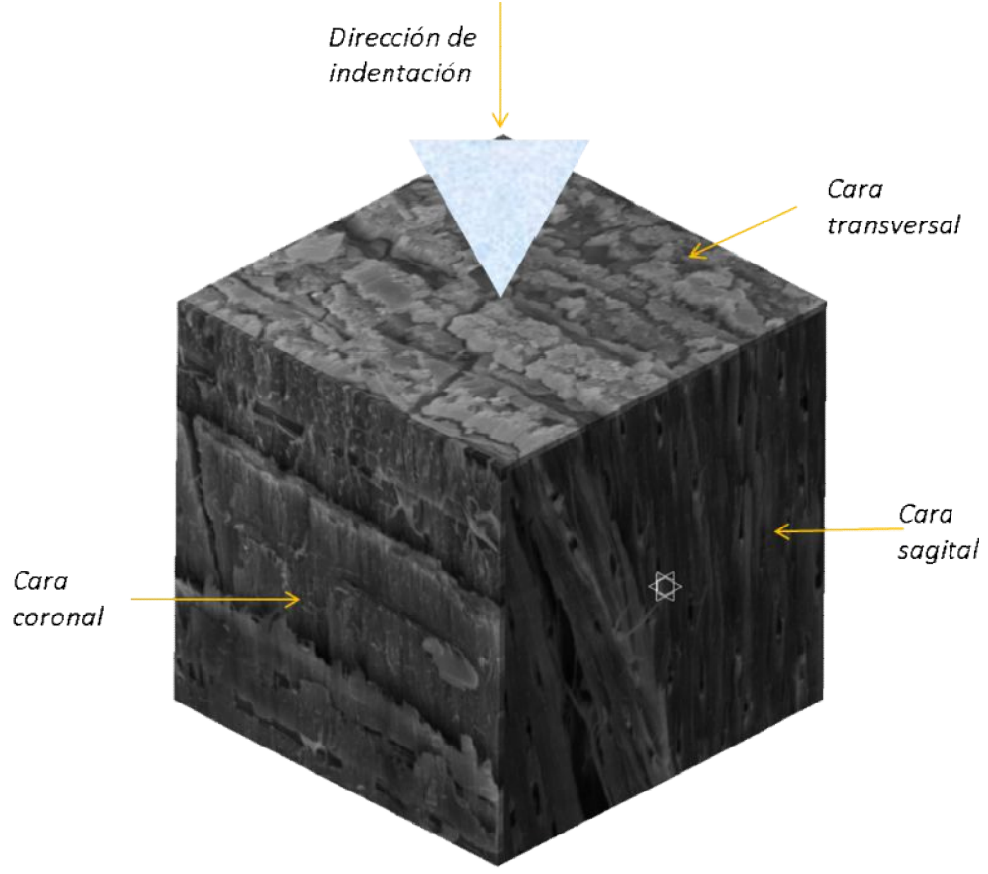

Figura 50 - Dirección de indentación de una porción de material de la región de estrías. Las imágenes SEM de cada cara fueron proporcionadas por Riverside. 


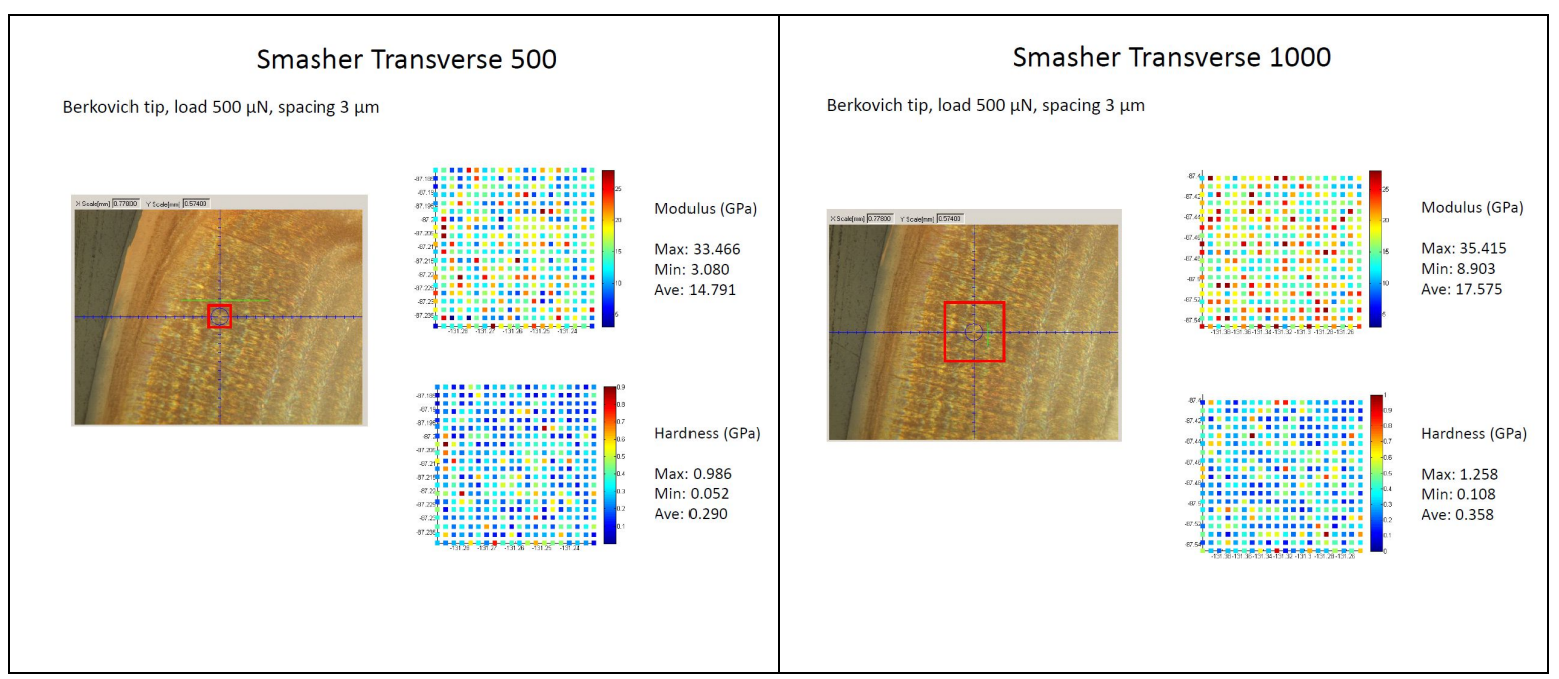

Figura 51 - Datos de indentación sobre la cara transversal. Información proporcionada por el laboratorio de Riverside.

Los datos muestran un valor de módulo elástico para la región de estrías que varía entre $3 \mathrm{MPa}$ y $35 \mathrm{MPa}$.

\section{III.II.IV - Modelado numérico}

Utilizamos condiciones de borde periódicas (PBC) y "rodamiento" para darle periodicidad a la celda unidad (Figura 52). Los modelos fueron considerados tanto para tensiones planas como deformaciones planas para obtener valores extremos como resultado.

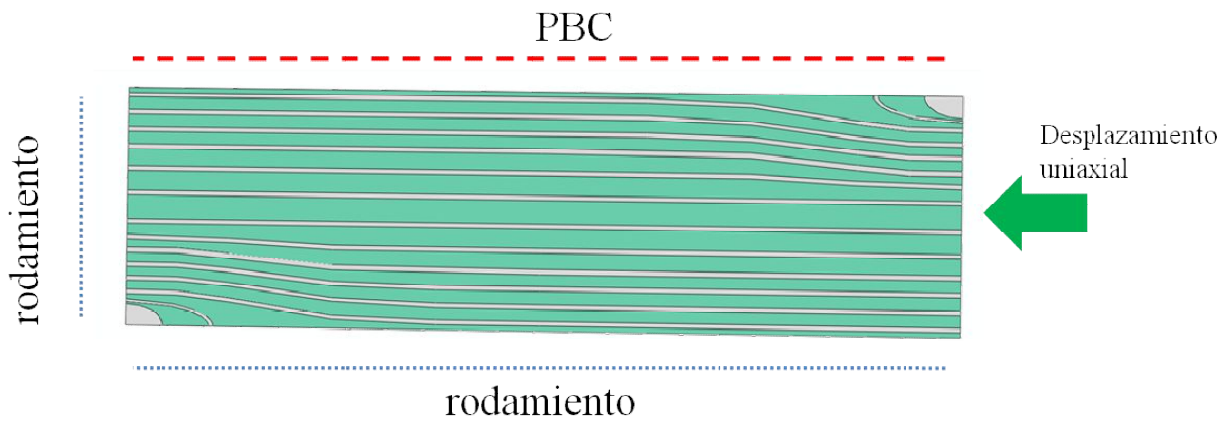

Figura 52 - Modelo numérico utilizado.

Para obtener las propiedades del material mencionado, es necesario realizar modelos a escalas inferiores. Asociamos los modelos a escalas inferiores del Estomatópodo con los descriptos por Nikolov et.al. [28] para la langosta roja. Sin embargo las proporciones de orgánico-inorgánico son diferentes para estos dos crustáceos. 
Consideramos un modelado jerárquico de tres niveles (Figura 53). Las propiedades mecánicas en esos modelos fueron calculadas utilizando herramientas de homogenización (Voig and Reuss) o modelado por el uso de elementos finitos.

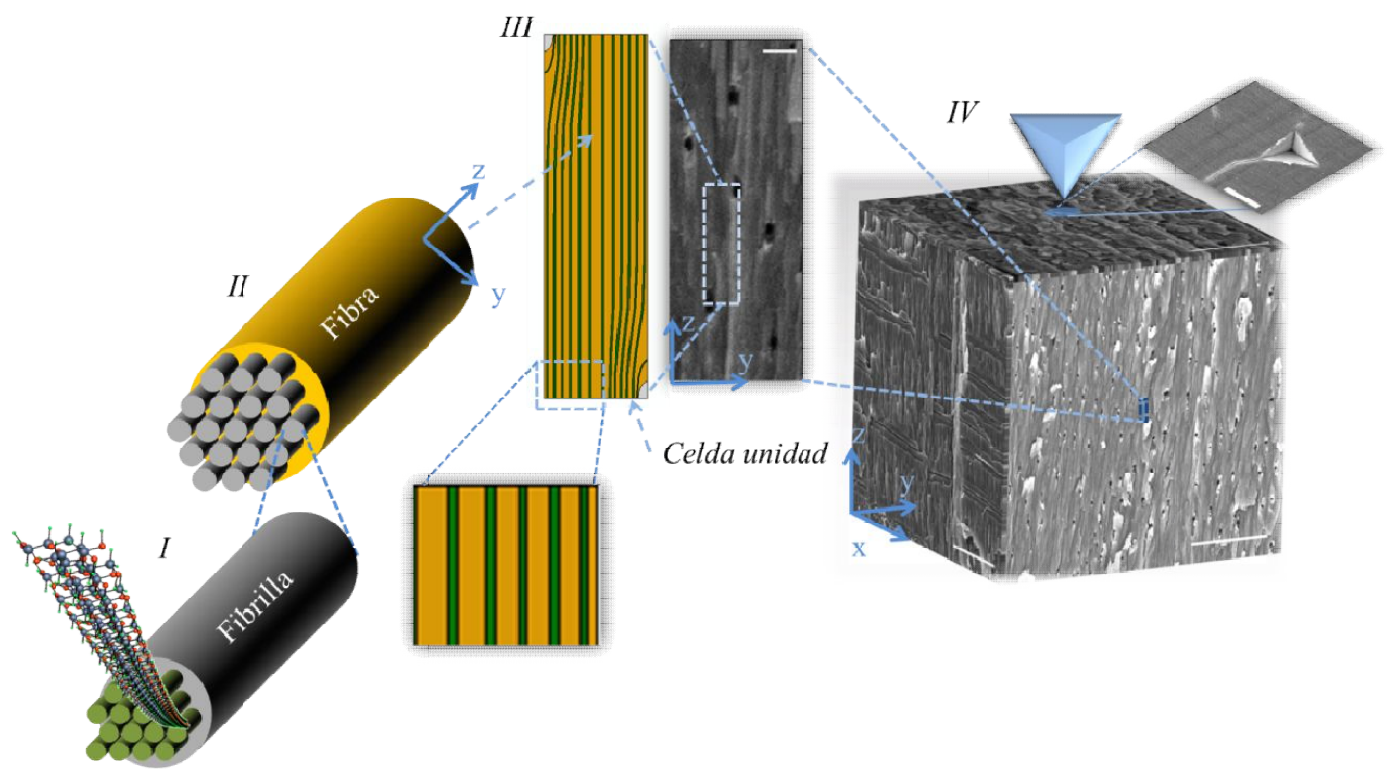

Figura 53 - Esquema de jerarquización de modelos-Estructura jerárquica de la región de estrías del Estomatópodo. (I) Primer orden jerárquico: fibrillas formadas por cadenas de $\alpha$-quitina recubiertas de proteínas. (II) Segundo orden jerárquico: fibras formadas por fibrillas en una matriz de mineral y proteína. (III) tercer orden jerárquico: Fibras (amarillo) rodeadas por una matriz mineral (verde). (Escala 0.5um en el cubo de la escala IV)

Se testearon muestras de regiones dentro del martillo dáctilo, para poder determinar los porcentajes de orgánico y mineral dentro de las mismas. Dado que la pérdida de masa, ocurre a diferentes temperaturas, mediante el uso de TGA se separó tanto agua, material orgánico y carbonato de calcio. Cabe aclarar que no fue posible la separación de la región de estrías y las periódicas, sin embargo las mismas poseen similitudes en composición de orgánicos y de mineral. La Figura 54 muestra los resultados del análisis gravimétrico. 


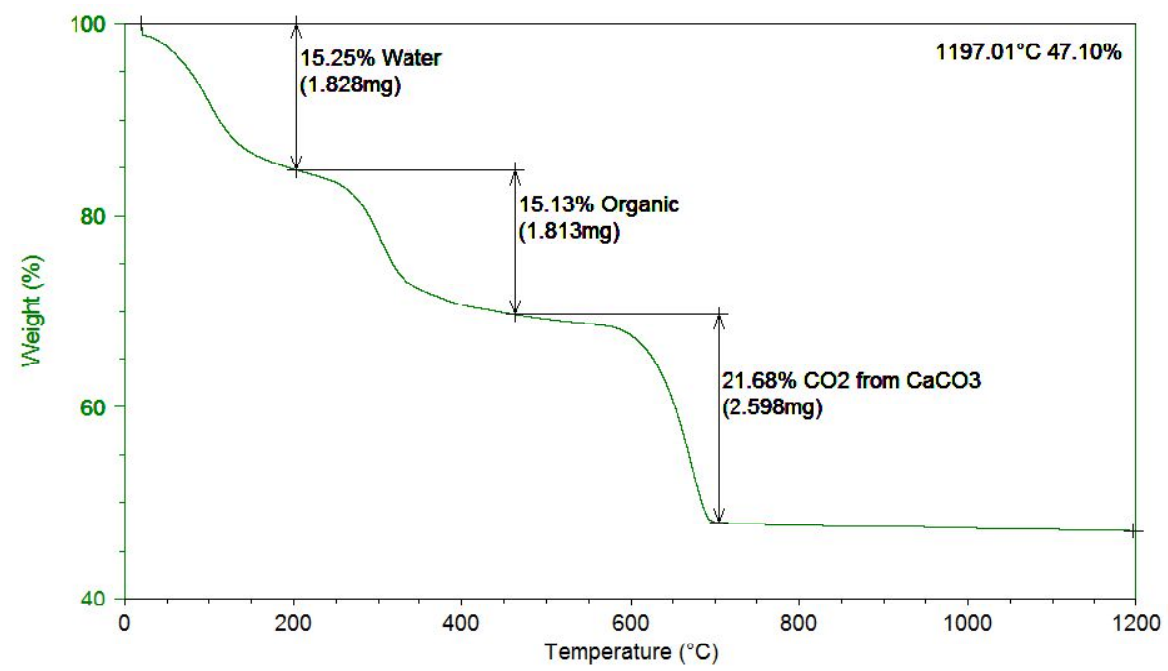

Figura 54 - Resultados de análisis térmico gravimétrico, mostrando el porcentaje de material orgánico versus material mineral. Debido a que la pérdida de masa ocurre a diferentes temperaturas es posible diferenciar dichos materiales. Información proporcionada por el laboratorio de Riverside, Universidad de California, EEUU.

El contenido de material orgánico fue aproximadamente $15 \%$ en peso, según datos obtenidos del TGA-DSC. Consideramos que esta cantidad de material orgánico está localizado en su gran mayoría en las fibrillas de la fibra y en una proporción menor en la matriz de la fibra. Un $70 \%$ constituye material mineral en la región de estrías.

Para el primer y segundo orden jerárquico se utilizó un modelo en elementos finitos que representa una celda unidad de una fibrilla y fibra respectivamente. El mismo modelo fue introducido en la sección III.I. Para este caso las fracciones volumétricas y materiales han cambiado respecto de la sección mencionada. En la Figura 55 se muestra los modelos correspondientes. 


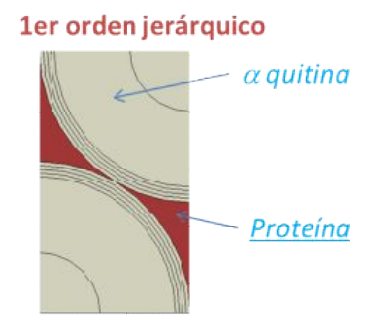

Fibrillas

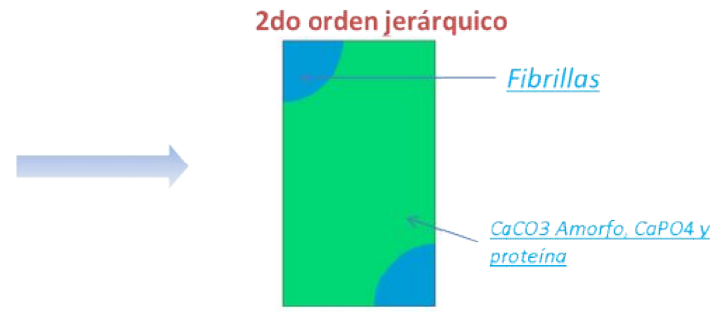

Fiber+Matrix

3er orden jerárquico

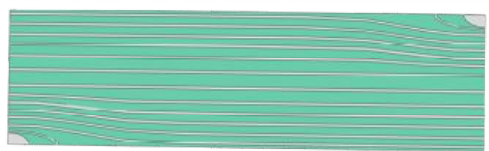

Fibras, estrías y agujeros.

Figura 55 - Modelo de fibrilla y fibra para FEM.

Con la modelización mostrada, podemos variar, en el primer nivel, la cantidad de quitina en la celda unidad y para el segundo nivel, la proporción de $\mathrm{CaCO}_{3}$ y hidroxiapatita. Esta variación nos permitirá ajustar el valor de módulo elástico obtenido a través de la indentación.

Las propiedades de los materiales son los siguientes:

Para la $\alpha$-quitina [28]:

$$
\underline{\underline{C_{\mathrm{CH}}}}(\mathrm{GPa})=\left[\begin{array}{cccccc}
119 & 0.1 & 1.1 & 0 & 0 & 0 \\
0.1 & 28 & 2 & 0 & 0 & 0 \\
1.1 & 2 & 24 & 0 & 0 & 0 \\
0 & 0 & 0 & 5 & 0 & 0 \\
0 & 0 & 0 & 0 & 8 & 0 \\
0 & 0 & 0 & 0 & 0 & 2
\end{array}\right]
$$

Parte de la información utilizada para el modelado es el siguiente: como punto de inicio, suponemos que la $\alpha$-quitina se encuentra en forma de cadenas cristalinas. Respecto a la hidroxiapatita $\left(\mathrm{Ca}_{5}\left(\mathrm{PO}_{4}\right)_{3}(\mathrm{OH})\right)$ los valores indican un módulo elástico de 68.5 GPa para cristales amorfos [39].Respecto al carbonato de calcio amorfo tenemos valores de 32-37 GPa de modulo elástico [28][40]. En cuanto a la proteína el modulo elástico ronda los 4 MPa y una relación de Poisson de 0.45. [28] 


\section{III.II.V - Observaciones en el modelo y resultados.}

Observaciones en las imágenes de microscopia electrónica, como la presentada en la Figura 56, muestran gran densidad de poros en el material. Más aún, el módulo elástico de cada uno de los componentes del material es superior al del compuesto obtenido en el ensayo de indentación, aun considerando la presencia de material orgánico y teniendo en cuenta que para la región periódica las propiedades de $\alpha$-quitina corresponden a un cristal amorfo. Podemos pensar que la porosidad en el material tiene gran influencia en la determinación del módulo elástico, por lo que construimos un modelo y tenemos en cuenta las consideraciones antes mencionadas para tratar de recrear los ensayos de indentación.
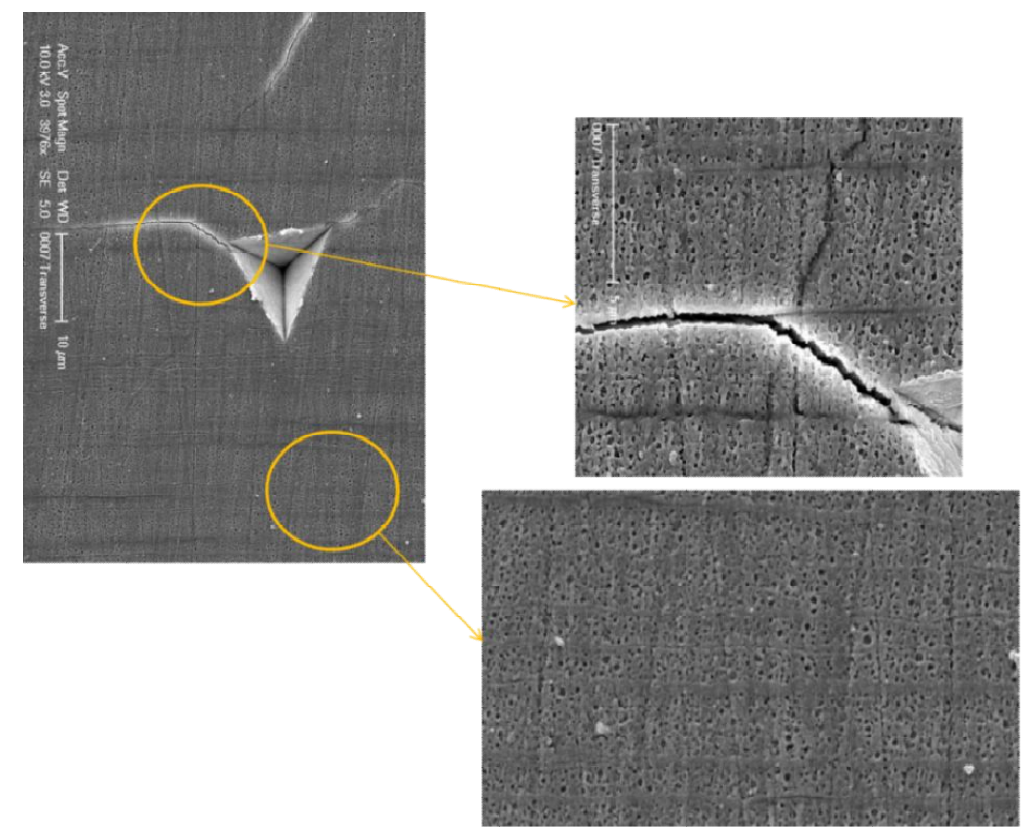

Figura 56 - Porosidad en la región de estrías. Imágenes SEM proporcionadas por Riverside.

Dada esta observación y para poder corroborar el grado de porosidad que tiene las muestras, consideramos en el modelo presentado en la Figura 52, la porosidad en el material.

A continuación se presentan las hipótesis del modelo:

- Consideramos despreciable la cantidad de $\alpha$-quitina en el material. Consideramos solo mineral con un modelo ortotrópico siguiendo la dirección de las fibras. 


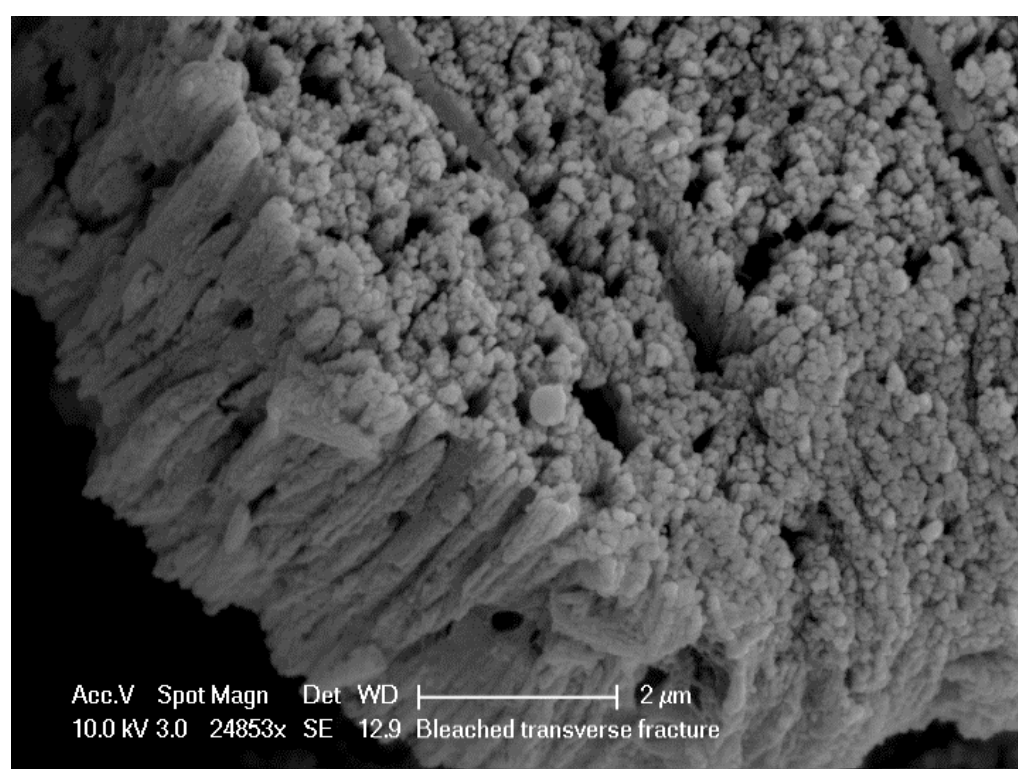

Figura 57 - Consideraciones de solo mineral $\sin \alpha$-quitina. Imagen SEM proporcionada por Riverside.

- El material mineral considera porosidad. Se modela la misma como una partícula de propiedades mecánicas nulas. (teoría de homogenización- MoriTanaka).

- La porosidad varia de 0 a $30 \%$ en volumen de toda la muestra.

- $\quad$ El núcleo de material será 100\% mineral amorfo $\mathrm{CaCO}_{3}$ (módulo elástico de 32 GPa). No consideramos para estos cálculos la contribución de fosfato de calcio a las propiedades mecánicas.

\section{III.II.VI - Resultados y conclusiones.}

En la Figura 58 mostramos la variación del módulo elástico en la cara transversal de la región de estrías versus el porcentaje de porosidad en la muestra. 


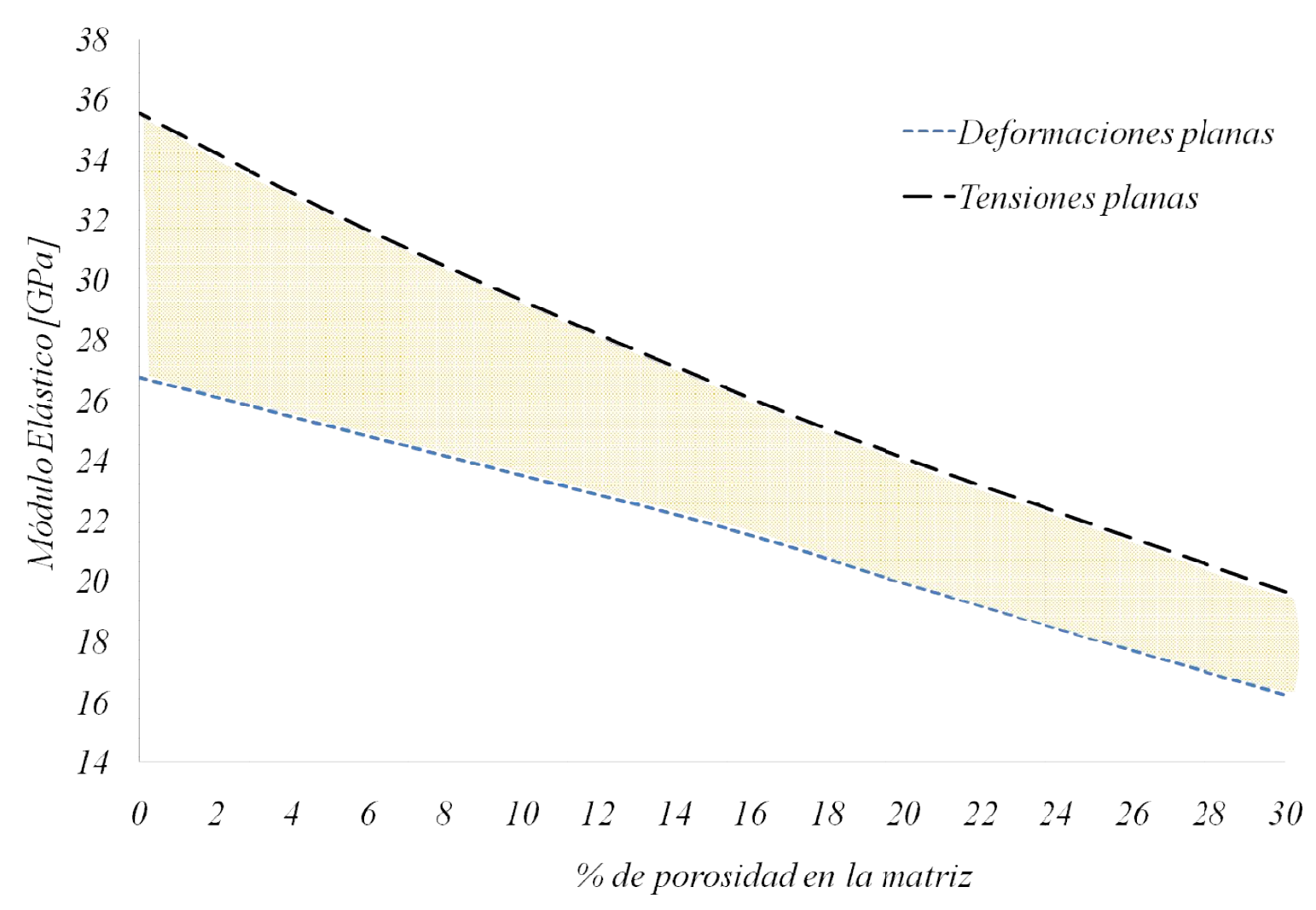

Figura 58 - Gráfica de módulo elástico del compuesto versus la porosidad en el material.

La gráfica muestra la dependencia del valor de indentación de la densidad de poros del material.

Comparando estos resultados con los obtenidos por indentación con un promedio de 15 GPa de módulo elástico, se observa que es necesario al menos un $30 \%$ de porosidad para alcanzar el valor de módulo elástico requerido. Además se ve que este fenómeno tiene mucho peso en el resultado del módulo elástico, más aún que las proporciones de materiales que componen las fibras o el mineral.

Como trabajo a futuro en esta región se requiere realizar estos cálculos con mediciones experimentales del grado de porosidad existente para poder, a partir de ello, determinar la composición de materiales y formas. 


\section{CAPÍtulo IV - MECANISMos DE DisiPACIÓN DE ENERGÍA.}

\section{I - Introducción}

La resistencia al inicio de fisura y su posterior propagación en materiales biológicos reside en la presencia de propiedades de dureza, resistencia y tenacidad a la fractura entre otros [1]. Sin embargo es esta última propiedad, así como los mecanismos utilizados para disipar la energía almacenada en el material, la que resulta de particular interés para nuestro estudio.

Las uniones rígidas presentes dentro de las interfases [41], que vinculan los "bloques de construcción" (fibras, placas, barras) de estos materiales, son actores fundamentales para entender la tolerancia al daño en estos compuestos. El comportamiento de la fisura en él, frente a la fractura de dichas uniones constituye un mecanismo de disipación de energía clave para el éxito de estos materiales y que intentaremos explicar.

En el nácar, la presencia de puentes impide (Figura 59A), en primera instancia, el deslizamiento de las placas, aporta una rigidez inicial al material [42][17] e impide la expansión lateral de las placas [13], contribuyendo al endurecimiento por deformación del material luego de la fractura de algunos puentes localizados en la periferia de las placas. Este comportamiento es característico del nácar y es generado por la presencia de una densidad mayor de puentes en la zona central de las placas [41]. Este factor, conjuntamente con un aumento de espesor en los extremos de las mismas produce un trabado o enclavamiento ante esfuerzos normales en el material dado que los puentes impiden la expansión del material al montarse una placa sobre otra.

La presencia de estas uniones rígidas es visible también en el diente de chitón (Figura 59B). Uniones minerales entre barras conjuntamente con nano- 
asperidades en las interfases, impiden el deslizamiento y alejamiento de las mismas dentro del material [5].

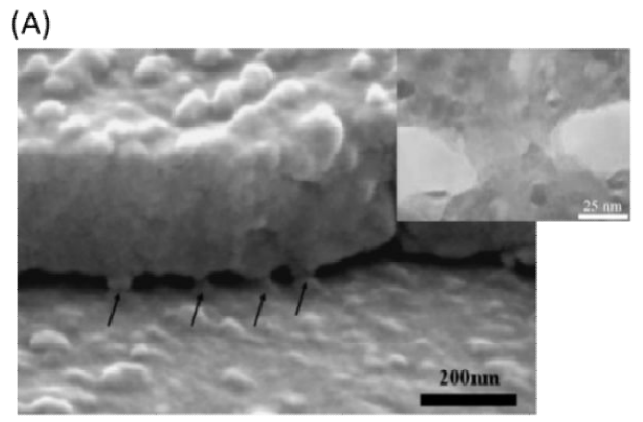

(B)

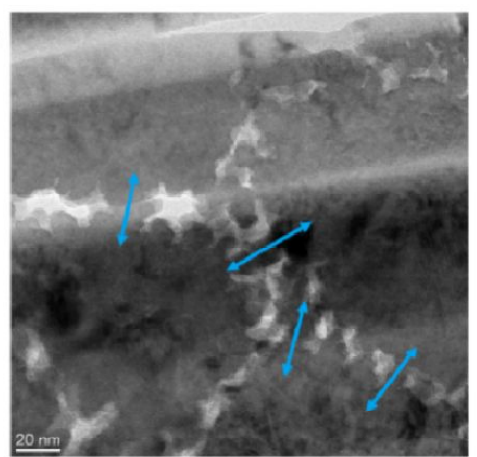

Figura 59 - (A) Puentes minerales entre placas de nácar. También se muestra un corte transversal de un puente a escalas menores [43][44]. (B) Se muestra la presencia de puentes entre barras de la microestructura del diente de chitón.

Para el caso del material perteneciente al martillo dáctilo del estomatópodo, la presencia de gran cantidad de fibras en las regiones interiores del martillo (periódica y de estrías) y sus interfases flexibles, otorgan zonas de generación de fisuras ante cargas externas elevadas y múltiples caminos de crecimiento para la misma. Aunque si bien no se han fotografiado aún uniones rígidas perpendiculares a las fibras, la presencia de nano-asperidades entre fibras o fibras no paralelas al resto supone mecanismos similares al de los puentes dentro del material. La Figura 60 muestra un acercamiento a fibras de la región de estrías, mostrando nanoasperidades o uniones rígidas entre ellas.
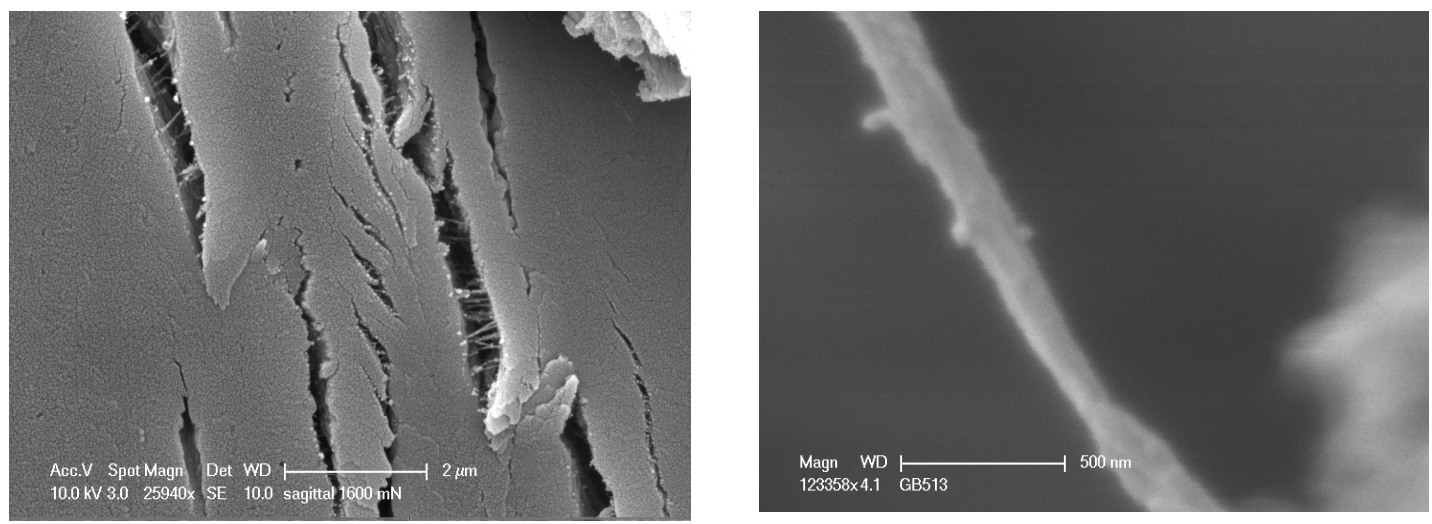

Figura 60 - (izquierda) Imagen de fractura de la región de estrías en su cara sagital del martillo dáctilo de la mantis marina. A diferencia del nácar o chitón, el tamaño de grano es tan pequeño dentro de las fibras mineralizadas que es difícil distinguir puentes entre fibras. (derecha) En una fibra perteneciente a los canales de la zona de estrías es posible ver las nano-asperidades en ella.

Imágenes SEM proporcionadas por Riverside. 
Las interfases de los materiales juegan un rol muy importante en su comportamiento mecánico, ya que a través de ellas se explican sus propiedades de resistencia y tenacidad a la fractura. Además de eso son también las zonas donde la fisura nace y se propaga, por lo que es de particular interés para esta investigación conocer sus características y comportamiento frente a la fractura.

La característica de un material a ser insensible estructuralmente a la generación de múltiples microfisuras en su microestructura, le otorga una alta tenacidad a la fractura en comparación con el mismo material sin esta propiedad. Es en las interfases donde estos materiales han demostrado que es posible un crecimiento de fisura estable.

El objetivo de este capítulo radica en demostrar que la interfase entre los elementos que conforman a los materiales naturales, presenta una contraposición de mecanismos funcionales a la hora de desperdigar el daño en el material. Por un lado, presentan una rigidización de las interfases a través de la utilización de puentes minerales, en números y configuraciones que elevan la disipación de energía a la hora de la fractura, pero manteniendo sin embargo, una debilidad estructural relativa a su entorno de modo que el crecimiento de la fisura se mantenga dentro de ella.

\section{IV.II - Análisis de las interfases.}

Desarrollamos un modelo numérico para testear el comportamiento de un material con diferentes configuraciones de interfases. Llevamos el modelo de material hasta la rotura y observamos el comportamiento de la fisura en el material y su evolución. 


\section{IV.II.I - Concepción del modelo numérico.}

El modelo elegido para el análisis consiste en una región semi-infinita donde el inicio de la fisura corresponde con el origen de coordenadas del modelo y con el lugar en el cual colocaremos el material a testear, tal como se muestra en la Figura 61.

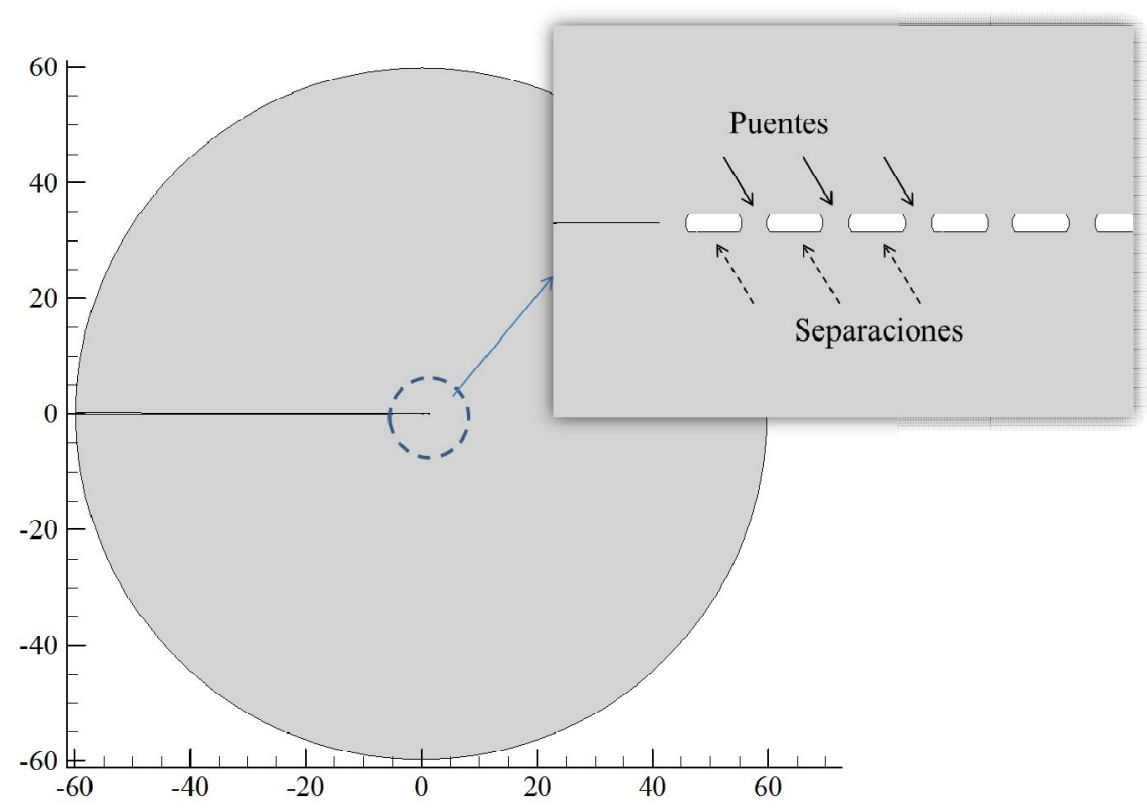

Figura 61 - Modelado de la región semi infinita

En esta región semi infinita se analizará una porción de material característico, donde se ubica la interfase del material alineada con el inicio de fisura. La interfase consta de una distribución de puentes ubicada dentro de una región elíptica de 1700 nm eje mayor y 600 nm eje menor. La región será sometida a un modo mixto de cargas hasta la rotura del material, de tal forma de analizar el crecimiento de fisura dentro o fuera de la interfase.

Planteamos un modelo numérico a ser resuelto por elementos finitos. Utilizaremos elementos cohesivos para simular el daño del material y posterior crecimiento de fisura. La resolución del modelo numérico transitorio se realiza a través del método explicito Newmark. 
El método de los elementos finitos es un método numérico que permite aproximar soluciones, a un sistema de ecuaciones diferenciales parciales muy complejas. Las mismas representan un comportamiento físico particular sobre un cuerpo o dominio (medio continuo) ante perturbaciones externas o internas. Los cálculos se realizan sobre una malla de puntos llamados nodos, que sirven a su vez de base para la discretización del dominio en elementos finitos. De acuerdo con la conectividad entre ellos y las variables incógnitas definidas en cada nodo (denominadas grados de libertad) se genera un sistema de ecuaciones lineales cuya solución satisface el problema planteado con cierto grado de error. El número de ecuaciones de dicho sistema es proporcional al número de nodos. Para mayor información sobre el método podemos leer autores como Cook [45], Bathe [46], Belytschko [47], etc.

\section{IV.II.II - Condiciones de borde}

Aplicaremos un modo de fractura mixto donde la energía liberada (G) estará dada por

$$
G=\frac{\kappa+1}{8 \mu}\left(K_{1}^{2}+K_{2}^{2}\right)
$$

Llamaremos $K_{1}$, al factor de intensidad de tensiones correspondiente a la dirección de modo I y $\mathrm{K}_{2}$ al correspondiente a la dirección de modo II (factores globales). La condición de crecimiento de fisura ocurre cuando $G=G_{c}$ (crítica). En ese caso

$$
\left(\frac{K_{1}}{K_{c}}\right)^{2}+\left(\frac{K_{2}}{K_{c}}\right)^{2}=1
$$

Donde Kc corresponde al factor de intensidad de tensiones crítico y está dado por

$$
K_{c}=\sqrt{\frac{8 \mu G_{c}}{\kappa+1}}
$$

La relación entre $\mathrm{K}_{1} \mathrm{y} \mathrm{K}_{2}$, corresponde al ángulo $\psi$ de modo mixto aplicado. 


$$
\operatorname{Tan} \psi=\frac{K_{2}}{K_{1}}
$$

En fractura lineal elástica (LEFM) el crecimiento de la fisura es controlado por la deformación y las tensiones alrededor del crack tip. Si el origen de coordenadas del sistema $(\mathrm{r}, \vartheta)$ está localizado en el crack tip, el campo de deformaciones alrededor del mismo puede ser escrito en términos de los factores de intensidad de tensiones $\mathrm{K}_{1} \mathrm{y} \mathrm{K}_{2}$.

Entonces:

$$
\begin{aligned}
& u_{1}=\frac{\|K\| R^{\frac{1}{2}}}{2 \pi \mu}\left[\left(\frac{7}{2}-4 v\right) \cos \left(\frac{\theta}{2}-\psi\right)+\cos \left(\frac{\theta}{2}+\psi\right)-\frac{1}{2} \cos \left(3 \frac{\theta}{2}+\psi\right)\right] \\
& u_{2}=\frac{\|K\| R^{\frac{1}{2}}}{2 \pi \mu}\left[\left(\frac{5}{2}-4 v\right) \operatorname{sen}\left(\frac{\theta}{2}-\psi\right)+\operatorname{sen}\left(\frac{\theta}{2}+\psi\right)-\frac{1}{2} \operatorname{sen}\left(3 \frac{\theta}{2}+\psi\right)\right]
\end{aligned}
$$

Donde,

$$
\begin{gathered}
\|K\|=\sqrt{K_{1}^{2}+K_{2}^{2}} \\
\mu=\frac{E}{2(1+v)}
\end{gathered}
$$

$k=3-4 v$ deformaciones planas

$$
k=\frac{3-v}{1+v} \text { tensiones planas }
$$

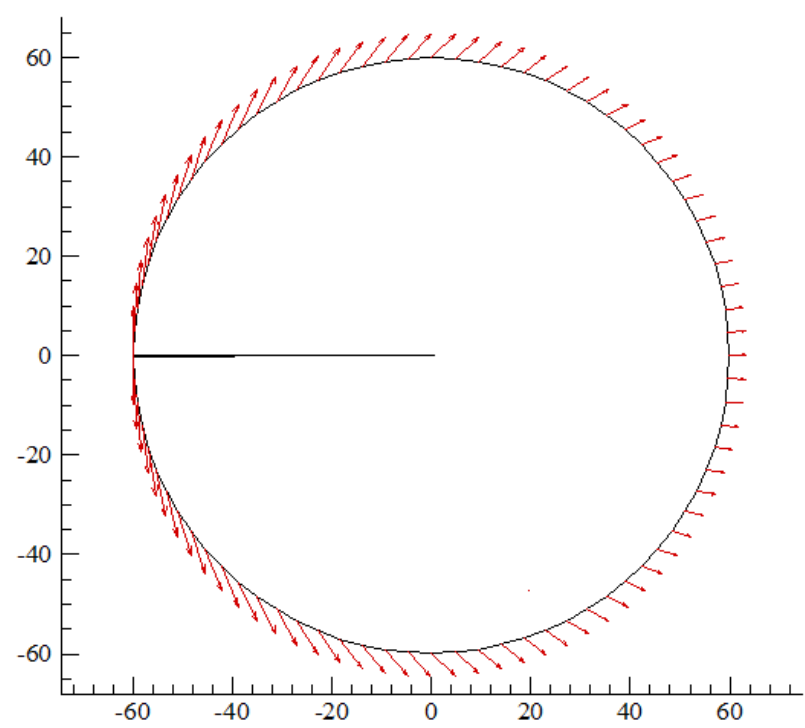

Figura 62 - Factor de intensidad de tensiones aplicado en términos de $u_{1} y u_{2}$ sobre la periferia de la región semi-infinita. 


\section{IV.II.III - Descripción del mallado utilizado.}

Uno de los métodos para poder modelar la fractura en un material reside en la inserción de elementos cohesivos entre los elementos de la malla. La fisura es forzada a propagarse a través de la interfase de estos elementos requiriendo más energía por unidad de longitud que la que le llevaría en un medio continuo, esto lleva a errores en los resultados que obtenemos. Para poder minimizar este error, hemos seguido el trabajo de Rimoli y Rojas [48] acerca de las estrategias de mallados para reducir los efectos de la malla en elementos cohesivos. En la publicación referenciada, se propone un método de mallado basado en "K-means" conjuntamente con "Direcciones Conjugadas".

La condición necesaria para reducir el error radica en que la longitud de los posibles caminos que siga la fisura a través de la malla y la longitud real, tienda a 1. El error tiende a 0 a medida que la relación anteriormente mencionada tiene a 1. Otra condición necesaria radica en que las desviaciones del camino que sigue la fisura sean independientes de la dirección que siga el camino de las interfases. Estas condiciones se satisfacen con la propiedad de isoperímetro y una malla con distribución aleatoria de elementos.

Un mallado aleatorio común, genera la aleatoriedad buscada pero a su vez genera elementos distorsionados. Un mejoramiento de esta malla utilizando el método K-means (método de clusters) agrega una gran proporción de elementos equiláteros. Luego, el método de "Subdivisión Baricéntrica" agrega direcciones ortogonales a las ya existentes.

Utilizamos aquí un mallado aleatorio con un laplaciano mejorado, optando a su vez con la opción de elementos equiláteros. La subdivisión baricéntrica se realizó mediante una subrutina utilizando el programa Matlab. 
En la Figura 63, mostramos una secuencia de mallado, la cual consiste en mallar la geometría (1) con elementos triangulares de distribución aleatoria usando el método K-means (2). Luego mediante una subrutina en matlab generamos una subdivisión baricéntrica (3). Por último, colocamos elementos cohesivos en el mallado resultante en las uniones entre los mismos.

(1)

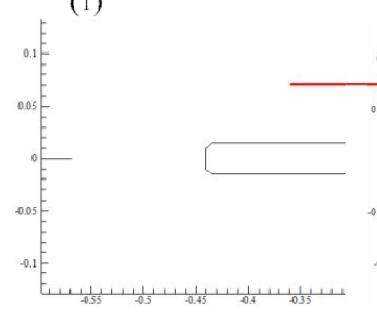

(4)
(2)

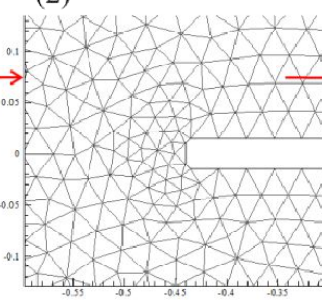

(3)

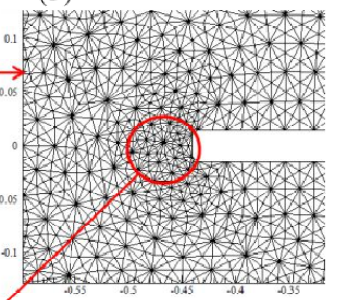

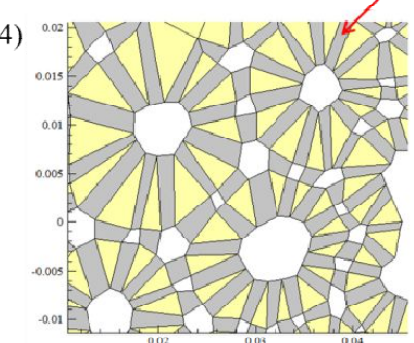

Figura 63 - Se muestra la secuencia de mallado de un modelo típico. La geometría en (1) con inicio de fisura en la coordenada $(0,0)$ es mallada con elementos triangulares en posición aleatoria usando K-means (2). Luego se subdividen cada uno de esos elementos (3) usando una subdivisión Baricéntrica. Finalmente se introducen los elementos cohesivos entre estos elementos $(4)$.

\section{IV.II.IV - Descripción del elemento cohesivo.}

En un modelo cohesivo o de zona cohesiva (CZM), la degradación mecánica del material en la zona de fractura (fpz) es modelada mediante una ley cohesiva de tracción separación que caracteriza el comportamiento inelástico del material.

Muchos modelos constitutivos cohesivos pueden ser utilizados para describir la zona cohesiva y de fractura delante del crack tip [23]. En las leyes de tracción compresión se relaciona el desplazamiento normal $\delta$ n y el desplazamiento tangencial $\delta \mathrm{t}$ con los esfuerzos normales $T_{n} \mathrm{y}$ tangenciales $T_{t}$ respectivamente. 


$$
\begin{gathered}
\lambda=\sqrt{\left(\frac{u_{n}}{\delta_{n}}\right)^{2}+\xi^{2}\left(\frac{u_{t}}{\delta_{t}}\right)^{2}} \\
T_{n}=\frac{\partial \phi}{\partial u_{n}}=\frac{\partial \phi}{\partial \lambda} \frac{\partial \lambda}{\partial u_{n}}=\frac{\sigma(\lambda)}{\lambda} \frac{u_{n}}{\delta_{n}} \\
T_{t}=\frac{\partial \phi}{\partial u_{t}}=\frac{\partial \phi}{\partial \lambda} \frac{\partial \lambda}{\partial u_{t}}=\xi^{2}\left(\frac{\delta_{n}}{\delta_{t}}\right) \frac{\sigma(\lambda)}{\lambda} \frac{u_{t}}{\delta_{t}}
\end{gathered}
$$

Asumiendo que $\phi$ es un potencial de características

$$
\begin{gathered}
\phi\left(u_{n}, u_{t}\right)=\delta_{n} \int \sigma\left(\lambda^{\prime}\right) d \lambda^{\prime} \\
\sigma(\lambda)=\frac{(1-\lambda)}{\left(1-\lambda_{c r}\right)} T_{\max } \\
\phi\left(u_{n}, u_{t}\right)=\left(2-\lambda^{2}\right) \frac{\delta_{n}}{2} \frac{T_{\max }}{1-\lambda_{c r}}
\end{gathered}
$$

Expresamos entonces los esfuerzos normales y tangenciales en función del desplazamiento normal y tangencial.

$$
\begin{gathered}
T_{n}=\frac{1-\lambda^{*}}{\lambda^{*}}\left(\frac{u_{n}}{\delta_{n}}\right) \frac{T_{\max }}{1-\lambda_{c r}} \\
T_{t}=\frac{1-\lambda *}{\lambda^{*}}\left(\frac{u_{t}}{\delta_{t}}\right) \frac{\alpha T_{\max }}{1-\lambda_{c r}} \\
\alpha=\xi^{2}\left(\frac{\delta_{n}}{\delta_{t}}\right) \\
\xi^{2}=\frac{G_{I I c}}{G_{I c}}
\end{gathered}
$$

$\lambda^{*} \quad$ Función monotónica creciente entre $\lambda_{\max } \mathrm{y} \lambda$.

\section{IV.II.V - Descripción del material cohesivo.}

La resistencia a la fractura del material esta modelizada mediante una ley cohesiva tracción-separación [23]. Como se muestra en la Figura 64, inicialmente tenemos una respuesta lineal hasta alcanzar la tensión máxima en el elemento $\left(\mathrm{T}_{\max }\right)$, seguida por una evolución lineal del daño hasta alcanzar la deformación máxima $\left(\delta_{\max }\right)$, dentro de la zona de fractura. El modelo es definido por tres parámetros, rigidez inicial $\mathrm{K}$, esfuerzo máximo $\mathrm{T}_{\max }$, energía de fractura $\mathrm{G}$. El parámetro K y G tienen unidades de tensión por unidad de longitud y energía por unidad de área respectivamente. 


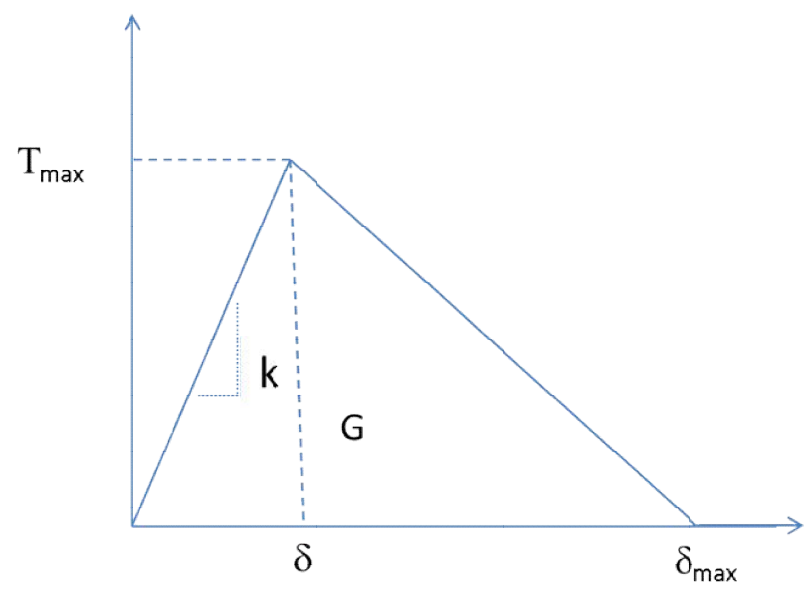

Figura 64 - Ley cohesiva tracción-separación para un elemento de interfase.

La energía de fractura o tenacidad a la fractura está dada por

$$
G_{c}=\frac{\delta_{\max } T_{\max }}{2}
$$

Donde la pendiente $k$ del elemento cohesivo debe ser

$$
\frac{E}{h}<<k
$$

Con $h$ correspondiente a la longitud del elemento cohesivo y $E$ al módulo elástico del material. El valor de rigidez $(k)$ mencionado está definido por

$$
k=\frac{T_{\max }}{\delta_{n} \lambda_{c}}
$$

La longitud de fractura definida por Rice en 1980 está dada por

$$
L_{c z} \cong \frac{\pi}{2} \frac{E}{\left(1-v^{2}\right)} \frac{G_{c}}{T_{\text {max }}^{2}}
$$

\section{IV.II.VI - Descripción de la curva proporcional aplicada.}

Inicialmente el desplazamiento colocado en los modelos seguía una ley lineal proporcional. Por lo que solo nos preocupábamos por una velocidad de carga baja de modo que al transcurrir el análisis explícito, la velocidad de carga (constante por ser lineal el desplazamiento introducido) genere condiciones cuasi-estáticas. Sin embargo ante un inicio de fractura observábamos inestabilidades del modelo. Esto se debe a que ante una velocidad de carga constante, la aceleración de esta carga 
no está definida. Es por ello que cambiamos la ley proporcional de carga por una senoidal de forma de tener definida la velocidad y aceleración de carga (Figura 65).

$$
f(x)=\operatorname{seno}\left[\operatorname{cte} \frac{\pi}{2}\left(t-t_{\min }\right)\right]
$$

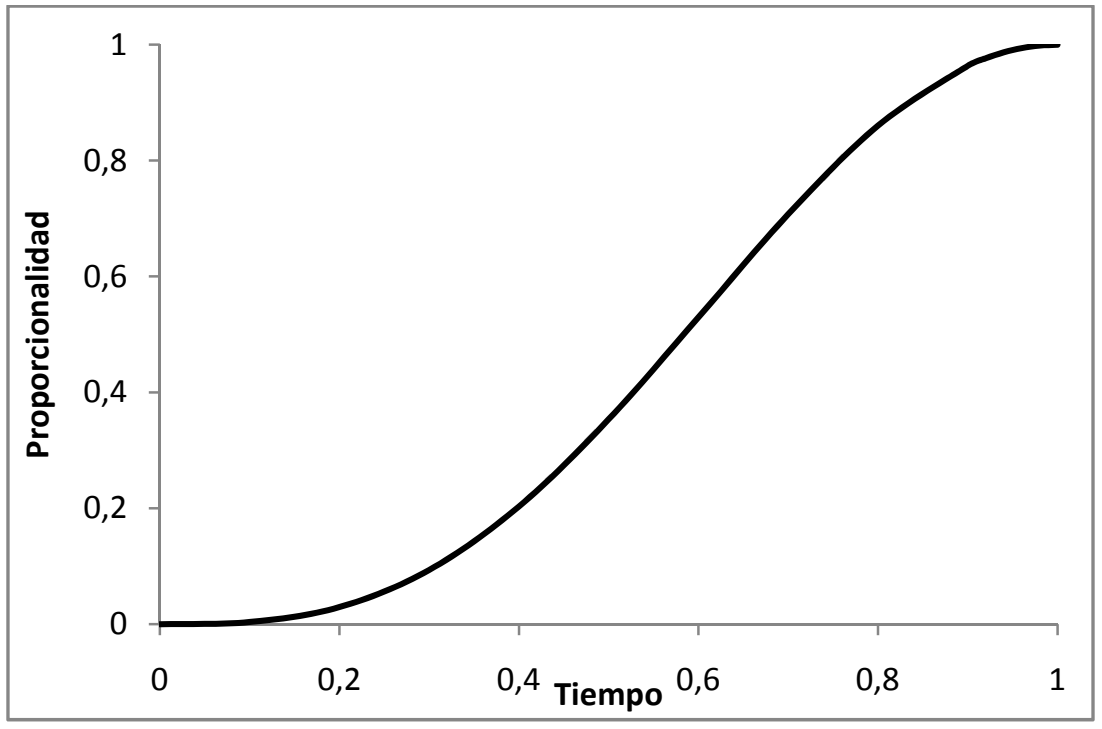

Figura 65 - Ley proporcional

\section{IV.II.VII - Ángulo de crecimiento de fisura.}

Basándonos en el criterio de máxima tensión para fractura mixta propuesto por Erdogan and Sih [49], el criterio asume que la fractura ocurre cuando la tensión circular $\sigma_{\theta \theta}$ adquiere su máximo en la zona cercana a la punta de fisura y $\sigma_{\theta \theta}$ coincide con la tensión máxima necesaria para que ocurra la fisura en modo I.

La distribución de tensiones en la zona cercana a la punta de fisura.

$$
\begin{aligned}
& \sigma_{x x}=\frac{K_{I}}{\sqrt{2 \pi r}} \cos \frac{1}{2} \theta\left[1-\sin \frac{1}{2} \theta \sin \frac{3}{2} \theta\right]-\frac{K_{I I}}{\sqrt{2 \pi r}} \sin \frac{1}{2} \theta\left[2+\cos \frac{1}{2} \theta \cos \frac{3}{2} \theta\right] \\
& \sigma_{y y}=\frac{K_{I}}{\sqrt{2 \pi r}} \cos \frac{1}{2} \theta\left[1+\sin \frac{1}{2} \theta \sin \frac{3}{2} \theta\right]+\frac{K_{I I}}{\sqrt{2 \pi r}} \sin \frac{1}{2} \theta \cos \frac{1}{2} \theta \cos \frac{3}{2} \theta \\
& \sigma_{x y}=\frac{K_{I}}{\sqrt{2 \pi r}} \sin \frac{1}{2} \theta \cos \frac{1}{2} \theta \cos \frac{3}{2} \theta+\frac{K_{I I}}{\sqrt{2 \pi r}} \cos \frac{1}{2} \theta\left[1-\sin \frac{1}{2} \theta \sin \frac{3}{2} \theta\right]
\end{aligned}
$$

Usando coordenadas polares $(r, \theta)$ centradas en la punta de la fisura $y$ usando el tensor de transformación. 


$$
\left\{\begin{array}{l}
\sigma_{x x} \\
\sigma_{y y} \\
\sigma_{x y}
\end{array}\right\}=\left[\begin{array}{ccc}
\cos ^{2} \theta & \sin ^{2} \theta & -\sin 2 \theta \\
\sin ^{2} \theta & \cos ^{2} \theta & \sin 2 \theta \\
\frac{1}{2} \sin 2 \theta & -\frac{1}{2} \sin 2 \theta & \cos 2 \theta
\end{array}\right]\left\{\begin{array}{c}
\sigma_{r r} \\
\sigma_{\theta \theta} \\
\sigma_{r \theta}
\end{array}\right\}
$$

La expresión de tensiones alrededor de la zona de fractura está dada por

$$
\begin{aligned}
& \sigma_{r r}=\frac{K_{I}}{\sqrt{2 \pi r}}\left[\frac{5}{4} \cos \frac{1}{2} \theta-\frac{1}{4} \cos \frac{3}{2} \theta\right]+\frac{K_{I I}}{\sqrt{2 \pi r}}\left[-\frac{5}{4} \sin \frac{1}{2} \theta+\frac{3}{4} \sin \frac{3}{2} \theta\right] \\
& \sigma_{\theta \theta}=\frac{K_{I}}{\sqrt{2 \pi r}}\left[\frac{3}{4} \cos \frac{1}{2} \theta+\frac{1}{4} \cos \frac{3}{2} \theta\right]+\frac{K_{I I}}{\sqrt{2 \pi r}}\left[-\frac{3}{4} \sin \frac{1}{2} \theta-\frac{3}{4} \sin \frac{3}{2} \theta\right] \\
& \sigma_{r \theta}=\frac{K_{I}}{\sqrt{2 \pi r}}\left[\frac{1}{4} \sin \frac{1}{2} \theta+\frac{1}{4} \sin \frac{3}{2} \theta\right]+\frac{K_{I I}}{\sqrt{2 \pi r}}\left[\frac{1}{4} \cos \frac{1}{2} \theta+\frac{3}{4} \cos \frac{3}{2} \theta\right]
\end{aligned}
$$

Simplificando y reescribiendo $\sigma_{\theta \theta}$ y $\sigma_{\mathrm{r} \theta}$;

$$
\begin{aligned}
& \sigma_{\theta \theta}=\frac{1}{\sqrt{2 \pi r}} \cos \frac{\theta}{2}\left[K_{I} \cos ^{2} \frac{\theta}{2}-\frac{3}{2} K_{I I} \operatorname{sen} \theta\right] \\
& \sigma_{r \theta}=\frac{1}{\sqrt{2 \pi r}} \cos \frac{\theta}{2}\left[\frac{1}{2} K_{I} \operatorname{sen} \theta+\frac{1}{2} K_{I I}\left(3 \cos \theta_{0}-1\right)\right]
\end{aligned}
$$

$\sigma_{\theta \theta}$ alcanza su máximo en $\theta=\theta_{0} \mathrm{y}$ donde $\sigma_{\mathrm{r} \theta}=0 . \theta_{0}$ es medido a partir del eje x de la Figura 66 y debe satisfacer la siguiente ecuación.

$$
\cos \frac{\theta_{0}}{2}\left[K_{I} \operatorname{sen} \theta_{0}+K_{I I}\left(3 \cos \theta_{0}-1\right)\right]=0
$$

$\theta_{0}$ corresponde al ángulo de crecimiento de fisura y se muestra su ubicación en la Figura 66.

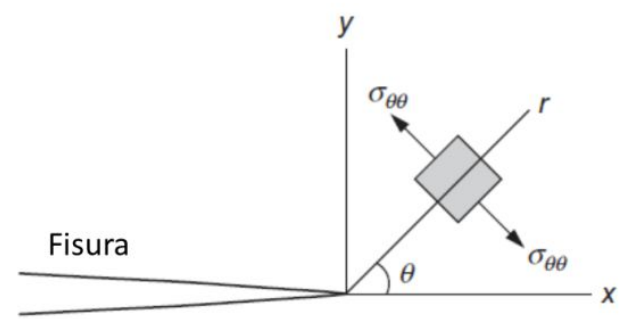

Figura 66 - Esquema de orientación de ejes adoptados ante el crecimiento de fisura. 


\section{IV.II.VIII - Regresión de datos- Mínimos cuadrados.}

Para determinar el ángulo de crecimiento de fisura respecto del modo mixto aplicado, se utilizó una regresión lineal por mínimos cuadrados. Donde el conjunto de puntos que forma la fisura es linealizado y posteriormente se calcula el ángulo de crecimiento y se compara con el ángulo de crecimiento teórico. Dado un conjunto de puntos $(\mathrm{x} 1, \mathrm{y} 1) ;(\mathrm{x} 2, \mathrm{y} 2) \ldots \ldots .(\mathrm{xn}, \mathrm{yn})$ y sea la recta

$$
\begin{gathered}
y=m * x+b \\
m=\frac{\left(n \sum_{(i=0)}^{n} x y-\sum_{(i=0)}^{n} x \sum_{(i=0)}^{n} \Sigma y\right)}{\left(n \sum_{(i=0)}^{n} x^{2}-\left(\sum_{(i=0)}^{n} x\right)^{2}\right)} \\
b=\frac{\sum_{i=0}^{n} y-m \sum_{i=0}^{n} x}{n}
\end{gathered}
$$

El error está dado por

$$
\begin{gathered}
x^{2}(m, b)=\sum_{i=0}^{n}\left(y_{i}-m x_{i}-b\right)^{2} \\
\frac{\delta x^{2}}{\delta m}=0 \quad ; \frac{\delta x^{2}}{\delta b}=0
\end{gathered}
$$

Los errores de una función pi $\rightarrow \delta p_{i}=\delta p=\sigma_{p}$ se estima a partir de la varianza.

$$
\sigma_{y}^{2}=\frac{1}{n-2} \sum_{i=1}^{n}\left(y_{i}-m^{*} x^{i}-b\right)^{2}=\frac{x^{2}(m, b)}{n-2}
$$

Propagando en la función

$$
\begin{gathered}
\sigma^{2} m=\sum_{i=1}^{n}\left(\frac{\partial m}{\partial y_{i}} \sigma_{y}\right)^{2} ; \quad \sigma^{2} b=\sum_{i=1}^{n}\left(\frac{\partial b}{\partial y_{i}} \quad \sigma_{y}\right)^{2} \\
\sigma^{2} m=\left[\frac{n}{n \sum_{i=0}^{n} x x-\sum_{i=0}^{n} x \sum_{i=0}^{n} x}\right] \frac{x^{2}(m, b)}{n-2} \\
\sigma^{2} b=\left[\frac{\sum_{i=0}^{n} x x}{n \sum_{i=0}^{n} x x-\sum_{i=0}^{n} x \sum_{i=0}^{n} x}\right] \frac{x^{2}(m, b)}{n-2}
\end{gathered}
$$

El coeficiente de correlación lineal r esta dado por: 


$$
r=\frac{n \sum_{i=0}^{n} x_{i} y_{i-}\left(\sum_{i=0}^{n} x_{i}\right)\left(\sum_{i=0}^{n} y_{i}\right)}{\sqrt{\left[n \sum_{i=0}^{n} x_{i}^{2}-\left(\sum_{i=0}^{n} x_{i}\right)^{2}\right]\left[n\left(\sum_{i=0}^{n} y_{i}^{2}\right)-\left(\sum_{i=0}^{n} y_{i}\right)^{2}\right]}}
$$

El valor r puede variar entre 1 y -1

Si $\mathrm{r}=-1$ todos los puntos se encuentran sobre la recta existiendo una correlación que es perfecta e inversa.

Si $\mathrm{r}=0$ no existe ninguna correlación entre las variables.

Si $\mathrm{r}=1$ todos los puntos se encuentran sobre la recta existiendo una correlación que es perfecta y directa.

Una vez determinada la recta, solo nos interesa el valor de la pendiente, el cual determina el ángulo de fractura.

\section{IV.II.IX - Elección del tamaño de malla y zona de análisis - Errores-}

En el transcurso de esta investigación, se analizó las variaciones de resultados frente a cambios en el discretización numérica, área analizada y parámetros de la resolución explicita. También se analizó la influencia de diferentes parámetros en la ley cohesiva.

a- Discretización del área analizada.

Por un lado se analizaron diferentes tamaños de elementos. Por otro se analizó el costo computacional asociado al tamaño de elemento. Se tomaron mallas de 10, 12.5 y $15 \mathrm{~nm}$ de tamaño de elemento. Se comparó los resultados numéricos del factor crítico de intensidad de tensiones (Kc) y el ángulo de crecimiento de fisura $\left(\theta_{0}\right)$ respecto a datos teóricos. Se calculó el error porcentual de dichos valores teniendo en cuenta la siguiente expresión 


$$
\text { Error } \%=\left(1-\left(\frac{\text { valor de simulación }}{\text { valor teórico }}\right)\right)
$$

El valor teórico del factor crítico de intensidad de tensiones $K_{c}$ surge de la ecuación (7) y el valor del teórico del ángulo de crecimiento de fisura $(\theta)$, surge de la ecuación (34).

Los resultados en cada punto de la curva mostrada en la Figura 67 constituyen un promedio de valores para diferentes ángulos de modo mixto que van de 0 a $40^{\circ}$.

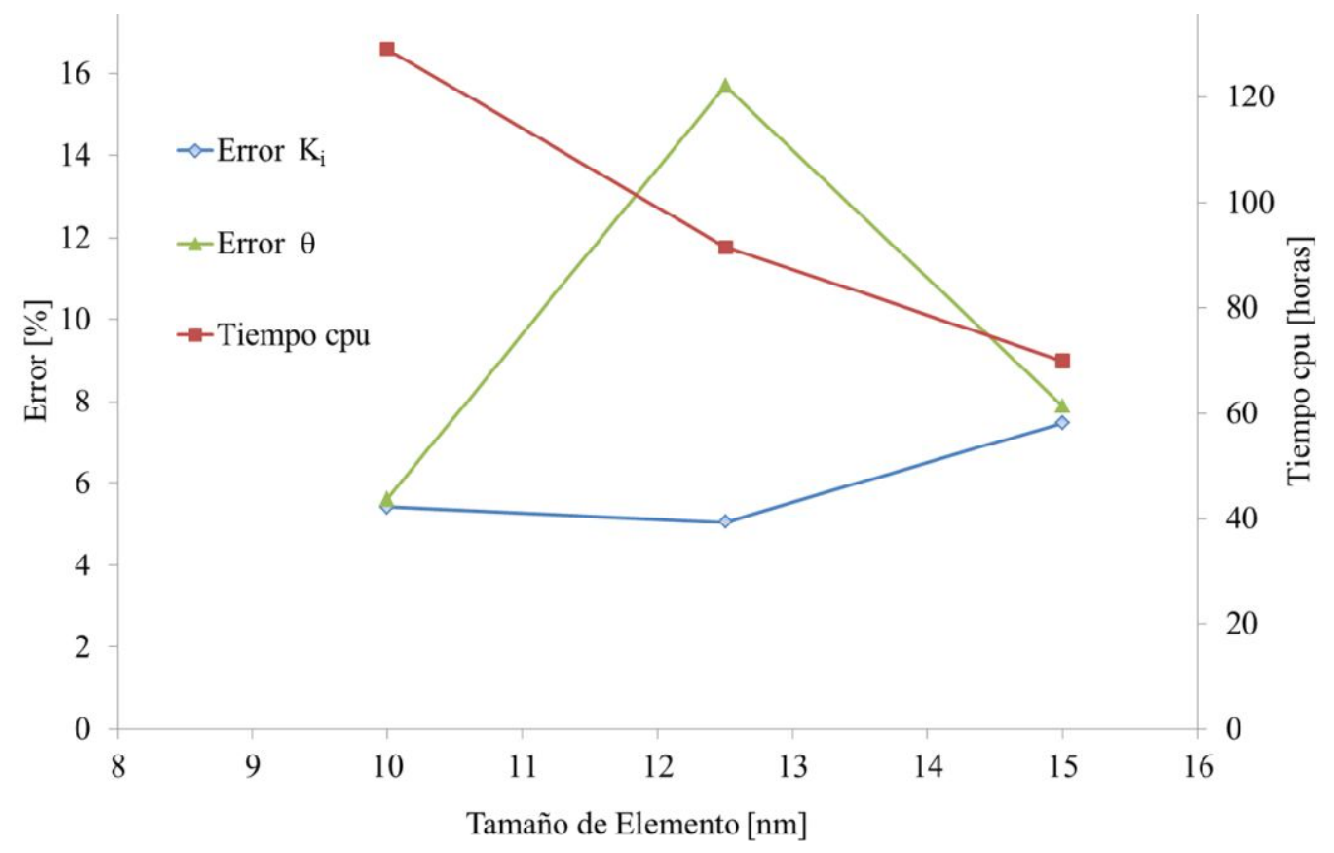

Figura 67 - Errores asociados al tamaño de elemento versus el costo computacional.

Dado que los errores para un tamaño de elemento de $10 \mathrm{~nm}$ y $15 \mathrm{~nm}$ son relativamente similares, pero el costo computacional es sensiblemente más bajo para $15 \mathrm{~nm}$, usaremos este último tamaño de elemento en nuestros mallados como valor nominal.

b- Elección de la región a analizar

Proponemos dos tipos de regiones donde los elementos cohesivos son introducidos. Comparamos el ángulo de crecimiento de fisura de una región de características rectangulares y otra elíptica (Figura 68) frente al ángulo de 
crecimiento teórico. Las dimensiones son de $1.5 \mathrm{um}$ por $0.6 \mathrm{um}$ y $1.75 \mathrm{um}$ semieje mayor por 0.92 um semieje menor respectivamente.
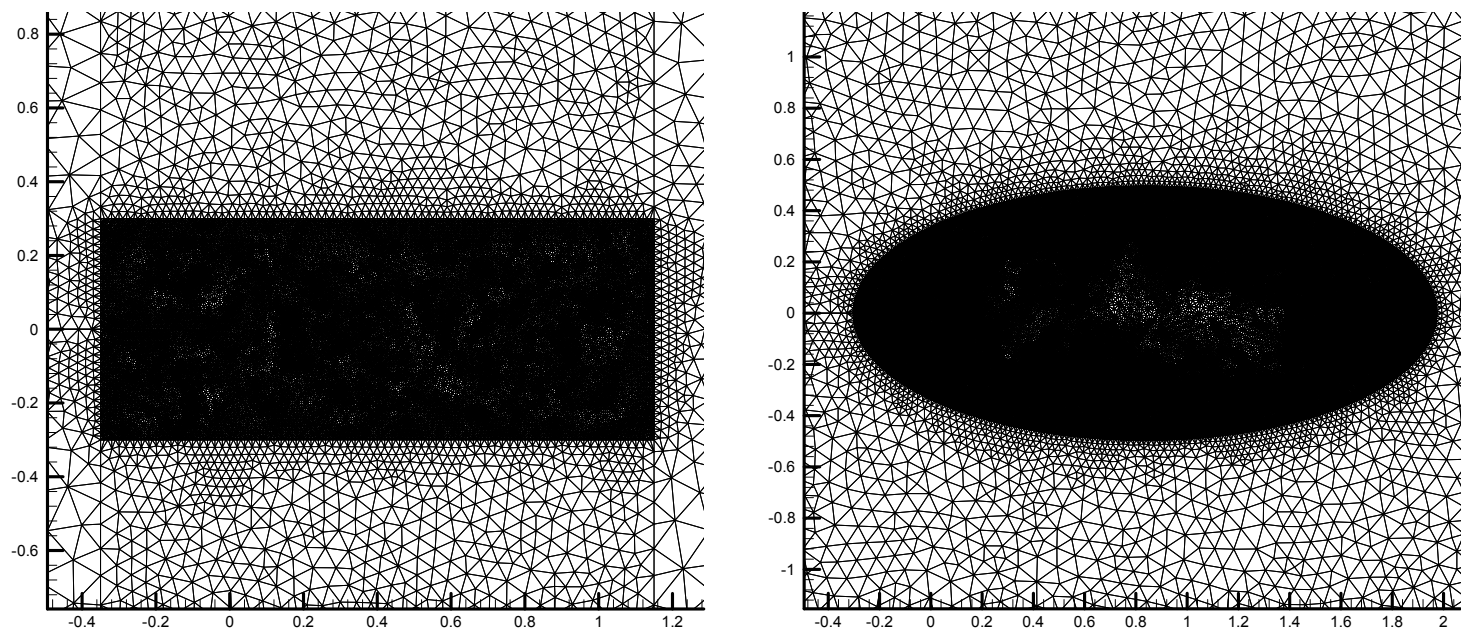

Figura 68 - La imagen de la izquierda corresponde a un area de estudio rectangular mientras que la de la derecha a una elíptica.

Paralelamente, se analizaron dichas regiones para los diferentes tamaños de elemento mencionados anteriormente: $10 \mathrm{~nm}, 12.5 \mathrm{~nm}$ y $15 \mathrm{~nm}$. Se compararon los resultados del factor de intensidad de tensiones Ki y ángulo de crecimiento $\theta$ como en el caso anterior (Figura 69).

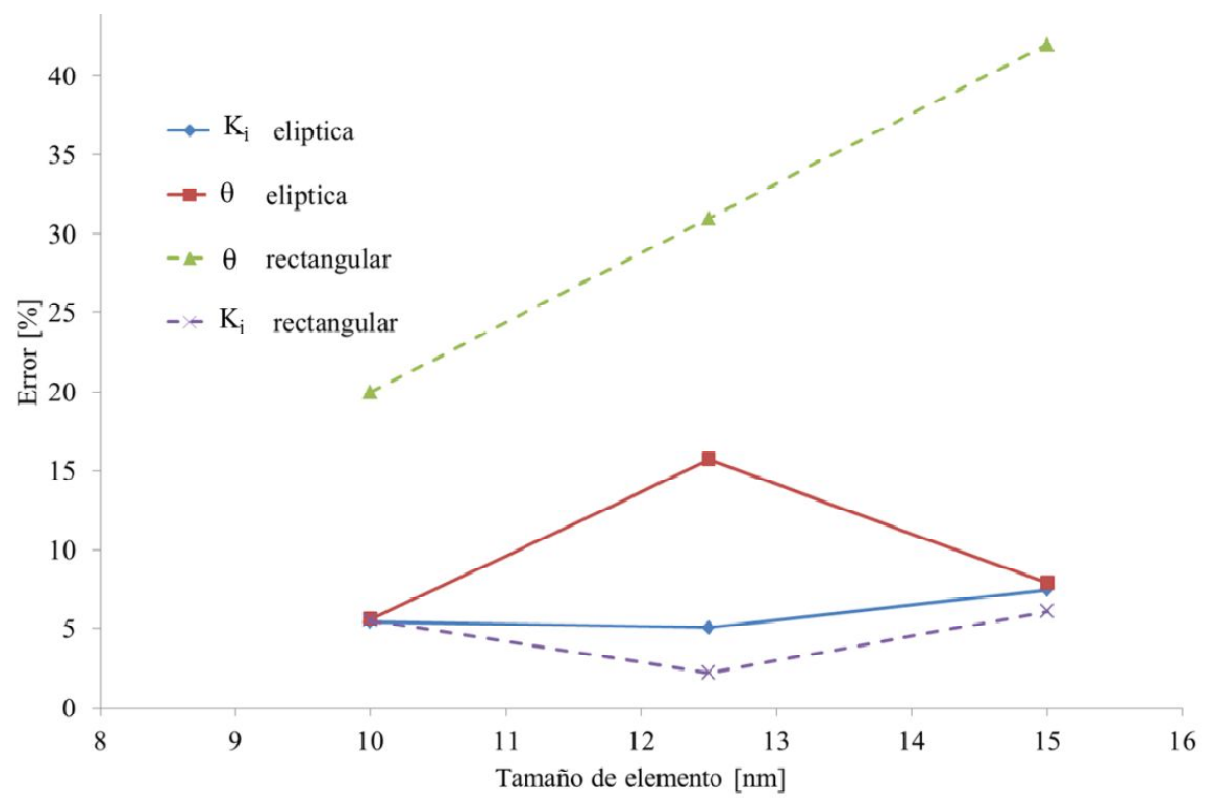

Figura 69 - Comportamiento de una región de análisis rectangular frente a una elíptica. Errores asociados a dichas configuraciones de áreas de análisis.

Si bien el comportamiento de las regiones frente al valor del factor de intensidad de tensiones son similares, la región rectangular presenta un mayor error 
en el ángulo de crecimiento de fisura. Es por esta razón que se optó por modelar el material dentro de una región elíptica.

\section{IV.III - Modelado de la interfase utilizando puentes.}

\section{IV.III.I - Elección del tamaño de los puentes.}

A escalas nanométricas la presencia de puentes rígidos entre elementos de escalas superiores (placas, barras o fibras) es una característica común de materiales como el nácar o el diente de chitón. El diámetro de los puentes varía entre 10 y $50 \mathrm{~nm}$ de ancho [50][13] con una altura que va de los 25 a los $32 \mathrm{~nm}$ [41] y su separación ronda entre los 100 a 200 nm [44].

Song establece mediciones en los puentes del orden de $46+/-8 \mathrm{~nm}$ en el diámetro de los mismos y una altura de $29+/-4 \mathrm{~nm}$. A partir del estudio de 16 placas de diferentes cortes del nácar y con una longitud promedio de $4 \mathrm{um}$, se contaron 650 puentes. A su vez se dividieron dichas placas en 16 unidades iguales alrededor de su longitud y se contaron los puentes en dichas porciones de placas. Se encontró que el $68 \%$ de los puentes se localizan en una zona central de aproximadamente $1 / 3$ de la longitud de la placa [51]. Song también observó para estos materiales un crecimiento de la fisura solo en la interfase y de un promedio de longitud de fractura de $1.3+/-0.2$ um.

Si observamos materiales como el diente de chitón, encontramos un elemento de unión entre las nano-barras que constituyen un elemento fundamental de su microestructura [5]. El diámetro de los puentes en esta microestructura es de $30 \mathrm{~nm}$ a 10nm y la separación está en el orden de los $10 \mathrm{~nm}$ a los $80 \mathrm{~nm}$.

Los valores adoptados para los cálculos numéricos que se van a realizar, se encuentran dentro de los rangos mencionados. Se eligió un diámetro de puente de 45nm y una altura de $30 \mathrm{~nm}$. Se analizaron varios valores de separación dentro de 
los rangos del material natural: 100, 150 y 200 nm. También elegimos separaciones menores: 25, 50 y $75 \mathrm{~nm}$.

\section{IV.III.II - Modelado matemático de características de puentes.}

La falla en materiales monolíticos frágiles ocurre por la propagación inestable de microfisuras que se inician por defectos en la superficie o el interior del material. A escalas macroscópicas (milimétricas o superiores) la resistencia del material no se ve afectada fuertemente por los defectos del material. Sin embargo a escalas microscópicas o inferiores, donde el número de defectos se ve reducido al reducir el tamaño del material, la resistencia del material depende fuertemente del tamaño utilizado. Estos efectos de tamaño pueden explicarse estadísticamente. Weibull fue el primero en desarrollar una teoría que describe la variabilidad de la resistencia de materiales frágiles en función del tamaño de la muestra.

Para determinar la tensión a la cual se produce la fractura de un material monolítico, las diferencias entre el material macroscópico y el microscópico deben ser tenidas en cuenta. Weibull asume que la probabilidad de supervivencia de un material de volumen $\mathrm{V}$ sometido a una tensión $\sigma$ está dado por:

$$
P_{s}(\sigma)=\exp \left\{-\frac{V}{V_{r e f}}\left(\frac{\sigma}{\sigma_{f}}\right)^{k}\right\}
$$

Donde $\sigma_{\mathrm{f}}$ es la tensión de falla del material, y $\mathrm{V}_{\text {ref }}$ el volumen de referencia.

La tensión a la cual un material monolítico de volumen $\mathrm{V}_{\mathrm{m}}$ sobrevive con una probabilidad de falla de 1/e está dado por

$$
\sigma_{m}=\left(-\frac{V_{r e f}}{V_{m}} \ln P_{s}\right)^{1 / k} \sigma_{f}=\left(\frac{V_{r e f}}{V_{m}}\right)^{1 / k} \sigma_{f}
$$

Teniendo en cuenta entonces las diferentes escalas en un material con una construcción jerárquica, hacemos un estudio particular del diámetro de puentes óptimo entre placas de material. Para ello, aislamos dos placas con puentes 
entremedio y aplicamos un modo 1 de forma tal de calcular la tensión sobre los puentes y sobre la placa. De acuerdo al radio de los puentes consideramos que los mismos trabajan a la tensión máxima de Weibull. Buscamos el radio de puentes para el cual la tensión sobre la placa corresponde a su tensión máxima dictada por Weibull. De esta forma la geometría de los puentes hace trabajar a la placa y a ellos mismos a su máxima tensión. Una imagen del modelado se muestra en la Figura 70.

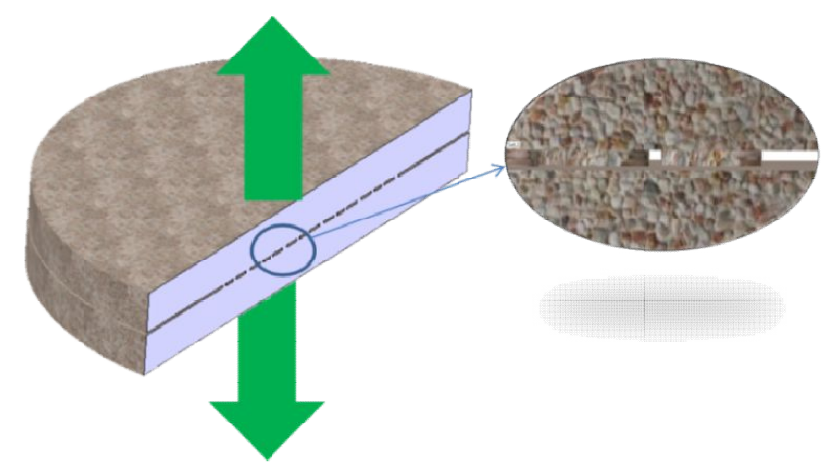

Figura 70 - Esquema del modelo utilizado para el cálculo de diámetro de puente optimo entre placas circulares.

Algunas consideraciones geométricas:

- Consideramos una forma cilíndrica de puentes y de la placa.

- La altura de los puentes es de $30 \mathrm{~nm}$.

- Consideramos un diámetro de placa de $6500 \mathrm{~nm}$ y un espesor de $500 \mathrm{~nm}$.

- La disposición de puentes es equidistante de carácter rectangular.

Planteamos un equilibrio de fuerzas entre los puentes (br) y la placa (p)

$$
\sigma_{p} A_{p}=N \sigma_{b r} A_{b r}
$$

Donde $N$ corresponde al número de puentes

$\mathrm{A}_{\mathrm{p}}$ es el área transversal de la placa.

$\mathrm{A}_{\mathrm{br}}$ es el área transversal de un puente.

Consideramos a los puentes trabajando a su máxima tensión dada por Weibull 


$$
\sigma_{b r}=\left(\frac{V_{r e f}}{V_{b r}}\right)^{1 / k} \sigma_{r e f}
$$

Donde k corresponde a un parámetro de forma de la distribución de

Weibull.

$\mathrm{V}_{\text {ref }}$ volumen de referencia del material

$\sigma_{\text {ref }}$ tensión de referencia máxima del material.

La tensión en la placa estará dada por

$$
\sigma_{p}=N\left(\frac{V_{r e f}}{V_{b r}}\right)^{1 / k} \frac{A_{b r}}{A_{p}} \sigma_{r e f}
$$

La tensión máxima en la placa dada por Weibull será

$$
\sigma_{p w}=\left(\frac{V_{r e f}}{V_{p}}\right)^{1 / k} \sigma_{r e f}
$$

Planteamos la relación entre la tensión de la placa y la tensión última dada por Weibull para diferentes separaciones de puentes $f\left(\frac{\sigma_{p}}{\sigma_{p w}}\right)$

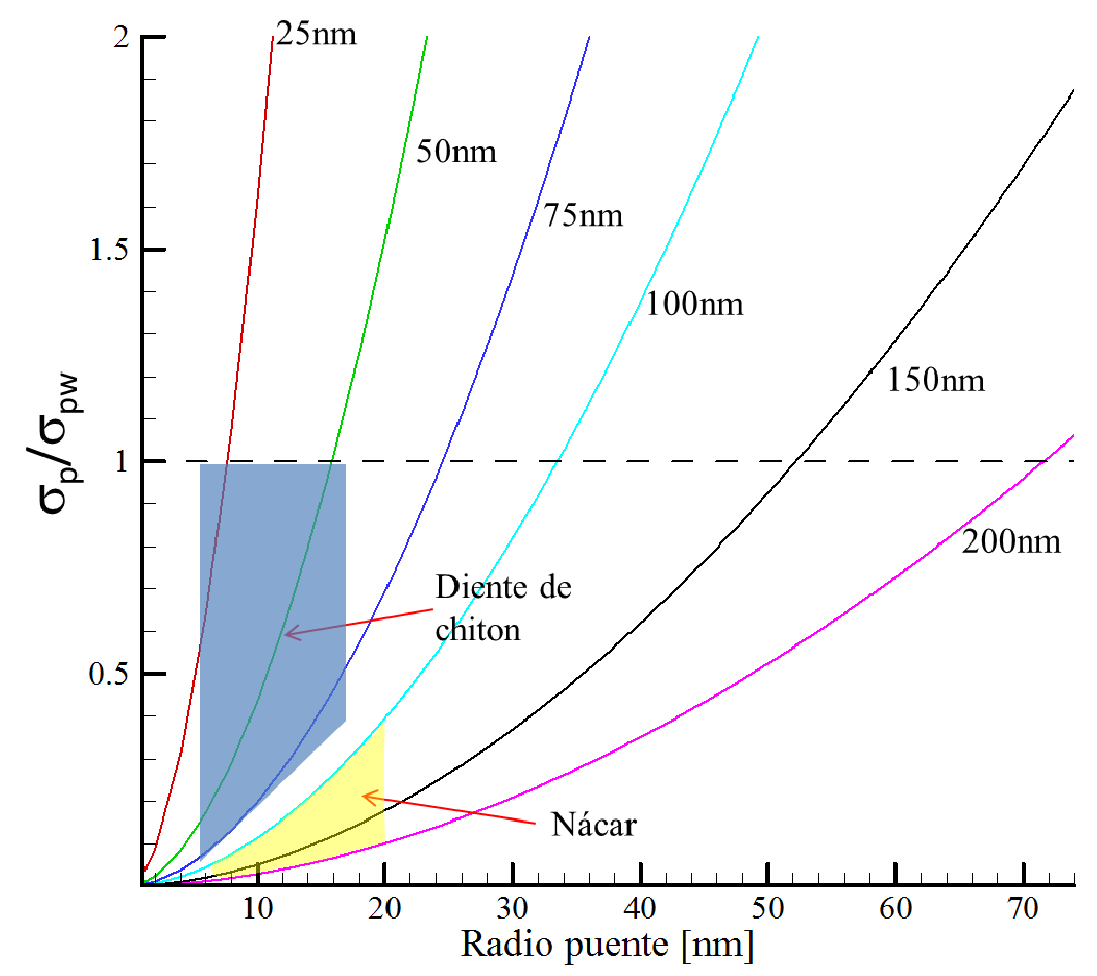

Figura 71 - Gráfica del radio de puentes en función de la tensión en la placa. Cuando la relación entre la tensión de la placa y la tensión de la placa por Weibull sea 1, significa que tanto los puentes como la placa se encuentran trabajando a la tensión máxima dada por Weibull para el material. 
La Figura 71 muestra la variación de la relación entre la tensión en la placa y la tensión máxima en la placa dada por Weibull en función del radio de los puentes. Los puentes están considerados que trabajan a su tensión máxima dada por Weibull. Cuando esta relación es igual a 1, los puentes y la placa trabajan de manera óptima desde el punto de vista de la tensión normal. Por ejemplo, para un diámetro de puentes de $45 \mathrm{~nm}$, una separación cercana a los $75 \mathrm{~nm}$ es la óptima desde el punto de vista de tensión normal. Sin embargo eso significa que la fisura puede crecer a través de los puentes o la placa. Es para valores menores a 1 en el eje de relación de tensiones que la fisura crece por la interfase. Cuando la relación de tensiones de la placa y su respectiva tensión de Weibull llega a la unidad, la fisura puede crecer tanto en la interfase como en el sólido.

Ya independizándonos de la distancia entre puentes y manteniendo el arreglo rectangular, analizamos el número de puentes necesarios para llegar a la misma condición óptima entre puentes y placa. La Figura 72 muestra que para llegar a la condición mencionada son necesarios una menor cantidad de puentes de mayor diámetro o más puentes de menor diámetro, tal como se esperaba. Sin embargo en términos de área total ocupada por los puentes en la placa, vemos en la Figura 73, que un diámetro menor es más eficiente para el trabajo de optimización descripto.

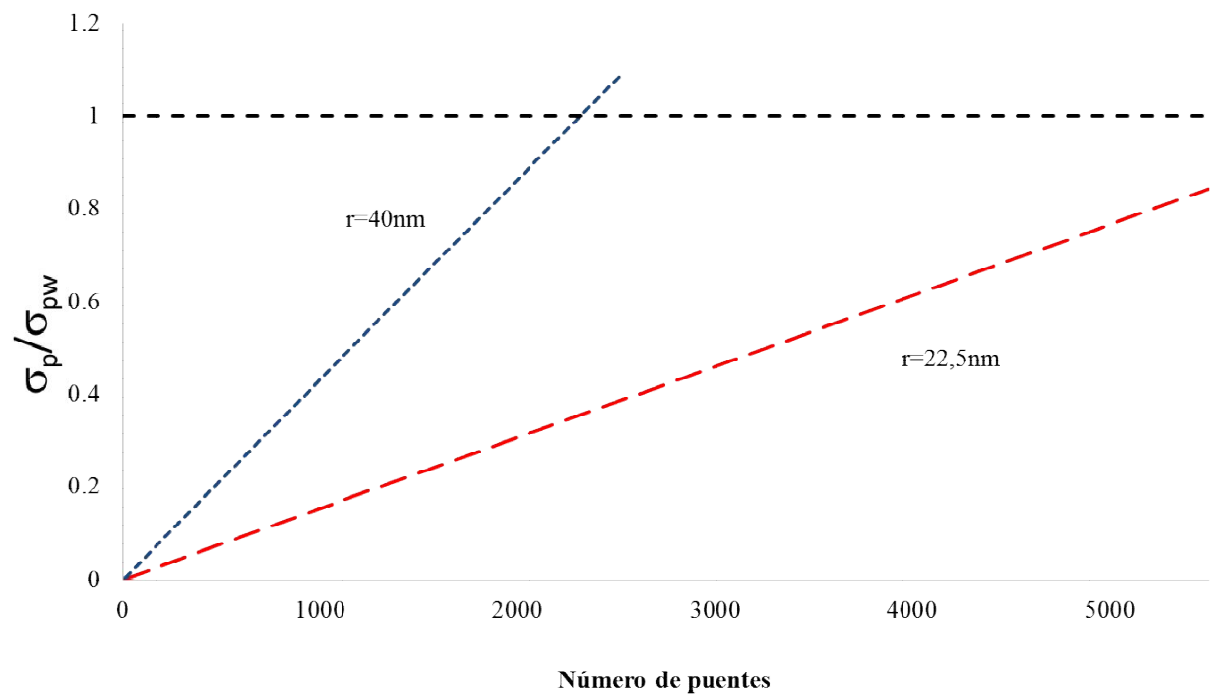

Figura 72 - Gráfica del número de puentes en función de la tensión en la placa. Cuando la relación entre la tensión de la placa y la tensión de la placa por Weibull sea 1, significa que 
tanto los puentes como la placa se encuentran trabajando a la tensión máxima dada por Weibull para el material. Particularmente en esta gráfica, se muestra que se necesita para llegar a esta condición un menor número de puentes de mayor diámetro que de menos diámetro.

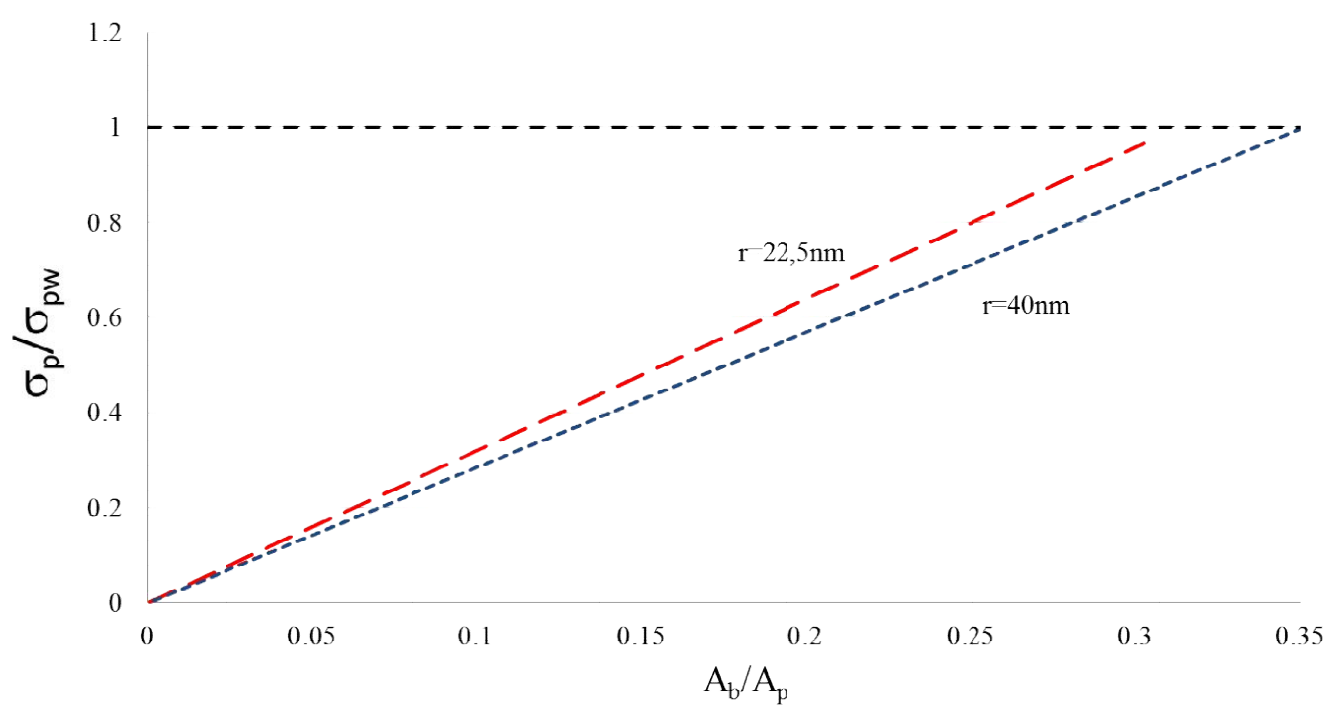

Figura 73 - Gráfica del área total de puentes $\left(\mathrm{A}_{\mathrm{b}}\right)$ en relación con del área de la placa $\left(\mathrm{A}_{\mathrm{p}}\right)$ versus la tensión en la placa en relación de la tensión máxima de la misma dada por Weibull. Particularmente en esta gráfica, muestra que en términos de eficiencia de área, un radio menor llega a la condición optima de tensiones antes que un radio mayor.

\section{IV.III.II - Datos de los materiales utilizados.}

El nácar constituye un material formado en un $95 \%$ por aragonita ortorómica $\left(\mathrm{CaCO}_{3}\right)$ y un 5\% por material orgánico. Autores como Jackson (1988) establecen un módulo elástico de 70 GPa y una tensión de rotura de $170 \mathrm{MPa}$ para muestras secas y presentan además un trabajo de separación que varía entre los 350 y 1240 j/m2. Otros autores Sarikaya (1994) establecen una tensión máxima de $185 \mathrm{MPa}+/-20 \mathrm{MPa}$ y un factor de intensidad de tensiones de $8+/-3 \mathrm{MPa} \mathrm{m}^{1 / 2}$. $[52]$

En el modelado numérico utilizamos elementos cohesivos con tres diferentes propiedades mecánicas. El material 1 posee una tensión máxima $\mathrm{T}_{\max }=1 \mathrm{GPa}$, una energía de fractura de $\mathrm{G}_{\mathrm{c}}=0.00004$ GPa.um y una pendiente de $\mathrm{K}=246666$ GPa/um. El material 2 posee una tensión máxima de $\mathrm{T}_{\max }=1 \mathrm{GPa}$, una energía de fractura de $\mathrm{G}_{\mathrm{c}}=0.0002 \mathrm{GPa}$ um y una pendiente de $\mathrm{K}=246666 \mathrm{GPa} / \mathrm{um}$. El material 3 posee una tensión máxima de Tmax=1Gpa, una energía de fractura de $\mathrm{G}_{\mathrm{c}}=0.0008 \mathrm{GPa}$. um y una pendiente de $\mathrm{K}=246666 \mathrm{GPa} / \mathrm{um}$. 
En la Figura 74 se muestra las longitudes de fractura en cada uno de las propiedades de material utilizadas

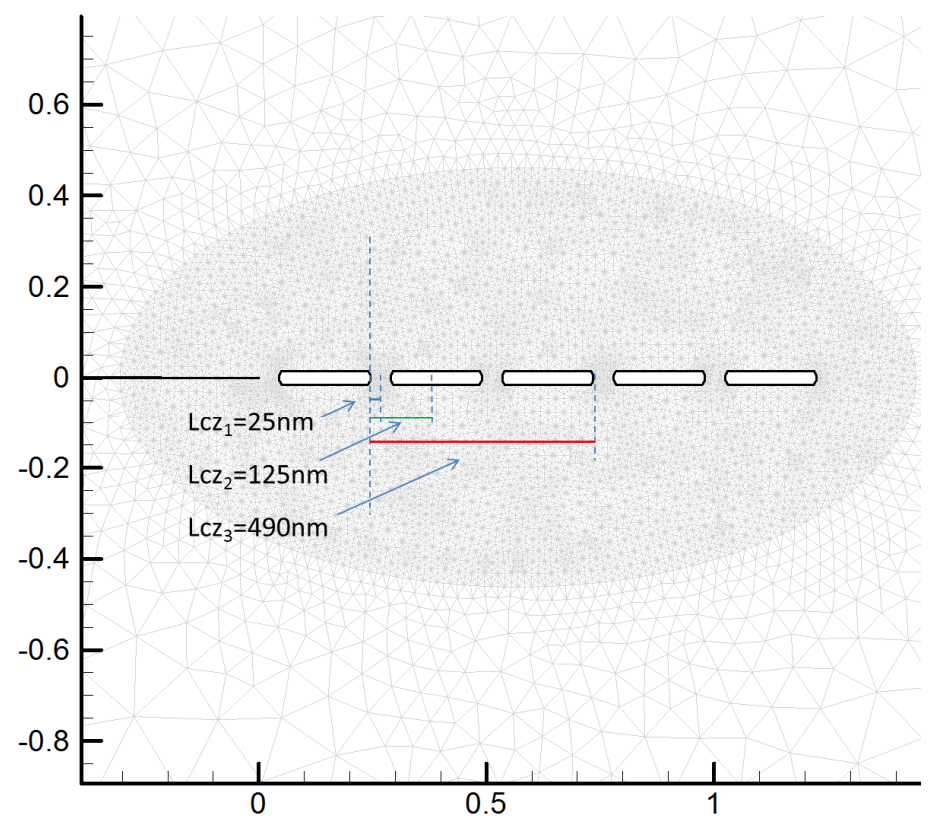

Figura 74 - Longitudes de fractura utilizadas en los modelos.

El material monolítico utilizado en el modelado numérico, corresponde a valores mecánicos de la alúmina, la cual constituye un cerámico elegido comúnmente para imitar al material nácar y sus características mecánicas [53]. El comportamiento es de características frágiles al igual que la aragonita. Tomamos valores de módulo elástico E=370 GPa, tensión máxima de 1 GPa y relación de Poisson de 0.23 .

\section{IV.III.III - Teorema de Buckingham - Análisis Dimensional}

Dada la cantidad de variables involucradas en el análisis, resulta indispensable el uso de alguna herramienta que permita tener en cuenta a las variaciones en las mismas. Es por ello que utilizaremos el siguiente teorema para su manejo.

Un análisis dimensional inicial muestra la dependencia del ángulo de crecimiento de fisura respecto del modo mixto aplicado expresado como una función que depende de: 


$$
\begin{gathered}
\theta=\Gamma\left(\frac{l}{l c z}, \frac{h}{l c z}, \frac{l^{*}}{l c z}, \psi, \frac{\sigma_{\max }}{E}, v\right) \\
\frac{K i c}{K_{0}}=\Gamma\left(\psi, \frac{\sigma_{\max }}{E}, v, \frac{l}{l c z}, \frac{l^{*}}{l c z}, \frac{h}{l c z}\right)
\end{gathered}
$$

$l \quad$ Longitud de la región a estudiar.

h $\quad$ Longitud del elemento.

lcz Longitud de fractura.

$\theta \quad$ Ángulo de modo mixto.

\% Ángulo de crack.

$l^{*} \quad$ Longitud para determinar el ángulo.

$v \quad$ Relación de Poisson.

E Módulo elástico.

$\sigma_{\max }$ Tensión máxima.

Kc Factor crítico de intensidad de tensiones.

Si pensamos en modelos con la presencia de una interfase con puentes en su interior, podemos expresarla como:

$$
\frac{\theta}{\theta_{0}}=\Gamma\left(\psi, \frac{\sigma_{\max }}{E}, v, \frac{l c z}{d}, \frac{s}{d}, \frac{h^{*}}{d}, \frac{l}{h^{*}}, \frac{h}{h^{*}}, \frac{l^{*}}{h^{*}}\right)
$$

Esta función agrega los siguientes parámetros a los ya introducidos:

$h^{*} \quad$ Altura del puente.

d Diámetro del puente.

s $\quad$ Separación entre puentes.

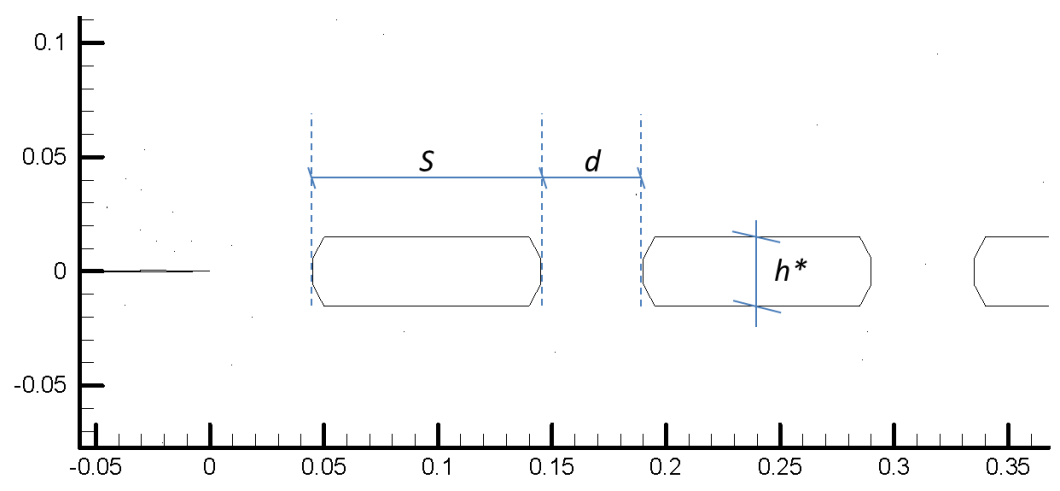

Figura 75 - Caracterización de la interfase. Se muestran los parámetros de separación, diámetro de puente y altura de la interfase 


\section{IV.III.III - Ángulos de modo mixto.}

Los modelos de fractura desarrollados fueron calculados para modo 1 puro $\left(0^{\circ}\right)$ y modo mixto entre ángulos de $10^{\circ}$ a $85^{\circ}$ en intervalos de 10 grados hasta $80^{\circ}$ y luego a $85^{\circ}$ para terminar.

\section{Grupos adimensionales.}

De acuerdo a los grupos adimensionales definidos anteriormente los valores para los diferentes casos a analizar son los presentados en Tabla 3:

Tabla 3 - Parámetros del análisis dimensional y los valores utilizados en los modelos.

\begin{tabular}{|c|c|c|c|c|c|c|c|c|c|c|c|c|c|c|c|c|c|c|c|}
\hline & & \multicolumn{18}{|c|}{ Plots } \\
\hline & & \multicolumn{3}{|c|}{ caso 1} & \multicolumn{3}{|c|}{ caso 2} & \multirow{2}{*}{\multicolumn{3}{|c|}{$\begin{array}{l}\text { caso } 3 \\
5.75\end{array}$}} & \multicolumn{3}{|c|}{ caso 4} & \multicolumn{3}{|c|}{ caso 5} & \multicolumn{3}{|c|}{ caso 6} \\
\hline & & \multicolumn{3}{|c|}{$\begin{array}{ll}45 \quad 25 \\
\end{array}$} & \multicolumn{3}{|c|}{$45 \quad 50$} & & & & \multicolumn{3}{|c|}{$\begin{array}{ll}45 & 100\end{array}$} & \multicolumn{3}{|c|}{$\begin{array}{ll}45 & 150\end{array}$} & \multicolumn{3}{|c|}{$45 \quad 200$} \\
\hline По & $\theta$ & Salida & Salida & Salida & \begin{tabular}{|l|} 
Salida \\
\end{tabular} & \begin{tabular}{|l|} 
Salida \\
\end{tabular} & Salida & \begin{tabular}{|l|} 
Salida \\
\end{tabular} & Salida & \begin{tabular}{|l|} 
Salida \\
\end{tabular} & \begin{tabular}{|l|} 
Salida \\
\end{tabular} & \begin{tabular}{|l|} 
Salida \\
\end{tabular} & \begin{tabular}{|l|} 
Salida \\
\end{tabular} & \begin{tabular}{|l|} 
Salida \\
\end{tabular} & \begin{tabular}{|l|} 
Salida \\
\end{tabular} & \begin{tabular}{|l|} 
Salida \\
\end{tabular} & \begin{tabular}{|l|} 
Salida \\
\end{tabular} & Salida & Salida \\
\hline П1 & $\Psi$ & 10 ang & 10 ang & 10 ang & 10 ang & 10 ang & 10 ang & 10 ang & 10 ang & 10 ang & 10 ang & 10 ang & 10 ang & 10 ang & 10 ang & 10 ang & 10 ang & 10 ang & 10 ang \\
\hline$\Pi 2$ & $\sigma \max / \mathrm{E}$ & cte & cte & cte & cte & cte & cte & cte & cte & cte & cte & cte & cte & cte & cte & cte & cte & cte & cte \\
\hline$\Pi 3$ & $v$ & cte & cte & cte & cte & cte & cte & cte & cte & cte & cte & cte & cte & cte & cte & cte & cte & cte & cte \\
\hline$\Pi 4$ & $\mathrm{Lcz} / \mathrm{d}$ & 0.55 & 2.73 & 10.91 & 0.55 & 2.73 & 10.91 & 0.55 & 2.73 & 10.91 & 0.55 & 2.73 & \begin{tabular}{|l|}
10.91 \\
\end{tabular} & 0.55 & 2.73 & 10.91 & 0.55 & 2.73 & 10.91 \\
\hline П5 & $s / d$ & \multicolumn{3}{|c|}{0.56} & \multicolumn{3}{|c|}{1.11} & \multicolumn{3}{|c|}{1.67} & \multicolumn{3}{|c|}{2.22} & \multicolumn{3}{|c|}{3.33} & \multicolumn{3}{|c|}{4.44} \\
\hline П6 & $h^{*} / d$ & \multicolumn{3}{|c|}{6.67} & \multicolumn{3}{|c|}{6.67} & \multicolumn{3}{|c|}{6.67} & \multicolumn{3}{|c|}{6.67} & \multicolumn{3}{|c|}{6.67} & \multicolumn{3}{|c|}{6.67} \\
\hline$\Pi 7$ & $L / h^{*}$ & 5.80 & 5.80 & 5.80 & 5.80 & 5.80 & 5.80 & 5.80 & 5.80 & 5.80 & 5.80 & 5.80 & 5.80 & 5.80 & 5.80 & 5.80 & 5.80 & 5.80 & 5.80 \\
\hline$\Pi 8$ & $\mathrm{~h} / \mathrm{h}^{*}$ & 0.05 & 0.05 & 0.05 & 0.05 & 0.05 & 0.05 & 0.05 & 0.05 & 0.05 & 0.05 & 0.05 & 0.05 & 0.05 & 0.05 & 0.05 & 0.05 & 0.05 & 0.05 \\
\hline П9 & $\mathrm{I}^{*} / \mathrm{h}^{*}$ & cte & cte & cte & cte & cte & cte & cte & cte & cte & cte & cte & cte & cte & cte & cte & cte & cte & cte \\
\hline
\end{tabular}

Tabla 3 muestra cuales son los grupos adimensionales que cambian con los diferentes casos de análisis. Se comparará casos para los cuales solo un grupo adimensional es el que varía.

En el diseño geométrico de las interfases solo se modificó la separación entre los puentes, tanto la altura como el diámetro de los puentes permanecen constantes (П6) a lo largo de las simulaciones. El cambio en los 6 casos presentados radica en la separación entre puentes. Durante toda esta investigación, se comparará casos en los cuales solo un grupo adimensional es el que cambia geométricamente (П5). En cuanto a materiales es el mismo a lo largo de toda la investigación (П2, П3) pero sin embargo la energía de fractura cambia dentro de cada caso y por lo tanto la longitud de fractura (П4). 
Cada caso posee 3 tipos diferentes de longitudes de fractura, para una longitud de fractura modelamos 10 diferentes ángulos (П1) y obtenemos el ángulo de fractura correspondiente en cada caso (П0). El ángulo correspondiente, será medido utilizando siempre la misma longitud de análisis (П9).

\section{Modelos}

En la Figura 76 a Figura 81 se muestra los diferentes modelos utilizados con valores de s/d que van desde 0.56 a 4.44 .

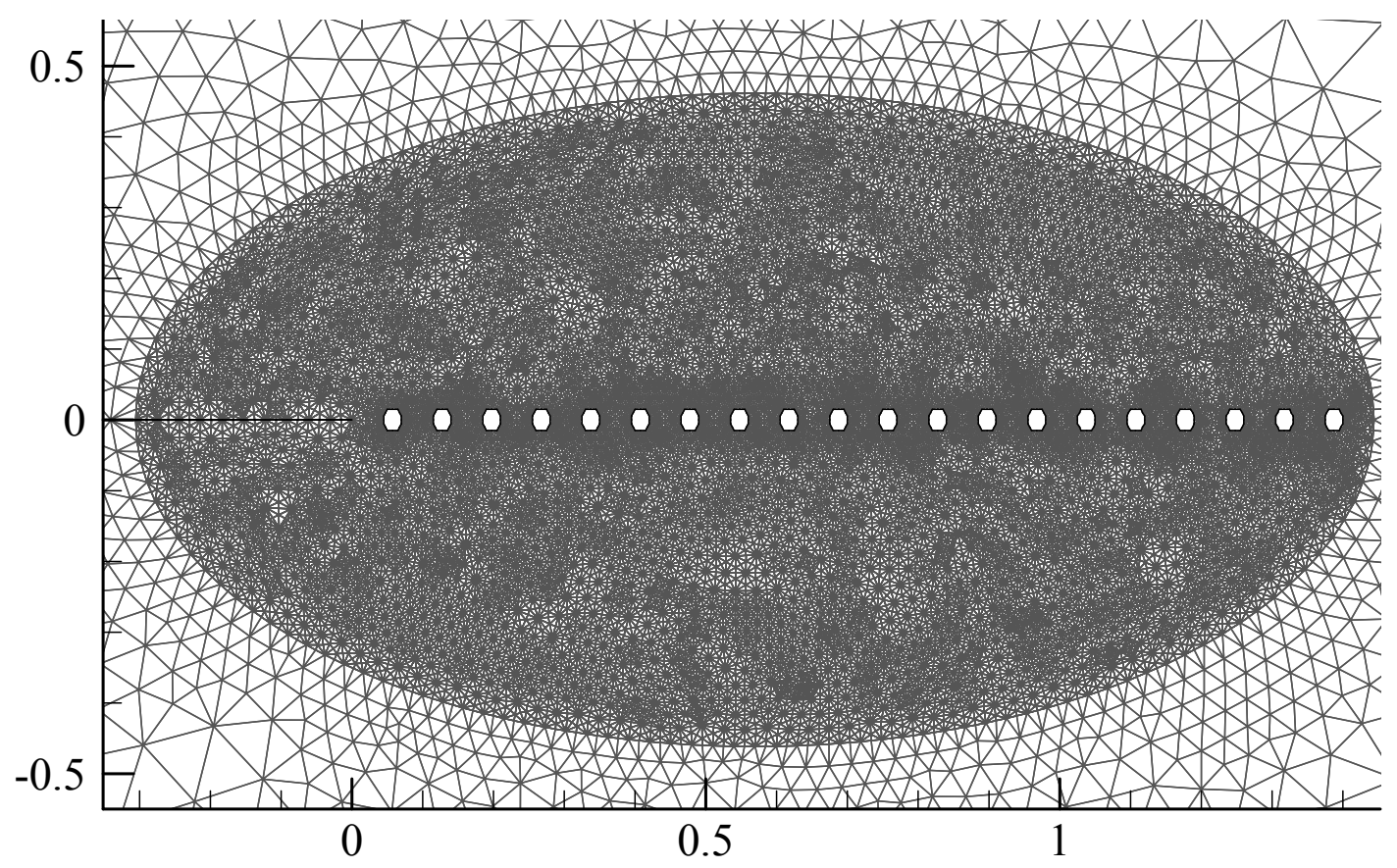

Figura $76-\mathrm{s} / \mathrm{d}=\mathbf{0 . 5 6}$ 
Capítulo IV - Mecanismos de disipación de energía.

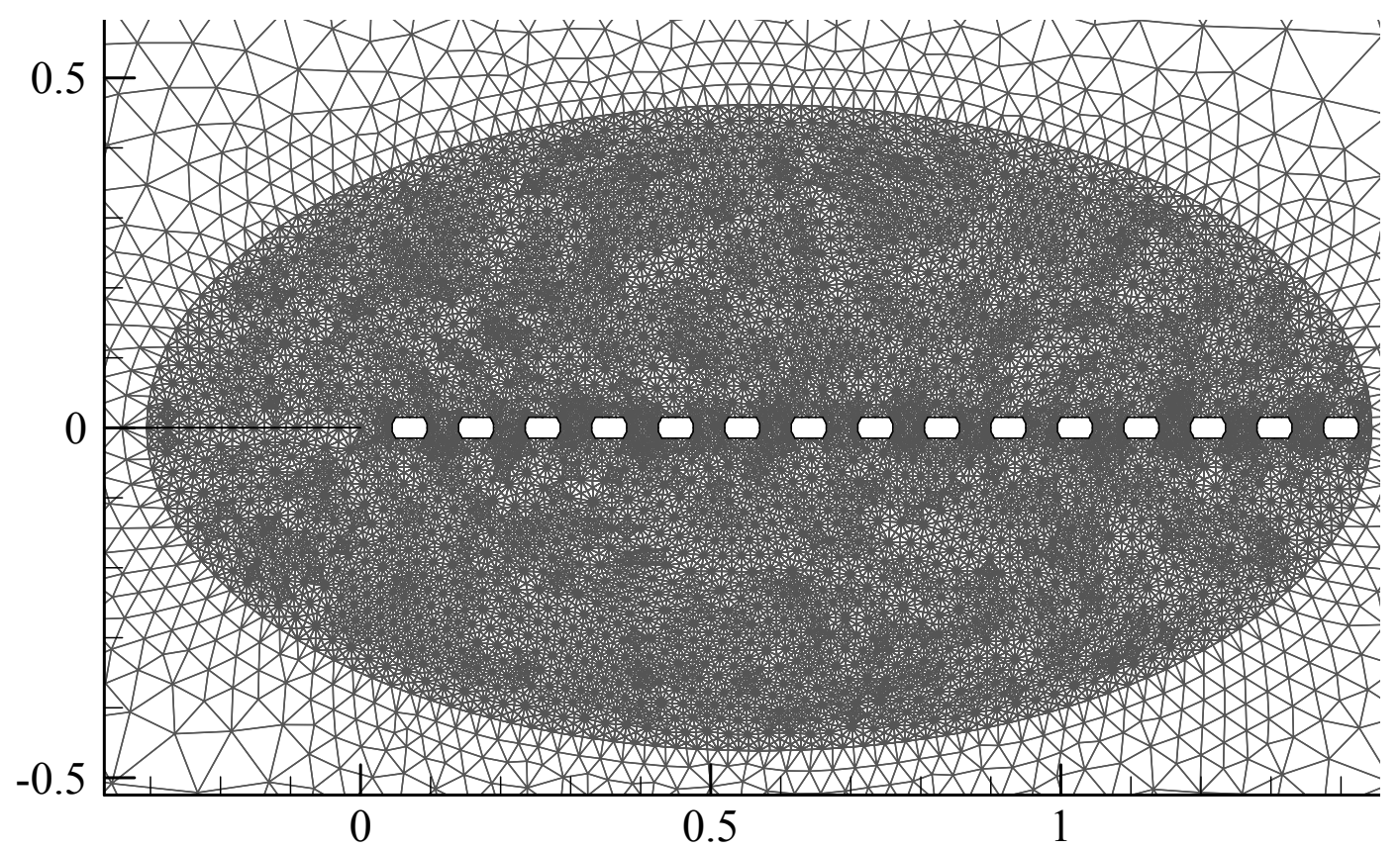

Figura $77-\mathrm{s} / \mathrm{d}=1.11$

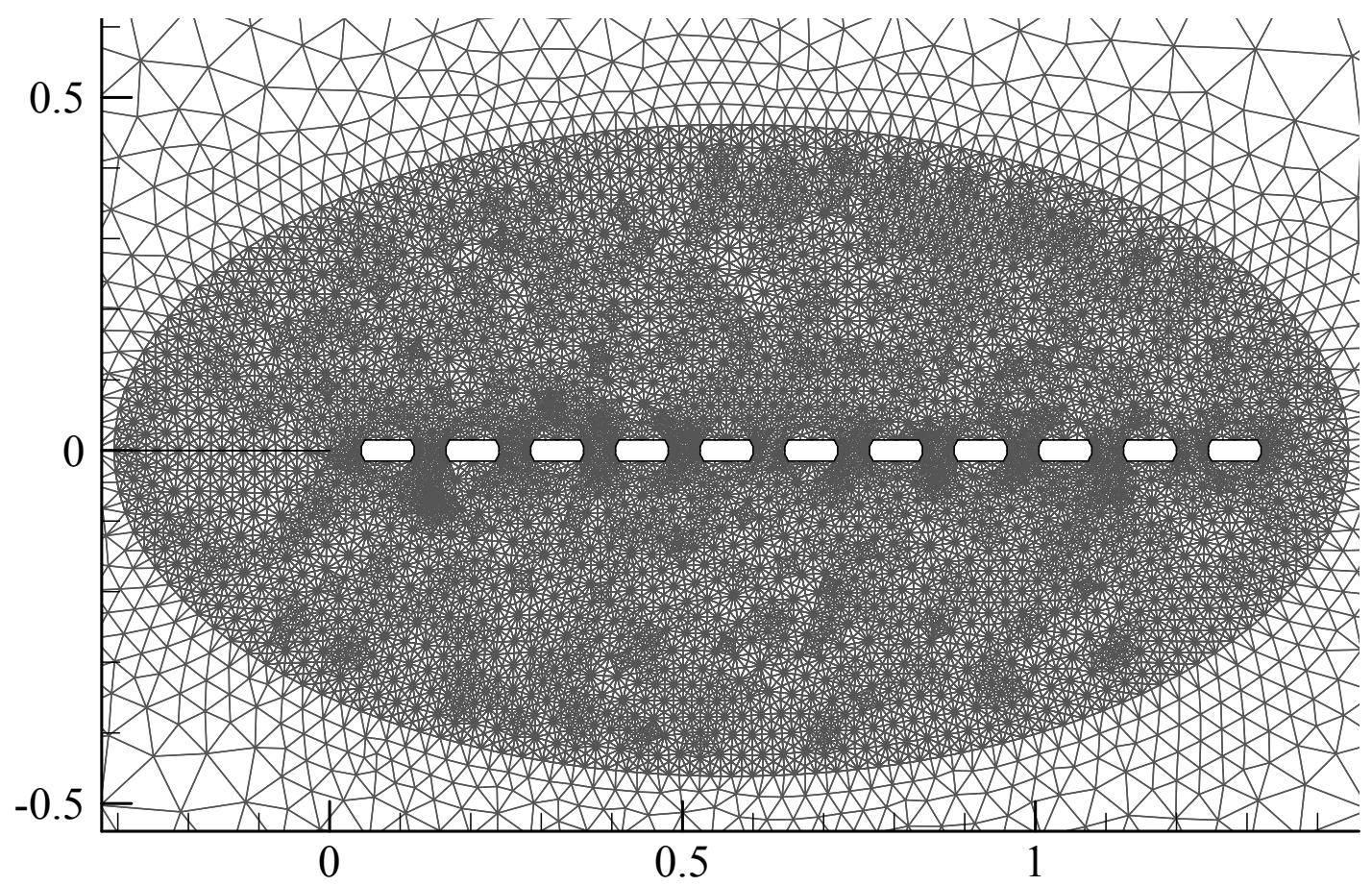

Figura $78-\mathrm{s} / \mathrm{d}=1.67$ 


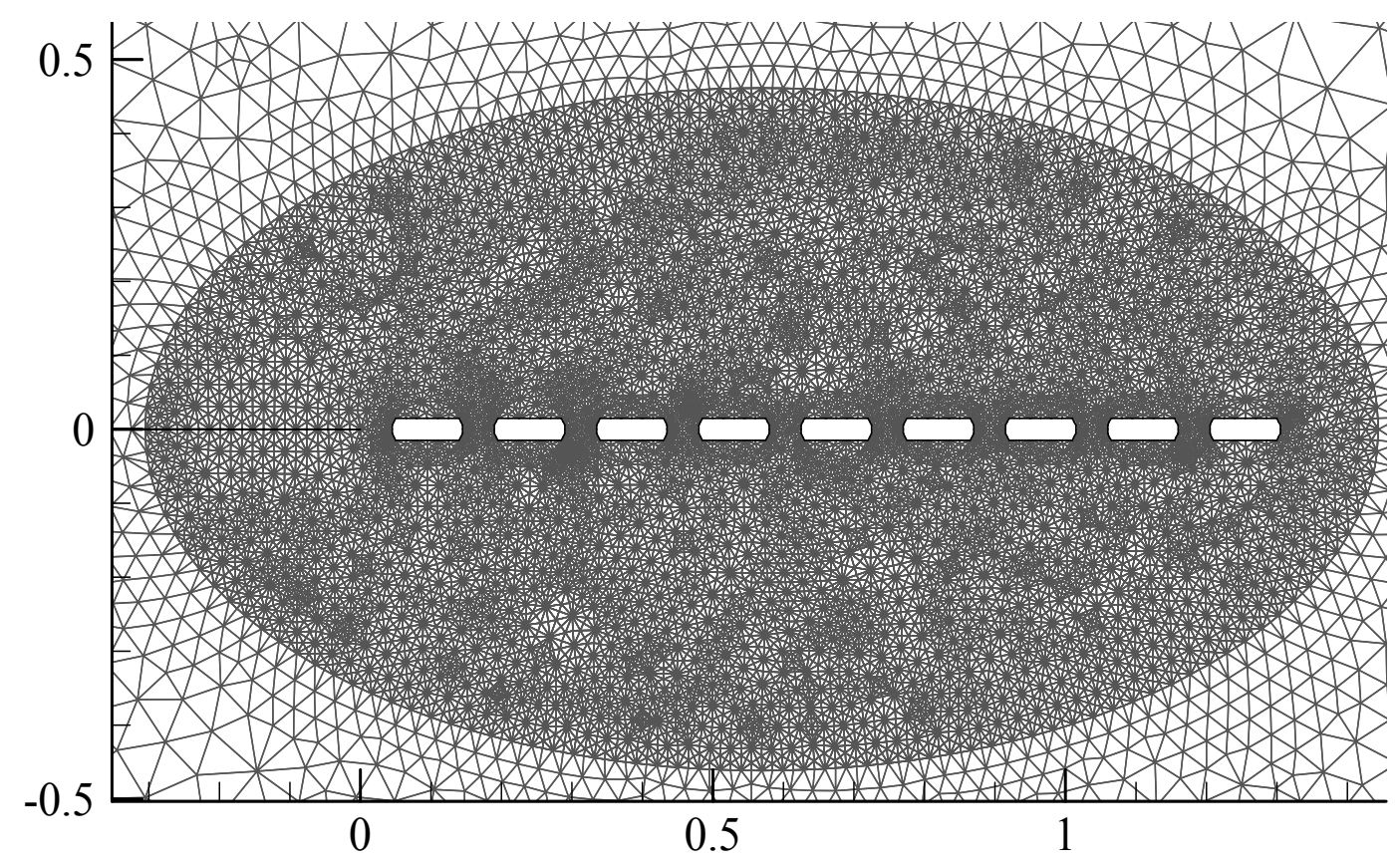

Figura $79-\mathrm{s} / \mathrm{d}=2.22$

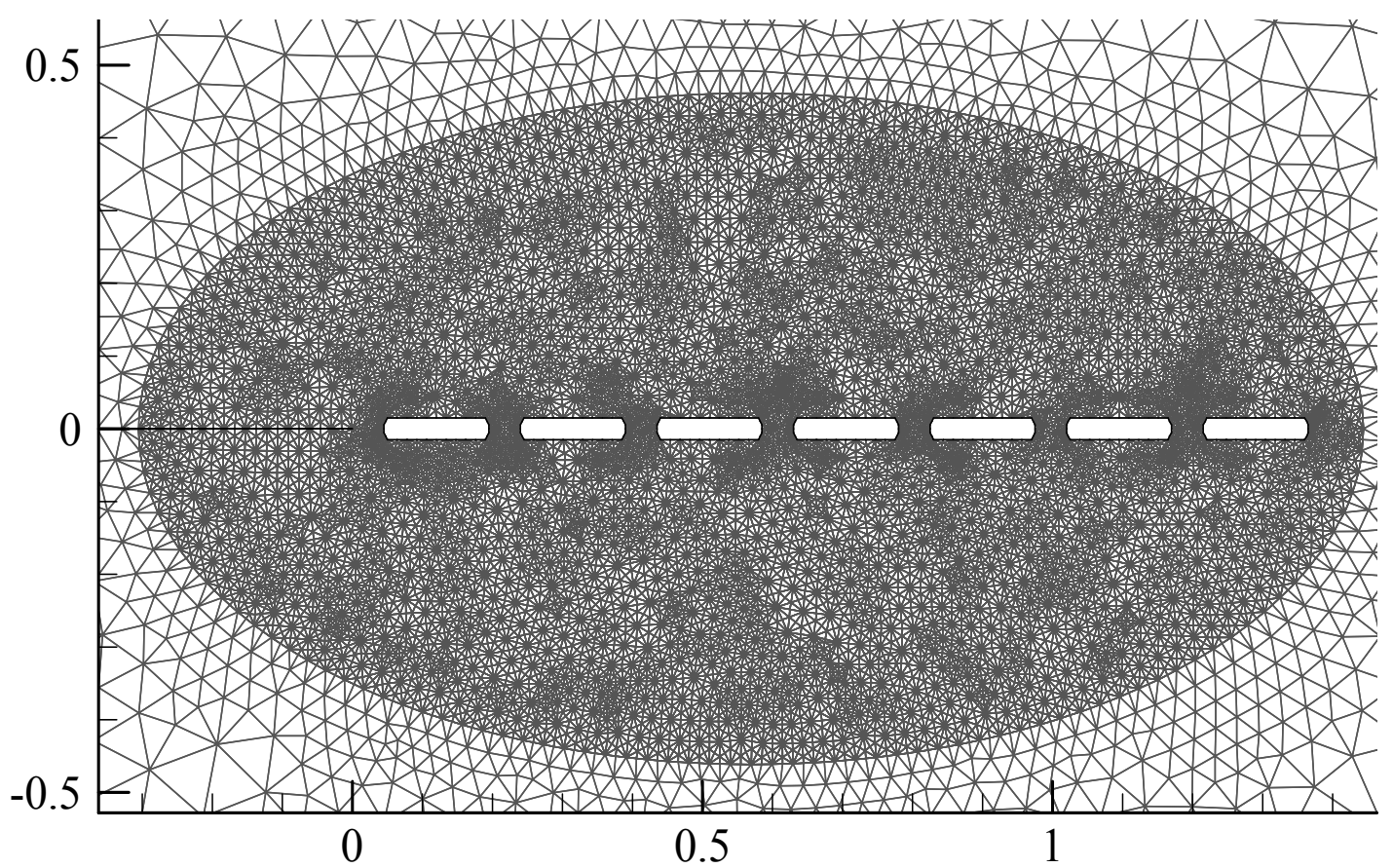

Figura $80-\mathrm{s} / \mathrm{d}=3.33$ 


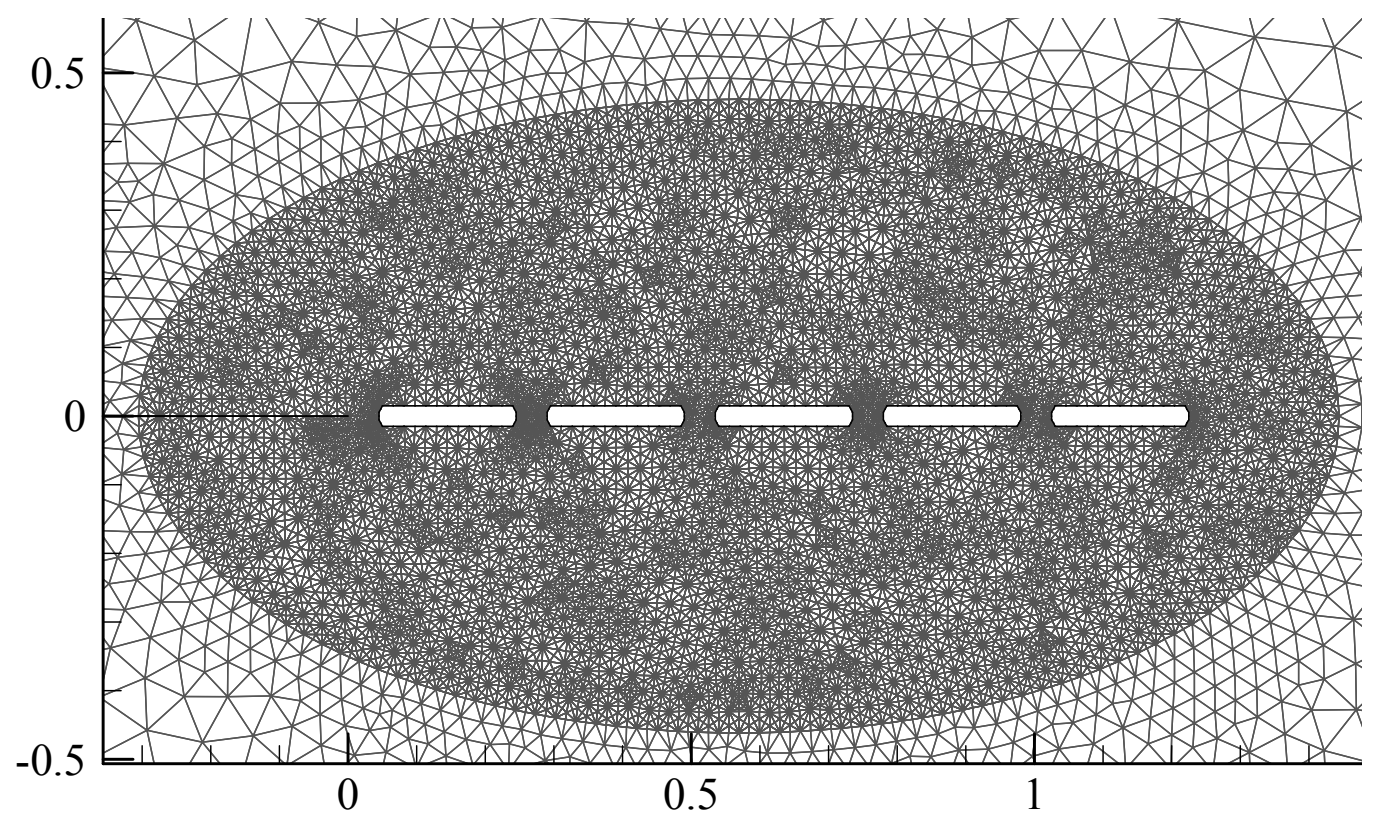

Figura $81-\mathrm{s} / \mathrm{d}=4.44$

Los modelos de elementos finitos se sitúan en el rango de los 71000 a 125000 nodos y 66000 a 110000 elementos respectivamente. El software utilizado como base para la resolución de estos modelos corresponde al paquete de código abierto FEAP (Finite Element Analysis Program) versión 8.4, desarrollado por la el departamento de Ingeniería Civil y Ambiental de la Universidad de California.

\section{IV.III.IV - Desviación de la fisura respecto de la dirección de la interfase.}

Dado el caso de dos materiales sólidos homogéneos con las mismas características mecánicas unidos a través de una interfase, y con una fisura ubicada co-linealmente con la dirección de la interfase. Entonces, ante una tensión $\sigma_{0}$, la fisura puede avanzar por la interfase o desviarse hacia el sólido. Esta decisión depende de la relación entre la energía almacenada en la interfase $\left(G_{0}\right)$ y la energía almacenada en el sólido $(G)$, la cual puede ser menor o mayor a la relación entre la tenacidad a la fractura de la interfase $\left(\Gamma_{0}\right)$ y del sólido en modo I $(\Gamma)$.

Entonces, para el caso de un material sometido a un modo mixto de carga $\sigma_{0}$ con fase $\Psi$ medido a partir del plano de la fisura inicial. 
$\mathrm{Si}$,

$$
\frac{\Gamma_{0}}{\Gamma}<\frac{G_{0}}{G}
$$

la fisura crecerá por la interfase. Si la inecuación es revertida, la fisura se deflectará y crecerá por el sólido.

$\mathrm{G} / \mathrm{G}_{0}$ estará dado por,

$$
\frac{G}{G_{0}}=|c|^{2}+|d|^{2}+2 \operatorname{Re}\left(c d e^{2 i \psi}\right)
$$

Donde $c$ y $d$ corresponden a factores definidos y tabulados por Hutchinson y He [54][55].

Las curvas de $G / G_{0}$ en función de $\theta_{0}$ para los distintos $\Psi$ serán los mostrados en la Figura 82.

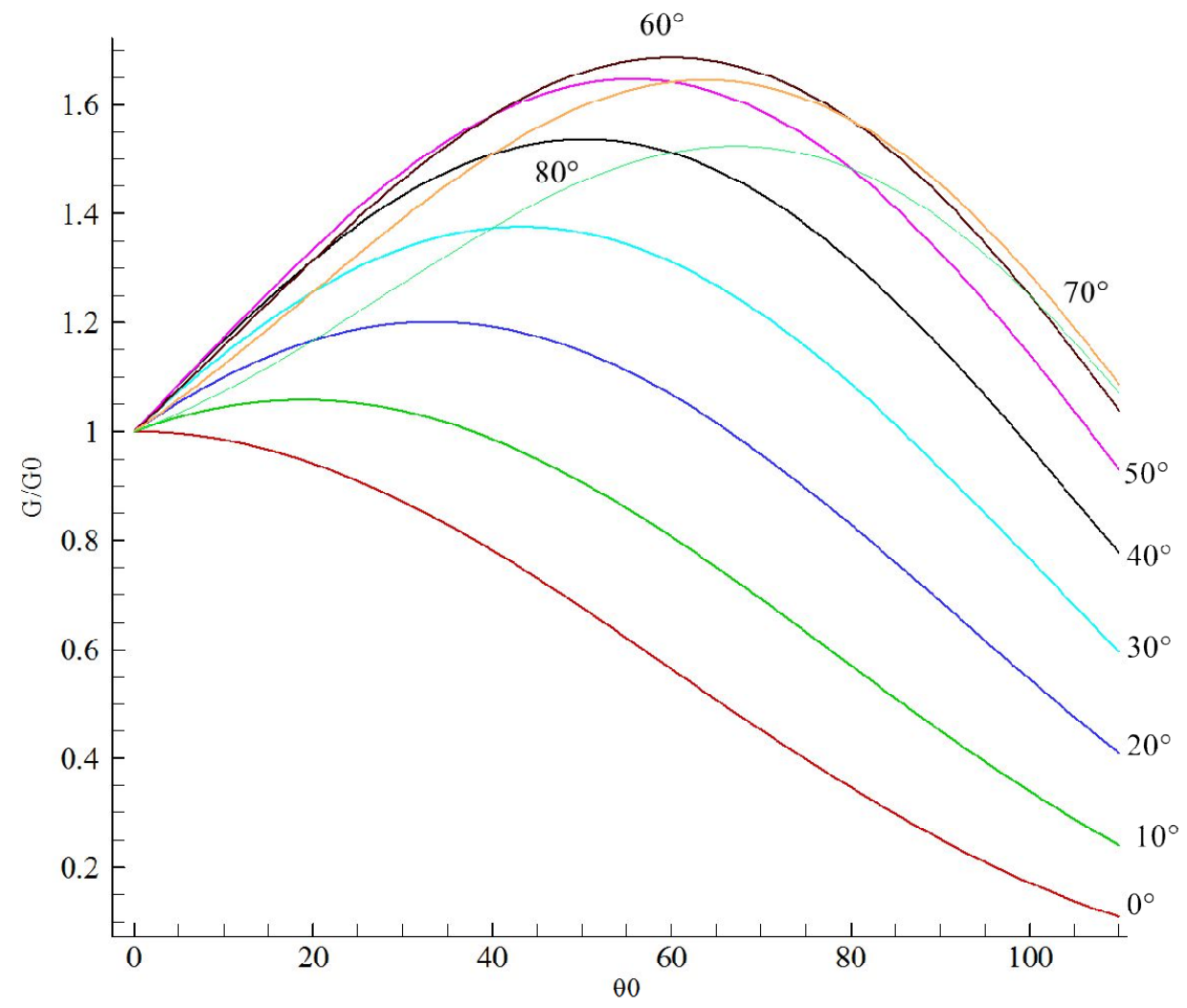

Figura 82 - Valores de $G / G_{0}$ en función de $\theta_{0}$. 


\section{Distribución de puentes.}

La distribución de puentes sobre la placa puede ser considerada de varias formas. Si consideramos a la placa como un elemento tridimensional, proponemos una distribución de puentes en la placa de forma rectangular o pentagonal (Figura 83) respetando las separaciones y diámetro de los puentes tal como se mencionó anteriormente.

(a)

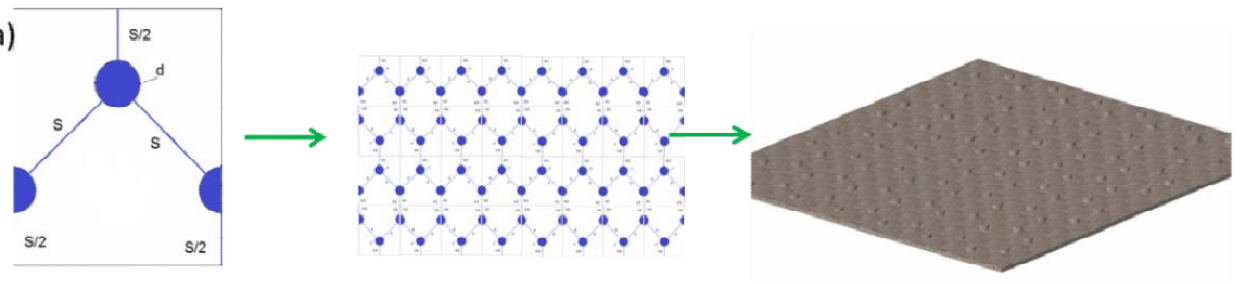

(b)

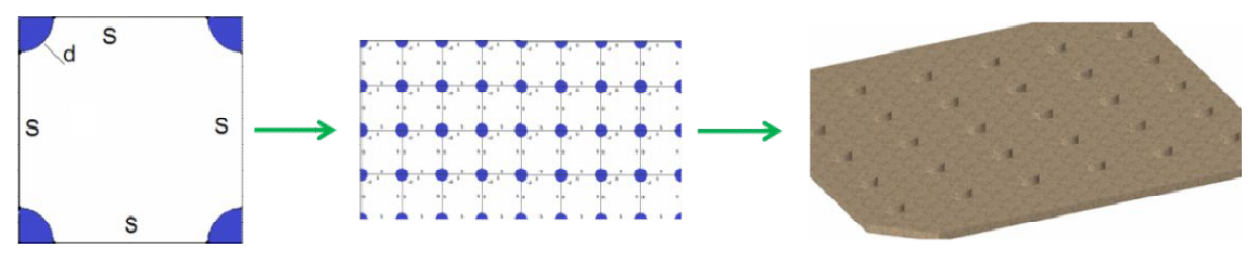

Figura 83 - (a) muestra una distribución pentagonal de puentes en la plata. (b) muestra una distribución rectangular de puentes en la placa.

El comportamiento de este tipo de distribución de puentes en relación con su diámetro y separación será el presentado en la Figura 84, donde $\mathrm{A}_{0}$ corresponde al valor de área de los puentes y el valor de A al área de la placa. En la Figura 84 también presentamos la distribución de puentes considerada para dos dimensiones, es decir, distribución lineal de puentes. 


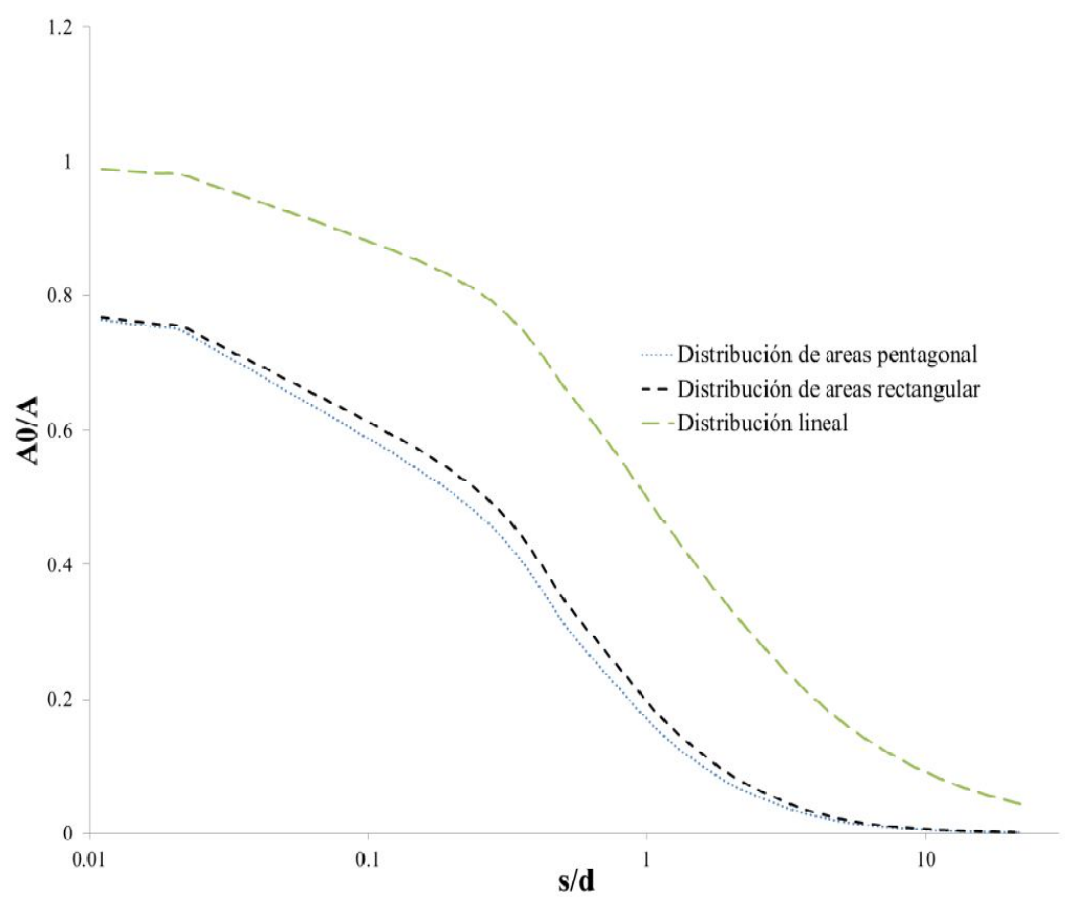

Figura 84 - Relación entre área de los puentes vs el área de la placa para distintas relaciones de diámetro de puente y separación, y distinta configuración ya sea un arreglo rectangular de puentes como pentagonal. El eje de las abscisas está representado en forma logarítmica para mejor visualización del gráfico.

La curva $\mathrm{A}_{0} / \mathrm{A}$ muestra además la variación de la energía disipada en la fractura de los puentes según la relación de s/d que componga la interfase. La energía disipada depende de la generación de nuevas superficies. Para una misma longitud de fractura, una relación de s/d cercana a cero, significa que los puentes se encuentran pegados uno al lado de otro por lo que al fracturarse los mismos, la energía disipada será proporcional a la cantidad de puentes fracturados y la misma será mayor que para valores de s/d mayores donde los puentes son más escasos.

En términos de módulo elástico, como forma de medir la rigidez de la interfase, el módulo elástico equivalente $\left(\mathrm{E}_{\mathrm{e}}\right)$ de una celda unidad estará dado por:

$$
E_{e}=E \frac{A_{0}}{A}
$$

El trabajo de separación requerido para generar nuevas superficies estará dado por 


$$
W_{s}=2 A_{g} \gamma_{s}
$$

$A_{g}$ es el área generada luego de la fractura y es igual a su longitud (a) por el espesor (B) (tomada como área rectangular)

Podemos escribir la energía de superficie como

$$
\gamma_{s}=\frac{\pi a \sigma_{f}^{2}}{2 E}
$$

$\sigma_{f}$ es la tensión de fractura del material.

E es el modulo elástico del material.

El trabajo de separación de una interfase con puentes $\left(\mathrm{W}_{\mathrm{s} 0}\right)$ en relación al trabajo de separación de una interfase sin puentes $\left(\mathrm{W}_{\mathrm{s}}\right)$ será función de la relación de áreas.

$$
\frac{W_{s 0}}{W_{s}}=\frac{A_{0}}{A}
$$

\section{Dirección de crecimiento de la fisura.}

Para el caso de las simulaciones numéricas, los diferentes resultados de las simulaciones nos determinan en que condición el modelo cumple con la ecuación (54). El modelo nos dirá si la fisura crece por la interfase o por el sólido. Sin embargo podemos construir la relación $\Gamma_{0} / \Gamma$ de la siguiente forma.

Tomando la relación de áreas antes descripta consideramos el valor de $\Gamma_{0}$ como:

$$
\Gamma_{0}=\frac{A_{0}}{A} \Gamma
$$

Donde el valor de $\Gamma$ corresponde al valor de $G$ cuando $G$ es crítico y sale de la ecuación (5). Teniendo en cuenta la ecuación (54) podemos graficar su resultado para la relación s/d de acuerdo a los distintos $\Psi$ de carga. Llamaremos a esta 
curva, Teórica rectangular o Teórica pentagonal dependiendo de la distribución de áreas que se utilice.

Otra forma de construir la relación de $\Gamma_{0} / \Gamma$ es considerando el valor de $\Gamma_{0}$ obtenido a través de la simulación numérica y $\Gamma$ definido anteriormente (valor de $G$ cuando G es crítico). Llamaremos a esta curva Semi-Teórica.

La relación definida anteriormente $\left(\Gamma_{0} / \Gamma\right)$ comparada con el valor de $G / G_{0}$ de las curvas de la Figura 82, nos permite determinar la dirección que tomará la fisura de acuerdo a la relación presentada en la ecuación (54).

Presentamos en la Figura 85 los resultados de las curvas mencionadas.

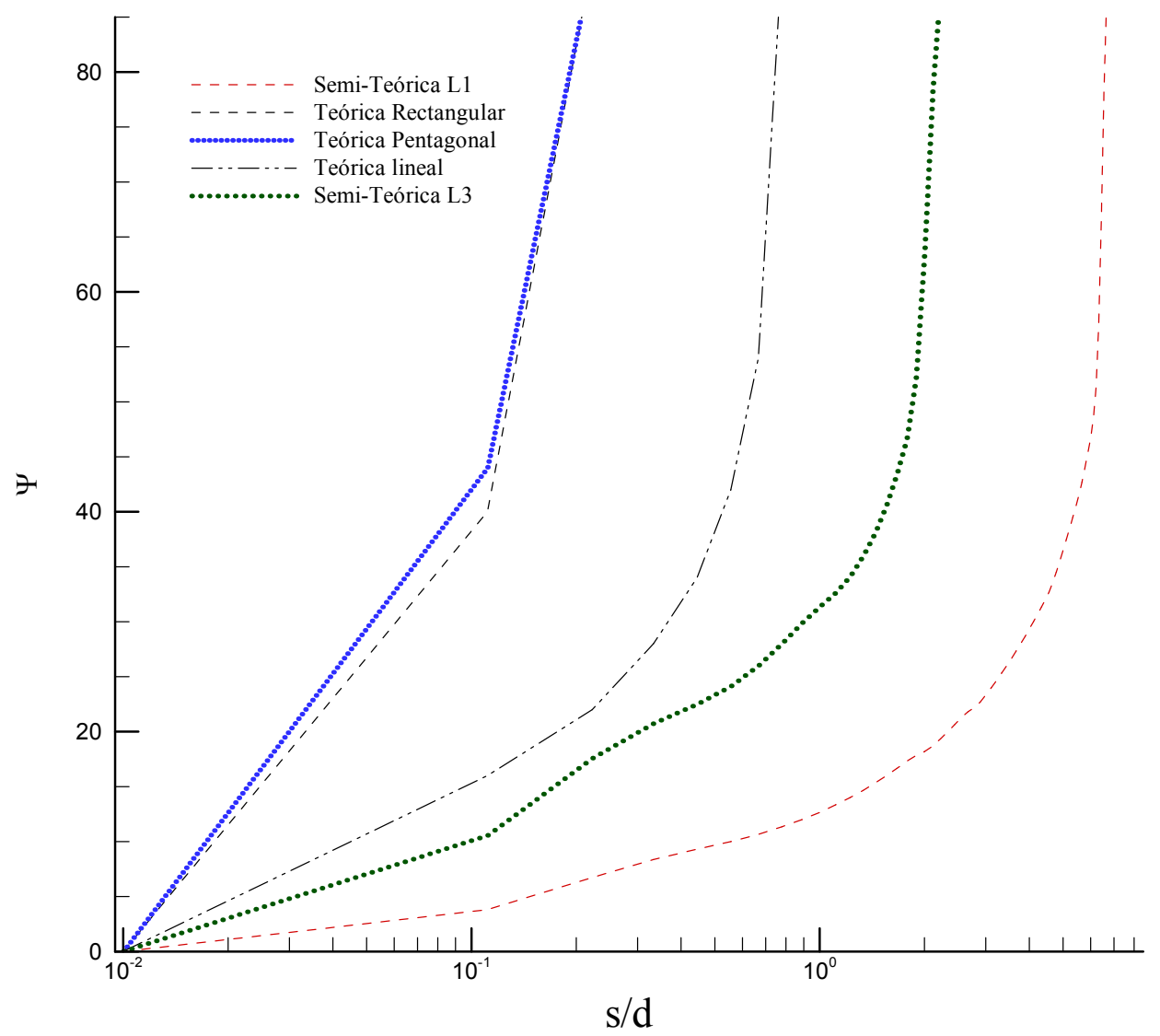

Figura 85 - En función de la relación del diámetro de los puentes y sus separaciones se muestra el comportamiento teórico y semi -teórico de la interfase para modos mixtos de carga. Las curvas separan dos regiones: la derecha corresponde a las relaciones de s/d y ángulos de modo mixto para el cual la fisura crece por la interfase. La zona de la izquierda a la curva indica donde crecerá por el sólido. L1 y L3 corresponden a longitudes de fractura donde L3>L1. 
La Figura 85 muestra la curva Semi Teórica y las curvas Teóricas para las diferentes configuraciones de áreas. Puede observarse que estas últimas son muy similares por lo que de aquí en adelante se considerará a la curva Teórica como la Teórica pentagonal. Cada una de ellas presenta la configuración de la interfase en términos del diámetro de puente y la separación, para que la fisura siga por la interfase o se desvíe de ella según el ángulo de carga sometida.

A medida que la longitud de fractura se incrementa, las curvas tienden hacia la izquierda en la gráfica. Vemos que esto ocurre con la curva semi-teórica L1 y L3, con L3 mayor a L1. Las curvas Teóricas, solo tienen en cuenta la relación de áreas

para determinar $\Gamma_{0}$, es por ello que representan el comportamiento para longitudes de fractura muy grandes, insensible a la forma y dimensiones de los puentes pero susceptible a la disminución de la rigidez producto de la presencia de los mismos respecto del sólido.

\section{IV.IV - Resultados numéricos y conclusiones.}

De los 180 casos analizados se determinó en cuáles de ellos la fisura seguía por la interfase y en cuales se desviaban. Dentro de estos últimos se determinó además el ángulo en el cual crece la fisura.

En las Figura 86 a Figura 90 se presentan observaciones de diferentes patrones de fisuras dependiendo del ángulo de cargas, la disposición de puentes y la longitud de fractura del material. 

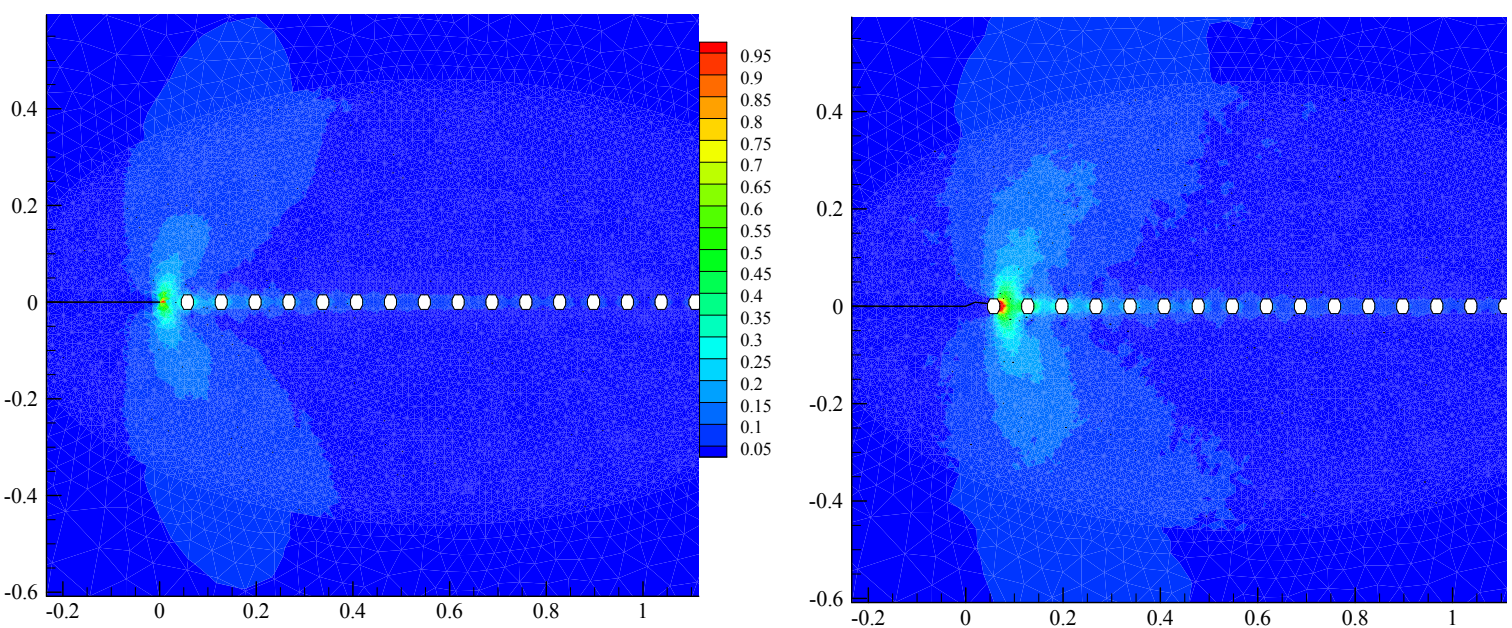

Figura $86-\mathrm{s} / \mathrm{d}=0.55 ; \Psi=0^{\circ} ; \mathrm{L} 1$. La figura de la izquierda muestra la distribución de tensiones antes de la fisura y la derecha una vez fracturado un puente y a un instante de producirse la fractura total de ellos. Las distancias en las figuras se encuentran en um.
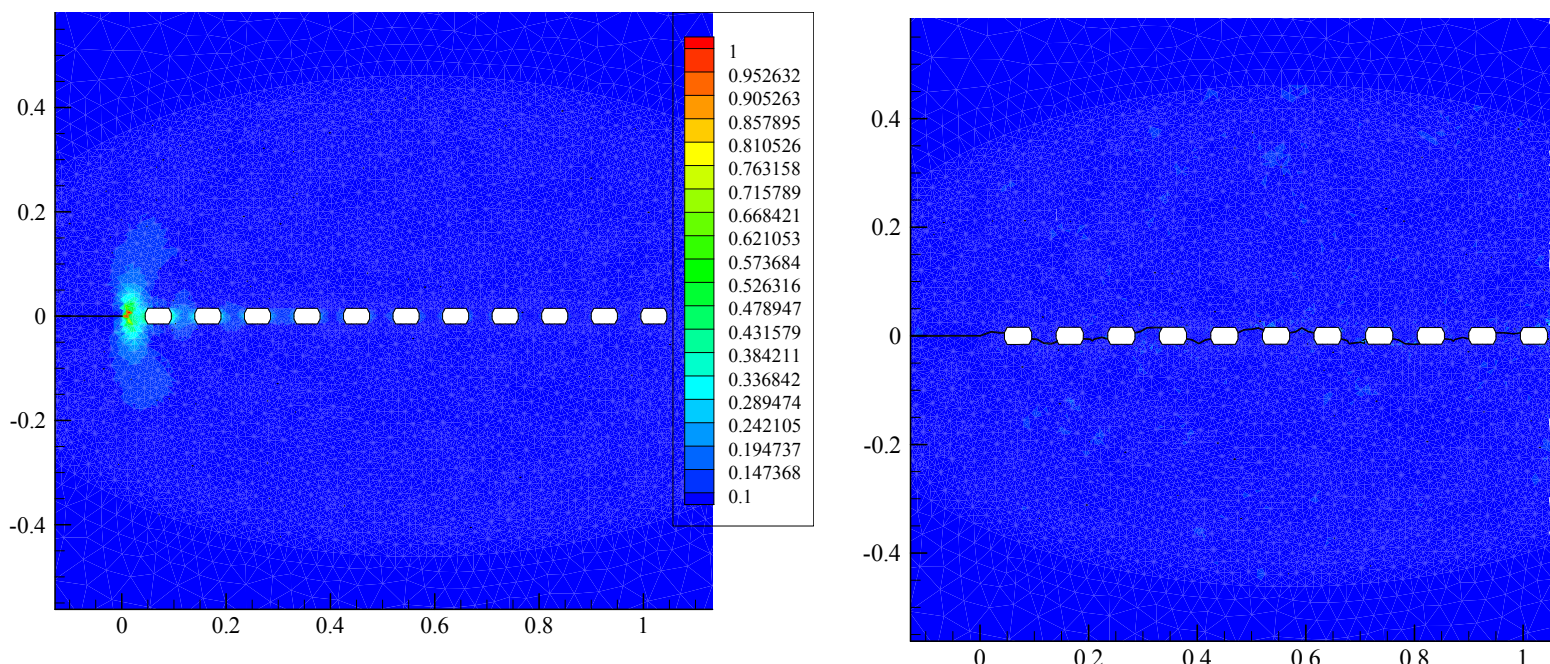

Figura $87-\mathrm{s} / \mathrm{d}=1.11 ; \Psi=0^{\circ} ; \mathrm{L} 1$. La figura de la izquierda muestra la distribución de tensiones antes de la fisura y la derecha una vez fracturado la totalidad de los puentes. Puede observarse que la fisura no es completamente recta y construye un zigzag dentro de la interfase. Las distancias en las figuras se encuentran en um.
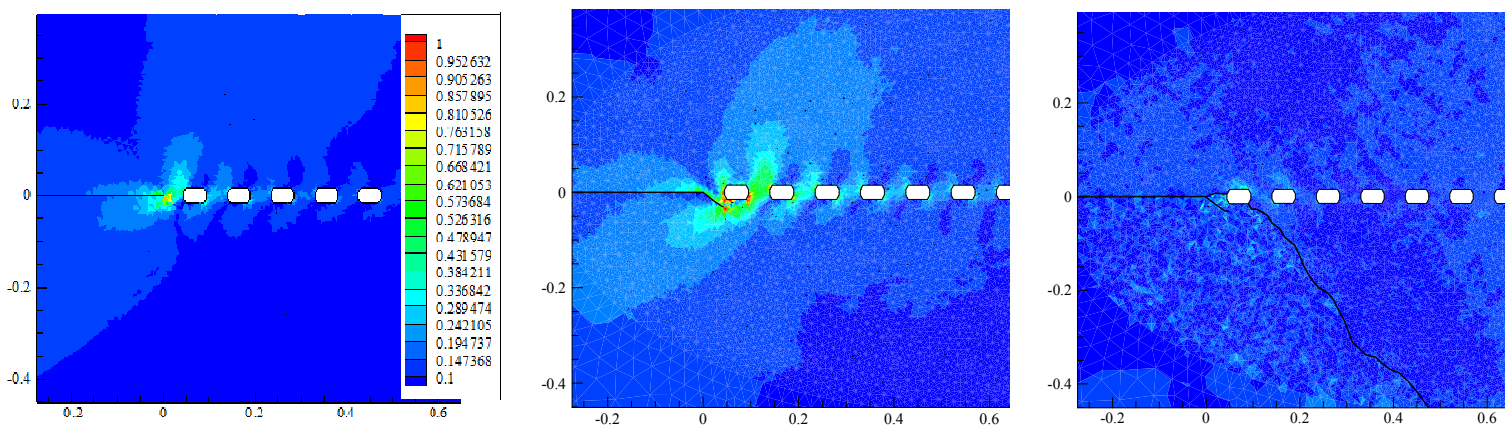

Figura $88-\mathrm{s} / \mathrm{d}=1.11 ; \Psi=40^{\circ} ; \mathrm{L} 1$. De izquierda a derecha se muestra la secuencia de la fractura, la cual inicia en una dirección y luego va hacia otra por el sólido. Las distancias en las figuras se encuentran en um. 

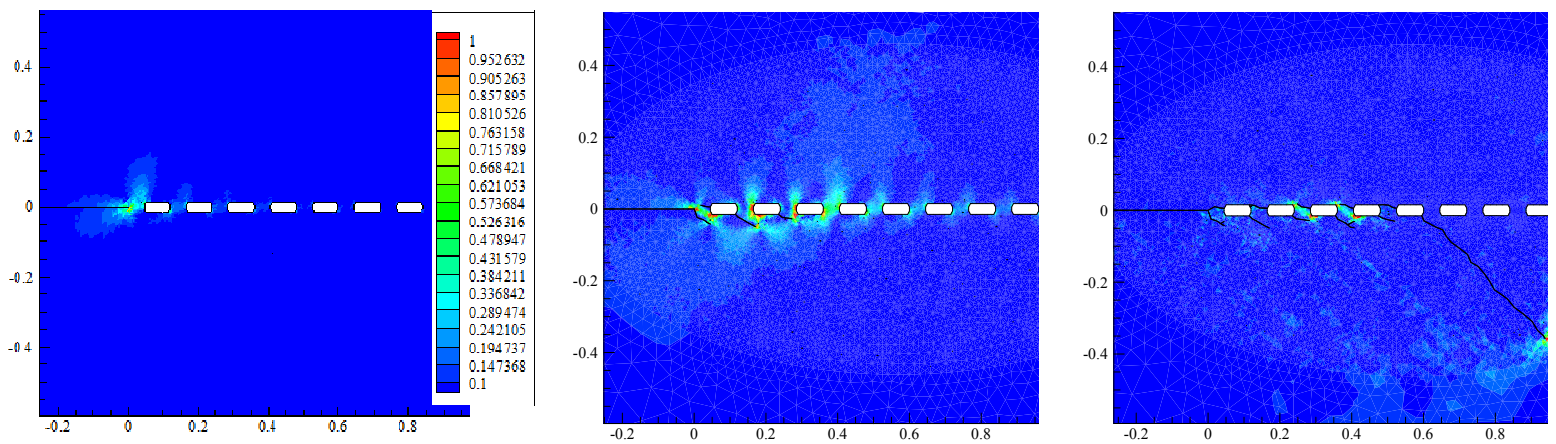

Figura $89-\mathrm{s} / \mathrm{d}=1.66 ; \Psi=40^{\circ} ; \mathrm{L} 1$. De izquierda a derecha se muestra la secuencia de la fractura, la cual se propaga por la interfase un par de puentes y luego se deflecta hacia el sólido. Las distancias en las figuras se encuentran en um.

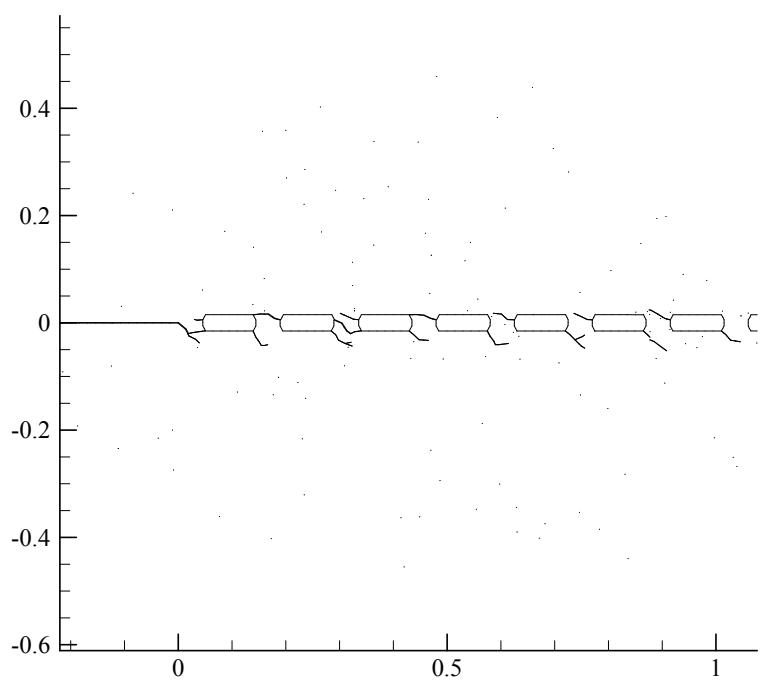

Figura $90-\mathrm{s} / \mathrm{d}=4.44 ; \Psi=85^{\circ} ; \mathrm{L} 1$. A pesar del ángulo de carga tan extremo, esta interfase resulta tan débil estructuralmente que la fisura crece a través de ella antes de continuar por el sólido. Las distancias en las figuras se encuentran en um

Se observó además, que de acuerdo a la longitud de fractura del material, el comportamiento de la fisura frente a los puentes cambia y se vuelve más susceptible a la presencia de ellos a medida que la longitud crece, tal como se muestra en las Figura 91 y Figura 92. 

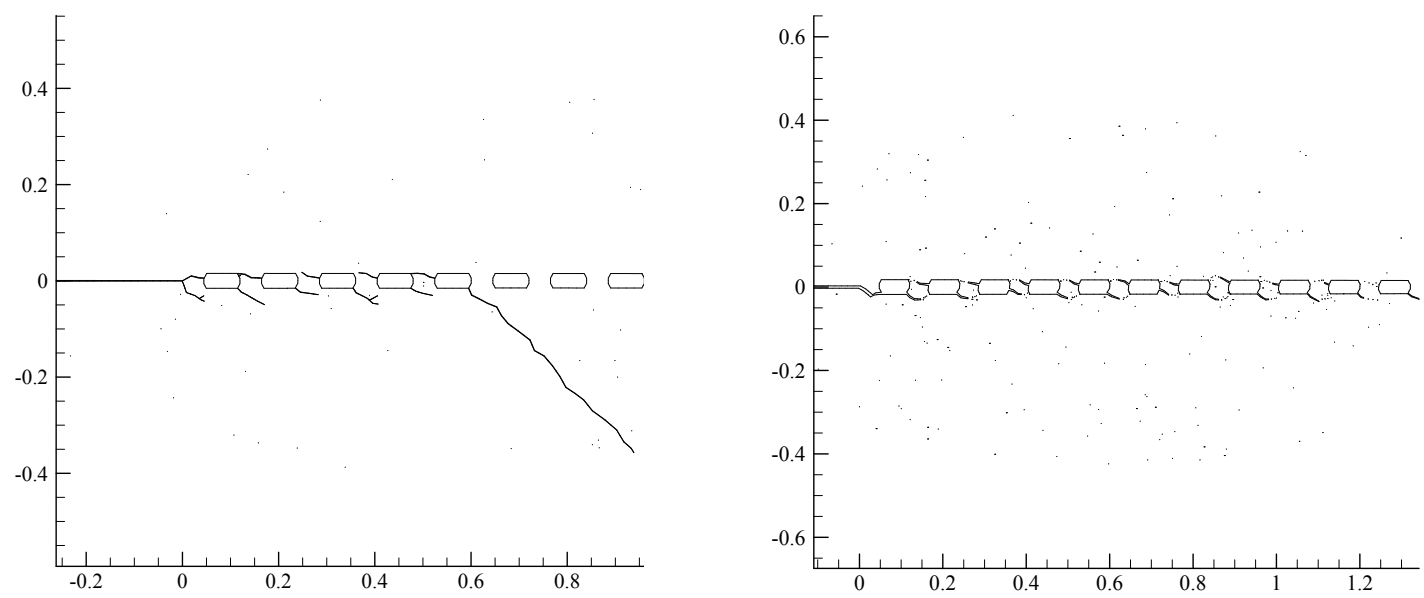

Figura $91-\mathrm{s} / \mathrm{d}=1.66 ; \Psi=40^{\circ}$. La figura de la izquierda corresponde a una longitud de fractura L1 y la de la derecha a L3. Las distancias en las figuras se encuentran en um.

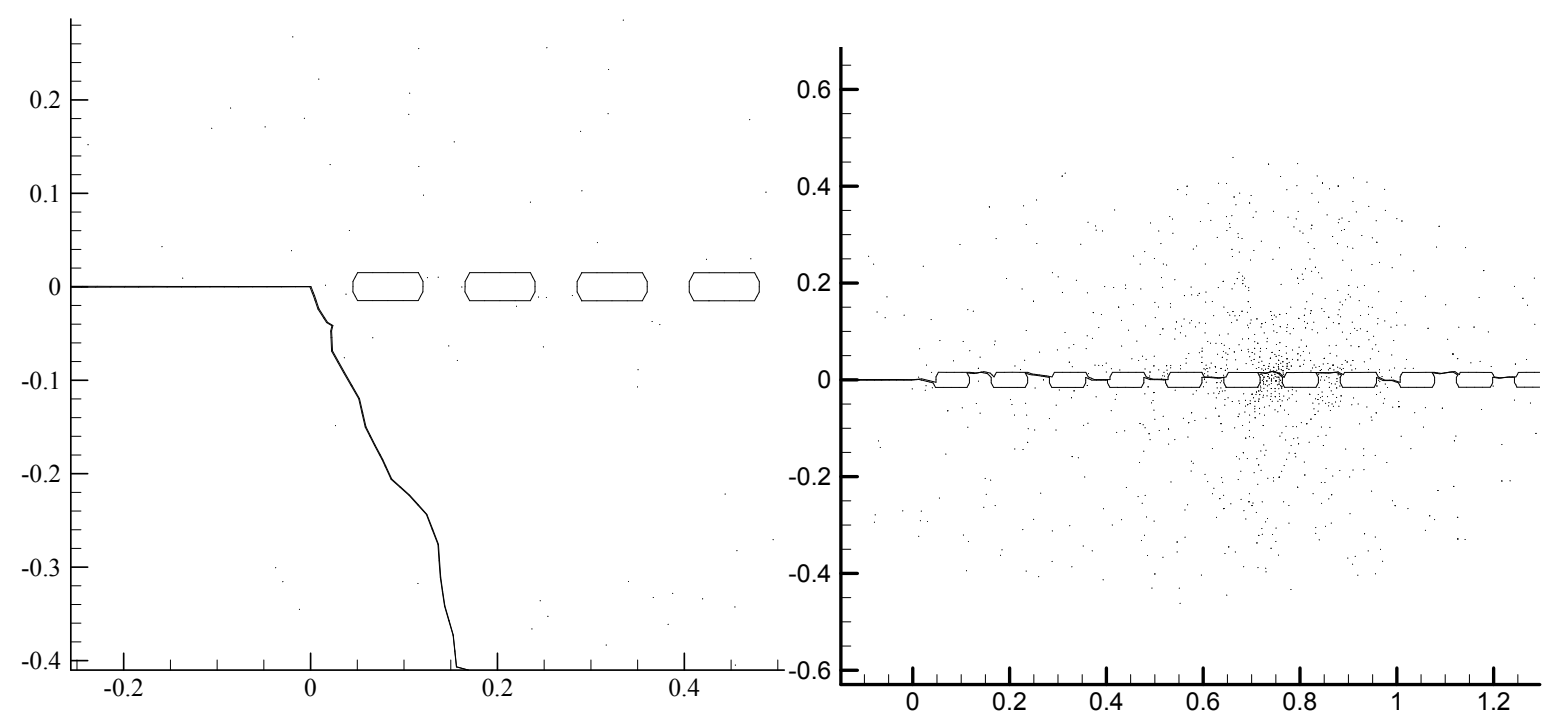

Figura $92-\mathrm{s} / \mathrm{d}=1.66 ; \Psi=80^{\circ}$. La figura de la izquierda corresponde a una longitud de fractura L1 y la de la derecha a L3. Las distancias en las figuras se encuentran en um.

Las Figura 91 y Figura 92 muestran los resultados de simulaciones para un mismo modelo con diferentes longitudes de fractura. Puede observarse que a medida que la longitud de fractura crece, la fisura se hace más susceptible a la presencia de los puentes.

$\mathrm{Al}$ analizar los resultados, nos encontramos con que interfases muy débiles (altas separaciones entre puentes) permiten direccionar la fractura a través de ella, independientemente del ángulo de carga. Interfases muy fuertes (bajas separaciones entre puentes), no son capaces de direccionar el crecimiento de fisura para otros ángulos de carga distintos de $0^{\circ}$. Existen interfases con distintas relaciones s/d y 
por lo tanto cierto grado de rigidez, para los cuales la fisura puede ser direccionada a través de ella para distintos ángulos de carga. Estas interfases combinan altos valores de disipación de energía, a la hora de la fractura, con un control en la dirección de propagación de la misma en la interfase.

Si transmitiéramos este concepto a un gráfico nos encontraríamos con el presentado en la Figura 93.

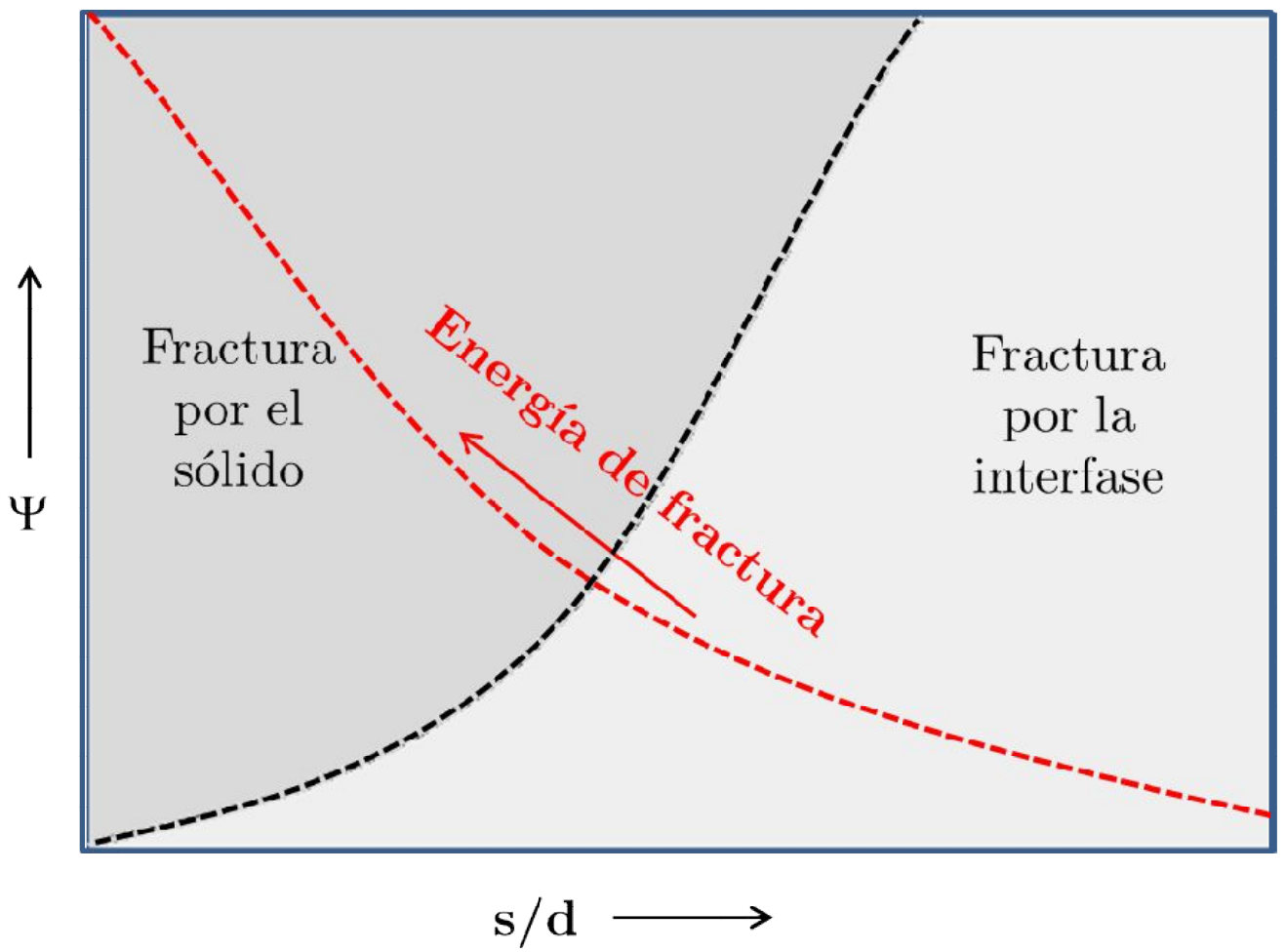

Figura 93 - Esquema del comportamiento de las interfases con puentes en su interior. A la hora de la fractura, la energía liberada en la interfase se contrapone al control de la dirección de propagación de fisura dentro de ella.

A partir de la utilización de los resultados de las simulaciones, se construyó un mapa de resultado para el cual según la densidad de puentes en la interfase y la longitud de fractura del material, se muestra el comportamiento del mismo. Paralelamente se compararon los resultados del análisis numérico con los resultados teóricos teniendo en cuenta las consideraciones antes mencionadas (Figura 94). En zona de color se ubica también los valores de densidad de puentes de los materiales como el nácar y el diente de chitón. 


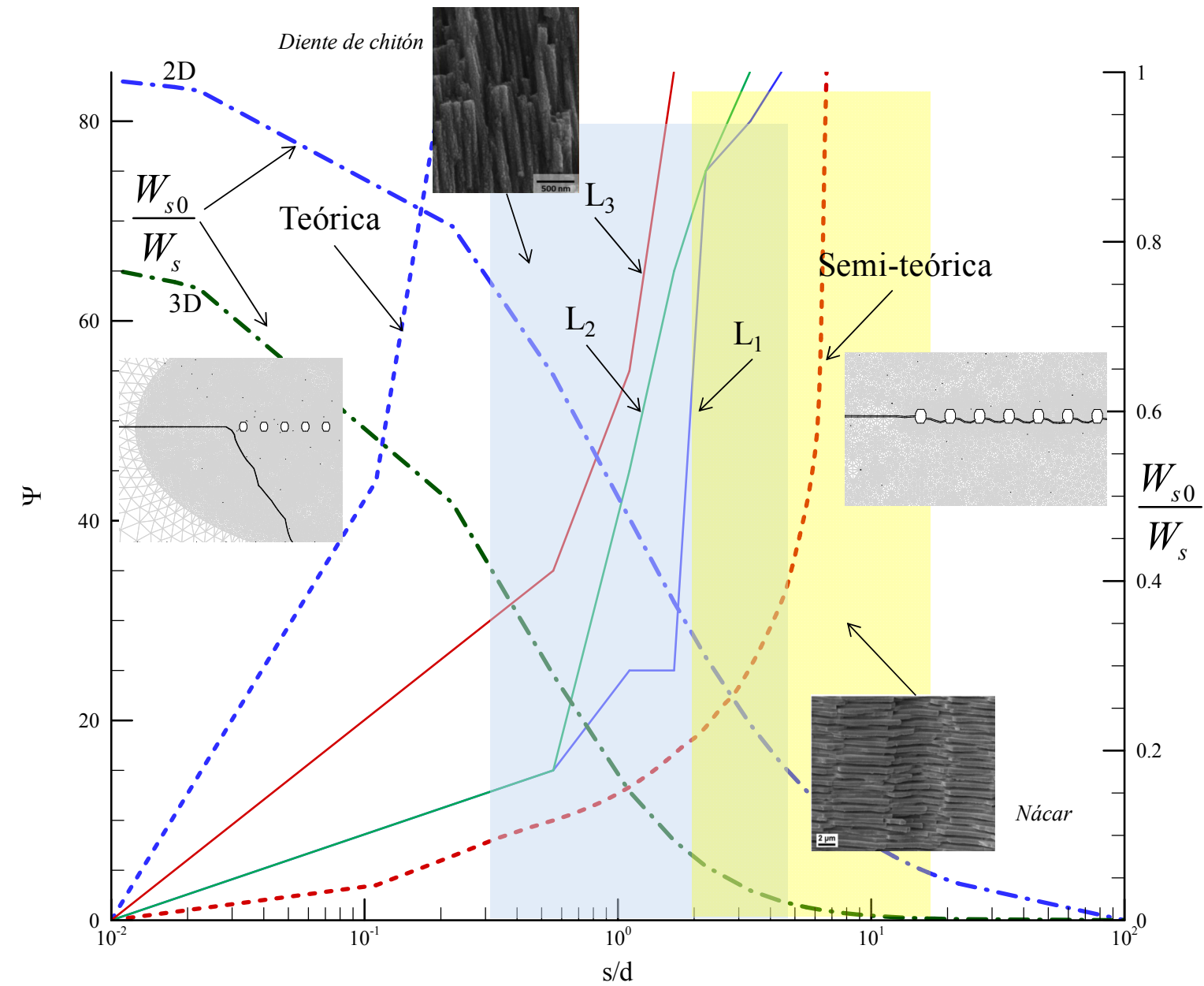

Figura 94 - Se muestran los resultados de los análisis numéricos de las interfases para tres tipos de longitudes de fractura L1, L2 y L3. Las curvas muestran para qué combinación de s/d y ángulo de carga $\Psi$ la fisura crece en la interfase y para cuál no lo hace. A estas curvas se agregó el resultado de curvas teóricas las cuales son comparables a los resultados numéricos pero sensibles al valor de $\Gamma_{0}$. En contraposición a los efectos de estas curvas se agregó la relación entre $W_{\mathrm{s} 0} / W_{\mathrm{s}}$ la cual indica en términos de presencia de material solido en la interfase la rigidez de misma. Para finalizar se indican los valores de s/d que ha elegido la naturaleza para sus diseños en el Nácar o diente de chitón.

La Figura 94 muestra un mapa del comportamiento de interfases con puentes para distintos ángulos de carga. Para valores altos de s/d la fisura crece siempre por la interfase independiente del ángulo de carga. Para valores pequeños de s/d la fisura se desvía por el sólido en un ángulo que depende del valor de ángulo de carga. Las curvas constituyen los valores límites para uno u otro comportamiento. La gráfica muestra además, en trazo segmentado, el comportamiento de las interfases desde un planteo teórico puro y un planteo semiteórico. Entre ellos se encuentran los resultados de las simulaciones numéricas para diferentes longitudes de fractura. Cada una de estas curvas separa dos zonas: la zona derecha de la curva presenta una región de combinaciones de diámetro de 
puente y separación donde la fisura crece por la interfase y la zona izquierda muestra la zona donde la fisura se deflecta y crece por el sólido. En contraposición a esto se muestra una curva de $\mathrm{W}_{\mathrm{s} 0} / \mathrm{W}_{\mathrm{s}}$ que corresponde al trabajo de separación entre una interfase con puentes $\left(\mathrm{W}_{\mathrm{s} 0}\right)$ y una interfase completamente sólida del material $\left(\mathrm{W}_{\mathrm{s}}\right)$. A medida que la relación $\mathrm{s} / \mathrm{d}$ se incrementa, la presencia de puentes disminuye y por lo tanto también lo hace la energía liberada en la fractura de los mismos.

La curva teórica, muestra el comportamiento de las interfases cuando la fisura es independiente de la longitud de fractura, es decir, cuando la longitud de fractura es tan grande que supera la muestra. La curva semi-teórica sin embargo tiene en cuenta la longitud de fractura y se comporta de igual manera que las numéricas tendiendo hacia la izquierda cuando la longitud de fractura se incrementa. En la gráfica solo se muestra la curva semi-teórica correspondiente a la longitud de fractura L1.

Existe entonces, una competencia de mecanismos dentro de la interfase, por un lado la presencia de interfases débiles permite el control de la dirección de crecimiento de la fisura. Bajo esa premisa no hay coalescencia de fisuras, si no hay conexiones entre las interfases, por lo que el daño se esparce por toda la pieza en microfisuras, siguiendo las interfases. Este es un mecanismo que incrementa la tenacidad a la fractura del material. La presencia de puentes en las mismas, endurecen y generan una disipación de energía mayor a medida que la fisura crece. Existe un límite en cantidad y distribución de esos puentes para la cual, la fisura ya no es controlable, la microfisuras no respetan las interfases, las mismas crecen a través del sólido, coalescen unas con otras y generan una fractura del material. En la Figura 95 se muestra un esquema básico de lo descripto anteriormente. 

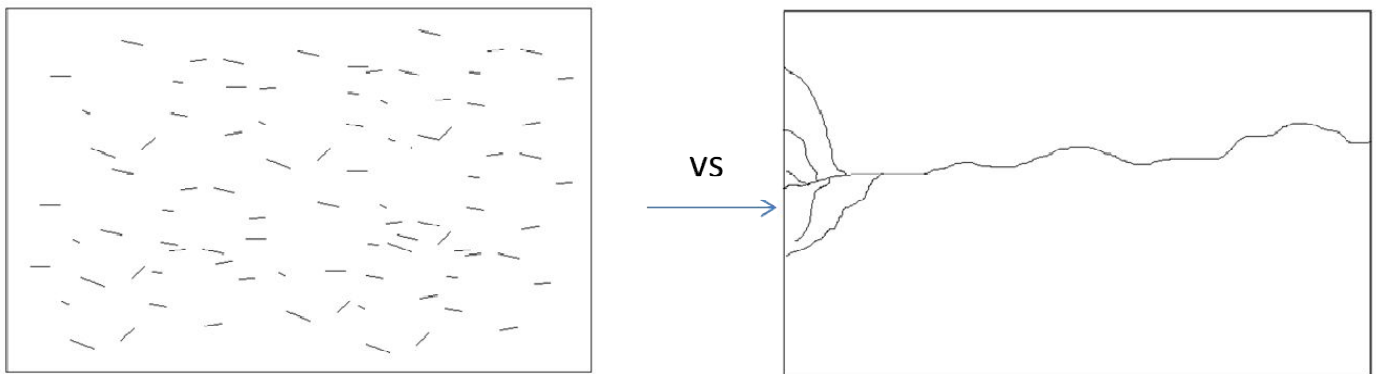

Figura 95 - Esquema del comportamiento de las microfisuras esparciéndose por todo el sólido versus la coalescencia de microfisuras en una fractura del material.

Los materiales estudiados aquí se caracterizan por una estructura jerárquica cargada de interfases entre sus elementos. Podemos mencionar la estructura característica del nácar, similar a una pared de ladrillo en la cual se disponen sus placas, la microestructura del diente de chitón con interfases que unen sus nanobarras o la microestructura de la Mantis marina que se caracteriza por fibras dispuestas en forma helicoidal o radial, en una matriz de material orgánico, dependiendo de la zona que se analice. En todas ellas el potencial de dirección de crecimiento de estas microfisuras es tal como elementos de construcción tenga el material. Para estos materiales además, su distribución geométrica los ubica dentro de los límites de comportamiento descripto tal como se muestra en la gráfica de la Figura 94. Más aún, en la Figura 71 ya se había presentado el comportamiento de los puentes desde el punto de vista tensional, ubicándolos en una zona donde se favorecía la rotura de los mismos antes que la de la placa para el caso del nácar.

Las microfisuras en zonas de alta concentración de tensiones pueden posponer el inicio de una fisura macroscópica inestable en materiales frágiles. Las mismas generan una reducción y redistribución de la tensión cerca de la punta de la fisura macroscópica. Hutchinson establece una reducción en valores de factor de intensidad de tensiones $\left(\mathrm{K}_{\text {tip }}\right)$ de hasta 30 o $40 \%$ [56]. Es importante remarcar que las microfisuras deben ser estables, muriendo en partículas o interfases. Finalmente, cuando la tensión se incremente y la fisura macroscópica se dispare, serán estas microfisuras las que contribuyan a su crecimiento. 
La tenacidad a la fractura del material crece con la presencia de microfisuras, aunque, es la coalescencia de ellas las que generan una fisura macroscópica mayor. Para materiales sólidos monolíticos donde no existen interfases por donde hacer crecer la fisura, no es posible un incremento de la tenacidad a la fractura por medio de este método, la presencia de múltiples fisuras, en estos materiales, tienden a unirse y coalecer hacia una sola. Es necesaria la presencia de interfases para que este fenómeno sea posible.

Una vez que la fisura macroscópica se genera y crece fuera de la interfase, pudimos observar que el ángulo en el cual lo hace continua satisfaciendo la ecuación (34) proveniente del criterio de máxima tensión de Erdogan y Sih[49]. La Figura 96 a Figura 98 muestran dicho comportamiento para las tres longitudes de fractura analizadas. Se puede notar en las gráficas que a medida que la longitud de fractura crece, la fisura se hace más sensible a los puentes y crece con mayor facilidad por la interfase.

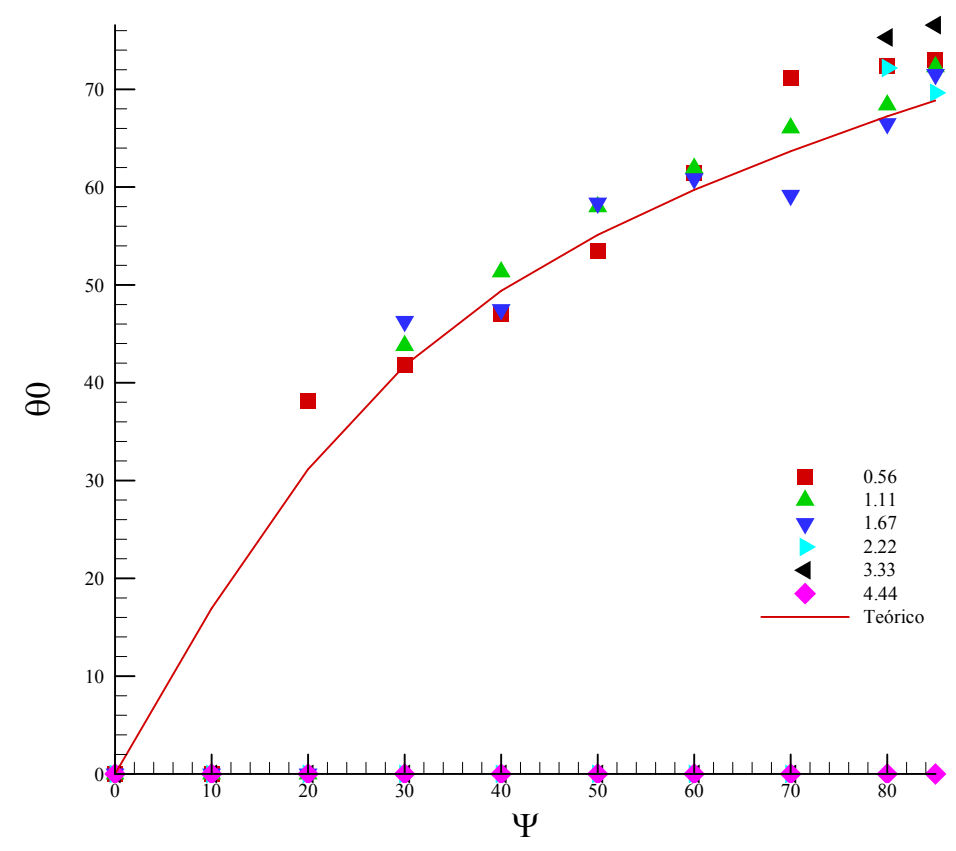

Figura 96 - Valores del angulo de crecimiento de fisura $\theta_{0}$ en función del ángulo de modo mixto $\Psi$ para una longitud de fractura $L 1=25 \mathrm{~nm}$ y distintos casos de análisis s/d. 


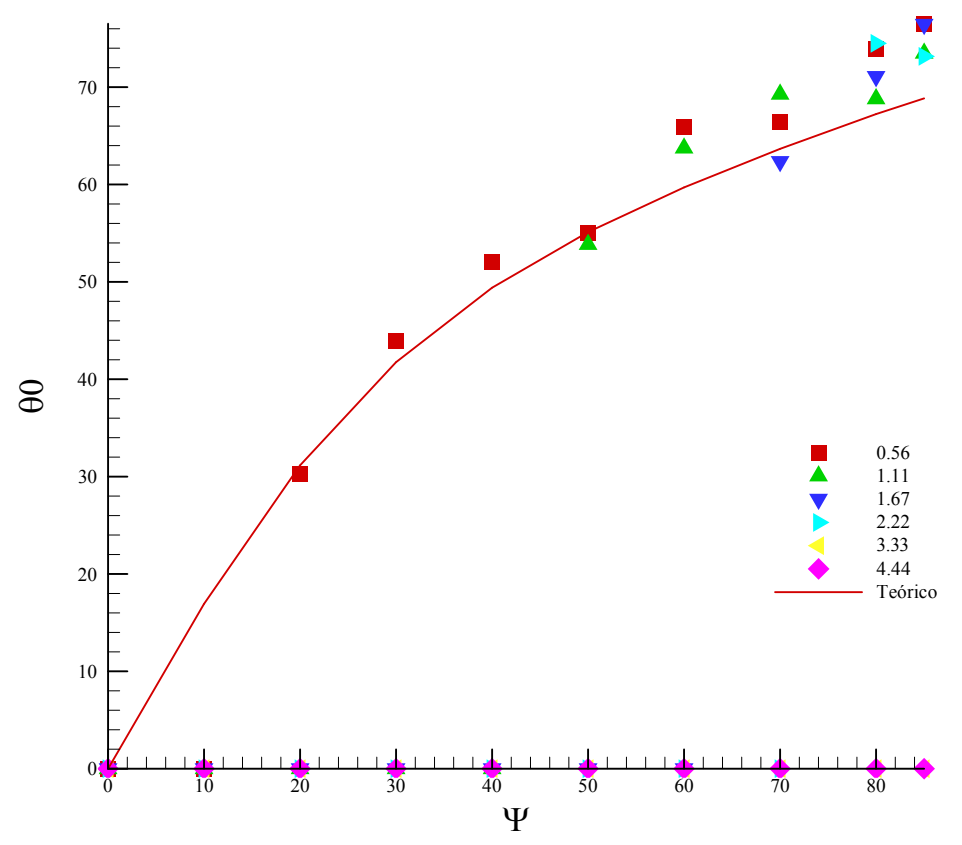

Figura 97 - Valores del ángulo de crecimiento de fisura $\theta_{0}$ en función del ángulo de modo mixto $\Psi$ para una longitud de fractura L2 $=125 \mathrm{~nm}$ y distintos casos de análisis s/d.

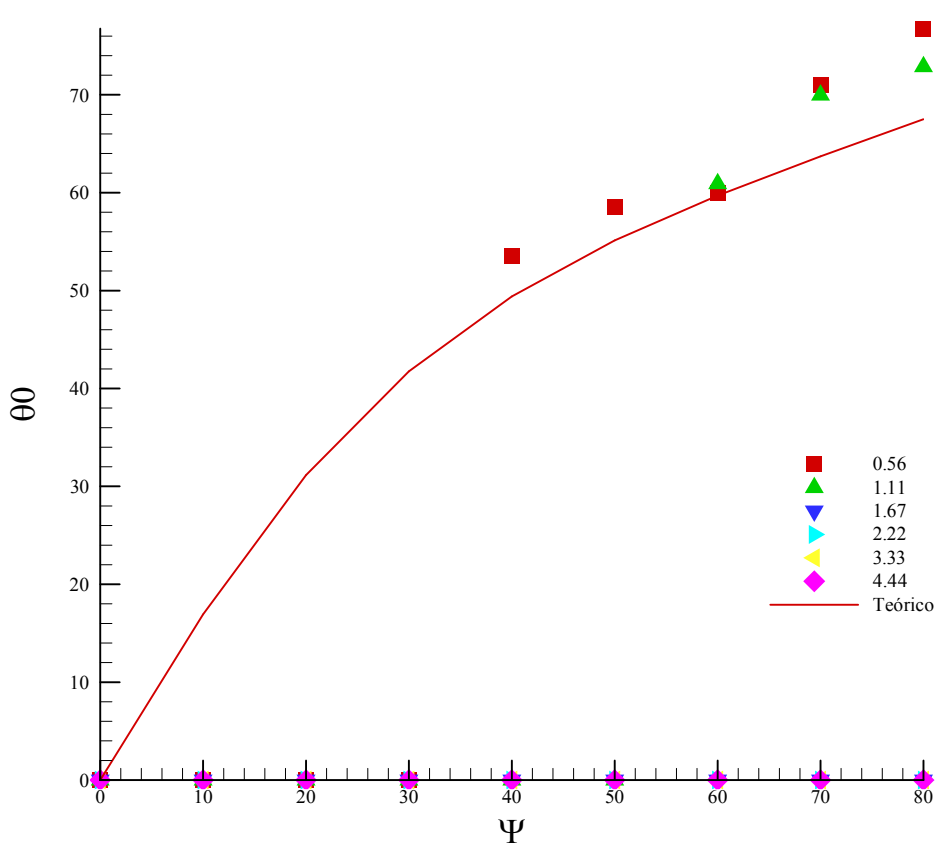

Figura 98 - Valores del ángulo de crecimiento de fisura $\theta_{0}$ en función del ángulo de modo mixto $\Psi$ para una longitud de fractura $\mathrm{L} 3=490 \mathrm{~nm}$ y distintos casos de análisis $\mathrm{s} / \mathrm{d}$.

Los materiales naturales en los cuales se inspira esta investigación, basan sus diseños de puentes de modo de ubicarse en las zonas cercanas a la transición entre control de la dirección de propagación o no, tratando de optimizar la energía disipada en la fractura. Si bien ha sido captada la infinidad de microfisuras en 
muestras de material (Figura 99) es el mecanismo de optimización en la interfase el que permite la efectividad del material en su tenacidad a la fractura.
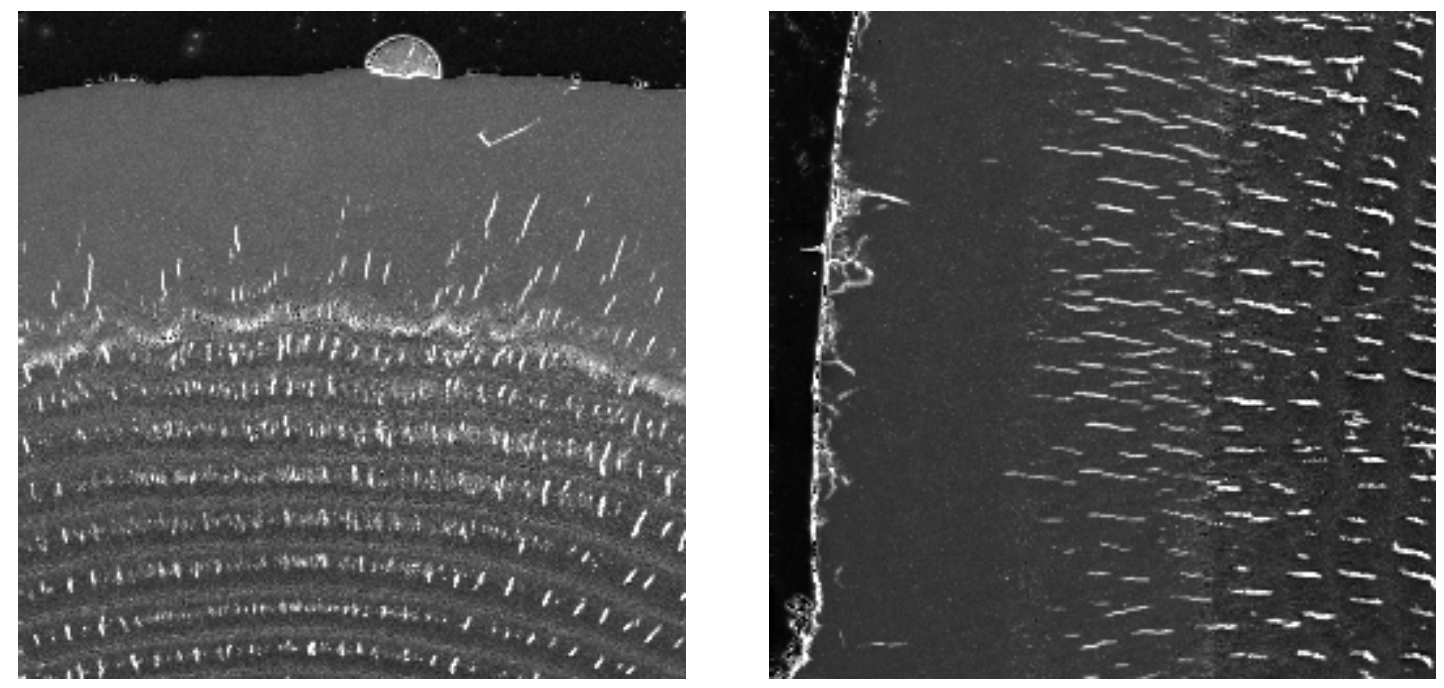

Figura 99 - Imágenes de microscopia electrónica de la zona periódica del martillo dáctilo de la mantis marina (izquierda) y de la zona de estrías (derecha) mostrando la presencia de microfisuras en el material. Imágenes SEM proporcionadas por Riverside. 


\section{Capítulo V - Conclusiones}

Esta investigación pone foco sobre las características microestructurales de algunos materiales naturales con comportamiento de alta tenacidad a la fractura. El material del martillo dáctilo de la mantis marina, es un material que ha captado la atención en estos últimos años y sus características son poco conocidas hasta el momento, por lo que la información proporcionada en esta investigación es de utilidad para comprender este material y su conjunto. A lo largo de este documento presentamos un análisis de su comportamiento desde una escala macroscópica a una escala microscópica, haciendo énfasis a su vez en que las características que lo definen, se encuentran en todo su rango dimensional.

El martillo dáctilo de la mantis marina constituye un material biológico con alta tolerancia al daño frente a cargas de impacto. Imágenes de microscopía electrónica permitieron conocer las características geométricas de las diferentes regiones. Un estudio numérico apoyado en una caracterización mecánica de cada una de las regiones e información de nanoindentación, determinó el estado tensional en las diferentes regiones que componen el dáctilo, encontrando altos valores de tensión en la región periódica pegada a la región de impacto. La presencia del propodio no mostró influencia en el máximo valor de fuerza por unidad de tiempo alcanzado en el impacto. Por otro lado, sobre un corte transversal del dáctilo pudo observarse la arquitectura de fibras mineralizadas dispuestas en forma helicoidal. La presencia de microfisuras en esta área indica la convivencia con el daño de este material, y la capacidad para desperdigar el daño por la región antes que canalizarlo hacia una fractura única y catastrófica. Los resultados de esta parte de la investigación fueron volcados a la publicación de Weaver et. al. en 2012 [24].

Observando las regiones de material podemos comprender que la región periódica es la responsable de disipar la energía absorbida en el impacto, trabaja como un amortiguador de la región de impacto. La misma está envuelta y sostenida 
por la región estriada que limita su expansión lateral. El grado de confinamiento de esta región define su distribución de tensiones. Las fibras trabajan en la dirección longitudinal y su flexión genera separación entre algunas fibras. La disipación de energía de impacto ocurre como se mencionó a través del crecimiento de múltiples microfisuras, producto de esta separación entre fibras. Es importante notar que no hay coalescencia de fisuras, evitando de esta forma una fractura completa del material.

En un afán de búsqueda de entendimiento sobre la microestructura y valiéndonos de información de nano-indentación, nos focalizamos en construir un modelo multiescala de las regiones tanto periódicas como de estrías. Tomamos como base de modelización a la langosta americana descripta por Nikolov et. al. (2010). A partir de resultados de EDS pudimos conocer parte de los compuestos tanto de las fibras como del mineral, pero no así la cristalinidad de cada compuesto. Los resultados de los modelos de homogenización creados, no arrojaron datos comparables con los de nanoindentación. El tipo de cristal en la quitina y el grado de porosidad de las muestras fueron características sensibles de nuestros modelos y por lo tanto del comportamiento del material. Sin embargo, una metodología y un esquema de modelado a diferentes escalas quedo construido y mayor información sobre los compuestos puede llevarnos a resultados comparables o mayor información sobre su comportamiento. Como trabajo a futuro nos quedará nutrir los modelos generados en esta investigación con información más fehaciente de los materiales involucrados en la microestructura.

En una menor escala dimensional abordamos los mecanismos de disipación de energía dentro de las interfases de material. Analizamos el arreglo de puentes en dichas interfase y la relación entre la rigidez de las juntas y el manejo de la dirección de propagación de la fisura. Pudimos observar que los materiales naturales de interés se encuentran en el límite de comportamiento, mostrando un balance entre las características mencionadas. Desde el punto de vista tensional, 
también fue posible encontrar, para el material nácar, una tendencia de los puentes dentro de las interfases a fracturarse antes que la placa. Se puede decir entonces que la naturaleza utiliza este tipo de solución para darle control a la dirección de propagación de fisura y así ganar tenacidad a la fractura en detrimento de la rigidez en las interfases. La presencia de muchas uniones entre elementos de construcción de estos materiales, favorece además el aumento de tenacidad. Esta característica es observada no solo en el nácar, sino en el diente de chitón y también hay indicios de que está presente en el material del martillo dáctilo de la mantis marina. El diseño de interfases basadas en las interfases analizadas no puede ser ignorado cuando intentamos diseñar materiales nuevos con alta tenacidad a la fractura. Como trabajo a futuro en el diseño de interfases y para completar el trabajo mencionado en esta última parte será el ensayo de probetas con los materiales mencionados aquí en escalas 1 : 1 donde se haga énfasis en las características de interfases mencionadas en este estudio. Actualmente hay trabajos realizados por Barthelat et. al. de impresión y ensayo de estos materiales, pero dado las limitaciones de las actuales impresoras, las características de las interfases están fuera de escala real. Los materiales de estas impresoras también son limitados a polímeros aunque algunas ya comenzaron a utilizar otros tipos de materiales con propiedades mecánicas más interesantes desde el punto de vista estructural. 


\section{REFERENCIAS}

[1] Meyers, M. A., P.-Y. Chen, A. Y.-M. Lin, and Y. Seki, "Biological materials: Structure and mechanical properties," Progress in Materials Science, vol. 53, no. 1. pp. 1-206, 2008.

[2] Fratzl, P., H. S. Gupta, E. P. Paschalis, and P. Roschger, "Structure and mechanical quality of the collagen mineral nano-composite in bone," $J$. Mater. Chem., vol. 14, no. 14, p. 2115, 2004.

[3] Bertoldi, K., D. Bigoni, and W. J. Drugan, "Nacre: An orthotropic and bimodular elastic material," Compos. Sci. Technol., vol. 68, pp. 1363-1375, 2008 .

[4] Rousseau, M. et al., "Multiscale structure of sheet nacre," Biomaterials, vol. 26, no. 31, pp. 6254-6262, 2005.

[5] Grunenfelder, L. K. et al., "Stress and Damage Mitigation from Oriented Nanostructures within the Radular Teeth of Cryptochiton stelleri," Adv. Funct. Mater., vol. 24, no. 39, pp. 6093-6104, 2014.

[6] Ji, B. and H. Gao, "Mechanical Principles of Biological Nanocomposites," Annu. Rev. Mater. Res., vol. 40, no. 1, pp. 77-100, 2010.

[7] Meyers, M. A., P. Chen, M. I. Lopez, Y. Seki, and A. Y. M. Lin, "Review article Biological materials: A materials science approach $\boldsymbol{\aleph}^{\prime}, " J$. Mech. Behav. Biomed. Mater., pp. 1-32, 2010.

[8] Currey, J. D., "Mechanical Properties of Mother of Pearl in Tension," Proc. R. Soc. B Biol. Sci., vol. 196, no. 1125, pp. 443-463, Apr. 1977.

[9] Lin, A. Y., P. Chen, and M. Andre, "The growth of nacre in the abalone shell," Acta Biomater., 2007.

[10] Ballarini, R., R. Kayacan, F. Ulm, and T. Belytschko, "Biological structures mitigate catastrophic fracture through various," Int. J. Fract., pp. 187-197, 2005.

[11] Barthelat, F., C. Li, C. Comi, and H. D. Espinosa, "Mechanical properties of nacre constituents and their impact," vol. 3111, no. July 2005, pp. 19771986, 2006.

[12] Barthelat, F., H. Tang, P. D. Zavattieri, C. M. Li, and H. D. Espinosa, "On the mechanics of mother-of-pearl: A key feature in the material hierarchical structure," J. Mech. Phys. Solids, vol. 55, no. 2, pp. 306-337, 2007.

[13] Rim, J. E., P. Zavattieri, A. Juster, and H. D. Espinosa, "Dimensional analysis and parametric studies for designing artificial nacre," J. Mech. Behav. Biomed. Mater., vol. 4, no. 2, pp. 190-211, 2011. 
[14] Barthelat, F., "Biomimetics for next generation materials.," Philos. Trans. A. Math. Phys. Eng. Sci., vol. 365, no. 1861, pp. 2907-2919, 2007.

[15] Espinosa, H. D., J. E. Rim, F. Barthelat, and M. J. Buehler, "Merger of structure and material in nacre and bone - Perspectives on de novo biomimetic materials," Progress in Materials Science, vol. 54, no. 8. Elsevier Ltd, pp. 1059-1100, 2009.

[16] Wang, R. Z., "Deformation mechanisms in nacre," no. i, pp. 2485-2493, 2001.

[17] Fan, S. and B. Yilong, "Mineral bridges of nacre and its effects," Acta Mech. Sin., vol. 17, no. 3, 2001.

[18] Mirkhalaf, M., a K. Dastjerdi, and F. Barthelat, "Overcoming the brittleness of glass through bio-inspiration and micro-architecture.," Nat. Commun., vol. 5, p. 3166, 2014.

[19] He, M.-Y. and J. Hutchinson, "Crack deflection at an interface between dissimilar elastic materials," International Journal of Solids and Structures, vol. 25, no. 9. pp. 1053-1067, 1989.

[20] Weaver, J. C. et al., "Analysis of an ultra hard magnetic biomineral in chiton radular teeth," Mater. Today, vol. 13, no. 1-2, pp. 42-52, 2010.

[21] Saunders, M., C. Kong, J. A. Shaw, D. J. Macey, and P. L. Clode, "Characterization of biominerals in the radula teeth of the chiton , Acanthopleura hirtosa," J. Struct. Biol., vol. 167, no. 1, pp. 55-61, 2009.

[22] Patek, S. N. and R. L. Caldwell, "Extreme impact and cavitation forces of a biological hammer: strike forces of the peacock mantis shrimp Odontodactylus scyllarus.," J. Exp. Biol., vol. 208, no. Pt 19, pp. 3655-64, Oct. 2005.

[23] Espinosa, H. D. and P. D. Zavattieri, A grain level model for the study of failure initiation and evolution in polycrystalline brittle materials. Part I: Theory and numerical implementation, vol. 35, no. 3-6. 2003.

[24] Weaver, J. C. et al., "The Stomatopod Dactyl Club: A Formidable Damage-Tolerant Biological Hammer," Science, vol. 336, no. 6086. pp. 1275-1280, 2012.

[25] Patek, S. N. and R. L. Caldwell, "Extreme impact and cavitation forces of a biological hammer: strike forces of the peacock mantis shrimp Odontodactylus scyllarus.," J. Exp. Biol., vol. 208, no. Pt 19, pp. 3655-64, Oct. 2005.

[26] Norman E. Dowling, V. P. I. \& S. U., Mechanical Behavior of Materials, 4th ed. 2013.

[27] Oliver, W. C. and G. M. Pharr, "An improved technique for determining 
hardness and elastic modulus using load and displacement sensing indentation experiments," Journal of Materials Research, vol. 7, no. 6. pp. 1564-1583, 1992.

[28] Nikolov, S. et al., "Revealing the design principles of high-performance biological composites using $\mathrm{Ab}$ initio and multiscale simulations: The example of lobster cuticle," Adv. Mater., vol. 22, no. 4, pp. 519-526, 2010.

[29] Suksangpanya, N., N. A. Yaraghi, D. Kisailus, and P. Zavattieri, "Twisting cracks in Bouligand structures," J. Mech. Behav. Biomed. Mater., no. June, pp. 1-20, 2017.

[30] Grunenfelder, L. K. et al., "Bio-inspired impact-resistant composites," Acta Biomater., vol. 10, no. 9, pp. 3997-4008, 2014.

[31] Apichattrabrut, T. and K. Ravi-Chandar, "Helicoidal Composites," Mech. Adv. Mater. Struct., vol. 13, no. 1, pp. 61-76, Jan. 2006.

[32] Zimmermann, E. a et al., "Mechanical adaptability of the Bouligand-type structure in natural dermal armour.," Nat. Commun., vol. 4, no. May, p. 2634, Jan. 2013.

[33] Raabe, D., C. Sachs, and P. Romano, "The crustacean exoskeleton as an example of a structurally and mechanically graded biological nanocomposite material," Acta Mater., vol. 53, pp. 4281-4292, 2005.

[34] Bruet, B. J. F., J. Song, M. C. Boyce, and C. Ortiz, "Materials design principles of ancient fish armour," Mater. Sci., vol. 1, pp. 1-9, 2008.

[35] Chen, P., J. Mckittrick, and M. A. Meyers, "Biological materials: Functional adaptations and bioinspired designs," J. Prog. Mater. Sci., no. February, 2012.

[36] Mori, T. and K. Tanaka, "Averge stress in matrix and averge elastic energy of materials with misfitting inclusions," Acta Metall., vol. 21, no. 5, pp. 571-574, 1973.

[37] Wan, A. C. A. and B. C. U. Tai, "CHITIN - A promising biomaterial for tissue engineering and stem cell technologies," Biotechnol. Adv., vol. 31, no. 8, pp. 1776-1785, 2013.

[38] Ifuku, S. et al., "Preparation of high-strength transparent chitosan film reinforced with surface-deacetylated chitin nanofibers," Carbohydr. Polym., vol. 98, no. 1, pp. 1198-1202, 2013.

[39] Fan, Y., Z. Sun, R. Wang, C. Abbott, and J. Moradian-Oldak, "Enamel inspired nanocomposite fabrication through amelogenin supramolecular assembly.," Biomaterials, vol. 28, no. 19, pp. 3034-42, Jul. 2007.

[40] Corni, I., T. J. Harvey, J. a Wharton, K. R. Stokes, F. C. Walsh, and R. J. K. Wood, "A review of experimental techniques to produce a nacre-like 
structure.," Bioinspir. Biomim., vol. 7, no. 3, p. 31001, Sep. 2012.

[41] Fan, S. and B. Yilong, "Mineral bridges of nacre and its effects," Acta Mechanica Sinica, vol. 17, no. 3. pp. 251-257, 2001.

[42] Lin, A. and M. Andr, "Growth and structure in abalone shell," Mater. Sci. Eng. A, vol. 390, pp. 27-41, 2005.

[43] Meyers, M., P. Chen, A. Lin, and Y. Seki, "Biological materials: structure and mechanical properties," Prog. Mater. Sci., vol. 53, pp. 1-206, 2008.

[44] Song, F., A. K. Soh, and Y. L. Bai, "Structural and mechanical properties of the organic matrix layers of nacre," Mater. Sci. Eng. (former title), vol. 24, pp. 3623-3631, 2003.

[45] Cook, R. D., D. S. Malkus, and M. E. Plesha, Concepts and Applications of Finite Element Analysis, 4th Editio. .

[46] Klaus-Jurgen Bathe, Finite Element Procedures. .

[47] Fish, J. and Ted Belytschko, A First Course in Finite Elements. 2007.

[48] Rimoli, J. J. and J. J. Rojas, "Meshing strategies for the alleviation of mesh-induced effects in cohesive element models," Int. J. Fract., vol. 193, no. 1, pp. 29-42, 2015.

[49] Erdogan, F. and G. C. Sih, "On the Crack Extension in Plates under Loading and Transverse Shear," J. Fluids Eng., vol. 85, no. 4, pp. 519-527, 1963.

[50] Shao, Y., H.-P. Zhao, and X.-Q. Feng, "Optimal characteristic nanosizes of mineral bridges in mollusk nacre," $R S C A d v$., vol. 4, pp. 32451-32456, 2014.

[51] Fan, S. and B. Yilong, "Mineral bridges of nacre and its effects," Acta Mech. Sin., vol. 17, no. 3, pp. 251-257, 2001.

[52] Meyers, M. A., A. Y. Lin, P. Chen, and J. Muyco, "Mechanical strength of abalone nacre : Role of the soft organic layer," vol. 1, pp. 76-85, 2008.

[53] Mayer, G., "Rigid Biological Systems as Models for Synthetic Composites," Source Sci. New Ser., vol. 310178101, no. 5751, pp. 1144-1147, 2005.

[54] Hutchinson and He, "He, Hutchinson - 1989 - Kinking of a Crack Out of an Interface.pdf." .

[55] He, M. and J. W. Hutchinson, "Kinking of a crack out of an interface: tabulated solution coefficients," Harvard Univ. Rep. MECH-113A, pp. 1-2, 1989.

[56] Hutchinson, J. W., "Crack tip shielding by micro-cracking in brittle solids," Acta Metall., vol. 35, no. 7, pp. 1605-1619, 1987. 